\title{
Mutanobactin D from the Human Microbiome: Total Synthesis, Configurational Assignment, and Biological Evaluation
}

Felix Pultar, ${ }^{\dagger}$ Moritz E. Hansen, ${ }^{\dagger}$ Susanne Wolfrum,${ }^{\dagger}$ Lennard Böselt, ${ }^{\dagger}$ Ricardo FróisMartins, ${ }^{\#}$ Susanne Bloch, ${ }^{\perp}$ Alberto G. Kravina, ${ }^{\dagger}$ Deren Pehlivanoglu, ${ }^{\dagger}$ Christina Schäffer, ${ }^{\perp}$ Salomé LeibundGut-Landmann, ${ }^{\#}$ Sereina Riniker, ${ }^{\star}$ Erick M. Carreira ${ }^{*} \dagger$

$\dagger$ Laboratorium für Organische Chemie, ETH Zürich, D-CHAB, Vladimir-Prelog-Weg 3, 8093 Zürich, Switzerland

† Laboratorium für Physikalische Chemie, ETH Zürich, D-CHAB, Vladimir-Prelog-Weg 2, 8093 Zürich, Switzerland

\# Section of Immunology, Vetsuisse Faculty, University of Zürich, Winterthurerstrasse 266a, 8057 Zürich, Switzerland and Institute of Experimental Immunology, University of Zürich, Winterthurerstrasse 190, 8057 Zürich, Switzerland

$\perp$ Department of NanoBiotechnology, NanoGlycobiology unit, Universität für Bodenkultur Wien, Muthgasse 11, 1190 Vienna, Austria

<erickm.carreira@org.chem.ethz.ch>

Supporting Information 


\section{TABLE OF CONTENTS}

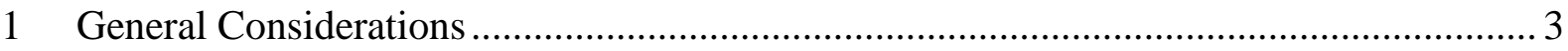

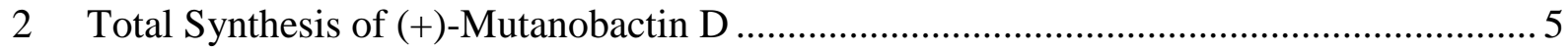

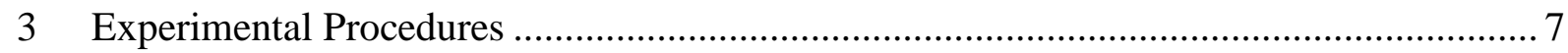

4 Comparison of NMR Spectra of Natural and Synthetic Mutanobactin D ...................... 49

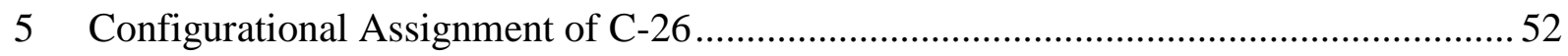

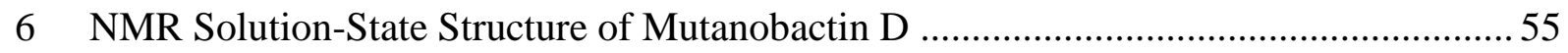

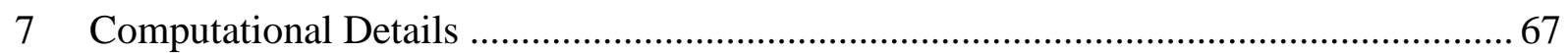

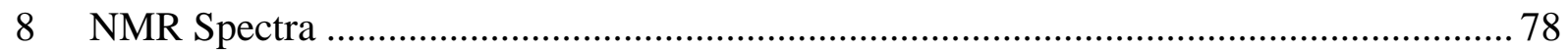

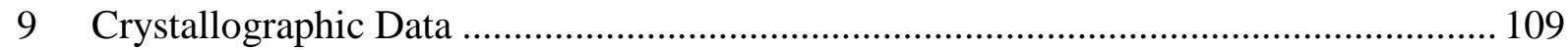

10 Biofilm Inhibition, Surface Area Reduction Assays, and Planktonic Growth Curves ... 114

11 Filamentation Assays and Virulence Gene Expression Analysis ................................ 170

12 Influence of Mutanobactin D on Bacteria of the Oral Microbiome............................... 173

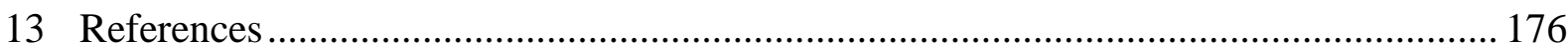




\section{General Considerations}

All chemicals and solvents were purchased from Acros, Fischer, Sigma-Aldrich, TCI, Fluorochem, Apex BIO, Bachem, ChemPep, or Thommen-Furler and used as received without further purification unless stated otherwise. Deuterated solvents were obtained from Cambridge Isotope Laboratories. Decanal oxime, ethyl 4-hydroxycrotonate, and $\mathrm{Mo}(\mathrm{CO})_{3}(\mathrm{MeCN})_{3}$ were prepared following published procedures. ${ }^{1-3}$

All reactions involving non-aqueous solvents were carried out in flame-dried glassware sealed with rubber septa and under a positive pressure of nitrogen unless otherwise stated. Reactions were stirred using magnetic stirring bars, monitored by TLC (Merck silica gel F254 TLC glass plates) and visualized with UV fluorescence quenching, $\mathrm{KMnO}_{4}$ stain $\left(\mathrm{KMnO}_{4}(3 \mathrm{~g}), \mathrm{K}_{2} \mathrm{CO}_{3}\right.$ (20 g), 5\% aq. $\mathrm{NaOH}(5 \mathrm{~mL})$, water $(300 \mathrm{~mL}))$ or "Seebach's magic stain" (Phosphomolybdic acid $(25 \mathrm{~g}), \mathrm{Ce}\left(\mathrm{SO}_{4}\right)_{2}(10 \mathrm{~g})$, conc. $\left.\mathrm{H}_{2} \mathrm{SO}_{4}(60 \mathrm{~mL}), \mathrm{H}_{2} \mathrm{O}(940 \mathrm{~mL})\right)^{4}$ followed by heating, unless stated otherwise. Alternatively, reactions were monitored by an LC-MS system from Waters consisting of an Acquity SQ Detector 2, column manager, and sample manager, C18 column UPLC BEH C18 $1.7 \mu \mathrm{m} 2.1$ x 50 mm column part NO 186002350, and UPLC PDA eLambda Detector with analytical flow cell $1 \mathrm{~cm}$.

Concentrations under reduced pressure were performed by rotary evaporation at $42{ }^{\circ} \mathrm{C}$ at the appropriate pressure. Chromatographic purification was performed as flash chromatography (using Silicycle SiliaFlash® Silica Gel P60). The yields given refer to chromatographically purified and spectroscopically pure compounds, unless otherwise stated.

NMR spectra were recorded at room temperature on Bruker AV and DRX (400 MHz), Bruker DRX and DRXII (500 MHz) or Bruker AVIII (600 MHz with cryoprobe) spectrometers. All chemical shifts are reported in ppm with the residual solvent peak as the standard $\left(\mathrm{CHCl}_{3}=\right.$ $7.26 \mathrm{ppm}$ and $77.16 \mathrm{ppm}$, DMSO $2.50 \mathrm{ppm}$ and $39.52 \mathrm{ppm}$ ). Signal multiplicities are denoted as follows: $\mathrm{s}=$ singlet, $\mathrm{d}=$ doublet, $\mathrm{t}=$ triplet, $\mathrm{q}=$ quartet, quint $=$ quintet, sept $=$ septet, $\mathrm{m}=$ multiplet, br = broad signal. Coupling constants are given in $\mathrm{Hz} .{ }^{13} \mathrm{C}-\mathrm{NMR}$ spectra were recorded with broadband ${ }^{1} \mathrm{H}$-decoupling. Measurements on Bruker DRX and or Bruker AVIII were performed by Mr. Rene Arnold, Mr. Rainer Frankenstein and Mr. Stephan Burkhardt under the direction of Dr. Marc-Olivier Ebert.

Infrared spectra were recorded on a Perkin Elmer Two-FT-IR spectrometer as thin films if not stated otherwise. Absorptions are given in wavenumbers $\left(\mathrm{cm}^{-1}\right)$. 
Mass spectrometric analyses were performed as high resolution ESI measurements by the mass spectrometry service of the Laboratorium für Organische Chemie at ETH Zürich by Mr. Louis Bertschi, Mr. Oswald Greter, Mr. Daniel Wirtz, and Mr. Michael Meier under the supervision of Dr. Bertran Gerrits.

X-ray diffraction (XRD) analysis was performed on an XtaLAB Synergy, Dualflex, Pilatus 300K diffractometer by Dr. Nils Trapp and Mr. Michael Solar at the Laboratorium für Organische Chemie at ETH Zürich. The data obtained was deposited at the Cambridge Crystallographic Data Centre.

Analytical RP-HPLC were performed on a Dionex UHPLC, Ultimate 3000 (Thermo Fisher Scientific, Waltham/USA). Acetonitrile and water containing $1 \%$ of acetonitrile and $0.1 \%$ TFA were used as eluents at a flow rate of $1 \mathrm{~mL} / \mathrm{min}$.

Preparative RP-HPLC purifications were carried out on a Waters Auto Purification System using a Reprosil Gold 120 C18 125 x 20 mm column (flow 26.5 mL/min). Compounds were eluted with water $(+0.1 \%(\mathrm{v} / \mathrm{v})$ formic acid) and acetonitrile in differing rations.

SFC analyses were performed on an analytical SFC with a diode array detector ACQUITYUPLCPDA from Waters using chiral stationary phase columns (Daicel Chiralpak AD-3 or Trefoil) (150 mm x $30 \mathrm{~mm}$ ) from Daicel or Waters under the reported conditions.

Optical rotations were recorded on a JASCO P-2000 Polarimeter, cuvette length $=10 \mathrm{~cm}$. $1 \mathrm{~mL}$ cell volume. The concentration $\mathrm{c}=1$ corresponds to $10 \mathrm{mg} \mathrm{mL}^{-1}$.

$\mathrm{Et}_{2} \mathrm{Zn}$ was titrated using $\mathrm{I}_{2}$ in $0.5 \mathrm{M} \mathrm{LiCl}$ in $\mathrm{THF}$ solution as described by Krasovskiy and Knochel (Synthesis 2006, 5, 890-891).

Reactions involving inorganic azides: Inorganic azides are highly toxic and in some cases explosive. Reactions involving those reagents must be handled by professionals using the required safety measurements such as a blast shield. The use of acid can lead to formation of toxic, volatile, and explosive hydrazoic azid, which can be detected with a strip of paper impregnated with ferric chloride. The use of chlorinated solvents for these transformations is highly discouraged due to the potential formation of highly dangerous diazidomethane. ${ }^{5-7}$ 


\section{Total Synthesis of (+)-Mutanobactin D}

\subsection{Second Generation Route}

Scheme 1. Second generation total synthesis of (+)-mutanobactin D as described in the main text of the manuscript.

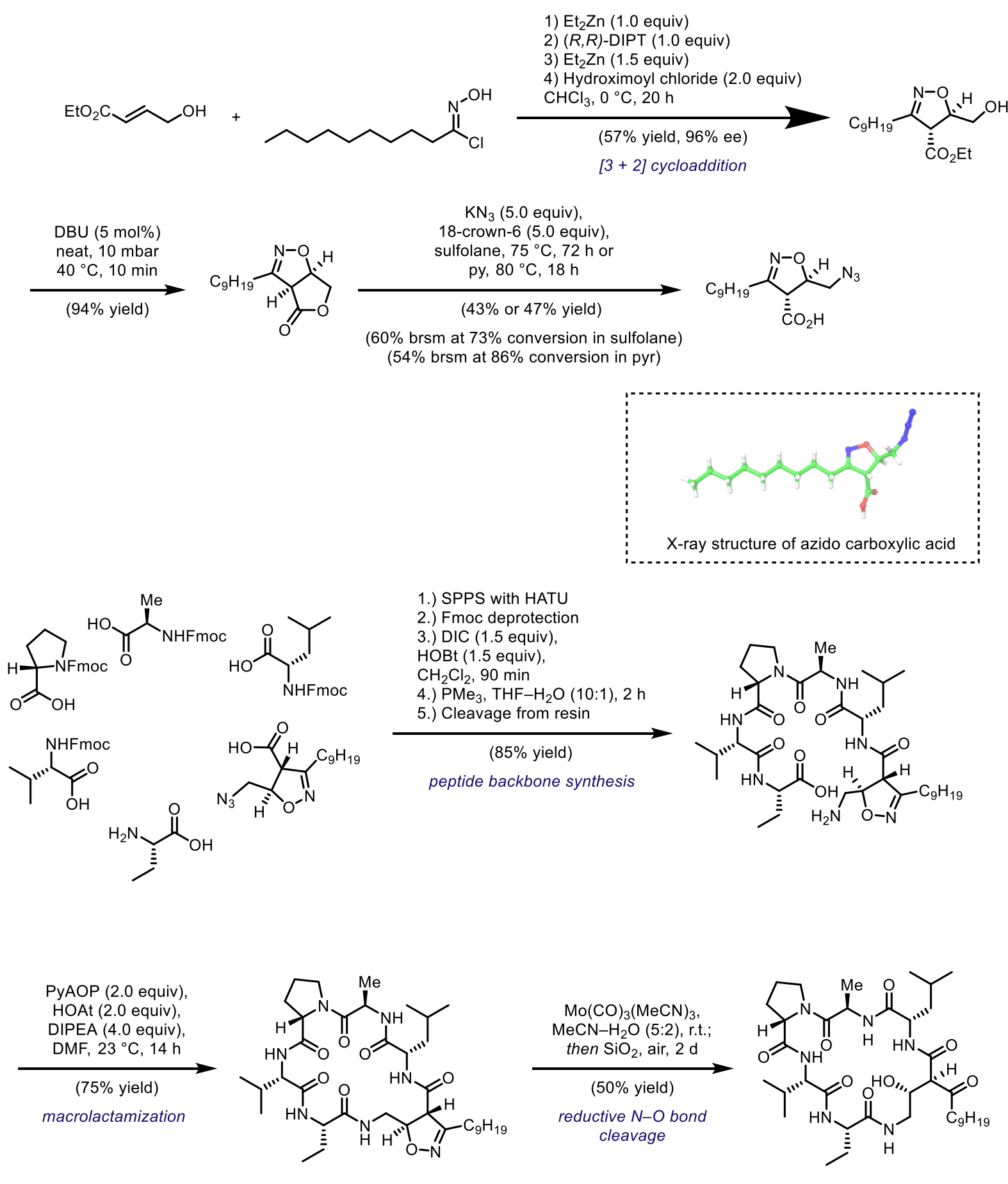

Mutanobactin D 


\subsection{First Generation Route}

Scheme 2. First Generation Route for the Synthesis of Lipopeptide Domain Compared to the Second Generation Route.

A. Initial Idea:<smiles>CCOC(=O)[C@H]1C(C2CCCCC2)=NO[C@@H]1CO</smiles>

B. First Generation Route

not observed

trace<smiles>CCOC(=O)[C@@H]1C(C2CCCCC2)=NO[C@@H]1CO</smiles>

$h \downarrow$

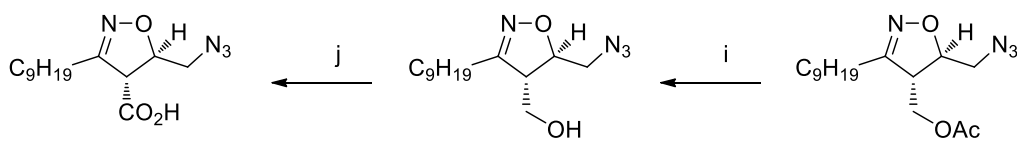

C. Second Generation Route<smiles>CCOC(=O)[C@H]1C(c2ccccc2)=NO[C@H]1CO</smiles>

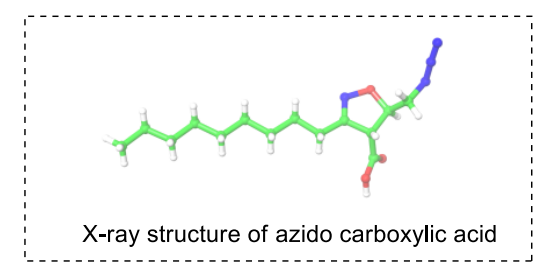

k epimerization

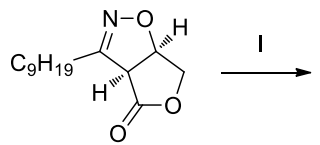

$\overbrace{\mathrm{CO}_{2} \mathrm{H}}^{\mathrm{C}_{9} \mathrm{H}_{19}}$<smiles>NC[C@H]1ON=C([Hg])[C@H]1C(=O)O</smiles>

syn

syn

anti

${ }^{a}$ Reagents and conditions: (a) $\mathrm{MsCl}, \mathrm{NEt}_{3}, \mathrm{CH}_{2} \mathrm{Cl}_{2}, 95 \%$; (b) $\mathrm{NaN}_{3}, \mathrm{DMF}, 40{ }^{\circ} \mathrm{C}$; traces; (c) TBSCl, im, DMF, $0{ }^{\circ} \mathrm{C}$, quant.; (d) $\mathrm{NaBH}_{4}, \mathrm{EtOH}, 96 \%$; (e) Ac2 $\mathrm{O}$, DMAP, py, quant.; (f) TBAF, THF, $0{ }^{\circ} \mathrm{C}$, quant.; (g) $\mathrm{MsCl}, \mathrm{NEt}_{3}, \mathrm{CH}_{2} \mathrm{Cl}_{2},-10{ }^{\circ} \mathrm{C}, 96 \%$; (h) $\mathrm{NaN}_{3}$, DMF, $60{ }^{\circ} \mathrm{C}$, $91 \%$; (i) $\mathrm{NaOH}$, THF- $\mathrm{H}_{2} \mathrm{O}$, quant.; (j) $\mathrm{CrO}_{3}\left(1.2 \mathrm{~mol} \%\right.$ ), $\mathrm{H}_{5} \mathrm{IO}_{6}$, wet $\mathrm{MeCN}, 0{ }^{\circ} \mathrm{C}, 92 \%$; (k) DBU $(5 \mathrm{~mol} \%)$, $\mathrm{MeCN}$, 96\%; (l) $\mathrm{KN}_{3}$, 18-crown-6, sulfolane, 47\%, $70{ }^{\circ} \mathrm{C}$. DMAP = 4-4-dimethylaminopyridine; $\mathrm{LDA}=$ lithium diisopropylamide. 


\section{Experimental Procedures}

\subsection{Decanal oxime ${ }^{1}$}

$\underbrace{N_{\mathrm{H}}^{\mathrm{OH}} \mathrm{A} \text { solution of hydroxylamine hydrochloride }(168 \mathrm{~g}, 2.42 \mathrm{~mol} \text {, }}$ (95.0 mL, $504 \mathrm{mmol}, 1.0$ equiv) in ethanol (1200 mL). Sodium hydroxide (185 mL of a 10\% aq solution, $514 \mathrm{mmol}, 1.0$ equiv) was added slowly. The reaction was heated to $70{ }^{\circ} \mathrm{C}$ and stirred for $90 \mathrm{~min}$. Then, it was cooled in an ice-bath (upon cooling a white precipitate forms) and aged for $22 \mathrm{~h}$ at $4{ }^{\circ} \mathrm{C}$. The suspension was filtered and the precipitate washed twice with $1 \mathrm{~L}$ of ice-cold water and dried in an air stream. The resulting slurry was further dried in a desiccator over $\mathrm{P}_{2} \mathrm{O}_{5}$ for $3 \mathrm{~d}$ to give the product as white platelets $80.6 \mathrm{~g}(0.471 \mathrm{~mol}, 93 \%$ yield $)$. The obtained spectra matched the data reported in the literature. ${ }^{1}$ 


\section{2 $N$-hydroxydecanimidoyl chloride ch $^{8,9}$}

$\mathrm{N}^{-} \mathrm{OH} \quad$ A solution of decanal oxime $\left(78.8 \mathrm{~g}, 0.461 \mathrm{~mol}, 1.0\right.$ equiv) in $\mathrm{CHCl}_{3}$

$\mathrm{Cl}(1670 \mathrm{~mL})$ and pyridine $(3.34 \mathrm{~mL})$ at $40{ }^{\circ} \mathrm{C}$ was stirred for $3 \mathrm{~min}$; then,

NCS (73.7 g, $0.552 \mathrm{~mol}, 1.2$ equiv) was added portionwise at $40{ }^{\circ} \mathrm{C}$. Stirring was continued at the same temperature for $30 \mathrm{~min}$. The mixture turned deep blue for some minutes, then the color slowly fainted.

The reaction was quenched by pouring the colorless solution onto ice-cold water $(1500 \mathrm{~mL})$. The phases were separated and the organic layer was extracted with $\mathrm{CHCl}_{3}(3 \times 500 \mathrm{~mL})$. The combined organic layers were washed with ice-cold water $(3 \times 1000 \mathrm{~mL})$, dried over magnesium sulfate, filtered and concentrated in vacuo to around $750 \mathrm{~mL}$. The remaining solution was used immediately in the next reaction. 


\subsection{Optimization of the Asymmetric [3 + 2] Dipolar Cycloaddition}

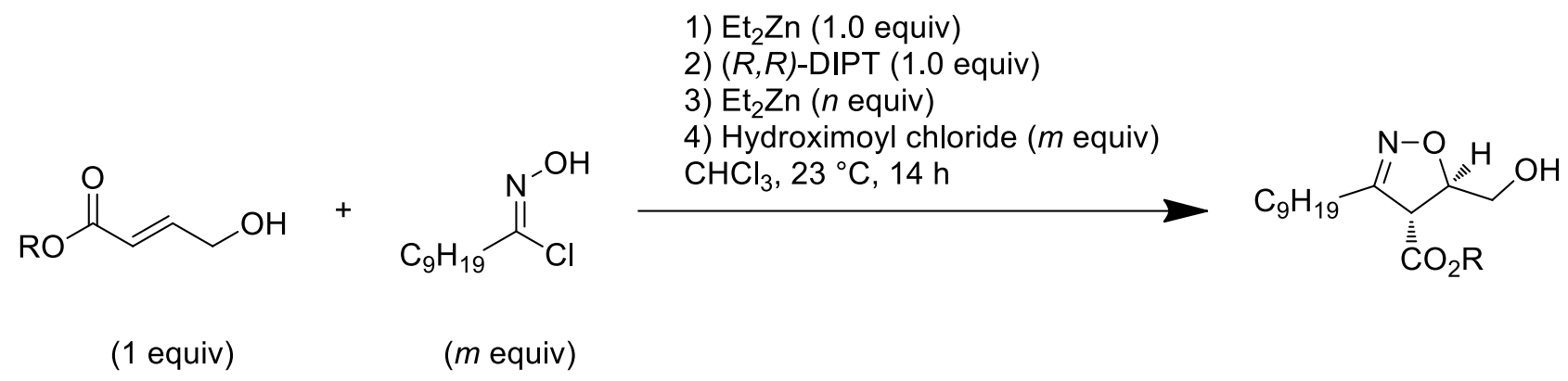

\begin{tabular}{ccccccc}
\hline Entry $^{\mathbf{a}}$ & $\mathbf{R}$ & $\boldsymbol{n}$ & $\boldsymbol{m}$ & Conversion (\%) $^{\mathbf{b}}$ & Yield (\%) $^{\mathbf{b}}$ & ee (\%) $^{\mathbf{c}}$ \\
\hline $\mathbf{1}$ & Et & 1.5 & 2.0 & 69 & 28 & 94 \\
$\mathbf{2}$ & Me & 1.5 & 2.0 & 69 & 16 & 89 \\
$\mathbf{3}$ & Et & 3.5 & 6.0 & 68 & 22 & 23 \\
$\mathbf{4}^{\mathbf{d}}$ & Et & 1.5 & 2.0 & 69 & 20 & 79 \\
$\mathbf{5}^{\mathbf{e}}$ & Et & 1.5 & 2.0 & 74 & 24 & 87 \\
$\mathbf{7}^{\mathbf{f}}$ & Et & 1.5 & 2.0 & 65 & 14 & 83 \\
$\mathbf{8}^{\mathbf{g}}$ & Et & 1.5 & 2.0 & 79 & 28 & 85 \\
$\mathbf{9}^{\mathbf{h}}$ & Et & 1.5 & 2.0 & 79 & 47 & 93 \\
$\mathbf{1 0}^{\mathbf{i}}$ & Et & 1.5 & 2.0 & 92 & 35 & 73 \\
$\mathbf{1 1}^{\mathbf{j}}$ & Et & 1.5 & 2.0 & 62 & 26 & 94 \\
$\mathbf{1 2}^{\mathbf{k}}$ & Et & 1.5 & 2.0 & 85 & 39 & 55 \\
$\mathbf{1 3}^{\mathbf{h}, \mathbf{l}}$ & $\mathbf{E t}$ & $\mathbf{1 . 5}$ & $\mathbf{2 . 0}$ & $\mathbf{9 1}$ & $\mathbf{5 7}$ & $\mathbf{9 6}$ \\
\hline
\end{tabular}

${ }^{\text {a }}$ Reaction run on a $5 \mathrm{mmol}$ scale, $0.1 \mathrm{M}$. ${ }^{\mathrm{b}}$ Determined by ${ }^{1} \mathrm{H}$ NMR analysis of the crude reaction mixture using 1,3,5trimethoxybenzene as an internal standard. ${ }^{c}$ Determined by SFC analysis using a chiral stationary phase ${ }^{\mathrm{d}}$ The oxime was added over a period of $6 \mathrm{~h} .{ }^{\mathrm{e}}$ The reaction was run for $72 \mathrm{~h} .{ }^{\mathrm{f}}$ The concentration of the reaction was increased to $0.2 \mathrm{M} .{ }^{\mathrm{g}}$ The reaction was run at $40{ }^{\circ} \mathrm{C}$. ${ }^{\mathrm{h}}$ The reaction was run at $0{ }^{\circ} \mathrm{C}$. ${ }^{\mathrm{i}} 2.0$ equiv more of the oxime chloride were added after $18 \mathrm{~h}$ reaction time. ${ }^{j}$ The reaction was run at -20 to $12{ }^{\circ} \mathrm{C}$ over $12 \mathrm{~h} .{ }^{k}$ The reaction was run at $0{ }^{\circ} \mathrm{C}$ and 2.0 equiv more of the oxime chloride were added after $10 \mathrm{~h}$ reaction time. ${ }^{1}$ Reaction run on a $50 \mathrm{mmol}$ scale. 


\subsection{Ethyl (4R,5R)-5-(hydroxymethyl)-3-nonyl-4,5-dihydroisoxazole-4-carboxylate ${ }^{10,11}$}<smiles>CCOC(=O)C1C(c2ccccc2)=NO[C@@H]1CO</smiles>

SI-1

To a solution of ethyl (E)-4-hydroxybut-2-enoate $(6.51 \mathrm{~g}, 50.1 \mathrm{mmol}$, 1.0 equiv) in dry $\mathrm{CHCl}_{3}(170 \mathrm{~mL})$ was added a $1.0 \mathrm{M}$ solution of $\mathrm{Et}_{2} \mathrm{Zn}$ in hexane (50.0 ml, $50.0 \mathrm{mmol}, 1.0$ equiv) at $0{ }^{\circ} \mathrm{C}$ under an atmosphere of argon. The colorless solution was stirred for $10 \mathrm{~min}$ at $0{ }^{\circ} \mathrm{C}$. A solution of $(+)-(R, R)$-diisopropyl tartrate $\left(11.7 \mathrm{~g}, 50.0 \mathrm{mmol}, 1.0\right.$ equiv) in dry $\mathrm{CHCl}_{3}(170 \mathrm{~mL})$ was added over $5 \mathrm{~min}$ and the resulting solution was stirred for $1 \mathrm{~h}$ at $0{ }^{\circ} \mathrm{C}$. Then, a $1.0 \mathrm{M}$ solution of $\mathrm{Et}_{2} \mathrm{Zn}$ in hexane $(75.0 \mathrm{~mL}, 75.0 \mathrm{mmol}, 1.5$ equiv) was added followed by a solution of $N$-hydroxydecanimidoyl chloride (20.6 g, $0.100 \mathrm{~mol}, 2.0$ equiv) in dry $\mathrm{CHCl}_{3}(170 \mathrm{~mL})$. The resulting slightly yellow solution was stirred for $20 \mathrm{~h}$ at $0{ }^{\circ} \mathrm{C}$.

The yellow solution was allowed to reach ambient temperature, quenched with a saturated, aqueous solution of $\mathrm{NH}_{4} \mathrm{Cl}$ and extracted with EtOAc $(3 \times 100 \mathrm{~mL})$. The combined organic layers were washed with brine $(150 \mathrm{~mL})$, dried over magnesium sulfate, filtered and concentrated in vacuo to yield the crude product as a yellow oil. Flash column chromatography $\left[\mathrm{CH}_{2} \mathrm{Cl}_{2}\right.$ to $\left.\mathrm{CH}_{2} \mathrm{Cl}_{2} / \mathrm{EtOAc}=9: 1\right]$ afforded a mixture of isoxazoline $(8.78 \mathrm{~g}, 29.3 \mathrm{mmol}, 57 \%$ yield) and $(R, R)$-diisopropyl tartrate as a colorless oil that was carried forth to the next step. An analytical sample was obtained by purification of a small fraction by flash column chromatography [hexane/EtOAc $=9: 1]$. Enantiomeric purity was determined by SFC analysis in comparison with racemic material $\left(t_{R}=1.37\right.$ min $($ major $) t_{R}=2.07 \mathrm{~min}$ (minor) $(96 \%$ ee shown); Daicel Chiralpak AD-3, 95\% $\mathrm{CO}_{2}$ to $5 \% \mathrm{MeOH}, 2.0 \mathrm{~mL} / \mathrm{min}, 214.0 \mathrm{~nm}, 2000 \mathrm{psi}$, $\left.40{ }^{\circ} \mathrm{C}\right)$.

$\mathbf{R}_{\mathbf{f}}=0.49$ [hexane/EtOAc $\left.=8: 2\right]$

$[\alpha]_{D}^{23}=-163\left(\mathrm{c}=1.0, \mathrm{CHCl}_{3}\right)$

${ }^{1}$ H NMR (400 MHz, CDCl3): $\delta=4.90(\mathrm{dt}, J=8.0,3.2 \mathrm{~Hz}, 1 \mathrm{H}), 4.32-4.13(\mathrm{~m}, 2 \mathrm{H}), 4.04(\mathrm{~d}, J$ $=8.0 \mathrm{~Hz}, 1 \mathrm{H}), 3.90(\mathrm{dd}, J=12.5,3.1 \mathrm{~Hz}, 1 \mathrm{H}), 3.62(\mathrm{dd}, J=12.5,3.5 \mathrm{~Hz}, 1 \mathrm{H}), 2.53-2.40(\mathrm{~m}$, 1H), 2.40-2.28 (m, 1H), 1.69-1.51 (m, 2H), 1.38-1.22 (m, 15H), 0.92-0.82 (m, 3H) ppm.

${ }^{13}$ C NMR (101 MHz, CDCl3): $\delta=168.6,156.7,83.6,62.8,62.1,56.2,32.0,29.6,29.39,29.36$, $29.3,27.1,26.2,22.8,14.27,14.25 \mathrm{ppm}$.

IR (ATR): $\tilde{\mathrm{v}}=3442$ (br), 2924 (s), 2855 (m), 1738 (vs), 1465 (m), 1371 (m), 1260 (m), 1179 (s), $1031(\mathrm{~m}), 865(\mathrm{~m}), 722(\mathrm{w}) \mathrm{cm}^{-1}$ 
HRMS (ESI): $\quad$ calcd. for $\mathrm{C}_{16} \mathrm{H}_{30} \mathrm{NO}_{4}{ }^{+} \quad 300.2169[\mathrm{M}+\mathrm{H}]^{+}$

found:

300.2167

The reaction was scalable:

This reaction was performed under argon. Every addition was performed carefully at a rate ensuring that the internal temperature of the reaction mixture never exceeded $0{ }^{\circ} \mathrm{C}$.

To a pre-cooled solution of ethyl $(E)$-4-hydroxybut-2-enoate $(30.0 \mathrm{~g}, 231 \mathrm{mmol}, 1.0$ equiv) in $\mathrm{CHCl}_{3}(770 \mathrm{~mL})$ was added a solution of $\mathrm{Et}_{2} \mathrm{Zn}$ in hexane $(1.07 \mathrm{M}, 215 \mathrm{~mL}, 231 \mathrm{mmol}$, 1.0 equiv). The colorless solution was stirred for $10 \mathrm{~min}$ at $0{ }^{\circ} \mathrm{C}$. A solution of $(+)-(R, R)-$ diisopropyl tartrate $\left(48.6 \mathrm{~mL}, 231 \mathrm{mmol}, 1.0\right.$ equiv) in $\mathrm{CHCl}_{3}(770 \mathrm{~mL})$ was added and the resulting solution was stirred for $1 \mathrm{~h}$ at $0{ }^{\circ} \mathrm{C}$. Then, a solution of $\mathrm{Et}_{2} \mathrm{Zn}$ in hexane $(1.07 \mathrm{M}$, $323 \mathrm{~mL}, \quad 346 \mathrm{mmol}, 1.5$ equiv) followed by a freshly prepared solution of $\mathrm{N}$ hydroxydecanimidoyl chloride $\left(95.0 \mathrm{~g}, 461 \mathrm{mmol}, 2.0\right.$ equiv) in $\mathrm{CHCl}_{3}$ (ca. $750 \mathrm{~mL}$ ) was added. The resulting slightly yellow solution was stirred for $20 \mathrm{~h}$ at $0{ }^{\circ} \mathrm{C}$. The yellow solution was allowed to reach ambient temperature and saturated, aqueous $\mathrm{NH}_{4} \mathrm{Cl}(500 \mathrm{~mL})$ was added. After stirring for $15 \mathrm{~min}$, water was added until two clear layers formed (ca. $250 \mathrm{~mL}$ ) and the phases separated. The aqueous layer is extracted with $\mathrm{CHCl}_{3}(2 \times 1000 \mathrm{~mL})$. The combined organic layers were washed with brine $(500 \mathrm{~mL})$, dried over magnesium sulfate, filtered and concentrated in vacuo to yield the crude product as a yellow oil. Flash column chromatography $[\mathrm{DCM}$ to DCM/EtOAc $=9: 1]$ afforded a mixture of the title compound and $(R, R)$-diisopropyl tartrate as a colorless oil that was carried forth to the next step $(74.0 \mathrm{~g}, 46 \% \mathrm{w} / \mathrm{w}$ in DIPT, $114 \mathrm{mmol}, 49 \%$ yield). Enantiomeric purity was determined by SFC analysis in comparison with racemic material $\left(t_{R}=1.37\right.$ min (major) $t_{R}=2.07$ min (minor) (95\% ee); Daicel Chiralpak $\left.\mathrm{AD}-3,95 \% \mathrm{CO}_{2}, 5 \% \mathrm{MeOH}, 2.0 \mathrm{~mL} / \mathrm{min}, 214.0 \mathrm{~nm}, 2000 \mathrm{psi}, 40{ }^{\circ} \mathrm{C}\right)$. The enantiomer was prepared by using (-)-(S,S)-diisopropyl tartrate under otherwise identical conditions. Enantiomeric purity was determined by SFC analysis in comparison with racemic material $\left(t_{R}\right.$ $=2.44 \min$ (major) $t_{\mathrm{R}}=2.67 \mathrm{~min}$ (minor) $\left(95 \%\right.$ ee); Trefoil, $95 \% \mathrm{CO}_{2}, 5 \% \mathrm{MeOH}, 2.0 \mathrm{~mL} / \mathrm{min}$, $\left.214.0 \mathrm{~nm}, 2000 \mathrm{psi}, 40^{\circ} \mathrm{C}\right)$. 


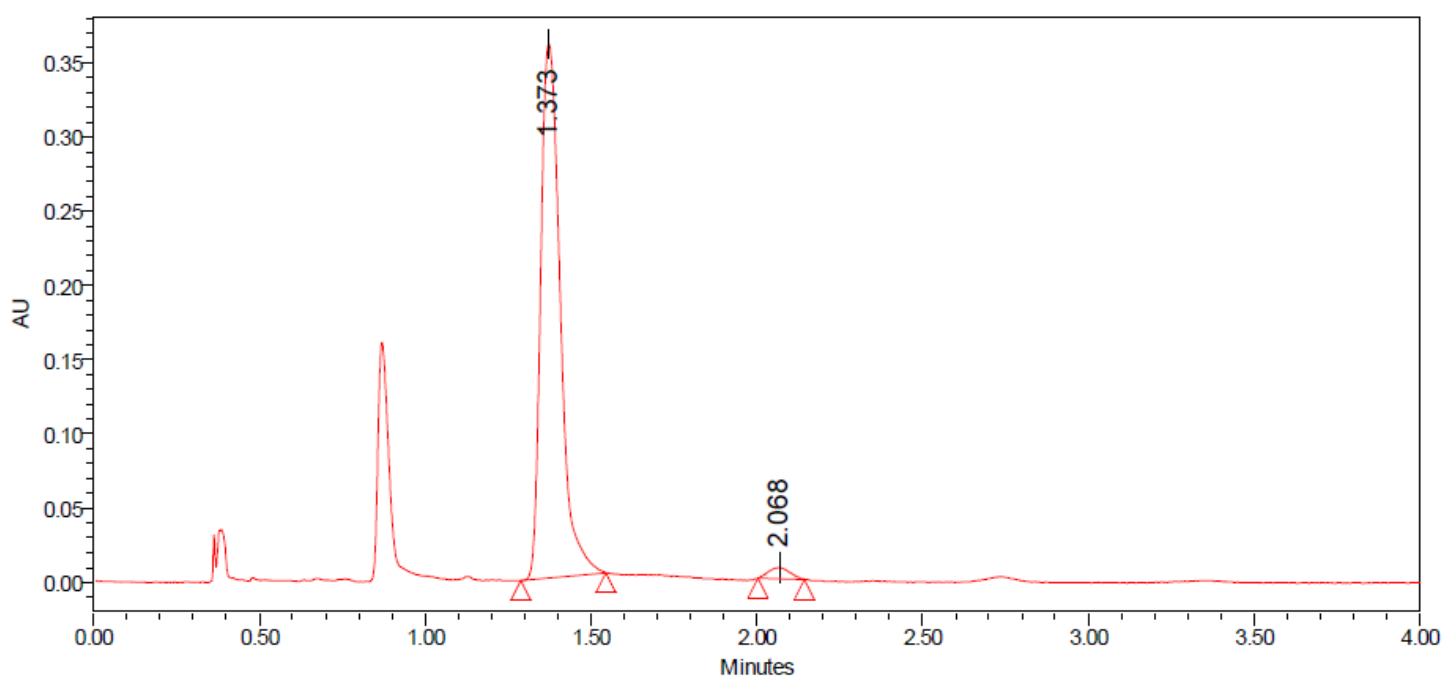

Processed Channel: PDA $214.0 \mathrm{~nm}$

$(190-400) \mathrm{nm}$

\begin{tabular}{|r|c|r|r|r|r|}
\hline & Processed Channel & $\begin{array}{r}\text { Retention } \\
\text { Time (min) }\end{array}$ & Area & \% Area & Height \\
\hline 1 & PDA 214.0 nm (190-400)nm & 1.373 & 1468583 & 97.74 & 359922 \\
\hline 2 & PDA 214.0 nm (190-400)nm & 2.068 & 33890 & 2.26 & 7644 \\
\hline
\end{tabular}

Figure 1. SFC analysis of the dipolar cycloaddition (enantioenriched sample), (+)-DIPT employed; AD-3 column.

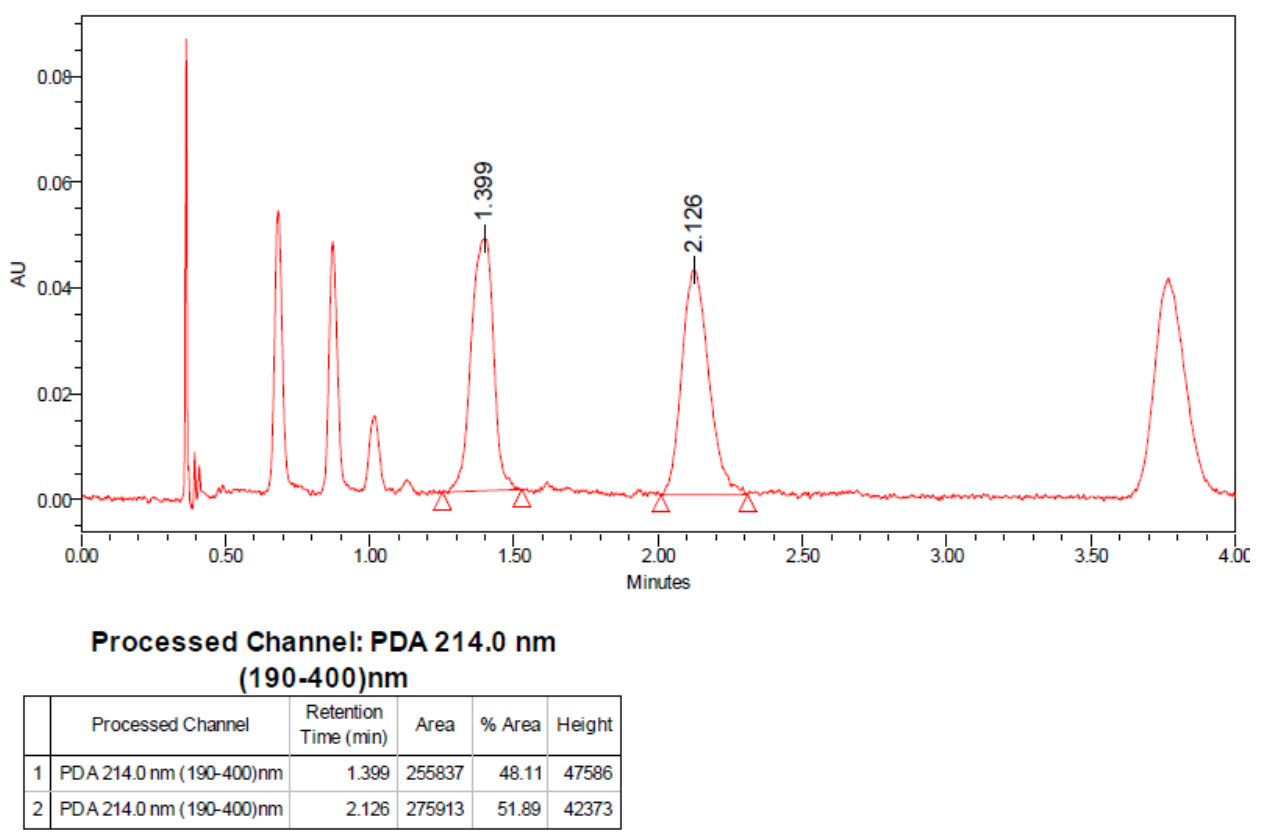

Figure 2. SFC analysis of the dipolar cycloaddition (racemic standard), (+)-DIPT employed; AD-3 column. 


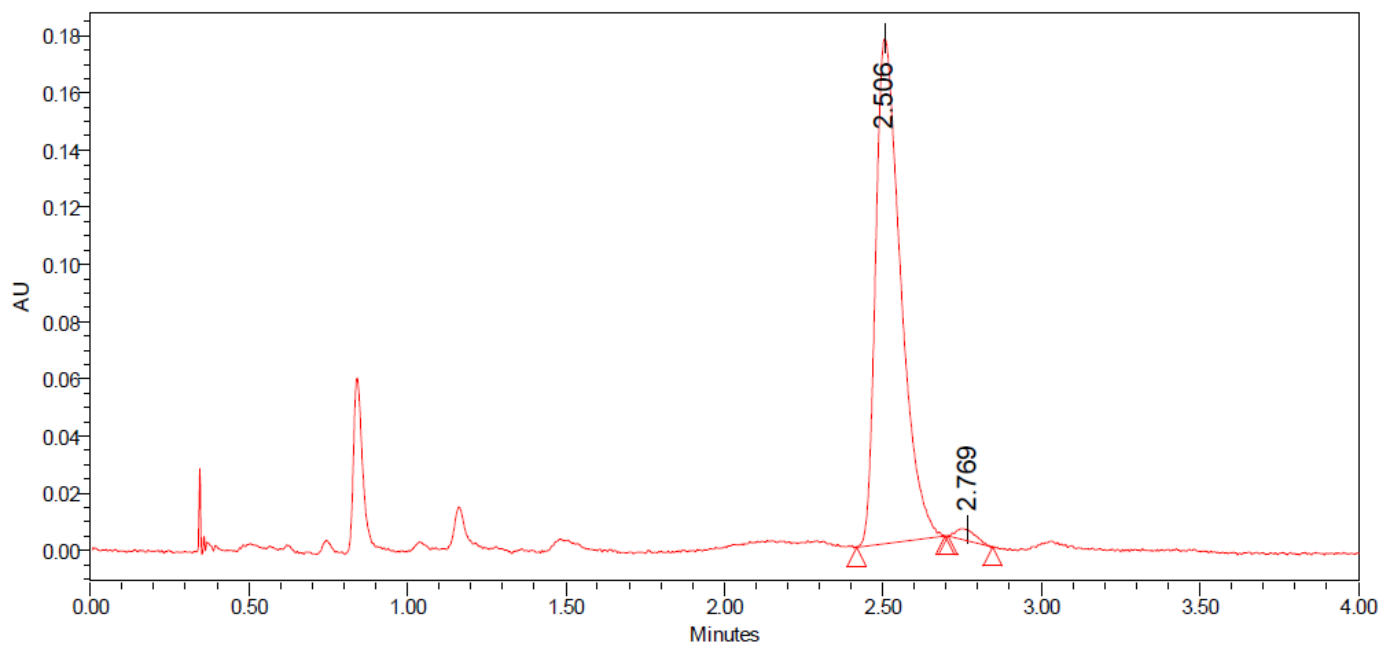

Processed Channel: PDA Ch2

214nm@1.2nm

\begin{tabular}{|l|c|r|r|r|r|}
\hline & Processed Channel & $\begin{array}{r}\text { Retention } \\
\text { Time }(\mathrm{min})\end{array}$ & Area & \% Area & Height \\
\hline 1 & PDA Ch2 214nm@1.2nm & 2.506 & 970927 & 98.27 & 176744 \\
\hline 2 & PDA Ch2 214nm@1.2nm & 2.769 & 17086 & 1.73 & 3936 \\
\hline
\end{tabular}

Figure 3. SFC analysis of the dipolar cycloaddition (enantioenriched sample), (-)-DIPT employed; Trefoil column.

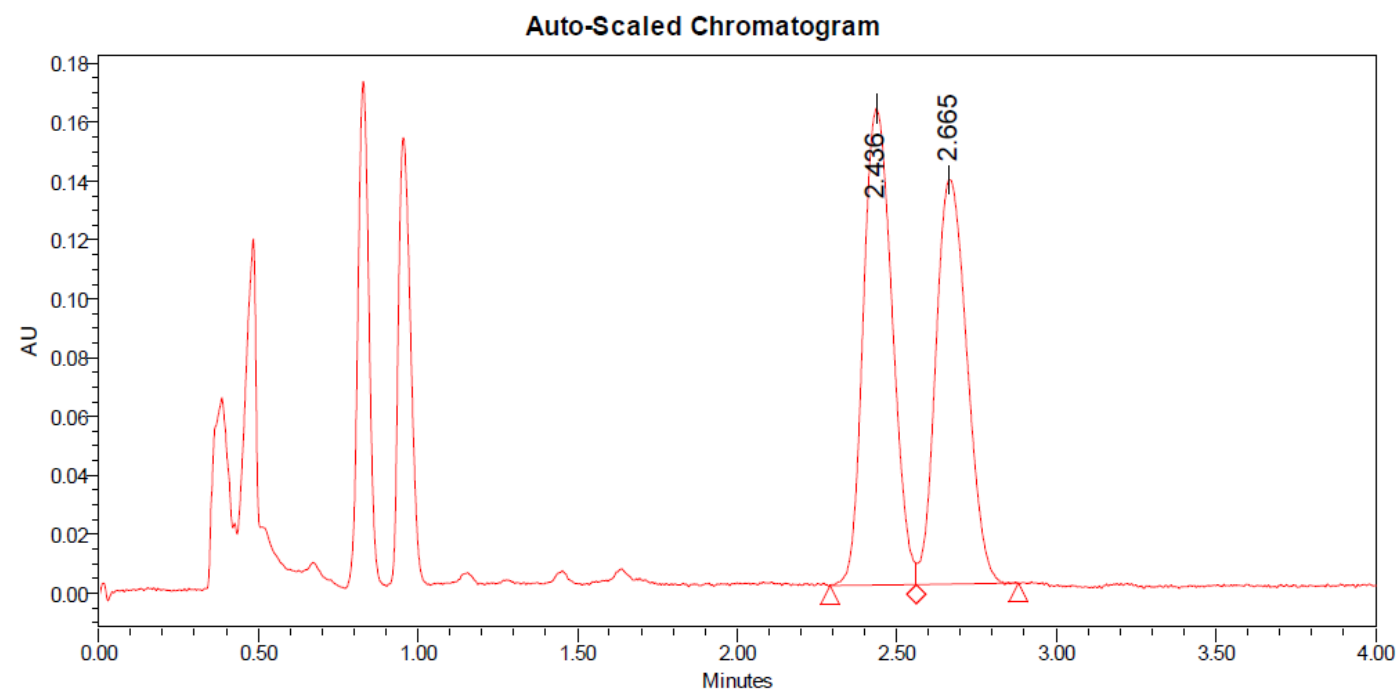

Processed Channel: PDA $214.0 \mathrm{~nm}$

$(190-400) \mathrm{nm}$

\begin{tabular}{|l|c|r|r|r|r|}
\hline & Processed Channel & $\begin{array}{r}\text { Retention } \\
\text { Time }(\mathrm{min})\end{array}$ & Area & \% Area & Height \\
\hline 1 & PDA 214.0 nm (190-400)nm & 2.436 & 1016290 & 52.10 & 161932 \\
\hline 2 & PDA 214.0 nm (190-400)nm & 2.665 & 934438 & 47.90 & 137459 \\
\hline
\end{tabular}

Figure 4. SFC analysis of the dipolar cycloaddition (enantioenriched sample), (-)-DIPT employed; Trefoil column. 


\subsection{Ethyl (4R,5R)-5-(((tert-butyldimethylsilyl)oxy)methyl)-3-nonyl-4,5-}

\section{dihydroisoxazole-4-carboxylate ${ }^{12}$}<smiles>CCO[SbH2]C[C@H]1ON=C(c2ccccc2)[C@H]1C(=O)OC</smiles>

SI-2

To a solution of SI-1 and $(R, R)-D I P T(32 \% \mathrm{wt})(11.7 \mathrm{~g}, 12.5 \mathrm{mmol}$, 1.0 equiv) and imidazole ( $3.57 \mathrm{~g}, 52.4 \mathrm{mmol}, 4.2$ equiv) in DMF $(60 \mathrm{~mL})$ was added TBSCl $\left(3.95 \mathrm{~g}, 26.2 \mathrm{mmol}, 2.1\right.$ equiv) at $0{ }^{\circ} \mathrm{C}$. The mixture was stirred for $1 \mathrm{~h}$. The solution was allowed to reach room temperature. Then, water $(60 \mathrm{~mL})$ and EtOAc $(30 \mathrm{~mL})$ were added. The layers were separated and the aqueous layer was extracted with EtOAc $(4 \times 40 \mathrm{~mL})$. The combined organic layers were washed with $5 \%$ aq $\mathrm{LiCl}$ solution $(3 \times 40 \mathrm{~mL})$, dried over magnesium sulfate, filtered and concentrated in vacuo to yield the crude product as a yellow oil. Flash column chromatography [hexane] to [hexane/EtOAc $=20: 1$ ] afforded the product as a colorless oil $(5.17 \mathrm{~g}, 12.5 \mathrm{mmol}$, quantitative).

$\mathbf{R}_{\mathbf{f}}=0.39[$ hexane/EtOAc $=9: 1]$

$[\boldsymbol{\alpha}]_{D}^{25}=-139\left(\mathrm{c}=1.0, \mathrm{CHCl}_{3}\right)$

${ }^{1} \mathbf{H}$ NMR (400 MHz, CDCl3): $\delta=4.86(\mathrm{dt}, J=7.5,4.3 \mathrm{~Hz}, 1 \mathrm{H}), 4.29-4.16(\mathrm{~m}, 2 \mathrm{H}), 4.04(\mathrm{~d}, J$ $=7.5 \mathrm{~Hz}, 1 \mathrm{H}), 3.74(\mathrm{dd}, J=4.2,0.9 \mathrm{~Hz}, 2 \mathrm{H}), 2.51-2.40(\mathrm{~m}, 1 \mathrm{H}), 2.36-2.27(\mathrm{~m}, 1 \mathrm{H}), 1.69-1.48$ $(\mathrm{m}, 2 \mathrm{H}), 1.30(\mathrm{t}, J=7.1 \mathrm{~Hz}, 3 \mathrm{H}), 1.35-1.25(\mathrm{~m}, 12 \mathrm{H}), 0.90-0.85(\mathrm{~m}, 3 \mathrm{H}), 0.88(\mathrm{~s}, 9 \mathrm{H}), 0.07$ (s, 3H), $0.06(\mathrm{~s}, 3 \mathrm{H}) \mathrm{ppm}$.

${ }^{13}$ C NMR (101 MHz, CDCl3): $\delta=169.0,155.7,83.8,63.1,61.9,56.7,32.0,29.6,29.4,27.1$, $26.3,25.9,22.8,18.4,14.3,14.3,-5.19,-5.30 \mathrm{ppm}$.

IR (ATR): $\tilde{\text { v }}=2954$ (m), 2927 (m), 2856 (m), 1740 (vs), 1464 (w), 1253 (s), 1134 (m), 836 (vs), $779(\mathrm{~m}), 668(\mathrm{w}) \mathrm{cm}^{-1}$

HRMS (ESI): $\quad$ calcd. for $\mathrm{C}_{22} \mathrm{H}_{44} \mathrm{NO}_{4} \mathrm{Si}^{+} \quad 414.3034[\mathrm{M}+\mathrm{H}]^{+}$ found: 414.3027 


\section{6 ((4S,5R)-5-(((Tert-butyldimethylsilyl)oxy)methyl)-3-nonyl-4,5-dihydroisoxazol-4- yl)methanol ${ }^{13}$}<smiles>CCCCCC1ON=C([OH2+])[C@H]1CO</smiles>

SI-3

To a solution of SI-2 $(12.0 \mathrm{~g}, 29.0 \mathrm{mmol}, 1.0$ equiv $)$ in ethanol $(58 \mathrm{~mL})$ was added sodium borohydride $(1.65 \mathrm{~g}, 43.5 \mathrm{mmol}$, 1.5 equiv). The mixture was stirred at room temperature for $12 \mathrm{~h}$. The colorless solution was diluted with ethyl acetate $(40 \mathrm{~mL})$ and quenched with a saturated, aqueous solution of ammonium chloride $(50 \mathrm{~mL})$. The layers were separated and the aqueous layer was extracted with EtOAc $(3 \times 30 \mathrm{~mL})$. The combined organic layers were washed with brine $(20 \mathrm{~mL})$, dried over magnesium sulfate, filtered and concentrated in vacuo to yield the crude product as a colorless oil. Flash column chromatography [hexane/EtOAc $=7: 3$ ] afforded the product as a colorless oil (10.8 g, $29.0 \mathrm{mmol}$, quantitative).

$\mathbf{R}_{\mathbf{f}}=0.33[$ hexane $/$ EtOAc $=7: 3]$

$[\alpha]_{D}^{25}=-51\left(\mathrm{c}=1.0, \mathrm{CHCl}_{3}\right)$

${ }^{1}$ H NMR (400 MHz, CDCl $): \delta=4.38(\mathrm{ddd}, J=7.9,7.1,4.3 \mathrm{~Hz}, 1 \mathrm{H}), 3.86(\mathrm{dd}, J=10.2$, $4.3 \mathrm{~Hz}, 1 \mathrm{H}), 3.83-3.80(\mathrm{~m}, 1 \mathrm{H}), 3.70(\mathrm{dd}, J=10.7,7.4 \mathrm{~Hz}, 1 \mathrm{H}), 3.63(\mathrm{dd}, J=10.3,7.0 \mathrm{~Hz}, 1 \mathrm{H})$, 3.33-3.26 (m, 1H), 2.45-2.33 (m, 1H), 2.26-2.14 (m, 1H), 1.69-1.48 (m, 2H), 1.39-1.18 (m, 12H), 0.90 (s, 9H), 0.88-0.86 (m, 3H), 0.10 (s, 3H), 0.09 (s, 3H) ppm.

${ }^{13}$ C NMR (101 MHz, CDCl 3$): \delta=159.1,84.1,64.0,62.1,55.8,32.0,29.6,29.5,29.4,26.8$, 26.2, 26.0, 22.8, 18.4, 14.3, $-5.30 \mathrm{ppm}$.

IR (ATR): $\tilde{\text { v }}=3403$ (br), 2954 (m), 2926 (s), 2856 (m), 1463 (w), 1253 (m), 1132 (m), 1096 (m), $836(\mathrm{~s}), 778(\mathrm{~s}), 670(\mathrm{w}) \mathrm{cm}^{-1}$

HRMS (ESI): $\quad$ calcd. for $\mathrm{C}_{20} \mathrm{H}_{42} \mathrm{NO}_{3} \mathrm{Si}^{+} \quad 372.2928[\mathrm{M}+\mathrm{H}]^{+}$ found: 372.2927 


\section{7 ((4S,5R)-5-(((Tert-butyldimethylsilyl)oxy)methyl)-3-nonyl-4,5-dihydroisoxazol-4-}

yl)methyl acetate ${ }^{14}$<smiles></smiles>

vacuo to obtain the crude product. Flash column chromatography [hexane] to [hexane/EtOAc $=20: 1]$ to $[$ hexane $/ \mathrm{EtOAc}=9: 1]$ afforded the product as a colorless oil $(5.05 \mathrm{~g}, 12.2 \mathrm{mmol}$, quantitative).

$\mathbf{R}_{\mathbf{f}}=0.24[$ hexane/EtOAc $=9: 1]$

$[\alpha]_{D}^{25}=-83\left(\mathrm{c}=1.0, \mathrm{CHCl}_{3}\right)$

${ }^{1} \mathbf{H}$ NMR (400 MHz, CDCl $): \delta=4.38(\mathrm{ddd}, J=6.6,5.5,4.2 \mathrm{~Hz}, 1 \mathrm{H}), 4.22(\mathrm{dd}, J=11.4$, $4.8 \mathrm{~Hz}, 1 \mathrm{H}), 4.15(\mathrm{dd}, J=11.4,6.1 \mathrm{~Hz}, 1 \mathrm{H}), 3.71(\mathrm{dd}, J=10.9,4.2 \mathrm{~Hz}, 1 \mathrm{H}), 3.64(\mathrm{dd}, J=10.8$, $5.5 \mathrm{~Hz}, 1 \mathrm{H}), 3.46-3.38(\mathrm{~m}, 1 \mathrm{H}), 2.47-2.34(\mathrm{~m}, 1 \mathrm{H}), 2.26-2.15(\mathrm{~m}, 1 \mathrm{H}), 2.07(\mathrm{~s}, 3 \mathrm{H}), 1.67-1.47$ (m, 2H), 1.39-1.20 (m, 12H), 0.88 (s, 9H), 0.91-0.86 (m, 3H), 0.07 (s, 3H), 0.06 (s, 3H).

${ }^{13}$ C NMR (101 MHz, CDCl $): \delta=170.9,158.2,83.0,63.4,62.6,51.0,32.0,29.6,29.4,29.4$, $29.4,26.6,26.3,26.0,22.8,20.9,18.4,14.3,-5.2,-5.3 \mathrm{ppm}$.

IR (ATR): $\tilde{\text { v }}=2954$ (m), 2927 (s), 2856 (m), 1748 (vs), 1464 (w), 1364 (w), 1226 (vs), 1118 (m), $837(\mathrm{~s}), 603(\mathrm{w}) \mathrm{cm}^{-1}$

HRMS (ESI): $\quad$ calcd. for $\mathrm{C}_{22} \mathrm{H}_{44} \mathrm{NO}_{4} \mathrm{Si}^{+} \quad 414.3034[\mathrm{M}+\mathrm{H}]^{+}$
414.3026 


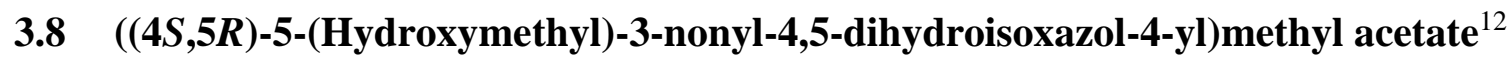<smiles>CC(=O)OC[C@H]1C([Hg]c2ccccc2)=NO[C@@H]1CO</smiles>

SI-5

To a solution of SI-4 $(9.67 \mathrm{~g}, 23.4 \mathrm{mmol}, 1.0$ equiv) in anhydrous THF (235 mL) was added dropwise a $1.0 \mathrm{M}$ solution of TBAF in THF (23.4 mL, $23.4 \mathrm{mmol}, 1.0$ equiv) at $0{ }^{\circ} \mathrm{C}$. The mixture was stirred at the same temperature for $20 \mathrm{~min}$. The solution was diluted with a 1:1

mixture of water and brine. The phases were separated and the aqueous layer extracted with EtOAc $(3 \times 20 \mathrm{~mL})$. The combined organic layers were washed with brine $(10 \mathrm{~mL})$, dried over magnesium sulfate, filtered and concentrated in vacuo to yield the crude product. Flash column chromatography [hexane/EtOAc $=4: 6$ ] afforded the product as a colorless oil $(7.00 \mathrm{~g}$, $23.4 \mathrm{mmol}$, quantitative).

$\mathbf{R}_{\mathbf{f}}=0.30[$ hexane/EtOAc $=4: 6]$

$[\alpha]_{D}^{25}=-99\left(\mathrm{c}=1.0, \mathrm{CHCl}_{3}\right)$

${ }^{1}$ H NMR (400 MHz, CDCl3): $\delta=4.44(\mathrm{ddd}, J=7.4,4.2,3.2 \mathrm{~Hz}, 1 \mathrm{H}), 4.28(\mathrm{dd}, J=11.4$, $4.6 \mathrm{~Hz}, 1 \mathrm{H}), 4.16$ (dd, $J=11.4,6.4 \mathrm{~Hz}, 1 \mathrm{H}), 3.83$ (dd, $J=12.2,3.2 \mathrm{~Hz}, 1 \mathrm{H}), 3.60$ (dd, $J=12.2$, $4.2 \mathrm{~Hz}, 1 \mathrm{H}), 3.42$ (dd, 7.3, 4.6 Hz, 1H), 2.46-2.36 (m, 1H), 2.28-2.19 (m, 1H), 2.08 (s, 3H), $1.68-1.49(\mathrm{~m}, 2 \mathrm{H}), 1.39-1.20(\mathrm{~m}, 12 \mathrm{H}), 0.90-0.85(\mathrm{~m}, 3 \mathrm{H})$.

${ }^{13}$ C NMR (101 MHz, CDCl3): $\delta$ 170.8, 159.2, 83.4, 63.3, 62.3, 50.6, 32.0, 29.6, 29.4, 26.6, 26.2, 22.8, 20.9, $14.3 \mathrm{ppm}$.

IR (ATR): $\tilde{v}=3419$ (br), 2924 (m), 1744 (vs), 1227 (vs), 1041 (m), 893 (w) cm-1

HRMS (ESI): $\quad$ calcd. for $\mathrm{C}_{16} \mathrm{H}_{29} \mathrm{NNaO}_{4}{ }^{+} \quad 322.1989[\mathrm{M}+\mathrm{Na}]^{+}$

found:

322.1988 


\section{9 ((4S,5R)-5-(((Methylsulfonyl)oxy)methyl)-3-nonyl-4,5-dihydroisoxazol-4-yl)methyl acetate $^{15}$}<smiles>COC[C@H]1ON=C(Cc2ccccc2)[C@H]1COC(C)=O</smiles>

SI-6

To a solution of SI-5 (3.65 g, $12.2 \mathrm{mmol}, 1.0$ equiv) and $\mathrm{NEt}_{3}$ (2.04 mL, $14.6 \mathrm{mmol}, 1.2$ equiv) in $\mathrm{CH}_{2} \mathrm{Cl}_{2}(120 \mathrm{~mL})$ at $-10{ }^{\circ} \mathrm{C}$ was added mesyl chloride (1.05 mL, $13.4 \mathrm{mmol}, 1.1$ equiv). The mixture was stirred at the same temperature for $30 \mathrm{~min}$. The colorless solution was diluted with water $(50 \mathrm{~mL})$ and $\mathrm{CH}_{2} \mathrm{Cl}_{2}(50 \mathrm{~mL})$. The layers were separated and the aqueous layer was extracted with $\mathrm{CH}_{2} \mathrm{Cl}_{2}(3 \times 20 \mathrm{~mL})$. The combined organic layers were washed with $1 \mathrm{M}$ aqueous $\mathrm{HCl}(50 \mathrm{~mL})$, followed by saturated, aqueous sodium bicarbonate solution $(50 \mathrm{~mL})$ and brine $(30 \mathrm{~mL})$, dried over magnesium sulfate, filtered and concentrated in vacuo to yield the crude product as a colorless oil. Flash column chromatography [hexane/EtOAc $=9: 1$ to 1:1] afforded the product as a colorless oil $(4.43 \mathrm{~g}, 11.7 \mathrm{mmol}, 96 \%$ yield).

$\mathbf{R}_{\mathbf{f}}=0.46[$ hexane/EtOAc $=1: 1]$

$[\alpha]_{D}^{25}=-70\left(\mathrm{c}=0.75, \mathrm{CHCl}_{3}\right)$.

${ }^{1}$ H NMR (400 MHz, CDCl3): $\delta=4.62(\mathrm{dt}, J=6.6,4.4 \mathrm{~Hz}, 1 \mathrm{H}), 4.35-4.25(\mathrm{~m}, 3 \mathrm{H}), 4.15(\mathrm{dd}$, $J=11.5,6.7 \mathrm{~Hz}, 1 \mathrm{H}), 3.41(\mathrm{ddd}, J=6.7,5.8,3.6 \mathrm{~Hz}, 1 \mathrm{H}), 3.08(\mathrm{~s}, 3 \mathrm{H}), 2.46-2.37(\mathrm{~m}, 1 \mathrm{H})$, 2.29-2.20 (m, 1H), 2.09 (s, 3H), 1.66-1.51 (m, 2H), 1.39-1.21 (m, 12H), 0.90-0.84 (m, 3H) ppm.

${ }^{13}$ C NMR (101 MHz, CDCl3): $\delta$ 170.7, 158.6, 80.2, 69.2, 62.0, 51.6, 37.9, 32.0, 29.6, 29.4, $29.4,26.5,26.2,22.8,20.8,14.3 \mathrm{ppm}$.

IR (ATR): $\tilde{\text { v }}=2926$ (m), 2855 (w), 1744 (s), 1357 (s), 1235 (s), 1176 (vs), 962 (m), 528 (w) $\mathrm{cm}^{-1}$

HRMS (ESI): $\quad$ calcd. for $\mathrm{C}_{17} \mathrm{H}_{32} \mathrm{NO}_{6} \mathrm{~S}^{+} \quad 378.1945[\mathrm{M}+\mathrm{H}]^{+}$

found: $\quad 378.1943$ 


\subsection{0 ((4S,5R)-5-(Azidomethyl)-3-nonyl-4,5-dihydroisoxazol-4-yl)methyl acetate ${ }^{16}$}<smiles>CC(=O)OC[C@H]1C(c2ccccc2)=NO[C@@H]1CN</smiles>

SI-7

A solution of SI-6 (420 mg, $1.11 \mathrm{mmol}, 1.0$ equiv) and sodium azide (362 $\mathrm{mg}, 5.56 \mathrm{mmol}, 5.0$ equiv) in anhydrous DMF $(5.5 \mathrm{~mL})$ was degassed by evacuating the atmosphere and replacing it with nitrogen gas (3 cycles). The mixture was stirred at $60^{\circ} \mathrm{C}$ for $20 \mathrm{~h}$. The brown suspension was allowed to reach room temperature and diluted with ethyl acetate $(10 \mathrm{~mL})$ and water $(10 \mathrm{~mL})$. The layers were separated and the aqueous layer was extracted with EtOAc (3 $\times 10 \mathrm{~mL}$ ). The combined organic layers were washed with $5 \%$ wt aqueous $\mathrm{LiCl}$ solution $(10 \mathrm{~mL})$, dried over magnesium sulfate, filtered and concentrated in vacuo to yield the crude product as a colorless oil. Flash column chromatography [hexane/EtOAc $=8: 2$ to 1:1] afforded the product as a colorless oil (365 mg, $1.12 \mathrm{mmol}$, quantitative).

$\mathbf{R}_{\mathbf{f}}=0.20[$ hexane/EtOAc $=8: 2]$

$[\alpha]_{D}^{25}=-161\left(\mathrm{c}=1.0, \mathrm{CHCl}_{3}\right)$

${ }^{1}$ H NMR (400 MHz, CDCl3): $\delta=4.51(\mathrm{dt}, J=6.5,4.6 \mathrm{~Hz}, 1 \mathrm{H}), 4.26(\mathrm{dd}, 11.4,4.6 \mathrm{~Hz}, 1 \mathrm{H})$, 4.12 (dd, 11.4, $6.7 \mathrm{~Hz}, 1 \mathrm{H}), 3.48(13.0,4.7 \mathrm{~Hz}, 1 \mathrm{H}), 3.39-3.29(\mathrm{~m}, 2 \mathrm{H}), 2.49-2.38$ (m, 1H), 2.29-2.19 (m, 1H), $2.08(\mathrm{~s}, 3 \mathrm{H}), 1.70-1.49(\mathrm{~m}, 2 \mathrm{H}), 1.40-1.21(\mathrm{~m}, 12 \mathrm{H}), 0.91-0.85(\mathrm{~m}, 3 \mathrm{H})$ ppm.

${ }^{13}$ C NMR (101 MHz, CDCl3): $\delta$ 170.7, 158.5, 81.4, 62.2, 53.1, 52.2, 32.0, 29.6, 29.4, 29.4, 26.5, 26.3, 22.8, 20.9, $14.3 \mathrm{ppm}$.

IR (ATR): $\tilde{\text { v }}=2926$ (m), 2102 (vs), 1746 (vs), 1466 (w), 1366 (w), 1228 (vs), 1040 (w), 890 (w) $\mathrm{cm}^{-1}$

HRMS (ESI): $\quad$ calcd. for $\mathrm{C}_{16} \mathrm{H}_{29} \mathrm{~N}_{4} \mathrm{O}_{3}{ }^{+} \quad 325.2234[\mathrm{M}+\mathrm{H}]^{+}$ found: 325.2229

Comments: Please consult the introductory comment about reactions involving azides. 


\subsection{1 ((4S,5R)-5-(Azidomethyl)-3-nonyl-4,5-dihydroisoxazol-4-yl)methanol ${ }^{17}$}

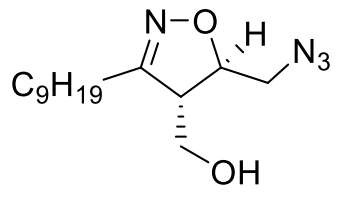

SI-8

To a solution of SI-7 (360 mg, $1.11 \mathrm{mmol}, 1.0$ equiv) in THF (5.5 mL) was added a $2 \mathrm{M}$ solution of sodium hydroxide in water $(6.6 \mathrm{~mL}$, $13.3 \mathrm{mmol}, 12.0$ equiv) at room temperature. The mixture was stirred for

$5 \mathrm{~h}$ at the same temperature before saturated, aqueous ammonium chloride solution $(10 \mathrm{~mL})$ was added. The layers were separated and the aqueous layer was extracted with EtOAc $(3 \times 10 \mathrm{~mL})$. The combined organic layers were washed with brine $(10 \mathrm{~mL})$, dried over magnesium sulfate, filtered and concentrated in vacuo to yield the crude product as a colorless oil. Flash column chromatography [hexane/EtOAc $=9: 1$ to 1:1] afforded the product as a colorless oil (312 $\mathrm{mg}, 1.10 \mathrm{mmol}$, quantitative).

$\mathbf{R}_{\mathbf{f}}=0.50[$ hexane/EtOAc $=1: 1]$

$[\alpha]_{D}^{25}=-194\left(\mathrm{c}=1.0, \mathrm{CHCl}_{3}\right)$

${ }^{1}$ H NMR (400 MHz, CDCl3): $\delta=4.57(\mathrm{dt}, J=6.5,4.8 \mathrm{~Hz}, 1 \mathrm{H}), 3.83(\mathrm{dd}, J=10.6,4.6 \mathrm{~Hz}$, $1 \mathrm{H}), 3.75(\mathrm{dd}, J=10.6,6.7 \mathrm{~Hz}, 1 \mathrm{H}), 3.50(\mathrm{dd}, J=12.9,4.7 \mathrm{~Hz}, 1 \mathrm{H}), 3.38(\mathrm{dd}, J=12.9,4.8 \mathrm{~Hz}$, $1 \mathrm{H}), 3.23(\mathrm{td}, J=6.5,4.7 \mathrm{~Hz}, 1 \mathrm{H}), 2.47-2.37$ (m, 1H), 2.29-2.19 (m, 1H), 1.69-1.50 (m, 2H), $1.40-1.21(\mathrm{~m}, 12 \mathrm{H}), 0.91-0.83(\mathrm{~m}, 3 \mathrm{H}) \mathrm{ppm}$.

${ }^{13}$ C NMR (101 MHz, CDCl3): $\delta$ 159.2, 81.4, 61.5, 55.2, 53.5, 32.0, 29.6, 29.4, 29.4, 26.7, 26.3, $22.8,14.3 \mathrm{ppm}$.

IR (ATR): $\tilde{v}=3390$ (br), 2927 (m), 2854 (m), 2100 (vs), 1466 (w), 1274 (w), 1047 (w) cm cm $^{-1}$

HRMS (ESI): $\quad$ calcd. for $\mathrm{C}_{14} \mathrm{H}_{27} \mathrm{~N}_{4} \mathrm{O}_{2}{ }^{+} \quad 283.2129[\mathrm{M}+\mathrm{H}]^{+}$

found:

283.2129 


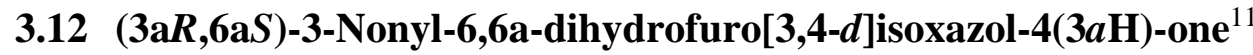<smiles>O=C1OC[C@H]2ON=C(c3ccccc3)[C@H]12</smiles>

SI-9

To neat SI-1 (46 wt\% in $(R, R)$-DIPT, $74.0 \mathrm{~g}, 114 \mathrm{mmol}, 1.0$ equiv) was added DBU ( $850 \mu \mathrm{L}, 5.68 \mathrm{mmol}, 0.05$ equiv). The solution turned yellow instantly. The flask was attached to a rotary evaporator $\left(5 \mathrm{mbar}, 40^{\circ} \mathrm{C}\right)$ for 10 min. Flash column chromatography $\left[\mathrm{CH}_{2} \mathrm{Cl}_{2}\right]$ to $\left[\mathrm{CH}_{2} \mathrm{Cl}_{2} / \mathrm{EtOAc}=9: 1\right]$ afforded the product as a colorless oil (27.0 g, $107 \mathrm{mmol}, 94 \%$ yield).

$\mathbf{R}_{\mathbf{f}}=0.45$ [hexane/EtOAc $\left.=7: 3\right]$

$[\alpha]_{D}^{25}=+78\left(\mathrm{c}=1.0, \mathrm{CHCl}_{3}\right)$

${ }^{1}$ H NMR (400 MHz, CDCl $): \delta 5.46(\mathrm{ddd}, J=9.7,6.0,2.3 \mathrm{~Hz}, 1 \mathrm{H}), 4.63(\mathrm{dd}, J=10.9,6.0 \mathrm{~Hz}$, 1H), 4.49 (dd, $J=10.9,2.3 \mathrm{~Hz}, 1 \mathrm{H}), 4.13$ (d, $J=9.6 \mathrm{~Hz}, 1 \mathrm{H}), 2.67-2.55$ (m, 1H), 2.51-2.40 (m, 1H), 1.79-1.55 (m, 2H), 1.41-1.20 (m, 12H), 0.91-0.80 (m, 3H) ppm.

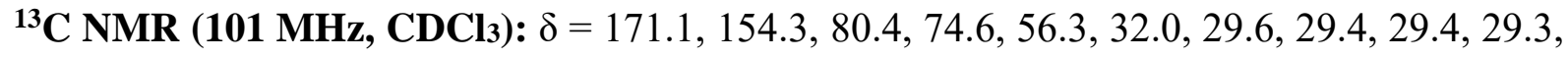
26.0, 25.9, 22.8, $14.2 \mathrm{ppm}$.

IR (ATR): $\tilde{\text { v }}=2962$ (w), 2915 (m), 1752 (vs), 1471 (m), $1177(\mathrm{~s}), 1036(\mathrm{w}), 754(\mathrm{w}) \mathrm{cm}^{-1}$

HRMS (ESI): $\quad$ calcd. for $\mathrm{C}_{14} \mathrm{H}_{24} \mathrm{NO}_{3}{ }^{+} \quad 254.1751[\mathrm{M}+\mathrm{H}]^{+}$

found:

254.1747 


\subsection{Optimization of the Lactone Opening}

Initial results for the lactone opening:<smiles>O=C1OC[C@H]2ON=C([Hg])[C@H]12</smiles>

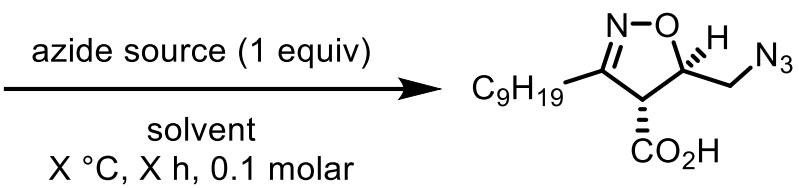

1 equiv

\begin{tabular}{|c|c|c|c|c|c|c|}
\hline Entry $^{\mathrm{a}}$ & Azide & Solvent & Temperature $\left({ }^{\circ} \mathbf{C}\right)$ & Time (h) & Yield $(\%)^{\mathrm{c}}$ & Conversion (\%) \\
\hline 1 & $\mathrm{NaN}_{3}$ & DMSO & 110 & 18 & $>1$ & 100 \\
\hline 2 & $\mathrm{NaN}_{3}$ & DMF & 90 & 18 & 9 & 51 \\
\hline 3 & $\mathrm{NaN}_{3}$ & HMPA & 90 & 18 & - & 33 \\
\hline 4 & $\mathrm{NaN}_{3}$ & $\mathrm{MeCN}$ & 90 & 18 & - & 10 \\
\hline 5 & $\mathrm{NaN}_{3}$ & DMF & 70 & 72 & 6 & 54 \\
\hline 6 & $\mathrm{TMSN}_{3}$ & DMSO & 80 & 18 & - & 10 \\
\hline $7^{\mathrm{b}, \mathrm{d}}$ & $\mathrm{TMSN}_{3}$ & $\mathrm{CH}_{2} \mathrm{Cl}_{2}$ & 40 & 96 & - & 10 \\
\hline
\end{tabular}

${ }^{\mathrm{a}}$ Reaction run on a $5 \mathrm{mg}$ scale. ${ }^{\mathrm{b}}$ Reaction run on a $50 \mathrm{mg}$ scale. ${ }^{\mathrm{c}}$ Determined by ${ }^{1} \mathrm{H}$ NMR analysis of the crude reaction mixture using 1,3,5-trimethoxybenzene as an internal standard. ${ }^{\mathrm{d}}$ With $10 \mathrm{~mol} \% \mathrm{FeCl}_{3}$.

\section{Effect of azide sources and additive:}<smiles>[13CH3]C1=NO[C@@H]2COC(=O)[C@@H]12</smiles>

1 equiv

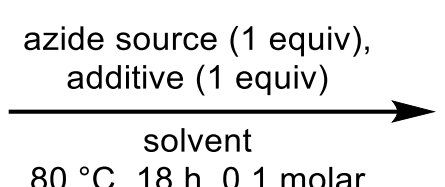

$80{ }^{\circ} \mathrm{C}, 18 \mathrm{~h}, 0.1$ molar<smiles>NC[C@H]1ON=C([Hg])[C@H]1C(=O)O</smiles>

\begin{tabular}{|c|c|c|c|c|c|}
\hline Entry ${ }^{a}$ & Azide & Additive & Solvent & Yield $(\%)^{\mathrm{c}}$ & Conversion (\%) ${ }^{\mathrm{c}}$ \\
\hline 1 & $\mathrm{KN}_{3}$ & 18-crown-6 & DMF & 18 & 45 \\
\hline 2 & $\mathrm{KN}_{3}$ & 18-crown-6 & $\mathrm{MeCN}$ & 10 & 32 \\
\hline $3^{\mathrm{b}}$ & $\mathrm{NaN}_{3}$ & 15-crown-5 & DMF & 9 & 39 \\
\hline $4^{\mathrm{b}}$ & $\mathrm{NaN}_{3}$ & 15-crown-5 & $\mathrm{MeCN}$ & 2 & 12 \\
\hline 5 & TBAA & - & DMF & 25 & 82 \\
\hline 6 & TBAA & - & $\mathrm{MeCN}$ & 22 & 37 \\
\hline
\end{tabular}

${ }^{\mathrm{a}}$ Reaction run on a $50 \mathrm{mg}$ scale. ${ }^{\mathrm{b}}$ Reaction run on a $5 \mathrm{mg}$ scale. TBAA $=$ tetrabutylammonium azide. ${ }^{\mathrm{c}}$ Determined by ${ }^{1} \mathrm{H}$ NMR analysis of the crude reaction mixture using 1,3,5-trimethoxybenzene as an internal standard. 


\section{Effect of increasing crown ether equivalents:}

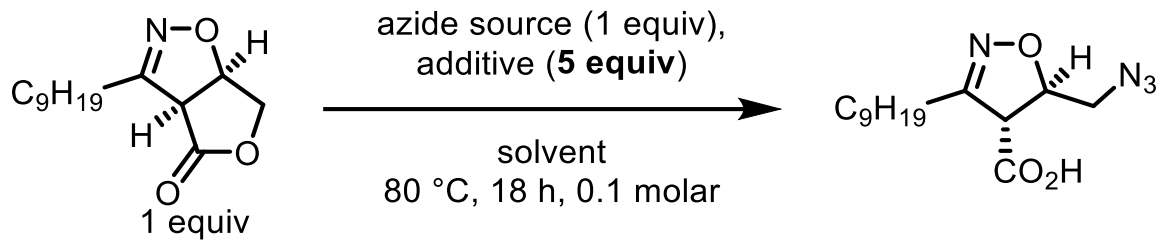

\begin{tabular}{cccccc}
\hline Entry & Azide & Additive & Solvent & Yield (\%) $^{\mathbf{c}}$ & Conversion (\%) $^{\mathbf{c}}$ \\
\hline $\mathbf{1}^{\mathbf{a}}$ & $\mathrm{KN}_{3}$ & $\mathbf{1 8}$-crown-6 & DMF & $\mathbf{3 0}$ & $\mathbf{7 0}$ \\
$2^{\mathrm{a}}$ & $\mathrm{KN}_{3}$ & 18 -crown-6 & $\mathrm{MeCN}$ & 20 & 50 \\
$3^{\mathrm{b}}$ & $\mathrm{NaN}_{3}$ & $15-$ crown-5 & $\mathrm{MeCN}$ & 5 & 35 \\
$4^{\mathrm{b}}$ & $\mathrm{NaN}_{3}$ & $15-$ crown-5 & $\mathrm{DMF}$ & 10 & 13 \\
\hline
\end{tabular}

${ }^{\mathrm{a}}$ Reaction run on a $50 \mathrm{mg}$ scale. ${ }^{\mathrm{b}}$ Reaction run on a $5 \mathrm{mg}$ scale. ${ }^{\mathrm{c}}$ Determined by ${ }^{1} \mathrm{H}$ NMR analysis of the crude reaction mixture using 1,3,5-trimethoxybenzene as an internal standard.

\section{Effect of concentration:}<smiles>O=C1OC[C@H]2ON=C([Hg])[C@H]12</smiles>

1 equiv

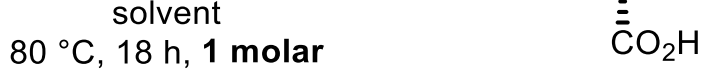

$80{ }^{\circ} \mathrm{C}, 18 \mathrm{~h}, 1$ molar

\begin{tabular}{cccccc}
\hline Entry $^{\mathbf{a}}$ & Azide & Additive & Solvent & Yield (\%) $^{\mathbf{b}}$ & ${\text { Conversion }(\%)^{\mathbf{b}}}^{\mathbf{b}}$ \\
\hline $\mathbf{1}$ & $\mathbf{K N}_{\mathbf{3}}$ & $\mathbf{1 8}$-crown -6 & DMF & $\mathbf{3 6}$ & $\mathbf{9 6}$ \\
2 & $\mathrm{KN}_{3}$ & 18 -crown-6 & MeCN & 33 & 100 \\
3 & $\mathrm{NaN}_{3}$ & 15 -crown-5 & DMF & 31 & 72 \\
4 & $\mathrm{NaN}_{3}$ & 15 -crown-5 & MeCN & 26 & 69 \\
5 & $\mathrm{TBAA}$ & - & $\mathrm{DMF}$ & 29 & 100 \\
\hline
\end{tabular}

${ }^{\mathrm{a}}$ Reaction run on a $50 \mathrm{mg}$ scale. ${ }^{\mathrm{b}}$ Determined by ${ }^{1} \mathrm{H}$ NMR analysis of the crude reaction mixture using 1,3,5-trimethoxybenzene as an internal standard.

\section{Effect of solvent:}

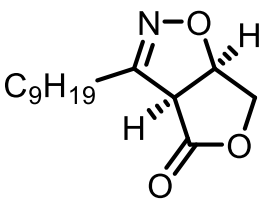

1 equiv

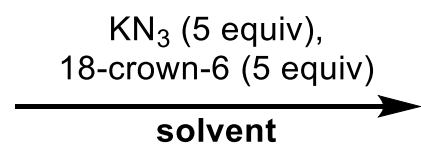

$80^{\circ} \mathrm{C}, 18 \mathrm{~h}, 1$ molar<smiles>NC[C@H]1ON=C(Cc2ccccc2)[C@H]1C(=O)O</smiles>

$\overline{\mathrm{C}} \mathrm{O}_{2} \mathrm{H}$

\begin{tabular}{ccccc}
\hline Entry $^{\mathbf{a}}$ & Solvent & ${\text { Yield }(\boldsymbol{\%})^{\mathbf{b}}}^{\mathbf{b}}$ & ${\text { Conversion }(\boldsymbol{\%})^{\mathbf{b}}}^{\mathbf{b}}$ & ${\text { Yield }(\mathbf{b r s m})^{\mathbf{b}}(\boldsymbol{\%})}$ \\
\hline 1 & Hexafluoroacetone trihydrate & - & - & - \\
2 & Propylene carbonate & - & - & - \\
3 & Hexafluorobenzene & - & - & $\mathbf{3 8}$ \\
$\mathbf{4}$ & Toluene & $\mathbf{1 2}$ & $\mathbf{3 2}$ & 38 \\
5 & Butyl formate & 18 & 48 & 33 \\
6 & Ethyl acetate & 20 & 61 & 21 \\
7 & HMPA & 20 & 97 & $\mathbf{3 9}$ \\
$\mathbf{8}$ & 2-Methylanisole & $\mathbf{2 1}$ & $\mathbf{5 4}$ & 52
\end{tabular}




$\begin{array}{lcccc}10 & \text { THF } & 22 & 74 & 30 \\ 11 & \text { Trifluorotoluene } & 24 & 50 & 48 \\ 12 & \text { 1,4-Dioxane } & 26 & 82 & 32 \\ 13 & \text { Isobutyronitrile } & 28 & 86 & 33 \\ 14 & \text { Butanone } & 28 & 87 & 32 \\ 15 & \text { Benzonitrile } & 31 & 80 & 39 \\ 16 & \text { Propionitrile } & 31 & 91 & 34 \\ \mathbf{1 7} & \text { DMSO } & \mathbf{3 2} & \mathbf{1 0 0} & \mathbf{3 2} \\ 18 & \text { 1,2-Dichlorobenzene } & 32 & 71 & \mathbf{3 3} \\ \mathbf{1 9} & \text { NMP } & \mathbf{3 3} & \mathbf{1 0 0} & \mathbf{3 4} \\ \mathbf{2 0} & \text { Sulfolane } & 34 & \mathbf{1 0 0} & 59 \\ 21 & \text { 1,2-Dimethoxybenzene } & 34 & 58 & 38 \\ 22 & \text { 2-Nitropropane } & 36 & \mathbf{7 6} & \mathbf{5 3} \\ \mathbf{2 3} & \text { Nitrobenzene } & \mathbf{4 0} & 92 & 46 \\ 24 & \text { DMPU } & \mathbf{4 3} & \mathbf{7 7} & \mathbf{5 6} \\ \mathbf{2 5} & \text { Nitromethane } & \mathbf{4 3} & \mathbf{8 6} & \mathbf{5 3} \\ \mathbf{2 6} & \text { Pyridine } & \mathbf{4 6} & \end{array}$

${ }^{\mathrm{a}}$ Reaction run on a $50 \mathrm{mg}$ scale. ${ }^{\mathrm{b}}$ Determined by ${ }^{1} \mathrm{H}$ NMR analysis of the crude reaction mixture using 1,3,5-trimethoxybenzene as an internal standard.

\section{Optimization of temperature and time:}

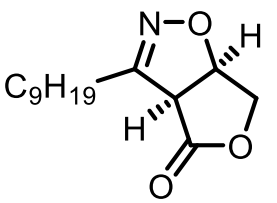

1 equiv

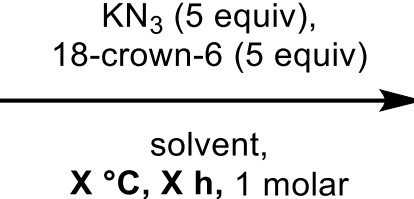

$\mathbf{X}^{\circ} \mathbf{C}, \mathbf{X} \mathbf{h}, 1$ molar<smiles>NC[C@H]1ON=C([Hg]c2ccccc2)[C@H]1C(=O)O</smiles>

\begin{tabular}{cccccc}
\hline Entry $^{\mathbf{a}}$ & Solvent & Temperature $\left({ }^{\circ} \mathbf{C}\right)$ & Time $(\mathbf{h})$ & ${\text { Yield }(\boldsymbol{\%})^{\mathbf{b}}}$ & ${\text { Conversion }(\boldsymbol{\%})^{\mathbf{b}}}^{\mathbf{2}}$ \\
\hline 1 & DMSO & 70 & 18 & 22 & 44 \\
2 & NMP & 70 & 18 & 20 & 45 \\
3 & 2-Methylanisole & 80 & 24 & 21 & 44 \\
4 & Toluene & 80 & 24 & 16 & 41 \\
5 & Pyridine & 70 & 24 & 19 & 35 \\
$\mathbf{6}$ & Pyridine & $\mathbf{7 0}$ & $\mathbf{7 2}$ & $\mathbf{4 7}$ & $\mathbf{9 7}$ \\
7 & Pyridine & 75 & 24 & 31 & 56 \\
8 & Pyridine & 75 & 72 & 37 & 100 \\
9 & Sulfolane & 70 & 18 & 26 & 35 \\
10 & Sulfolane & 70 & 24 & 30 & 61 \\
$\mathbf{1 1}$ & Sulfolane & $\mathbf{7 0}$ & $\mathbf{7 2}$ & $\mathbf{4 7}$ & $\mathbf{8 9}$ \\
12 & Sulfolane & 75 & 24 & 43 & 73 \\
13 & Sulfolane & 75 & 72 & 38 & 100 \\
\hline
\end{tabular}

${ }^{\mathrm{a}}$ Reaction run on a $50 \mathrm{mg}$ scale. ${ }^{\mathrm{b}}$ Determined by ${ }^{1} \mathrm{H}$ NMR analysis of the crude reaction mixture using 1,3,5-trimethoxybenzene as an internal standard. 
Influence of temperature and molarity:
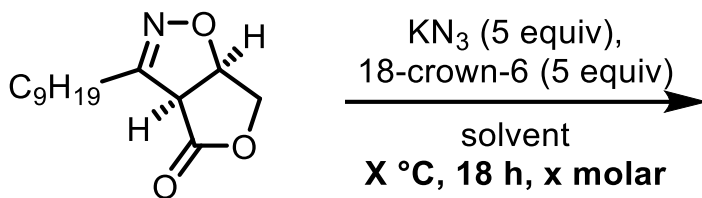

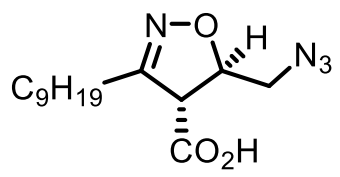

1 equiv

\begin{tabular}{|c|c|c|c|c|c|}
\hline Entry $^{a}$ & Solvent & Temperature $\left({ }^{\circ} \mathbf{C}\right)$ & Molarity (mol/L) & Yield $(\%)^{b}$ & Conversion (\%) \\
\hline 1 & Sulfolane & 70 & 1.5 & 19 & 35 \\
\hline 2 & Sulfolane & 70 & 2 & 17 & 34 \\
\hline 3 & Pyridine & 70 & 2 & 15 & 41 \\
\hline 4 & Pyridine & 75 & 2 & 27 & 49 \\
\hline 5 & Nitromethane & 70 & 2 & 12 & 44 \\
\hline 6 & Nitromethane & 75 & 2 & 12 & 42 \\
\hline 7 & Nitrobenzene & 70 & 2 & 14 & 30 \\
\hline 8 & Nitrobenzene & 75 & 2 & 17 & 75 \\
\hline
\end{tabular}

${ }^{\mathrm{a}}$ Reaction run on a $50 \mathrm{mg}$ scale. ${ }^{\mathrm{b}}$ Determined by ${ }^{1} \mathrm{H}$ NMR analysis of the crude reaction mixture using 1,3,5-trimethoxybenzene as an internal standard.

\section{Deuterium incorporation study}

A solution of lactone SI-9 or acid SI-10 was heated in an NMR tube in a mixture of $\mathrm{D}_{2} \mathrm{O}$ in pyridine-d $(5: 95, \mathrm{v} / \mathrm{v}) .{ }^{1} \mathrm{H}$ NMR spectra were recorded every $10 \mathrm{~min}$.<smiles>[13CH3]C1=NO[C@@H]2COC(=O)[C@@H]12</smiles>

syn

SI-9

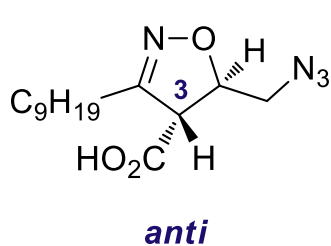

SI-10

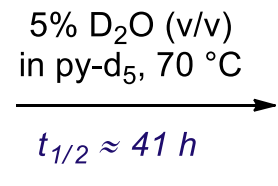

$\mathrm{C}_{9} \mathrm{H}_{19}$

syn

SI-9

$5 \% \mathrm{D}_{2} \mathrm{O}(\mathrm{v} / \mathrm{v})$

in py-d ${ }_{5}, 70^{\circ} \mathrm{C}$

$t_{1 / 2} \approx 50 \mathrm{~min}$

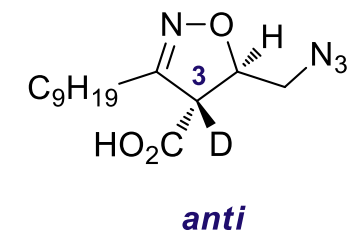

SI-10

Data analysis was performed using python v.3.8.5. The integral of H-3 was plotted against the time using pandas v1.1.3 ${ }^{18}$ and matplotlib v3.3.1 ${ }^{19}$ (Figure 5 and Figure 6). 
Deuterium Incorporation Lactone at $70{ }^{\circ} \mathrm{C}$ in Pyridine- $\mathrm{d}_{5}$ with $5 \% \mathrm{D}_{2} \mathrm{O}$

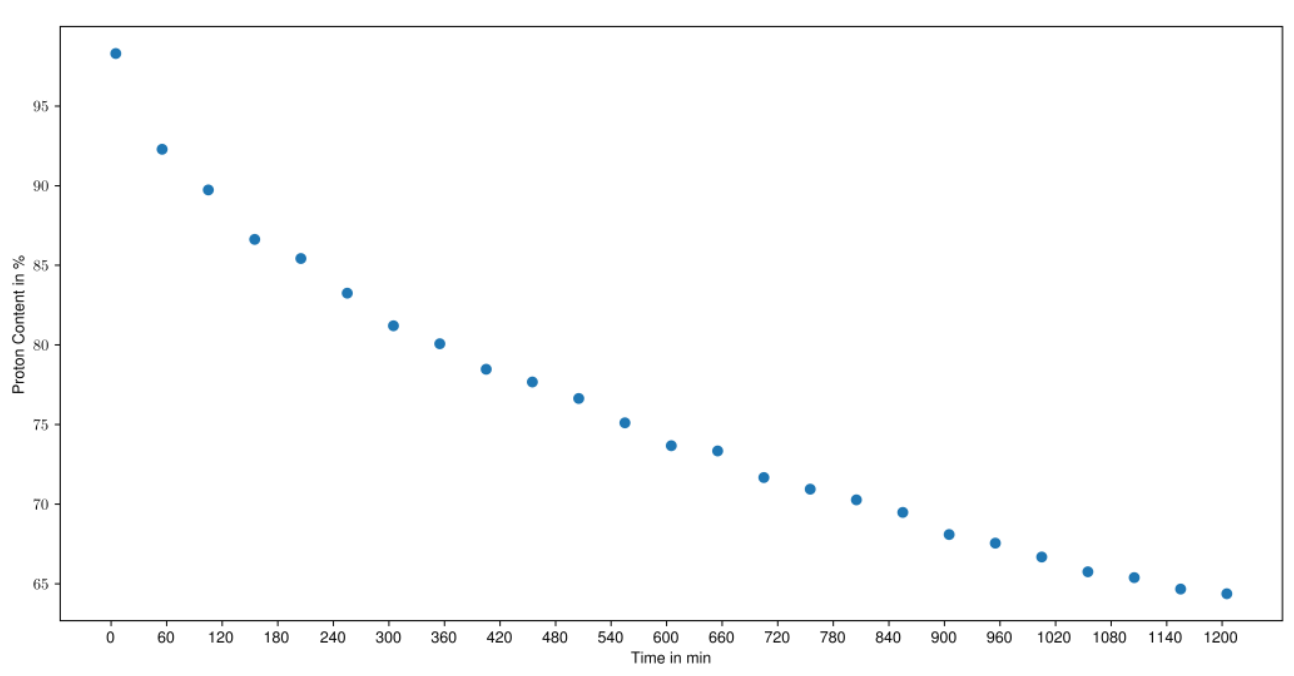

Figure 5. Integral of H-3 in lactone SI-9 as a function of time in a mixture of $\mathrm{D}_{2} \mathrm{O}$ in pyridine- $\mathrm{d}_{5}(5: 95, \mathrm{v} / \mathrm{v})$.

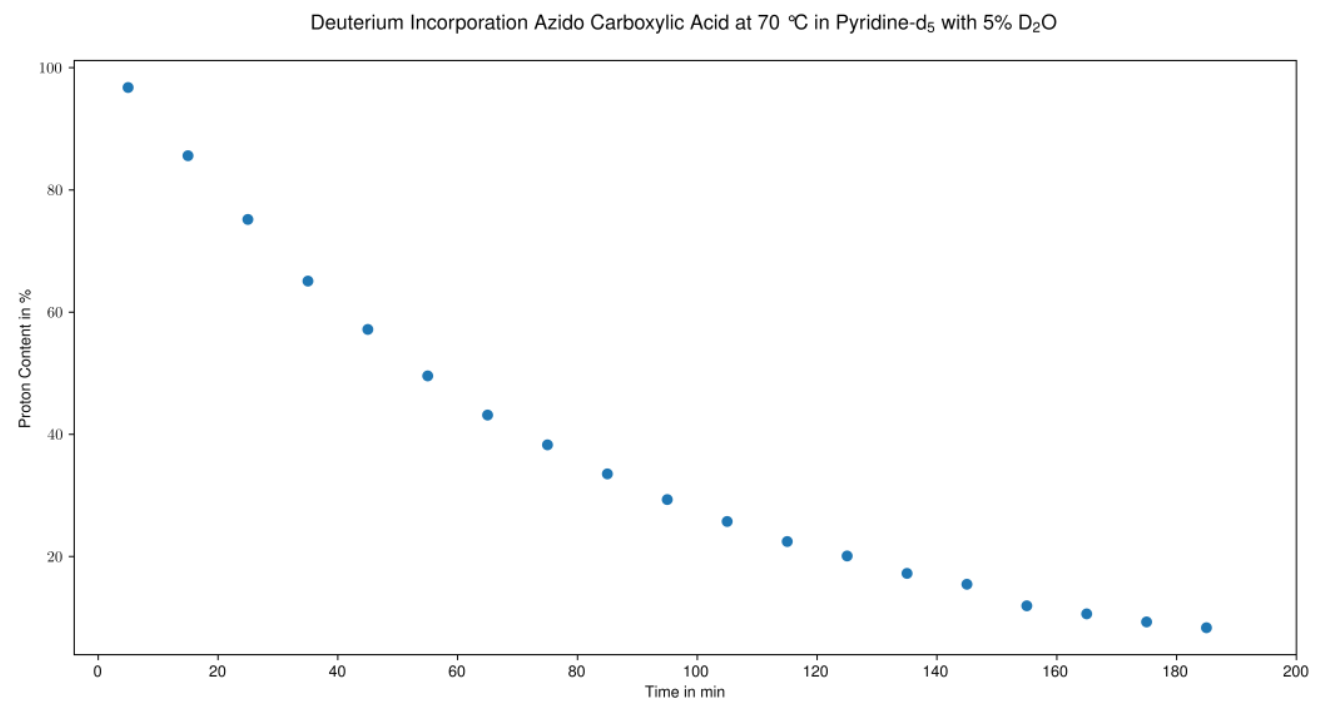

Figure 6. Integral of H-3 in acid SI-10 as a function of time in a mixture of $\mathrm{D}_{2} \mathrm{O}$ in pyridine-d5 (5:95, v/v).

Linear regression of the natural logarithm $\ln$ of the integral of $\mathrm{H}-3$ against the time was performed using sklearn v0.23.2 20 and numpy v1.19.1 ${ }^{21}$ (Figure 7 and Figure 8 ) and resulted in a half life = $51 \mathrm{~min}$ for SI-10 and $41 \mathrm{~h}$ for lactone SI-9. The findings suggest that both species may undergo exchange at C-3, however, acid SI-10 much more rapidly than lactone SI-9 indicating nucleophilic lactone opening with azide precedes epimerization of C-3. 


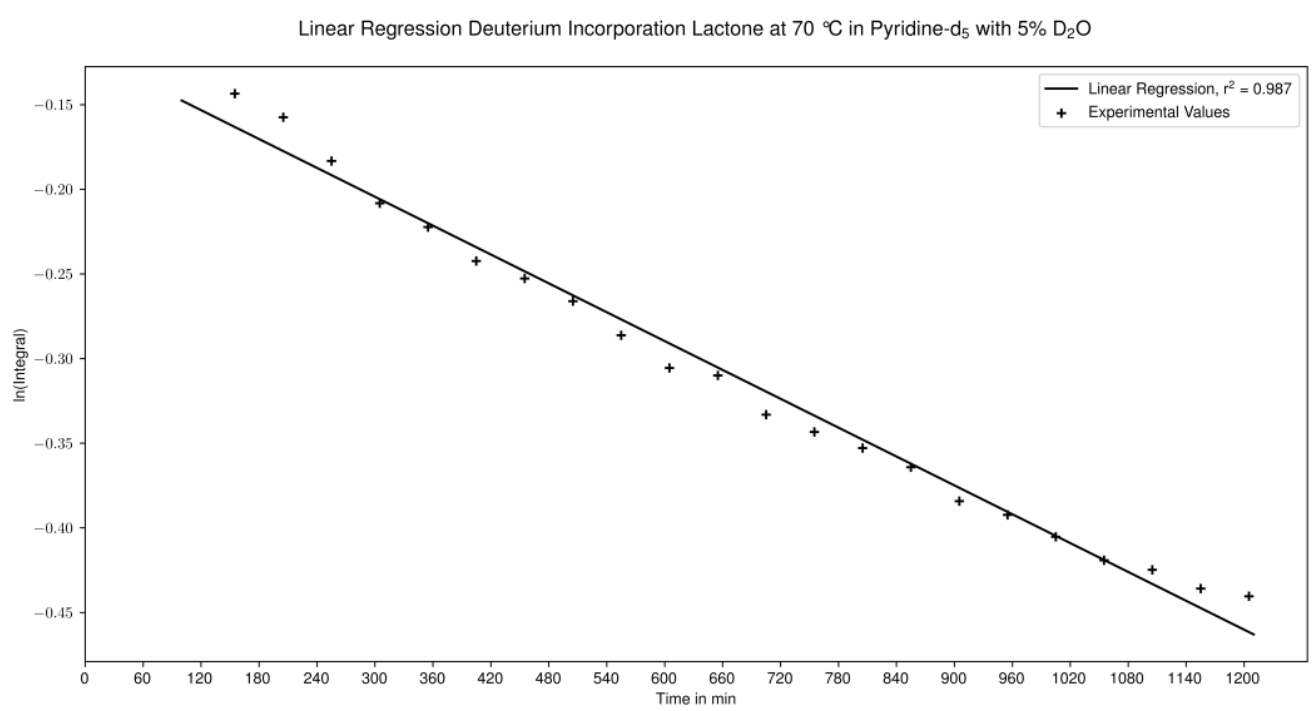

Figure 7. Linear regression analysis of deuterium incorporation of H-3 in lactone SI-9 as a function of time in a mixture of $\mathrm{D}_{2} \mathrm{O}$ in pyridine- $\mathrm{d}_{5}(5: 95, \mathrm{v} / \mathrm{v})$.

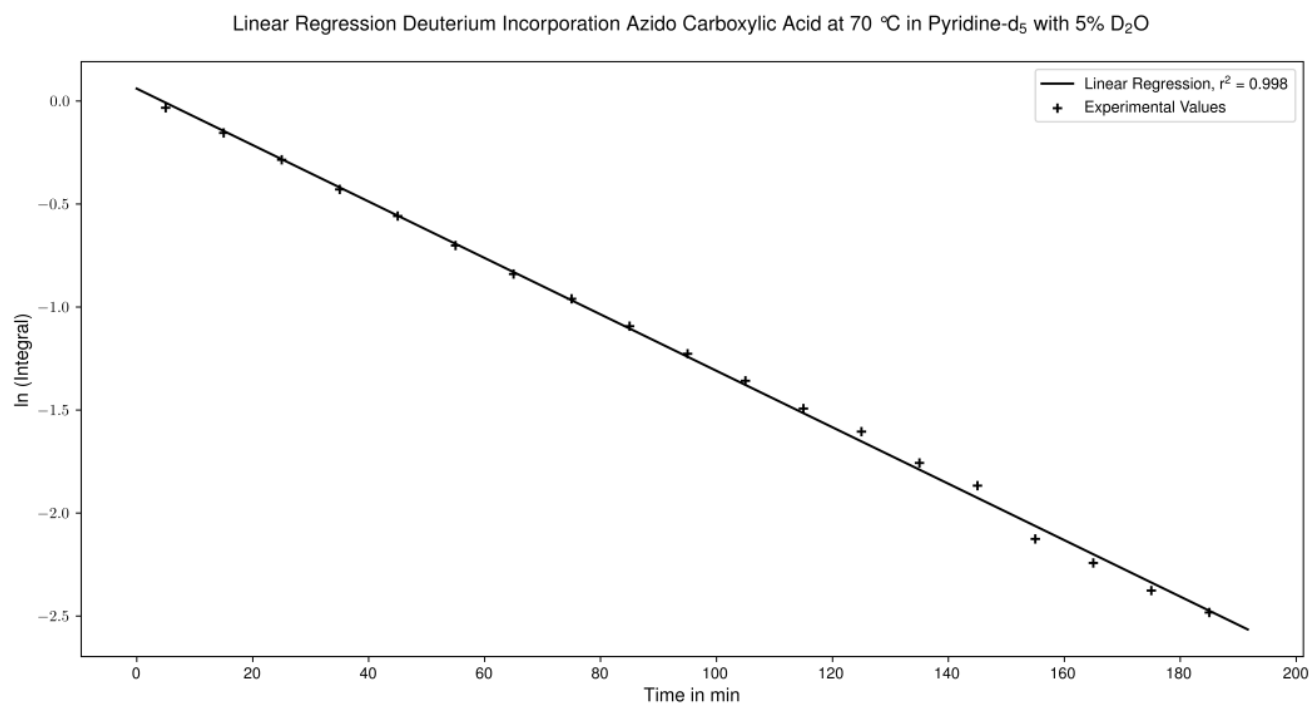

Figure 8. Linear regression analysis of deuterium incorporation of H-3 in acid SI-10 as a function of time in a mixture of $\mathrm{D}_{2} \mathrm{O}$ in pyridine- $\mathrm{d}_{5}(5: 95, \mathrm{v} / \mathrm{v})$. 


\subsection{4 (4R,5R)-5-(Azidomethyl)-3-nonyl-4,5-dihydroisoxazole-4-carboxylic acid ac-25 $^{22}$}<smiles>NC[C@H]1ON=C(c2ccccc2)[C@H]1C(=O)O</smiles>

SI-10

Procedure 1: To a solution of SI-8 (1.69 g, $6.00 \mathrm{mmol}, 1.0$ equiv) in wet acetonitrile $(30 \mathrm{~mL}, 0.75 \% \mathrm{v})$ at $0{ }^{\circ} \mathrm{C}$ was added a solution of $\mathrm{CrO}_{3}$ (7.20 mg, $0.0720 \mathrm{mmol}, 1.20 \mathrm{~mol} \%)$ and $\mathrm{H}_{5} \mathrm{IO}_{6}(3.42 \mathrm{~g}, 15.0 \mathrm{mmol}$,

2.5 equiv) in wet acetonitrile ( $35 \mathrm{~mL}, 0.75 \% \mathrm{v}$ ) over $60 \mathrm{~min}$. The mixture was stirred at $0{ }^{\circ} \mathrm{C}$ for $30 \mathrm{~min}$. The reaction was quenched by addition of $\mathrm{Na}_{2} \mathrm{HPO}_{4}(1.80 \mathrm{~g}$ in $\left.30 \mathrm{~mL} \mathrm{H}_{2} \mathrm{O}\right)$ and extracted with toluene $(3 \times 50 \mathrm{~mL})$. The combined organic layers were washed with a 1:1 mixture of water and brine $(2 \times 30 \mathrm{~mL}), 5 \%$ aqueous $\mathrm{NaHSO}_{3}(15 \mathrm{~mL})$ and brine $(15 \mathrm{~mL})$, dried over magnesium sulfate, filtered and concentrated in vacuo. Flash column chromatography [hexane/EtOAc $=7: 3$ ] to [hexane/EtOAc $=7: 3+1 \% \mathrm{AcOH}]$ afforded the product as a colorless oil (1.63 g, $5.50 \mathrm{mmol}, 92 \%$ yield).

\section{Procedure 2:}

In order to increase the overall yield and decrease reaction times, we ran the reaction at $80{ }^{\circ} \mathrm{C}$ for only $18 \mathrm{~h}$. Application of these conditions led to lower conversion of the starting material to the product albeit higher overall yield based on recovered starting material. Re-isolation of starting material was straightforward and the re-isolated starting material performed similarly in a second run.

A suspension of SI-9 (1.00 g, $3.95 \mathrm{mmol}, 1.0$ equiv), potassium azide (1.67 g, $20.6 \mathrm{mmol}, 5.0$ equiv) and 18-crown-6 (5.48 g, $20.7 \mathrm{mmol}, 5.0$ equiv) in dry pyridine (4 mL) was heated to 80 ${ }^{\circ} \mathrm{C}$ for $18 \mathrm{~h}$. The reaction mixture homogenized and gradually changed color to a very dark red. Then, it was cooled to room temperature and sat. aq. $\mathrm{NaHCO}_{3}(50 \mathrm{~mL})$ and EtOAc $(50 \mathrm{~mL})$ were added. The phases were separated, and the aqueous layer was further extracted with EtOAc $(2 \times 50 \mathrm{~mL})$. The combined organic layers were washed with $1 \mathrm{M}$ aq. $\mathrm{HCl}(20 \mathrm{~mL})($ after the test with ferric chloride impregnated paper was negative) and brine (20 mL), dried over magnesium sulfate, filtered and concentrated in vacuo. Flash column chromatography $[$ hexane/EtOAc $=1: 1]$ to $[$ hexane/EtOAc $=1: 1+1 \% \mathrm{AcOH}]$ afforded the product as a brown wax (543 mg, $1.83 \mathrm{mmol}, 46 \%$ [53\% brsm]) as well as starting material (142 mg, $0.561 \mathrm{mmol}$, $14 \%)$ as a brown wax and decarboxylated product SI-11 (77.6 $\mathrm{mg}, 0.308 \mathrm{mmol}, 8 \%)$ as a brown wax.

$\mathbf{R}_{\mathbf{f}}=0.26[$ hexane/EtOAc $=1: 1+1 \% \mathrm{AcOH}]$

$[\alpha]_{D}^{25}=-189\left(\mathrm{c}=0.5, \mathrm{CHCl}_{3}\right)$ 
${ }^{1}$ H NMR (400 MHz, CDCl $): \delta 5.02(\mathrm{dt}, J=7.1,4.1 \mathrm{~Hz}, 1 \mathrm{H}), 4.01(\mathrm{~d}, J=7.0 \mathrm{~Hz}, 1 \mathrm{H}), 3.61$ (dd, $J=13.3,4.2 \mathrm{~Hz}, 1 \mathrm{H}), 3.38(\mathrm{dd}, J=13.3,4.0 \mathrm{~Hz}, 1 \mathrm{H}), 2.63-2.50(\mathrm{~m}, 1 \mathrm{H}), 2.48-2.34$ (m, 1H), 1.76-1.52 (m, 2H), 1.42-1.19 (m, 12H), 0.95-0.81 (m, 3H).

${ }^{13}$ C NMR (101 MHz, CDCl3): $\delta=171.1,155.5,81.4,56.8,52.3,32.0,29.6,29.40,29.38,29.3$, 26.9, 26.2, 22.8, $14.3 \mathrm{ppm}$.

IR (ATR): $\tilde{\text { v }}=2925$ (s), 2105 (vs), 1739 (vs), 1464 (w), 1378 (w), 1261 (vs), 1021 (m), 801 (s), $722(\mathrm{w}) \mathrm{cm}^{-1}$

HRMS (ESI): $\quad$ calcd. for $\mathrm{C}_{14} \mathrm{H}_{23} \mathrm{~N}_{4} \mathrm{O}_{3}{ }^{+} \quad 295.1776[\mathrm{M}-\mathrm{H}]^{+}$ found: 295.1776

XRD: $\quad$ Crystals suitable for X-ray diffractions were obtained by recrystallization from EtOAc.

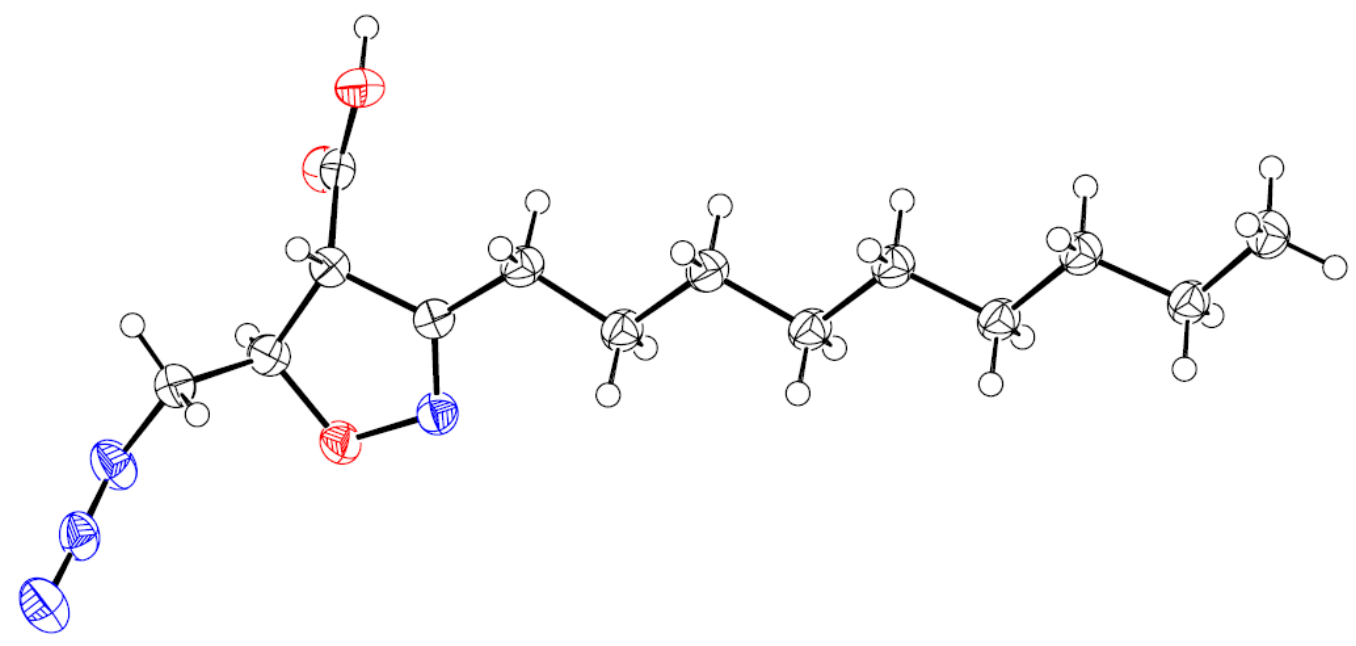

Comments: Please consult the introductory comment about reactions involving azides.

The reaction could be scaled:

A suspension of SI-9 $(5.07 \mathrm{~g}, 20.0 \mathrm{mmol}, 1.0$ equiv), potassium azide $(8.03 \mathrm{~g}, 99.0 \mathrm{mmol}$, 5.0 equiv) and 18-crown-6 (26.8 g, $101 \mathrm{mmol}, 5.0$ equiv) in dry pyridine (20 mL) was heated to $80{ }^{\circ} \mathrm{C}$ for $18 \mathrm{~h}$. The reaction mixture homogenizes and gradually changes color to a very dark red. Then, it was cooled to room temperature and sat. aq. $\mathrm{NaHCO}_{3}(100 \mathrm{~mL})$ and EtOAc 
$(100 \mathrm{~mL})$ were added. The phases were separated, and the aqueous layer was further extracted with EtOAc $(2 \times 100 \mathrm{~mL})$. The combined organic layers were washed with $1 \mathrm{M} \mathrm{aq} . \mathrm{HCl}(50 \mathrm{~mL})$ and brine $(50 \mathrm{~mL})$, dried over magnesium sulfate, filtered and concentrated in vacuo. Flash column chromatography [hexane/EtOAc $=1: 1]$ to $[$ hexane/EtOAc $=1: 1+1 \% \mathrm{AcOH}$ ] afforded the product as a brown wax $(2.22 \mathrm{~g}, 7.49 \mathrm{mmol}, 37 \%$ yield [53\% yield brsm] $)$ as well as starting material (1.54 g, $6.08 \mathrm{mmol}, 30 \%$ yield) as a brown wax and decarboxylated product SI-11 (0.596 g, $2.36 \mathrm{mmol}, 12 \%$ yield) as a brown wax.

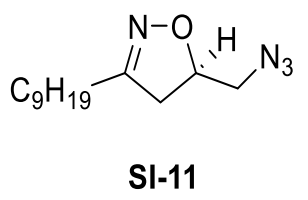

$\mathbf{R}_{\mathbf{f}}=0.80[$ hexane/EtOAc $=1: 1+1 \% \mathrm{AcOH}]$

${ }^{1} \mathbf{H}$ NMR (400 MHz, CDCl3): $\delta=4.71(\mathrm{ddt}, J=11.3,6.7,4.7 \mathrm{~Hz}, 1 \mathrm{H}), 3.42(\mathrm{dd}, J=12.9,4.6$ $\mathrm{Hz}, 1 \mathrm{H}), 3.33(\mathrm{dd}, J=12.9,4.9 \mathrm{~Hz}, 1 \mathrm{H}), 3.03(\mathrm{dd}, J=17.0,10.6 \mathrm{~Hz}, 1 \mathrm{H}), 2.78(\mathrm{dd}, J=17.1$, $6.7 \mathrm{~Hz}, 1 \mathrm{H}), 2.36$ (t, $J=7.7 \mathrm{~Hz}, 2 \mathrm{H}), 1.57$ (app. p, $J=7.5 \mathrm{~Hz}, 2 \mathrm{H}), 1.40-1.17$ (m, 12H), 0.88 $(\mathrm{t}, \mathrm{J}=7.1 \mathrm{~Hz}, 3 \mathrm{H}) \mathrm{ppm}$.

${ }^{13}$ C NMR (101 MHz, $\left.\mathbf{C D C l}_{3}\right): \delta$ 159.1, 77.9, 53.7, 40.1, 32.0, 29.6, 29.4, 29.3, 27.7, 26.5, 22.8, $14.3 \mathrm{ppm}$.

HRMS (ESI): $\quad$ calcd. for $\mathrm{C}_{13} \mathrm{H}_{24} \mathrm{~N}_{4} \mathrm{NaO}^{+} \quad 275.1842[\mathrm{M}+\mathrm{Na}]^{+}$ found: 275.1845 


\section{$3.15(S)-2-((S)-2-((S)-1-(((4 R, 5 R)-5-($ Aminomethyl)-3-nonyl-4,5-dihydroisoxazole-4-}

carbonyl)-L-leucyl-D-alanyl)pyrrolidine-2-carboxamido)-3methylbutanamido)butanoic acid ${ }^{26}$

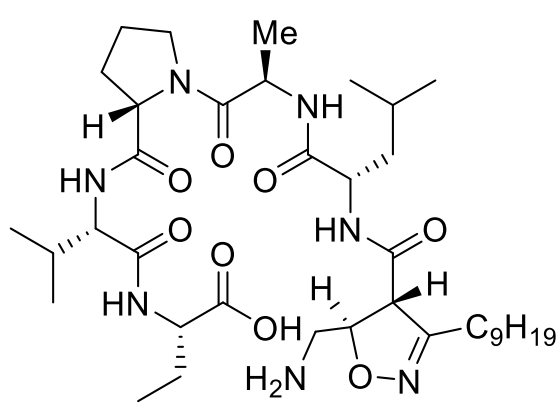

SI-12
Loading of the resin:

2-Cl-Trt resin $(5.00 \mathrm{~g})$ was suspended in dry $\mathrm{CH}_{2} \mathrm{Cl}_{2}$ and agitated with a flow of nitrogen for $30 \mathrm{~min}$. The resin was drained and a solution of Fmoc-Abu-OH (716 mg, $2.20 \mathrm{mmol}, 1.0$ equiv) and DIPEA (1.54 mL, $8.80 \mathrm{mmol}$, 4.0 equiv) in dry $\mathrm{CH}_{2} \mathrm{Cl}_{2}$ was added. The resin was agitated with a flow of nitrogen for $2 \mathrm{~h}$. The solution was drained and the resin washed thoroughly with $\mathrm{CH}_{2} \mathrm{Cl}_{2}, \mathrm{DMF}$, and $\mathrm{Et}_{2} \mathrm{O}$. Residual solvent was removed under a constant flow of nitrogen for $30 \mathrm{~min}$. Unreacted positions were capped with a mixture of $10 \% \mathrm{MeOH}$ and 5\% DIPEA in DMF $(2 \times 5 \mathrm{~min})$. The loading of the resin was determined by the way described by Dong et al. $(0.37 \mathrm{mmol} / \mathrm{g}){ }^{27}$

\section{Fmoc cleavage:}

The resin was washed with DMF, then treated with a mixture of $20 \%$ piperidine in DMF $(3 \times$ 5 min). Subsequently, it was washed with $\mathrm{CH}_{2} \mathrm{Cl}_{2}$, DMF, and $\mathrm{Et}_{2} \mathrm{O}$.

\section{Amino acid coupling:}

The corresponding Fmoc-protected amino acid (6.60 mmol, 3.0 equiv), HATU (2.43 g, $6.38 \mathrm{mmol}, 2.9$ equiv) and DIPEA (1.11 mL, $6.38 \mathrm{mmol}, 2.9$ equiv) were dissolved in DMF. The solution was aged for $5 \mathrm{~min}$ and then added to the resin. The suspension was agitated with a flow of nitrogen for $30 \mathrm{~min}$ (45 $\mathrm{min}$ in case of D-Ala), after which the solution was drained. The coupling process was repeated once. The resin was washed thoroughly with $\mathrm{CH}_{2} \mathrm{Cl}_{2}, \mathrm{DMF}$, and $\mathrm{Et}_{2} \mathrm{O}$. Unreacted $\mathrm{N}$-termini were capped with a freshly prepared mixture of acetic anhydride, DIPEA and DMF (1:1:3) for 15 min after which the resin was washed again.

\section{Coupling of SI-10:}

SI-10 (267 mg, $0.900 \mathrm{mmol}, 1.5$ equiv), HOBt (137 mg, $0.894 \mathrm{mmol}, 1.49$ equiv), and DIC (139 $\mu \mathrm{L}, 0.894 \mathrm{mmol}, 1.49$ equiv) were dissolved in $\mathrm{CH}_{2} \mathrm{Cl}_{2}$. The mixture was aged for $30 \mathrm{~min}$ and then added to the resin $(1.94 \mathrm{~g}, 0.600 \mathrm{mmol}, 0.31 \mathrm{mmol} / \mathrm{g}$ loading). The suspension was agitated with a flow of nitrogen for 90 min. The resin was washed thoroughly with $\mathrm{CH}_{2} \mathrm{Cl}_{2}$, 
$\mathrm{DMF}$, and $\mathrm{Et}_{2} \mathrm{O}$. Unreacted $\mathrm{N}$-termini were capped with a freshly prepared mixture of acetic anhydride, DIPEA and DMF (1:1:3) for $15 \mathrm{~min}$; the resin was washed again.

$\underline{\text { Reduction of the azide: }}$

A solution of trimethylphosphine $(9.00 \mathrm{~mL}, 9.00 \mathrm{~mL}, 15$ equiv, $1.0 \mathrm{M}$ in THF) and water $(900 \mu \mathrm{L})$ was added to the resin. The reaction vessel was put under an atmosphere of nitrogen, sealed, and agitated for $2 \mathrm{~h}$ using a shaker. The reaction solution was drained and the resin washed with $\mathrm{CH}_{2} \mathrm{Cl}_{2}$, DMF, and $\mathrm{Et}_{2} \mathrm{O}$. Residual solvent was removed under a constant flow of nitrogen for $30 \mathrm{~min}$.

Final cleavage of the product:

The resin was treated with a mixture of HFIP and $\mathrm{CH}_{2} \mathrm{Cl}_{2}$ (1:4) for $30 \mathrm{~min}$. The solution was collected and the cleavage process repeated twice. The combined solutions were concentrated in vacuo to yield the crude title compound as a colorless foam $(375 \mathrm{mg}, 0.510 \mathrm{mmol}, 85 \%$ yield). The purity of the product was determined by analytical HPLC to be $89 \%$ (5-100\% acetonitrile). An analytical sample was obtained by preparative HPLC purification as a mixture of rotamers (all peaks reported).

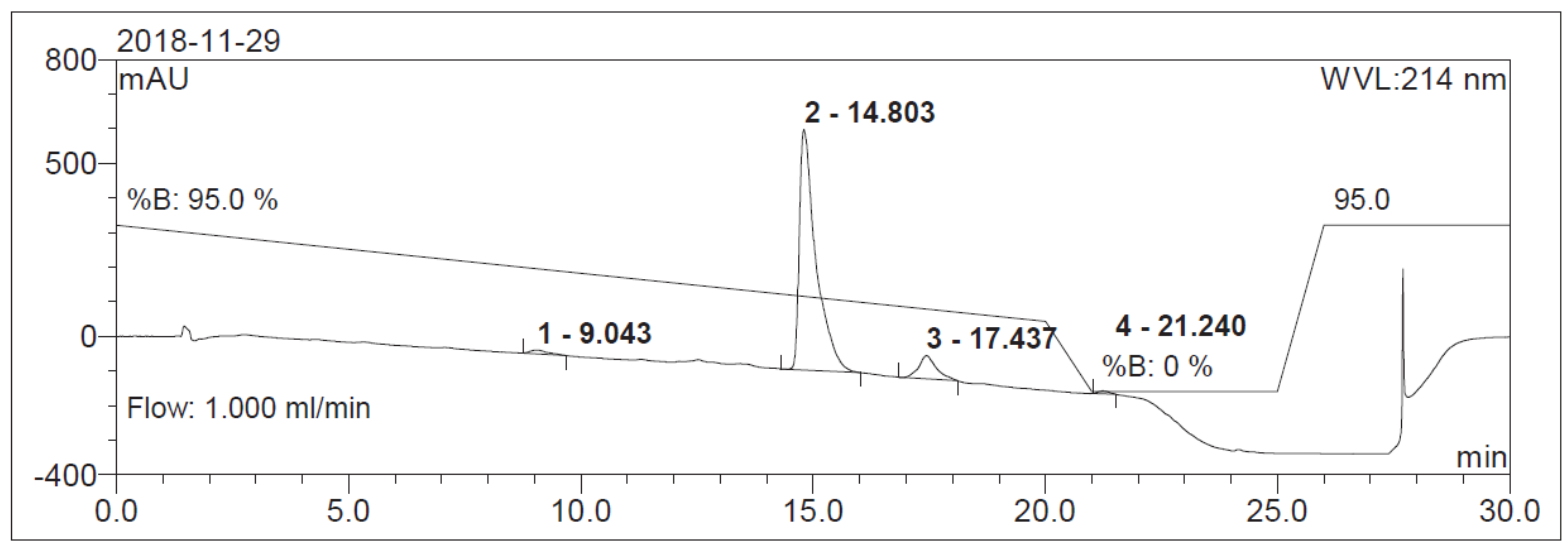

\begin{tabular}{|c|l|r|r|r|r|}
\hline $\begin{array}{c}\text { Peak } \\
\text { No. }\end{array}$ & $\begin{array}{l}\text { Component } \\
\text { Name }\end{array}$ & $\begin{array}{c}\text { Retention } \\
\text { Time }\end{array}$ & $\begin{array}{c}\text { Height } \\
\text { mAU }\end{array}$ & $\begin{array}{c}\text { Area } \\
\text { mA*min }\end{array}$ & $\begin{array}{c}\text { Rel.Area } \\
\%\end{array}$ \\
\hline 1 & n.a. & 9.04 & 11.365 & 4.857 & 1.49 \\
2 & n.a. & 14.80 & 695.126 & 288.246 & 88.56 \\
3 & n.a. & 17.44 & 67.485 & 30.176 & 9.27 \\
4 & n.a. & 21.24 & 8.319 & 2.220 & 0.68 \\
\hline
\end{tabular}

Figure 9. Analytical HPLC trace of crude SI-12 after cleavage from the resin.

$\mathbf{R}_{\mathbf{f}}=0.41\left[20 \% \mathrm{MeOH} / \mathrm{CH}_{2} \mathrm{Cl}_{2}\right]$

$[\alpha]_{D}^{25}=-249\left(\mathrm{c}=0.25, \mathrm{CHCl}_{3}\right)$. 
${ }^{1}$ H NMR (400 MHz, DMSO-d6): $\delta 10.34$ (d, $\left.J=8.9 \mathrm{~Hz}, 1 \mathrm{H}\right), 8.45(\mathrm{~d}, J=8.5 \mathrm{~Hz}, 0.18 \mathrm{H}), 8.38$ $(\mathrm{d}, J=7.1 \mathrm{~Hz}, 0.18 \mathrm{H}), 8.19-8.16(\mathrm{~m}, 0.18 \mathrm{H}), 8.14(\mathrm{~d}, J=5.5 \mathrm{~Hz}, 1 \mathrm{H}), 7.86(\mathrm{~d}, J=7.2 \mathrm{~Hz}$, $0.2 \mathrm{H}), 7.75(\mathrm{~d}, J=9.1 \mathrm{~Hz}, 1 \mathrm{H}), 7.29(\mathrm{~d}, J=6.2 \mathrm{~Hz}, 1 \mathrm{H}), 4.85(\mathrm{dd}, J=8.7,2.6 \mathrm{~Hz}, 0.2 \mathrm{H}), 4.67$ $(\mathrm{dt}, J=9.2,4.7 \mathrm{~Hz}, 1 \mathrm{H}), 4.55(\mathrm{~d}, J=8.5 \mathrm{~Hz}, 1 \mathrm{H}), 4.51-4.42(\mathrm{~m}, 1 \mathrm{H}), 4.42-4.31(\mathrm{~m}, 1 \mathrm{H})$, 4.29-4.14 (m, 1H), 4.09-3.96 (m, 3H), 3.90-3.83 (m, 1H), 3.82-3.75 (m, 1H), 3.53-3.42 (m, $1 \mathrm{H}), 3.42-3.29(\mathrm{~m}, 0.25 \mathrm{H}), 3.07(\mathrm{dd}, J=13.6,5.3 \mathrm{~Hz}, 1 \mathrm{H}), 2.91(\mathrm{dd}, J=13.6,4.2 \mathrm{~Hz}, 1 \mathrm{H})$, 2.85-2.69 (m, 0.36H), 2.37-2.25 (m, 1H), 2.25-2.14 (m, 1H), 2.14-2.01 (m, 2H), 1.98-1.79 (m, 3H), 1.79-1.64 (m, 1H), 1.67-1.40 (m, 6H), 0.89-0.81 (m, 19H), $0.78(\mathrm{t}, J=7.4 \mathrm{~Hz}, 3 \mathrm{H})$ ppm.

${ }^{13}$ C NMR (101 MHz, DMSO-d6): $\delta$ 174.7, 171.8, 171.5, 170.8, 170.6, 168.1, 158.8, 81.4, 61.2, 59.7, 59.0, 55.7, 52.0, 47.7, 47.0, 41.5, 31.8, 30.7, 30.1, 29.5, 29.2, 29.1, 29.1, 26.5, 25.7, 25.4, 24.8, 24.7, 23.4, 22.6, 22.0, 19.9, 19.5, 18.3, 17.4, 14.4, 10.2 ppm.

IR (ATR): $\tilde{\text { v }}=3283$ (w), 2958 (m), 2924 (m), 2854 (m), 1641 (vs), 1532 (s), 1459 (m), 1261 (m), $732(\mathrm{~s}), 646(\mathrm{w}) \mathrm{cm}^{-1}$

HRMS (MALDI): calcd. for $\mathrm{C}_{37} \mathrm{H}_{65} \mathrm{~N}_{7} \mathrm{NaO}_{8}{ }^{+}$

found:
$758.4787[\mathrm{M}+\mathrm{Na}]^{+}$

758.4786

The reaction sequence was scalable:

We did not encounter yield loss upon scaling of this reaction and successfully prepared $4.06 \mathrm{~g}$, (5.52 mmol, 93\% yield starting from L-Abu) of SI-12 in a single run via this procedure. 


\subsection{6 (7S,10S,12aS,18R,21S)-7-Ethyl-21-isobutyl-10-isopropyl-18-methyl-1-nonyl-}

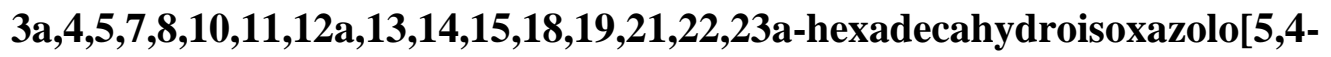
r]pyrrolo[1,2-g][1,4,7,10,13,16]hexaazacycloicosine-6,9,12,17,20,23-hexaone ${ }^{28,29}$

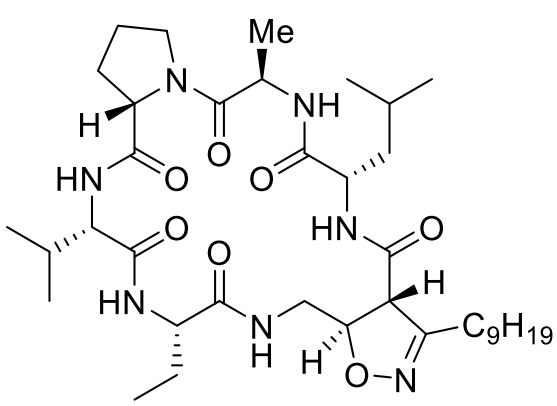

SI-13

To a solution of PyAOP (136 mg, $0.261 \mathrm{mmol}, 2.0$ equiv) and HOAt (35.5 mg, $0.261 \mathrm{mmol}, 2.0$ equiv) in dry DMF $(110 \mathrm{~mL})$ was added a solution of crude SI-11 (96.0 mg, $0.130 \mathrm{mmol}, 1.0$ equiv) and DIPEA $(91 \mu \mathrm{L}, 0.52 \mathrm{mmol}$, 4.0 equiv) in DMF (23 mL) over $6 \mathrm{~h}$ via syringe pump. Stirring was continued for $14 \mathrm{~h}$ at room temperature. Most of the solvent was removed in vacuo. The mixture was

filtered and submitted directly to preparative HPLC purification $50 \% \mathrm{MeCN}$ in water with $0.1 \%$ formic acid to $70 \% \mathrm{MeCN}$ in water with $0.1 \%$ formic acid) to yield the title compound as a colorless powder after lyophilization $(70.7 \mathrm{mg}, 0.0980 \mathrm{mmol}, 75 \%$ yield).

$\mathbf{R}_{\mathbf{f}}=0.32\left[5 \% \mathrm{MeOH} / \mathrm{CH}_{2} \mathrm{Cl}_{2}\right]$

$[\alpha]_{D}^{25}=-123\left(\mathrm{c}=0.5, \mathrm{CHCl}_{3}\right)$

${ }^{1}$ H NMR (500 MHz, DMSO-d6): $\delta 8.78(\mathrm{~d}, J=3.9 \mathrm{~Hz}, 1 \mathrm{H}), 8.15(\mathrm{~d}, J=2.9 \mathrm{~Hz}, 1 \mathrm{H}), 8.07$ (dd, $J=9.6,2.1 \mathrm{~Hz}, 1 \mathrm{H}), 7.86(\mathrm{~d}, J=8.1 \mathrm{~Hz}, 1 \mathrm{H}), 7.41(\mathrm{~d}, J=9.3 \mathrm{~Hz}, 1 \mathrm{H}), 4.60(\mathrm{dt}, J=10.1,3.0$ $\mathrm{Hz}, 1 \mathrm{H}), 4.50-4.39(\mathrm{~m}, 2 \mathrm{H}), 4.35-4.25(\mathrm{~m}, 2 \mathrm{H}), 4.18(\mathrm{t}, J=8.8 \mathrm{~Hz}, 1 \mathrm{H}), 3.93-3.73(\mathrm{~m}, 3 \mathrm{H})$, $3.52(\mathrm{td}, J=9.8,6.8 \mathrm{~Hz}, 1 \mathrm{H}), 2.94(\mathrm{dt}, J=14.7,2.3 \mathrm{~Hz}, 1 \mathrm{H}), 2.38-2.23(\mathrm{~m}, 2 \mathrm{H}), 2.23-2.11(\mathrm{~m}$, 1H), 2.10-2.02 (m, 1H), 2.01-1.87 (m, 2H), 1.84-1.68 (m, 1H), 1.66-1.35 (m, 6H), 1.35-1.12 $(\mathrm{m}, 16 \mathrm{H}), 1.02-0.79(\mathrm{~m}, 18 \mathrm{H}) \mathrm{ppm}$.

${ }^{13}$ C NMR (126 MHz, DMSO-d6): $\delta=171.5,171.3,171.2,170.9,170.7,167.7,159.2,83.1$, 60.0, 57.2, 56.3, 55.8, 50.9, 47.4, 46.3, 40.9, 37.9, 31.3, 30.1, 29.2, 29.1, 29.0, 28.7, 28.7, 26.1, 25.3, 24.5, 23.9, 23.6, 23.1, 22.12, 22.08, 19.1, 19.0, 14.9, 14.0, $10.2 \mathrm{ppm}$.

IR (ATR): $\tilde{\text { v }}=3299$ (w), 2956 (m), 2928 (m), 2872 (m), 1645 (vs), 1532 (s), 1370 (m), 1258 (m) $\mathrm{cm}^{-1}$

HRMS (ESI): $\quad$ calcd. for $\mathrm{C}_{37} \mathrm{H}_{64} \mathrm{~N}_{7} \mathrm{O}_{7}{ }^{+} \quad 718.4862[\mathrm{M}+\mathrm{H}]^{+}$ found: 


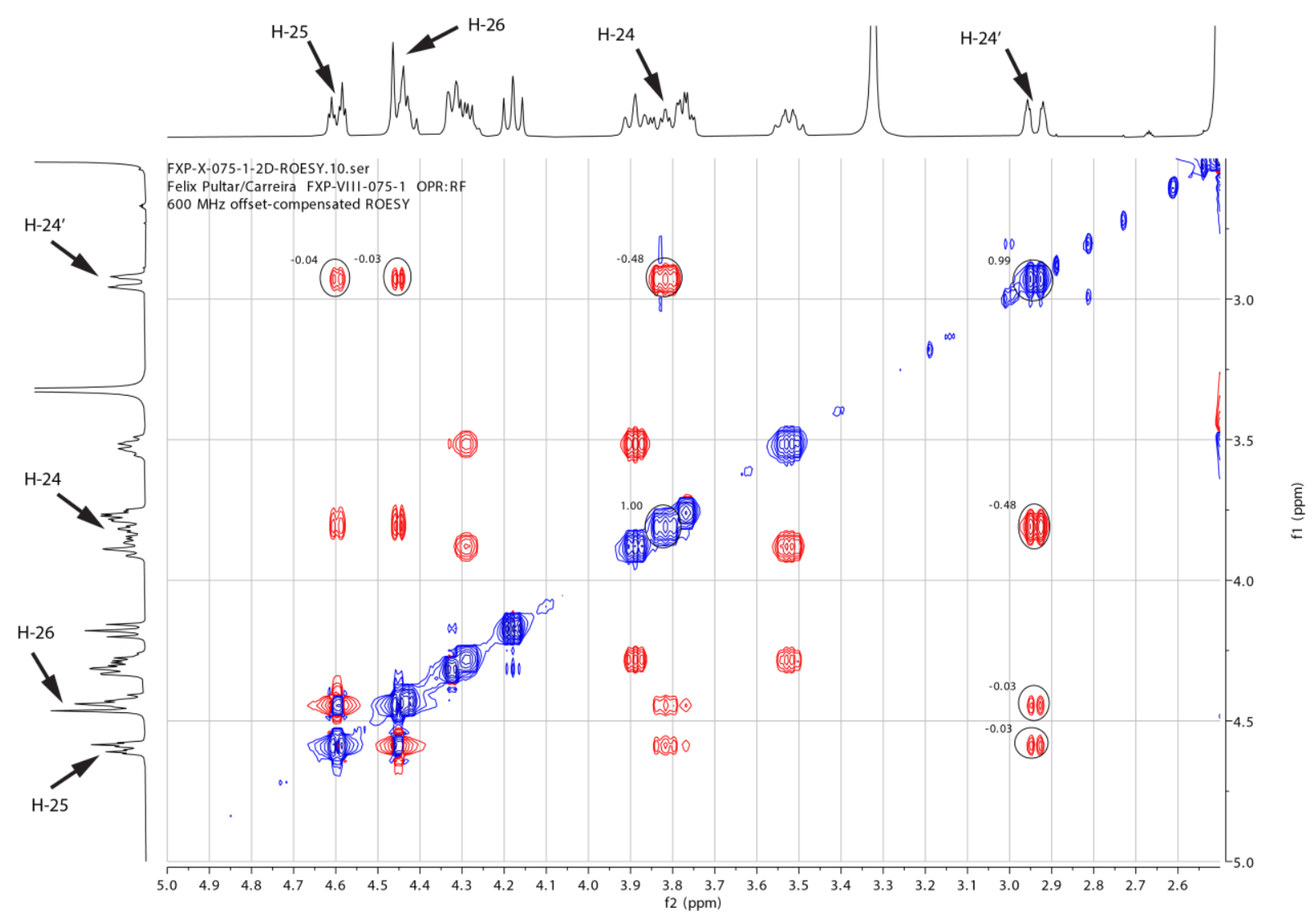

Figure 10. ROESY spectrum of SI-13. The cross-peaks from H-24 to H-26 indicate a syn-relationship between the protons and consequently a trans-relationship between $\mathrm{H}-25$ and $\mathrm{H}-26$.

Table 1. The observed NOE between H-24 and H-26 indicates that no epimerization of H-26 had occurred.

NOE H-24 and $\mathrm{H}-24$ ' to $\mathrm{H}-26$ observed.

The reaction was scalable:

The reaction sequence from L-Abu to SI-13 was successfully scaled. Starting from Fmoc-LAbu (2.02 g, 5.95 mmol, 1.0 equiv) we could isolate SI-13 (1.86 g, 2.59 mmol, 47\% overall 
yield after preparative HPLC purification). The molarity during macrocyclization was increased to 5 mmolar (1100 mL DMF for PyAOP and HOAt, 36 mL DMF for SI-12 and DIPEA). 
3.17 (4S,5S)-5-(Azidomethyl)-3-nonyl-4,5-dihydroisoxazole-4-carboxylic acid ar-25 $^{22}$

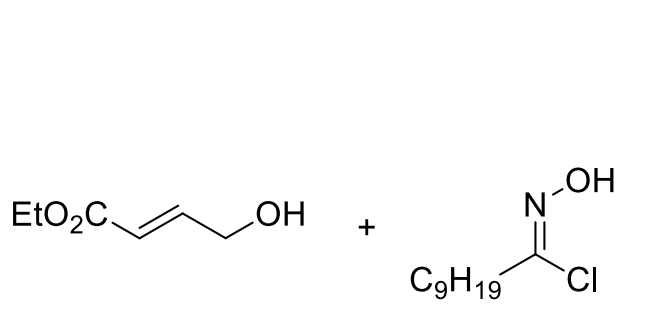

1) $\mathrm{Et}_{2} \mathrm{Zn}$ (1.0 equiv)

2) (S,S)-DIPT (1.0 equiv)

3) $\mathrm{Et}_{2} \mathrm{Zn}$ (1.5 equiv)

4) Hydroximoyl chloride (2.0 equiv) $\mathrm{CHCl}_{3}, 0^{\circ} \mathrm{C}, 20 \mathrm{~h}$

(57\% yield, $96 \%$ ee)

[3+2] cycloaddition<smiles>CCCCC1=NO[C@@H](CO)[C@H]1C(=O)OCC</smiles>

ent-SI-1

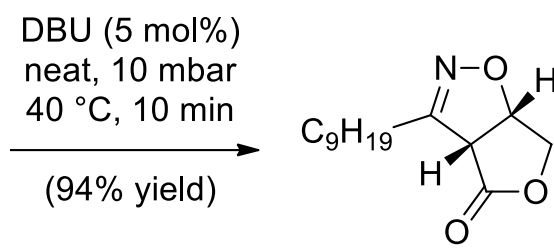

ent-SI-9
$\mathrm{KN}_{3}$ (5.0 equiv),

18-crown-6 (5.0 equiv), sulfolane, $70^{\circ} \mathrm{C}, 72 \mathrm{~h}$

$(47 \%$ yield $)$<smiles>NC[C@H]1ON=C(Cc2ccccc2)[C@H]1C(=O)O</smiles>

ent-SI-10

Figure 11. Adapted synthetic route for the preparation of ent-SI-10.

ent-SI-10 was prepared in analogous fashion to SI-1 by employing the (-)-(S,S)-DIPT ligand in the cycloaddition reaction. Spectroscopic properties were identical in all regards except for optical rotation, which showed the opposite sign but the same absolute value. 


\subsection{8 (3aS,7S,10S,12aS,18R,21S,23aS)-7-Ethyl-21-isobutyl-10-isopropyl-18-methyl-1- nonyl-4,5,7,8,10,11,12a,13,14,15,18,19,21,22-tetradecahydroisoxazolo[5,4- r]pyrrolo[1,2-g][1,4,7,10,13,16]hexaazacycloicosine-6,9,12,17,20,23(3aH,23aH)- hexaone $^{28,29}$}

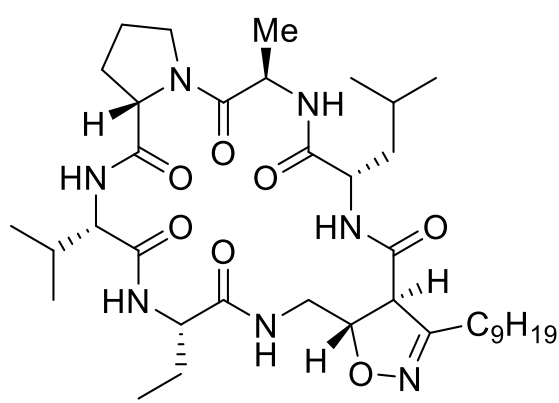

SI-14

ent-SI-10 was reacted in the same fashion as described beforehand for the preparation of SI-12 and cleaved from the solid support. The resulting crude hexameric peptide $0.150 \mathrm{~g}, 0.204 \mathrm{mmol}, 1.0$ equiv) in $\mathrm{DMF}(34 \mathrm{~mL})$ with DIPEA $(0.140 \mathrm{~mL}, 0.815 \mathrm{mmol}, 4.0$ equiv) was added dropwise to a solution of PyAOP $(213 \mathrm{mg}, 0.408 \mathrm{mmol}$, 2.0 equiv) and HOAt (55.5 mg, $0.408 \mathrm{mmol}, 2.0$ equiv) in

dry DMF $(170 \mathrm{~mL})$ over $6 \mathrm{~h}$ via syringe pump. Stirring was continued for $14 \mathrm{~h}$ at room temperature. Most of the solvent was removed in vacuo. The mixture was filtered and submitted directly to preparative HPLC purification $(50 \% \mathrm{MeCN}$ in water with $0.1 \%$ formic acid to $70 \%$ $\mathrm{MeCN}$ in water with $0.1 \%$ formic acid) to yield the title compound as a colorless powder after lyophilization $(55.2 \mathrm{mg}, 0.0770 \mathrm{mmol}, 38 \%$ yield $)$.

$\mathbf{R}_{\mathbf{f}}=0.44\left[10 \% \mathrm{MeOH} / \mathrm{CH}_{2} \mathrm{Cl}_{2}\right]$

$[\alpha]_{D}^{25}=-35\left(\mathrm{c}=0.1, \mathrm{CHCl}_{3}\right)$

${ }^{1}$ H NMR (600 MHz, DMSO-d6): $\delta 8.86(\mathrm{~d}, J=3.7 \mathrm{~Hz}, 1 \mathrm{H}), 8.59(\mathrm{~d}, J=3.8 \mathrm{~Hz}, 1 \mathrm{H}), 8.21$ (d, $J=5.0 \mathrm{~Hz}, 1 \mathrm{H}), 8.13(\mathrm{dd}, J=10.2,2.5 \mathrm{~Hz}, 1 \mathrm{H}), 7.44(\mathrm{~d}, J=9.7 \mathrm{~Hz}, 1 \mathrm{H}), 4.60(\mathrm{ddd}, J=11.4$, 5.4, $2.7 \mathrm{~Hz}, 1 \mathrm{H}), 4.34-4.25(\mathrm{~m}, 2 \mathrm{H}), 4.24-4.17(\mathrm{~m}, 1 \mathrm{H}), 4.15(\mathrm{t}, J=10.0 \mathrm{~Hz}, 1 \mathrm{H}), 3.92(\mathrm{td}$, $J=9.3,2.2 \mathrm{~Hz}, 1 \mathrm{H}), 3.73(\mathrm{~d}, J=2.7 \mathrm{~Hz}, 1 \mathrm{H}), 3.59-3.51(\mathrm{~m}, 2 \mathrm{H}), 3.43(\mathrm{ddd}, J=13.0,11.3$, $10.1 \mathrm{~Hz}, 1 \mathrm{H}), 2.82-2.75(\mathrm{~m}, 1 \mathrm{H}), 2.22(\mathrm{ddd}, J=14.8,9.8,6.7 \mathrm{~Hz}, 1 \mathrm{H}), 2.10-1.92(\mathrm{~m}, 5 \mathrm{H})$, $1.80-1.71(\mathrm{~m}, 1 \mathrm{H}), 1.62-1.39(\mathrm{~m}, 7 \mathrm{H}), 1.29-1.21(\mathrm{~m}, 12 \mathrm{H}), 1.20(\mathrm{~d}, J=6.9 \mathrm{~Hz}, 3 \mathrm{H}), 0.92$ $(\mathrm{t}, J=6.4 \mathrm{~Hz}, 6 \mathrm{H}), 0.85(\mathrm{dt}, J=10.3,7.1 \mathrm{~Hz}, 12 \mathrm{H}) \mathrm{ppm}$.

${ }^{13}$ C NMR (151 MHz, DMSO-d6): $\delta$ 172.0, 171.9, 171.5, 171.1, 170.2, 167.7, 156.2, 81.2, 60.1, 57.7, 57.4, 56.5, 51.7, 47.3, 46.6, 42.6, 38.4, 31.2, 30.1, 29.4, 28.9, 28.7, 28.6, 28.2 25.5, 24.4, 23.7, 23.6, 23.3, 22.1, 22.0, 19.4, 18.8, 15.3, 13.9, $10.5 \mathrm{ppm}$.

IR (ATR): $\tilde{v}=3289$ (m), 2957 (m), 2926 (w), 1635 (vs), 1533 (m), 1386 (w), 869 (w), 507 (w) $\mathrm{cm}^{-1}$ 

HRMS (ESI):
calcd. for $\mathrm{C}_{37} \mathrm{H}_{64} \mathrm{~N}_{7} \mathrm{O}_{7}{ }^{+}$
$718.4862[\mathrm{M}+\mathrm{H}]^{+}$
found:

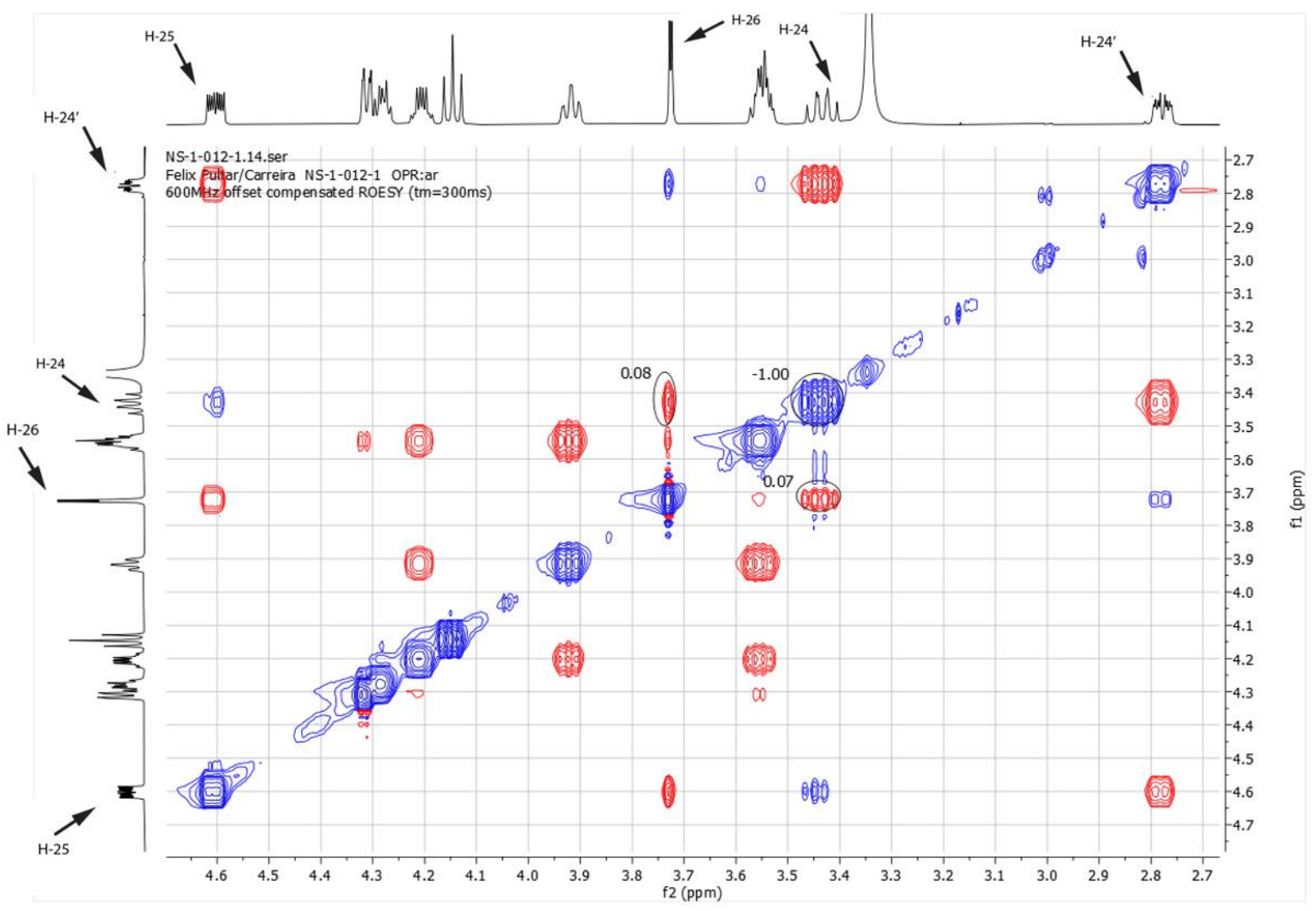

Figure 12. ROESY spectrum of SI-14. The cross-peaks from H-24 to H-26 indicate a syn-relationship between the protons and consequently a trans-relationship between $\mathrm{H}-25$ and H-26.

Table 2. The observed NOE between H-24 and H-26 indicates that no epimerization of H-26 had occurred.

NOE H-24 and $\mathrm{H}-24$ ' to $\mathrm{H}-26$ observed.




\subsection{Synthetic (+)-Mutanobactin $D^{30}$}

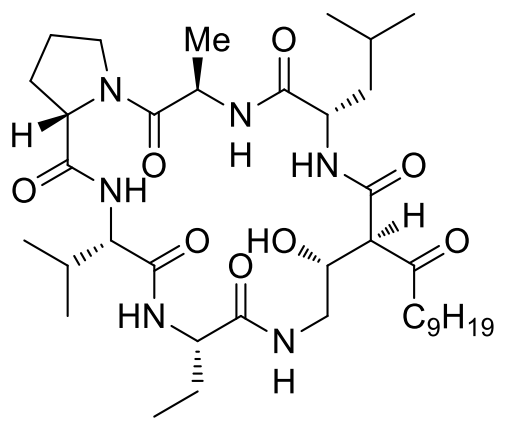

Mutanobactin D

A suspension of molybdenum hexacarbonyl (1.00 g, $3.79 \mathrm{mmol}, 1.0$ equiv) in acetonitrile $(14 \mathrm{~mL})$ was heated to reflux for $6 \mathrm{~h}$. The brown solution was allowed to reach room temperature before $0.730 \mathrm{~mL}(0.196 \mathrm{mmol}, 3.0$ equiv) of this solution were added to a solution of SI-13 (47.0 mg, $0.0650 \mathrm{mmol}, 1.0$ equiv) in a mixture of acetonitrile and water (0.820 mL, 5:2 mixture). The resulting solution was stirred for $3 \mathrm{~h}$ before silica gel was added and the mixture was exposed to air for 2 days. Residual solvent was removed in vacuo and the crude product was eluted on a column with silica gel $\left[\mathrm{CH}_{2} \mathrm{Cl}_{2}\right]$ to $\left[\mathrm{CH}_{2} \mathrm{Cl}_{2} / \mathrm{MeOH}=8: 2\right]$. Fractions containing product were combined and $2 \mathrm{~mL}$ DMSO were added. Most of the solvents was removed in vacuo and the remaining solution was filtered, and submitted directly to preparative HPLC purification (50\% $\mathrm{MeCN}$ in water with $0.1 \%$ formic acid to $70 \% \mathrm{MeCN}$ in water with $0.1 \%$ formic acid) to yield the title compound as a colorless powder after lyophilization $(23.6 \mathrm{mg}, 0.0327 \mathrm{mmol}, 50 \%$ yield).

$\mathbf{R}_{\mathbf{f}}=0.41\left[10 \% \mathrm{MeOH} / \mathrm{CH}_{2} \mathrm{Cl}_{2}\right]$

$[\alpha]_{D}^{25}=+12(\mathrm{c}=0.12, \mathrm{MeOH})$.

${ }^{1}$ H NMR (600 MHz, DMSO-d6): $\delta 9.03$ (brs, 1H), 8.45 (d, $\left.J=3.1 \mathrm{~Hz}, 1 \mathrm{H}\right), 8.12$ (d, $J=4.7 \mathrm{~Hz}$, 1H), $7.80(\mathrm{dd}, J=10.0,3.1 \mathrm{~Hz}, 1 \mathrm{H}), 7.63(\mathrm{~d}, J=9.2 \mathrm{~Hz}, 1 \mathrm{H}), 4.67$ (brs, $1 \mathrm{H}), 4.36$ (d, $J=7.0 \mathrm{~Hz}$, 1H), 4.28-4.23 (m, 1H), 4.23-4.19 (m, 1H), 4.05 (brt, $J=9.9 \mathrm{~Hz}, 1 \mathrm{H}), 3.98$ (d, $J=10.4 \mathrm{~Hz}$, $1 \mathrm{H}), 3.91(\mathrm{t}, J=9.4 \mathrm{~Hz}, 1 \mathrm{H}), 3.80(\mathrm{td}, J=7.2,3.0 \mathrm{~Hz}, 1 \mathrm{H}), 3.58-3.51(\mathrm{~m}, 1 \mathrm{H}), 3.42-3.33(\mathrm{~m}$, $1 \mathrm{H}), 2.66(\mathrm{brd}, J=13.3 \mathrm{~Hz}, 1 \mathrm{H}), 2.37-2.32(\mathrm{~m}, 1 \mathrm{H}), 2.23(\mathrm{ddd}, J=17.6,8.7,6.0 \mathrm{~Hz}, 1 \mathrm{H})$, 2.16-2.10 (m, 1H), 2.07-2.02 (m, 1H), 2.02-1.94 (m, 1H), 1.80-1.74 (m, 1H), 1.74-1.68 (m, 1H), 1.60-1.53 (m, 1H), 1.52-1.48 (m, 1H), 1.49-1.40 (m, 2H), 1.39-1.31 (m, 2H), 1.28-1.11 (br, 17H), $0.97(\mathrm{~d}, J=6.7 \mathrm{~Hz}, 3 \mathrm{H}), 0.91(\mathrm{~d}, J=6.6 \mathrm{~Hz}, 6 \mathrm{H}), 0.85(\mathrm{t}, J=7.4 \mathrm{~Hz}, 3 \mathrm{H}), 0.84$ (t, $J$ $=6.9 \mathrm{~Hz}, 3 \mathrm{H}), 0.82(\mathrm{~d}, J=6.4 \mathrm{~Hz}, 3 \mathrm{H}) \mathrm{ppm}$.

${ }^{13}$ C NMR (151 MHz, DMSO-d6): $\delta$ 204.5, 172.5, 172.0, 171.0, 170.5, 166.3, 66.8, 61.9, 59.9, 58.2, 56.5, 52.3, 47.5, 46.5, 42.1, 40.5, 40.1, 31.2, 29.5, 29.3, 28.9, 28.6, 28.4, 24.5, 23.8, 23.5, 22.5, 22.1, 21.6, 19.8, 19.4, 15.1, 13.9, $10.3 \mathrm{ppm}$.

IR (ATR): $\tilde{\mathrm{v}}=3287$ (w), $2930(\mathrm{w}), 1640$ (vs), $1533(\mathrm{~m}), 1463(\mathrm{w}) \mathrm{cm}^{-1}$ 
HRMS (ESI):

found:

743.4660

An additional IR spectrum of the lyophilized powder was recorded for the application of the IRSA algorithm.

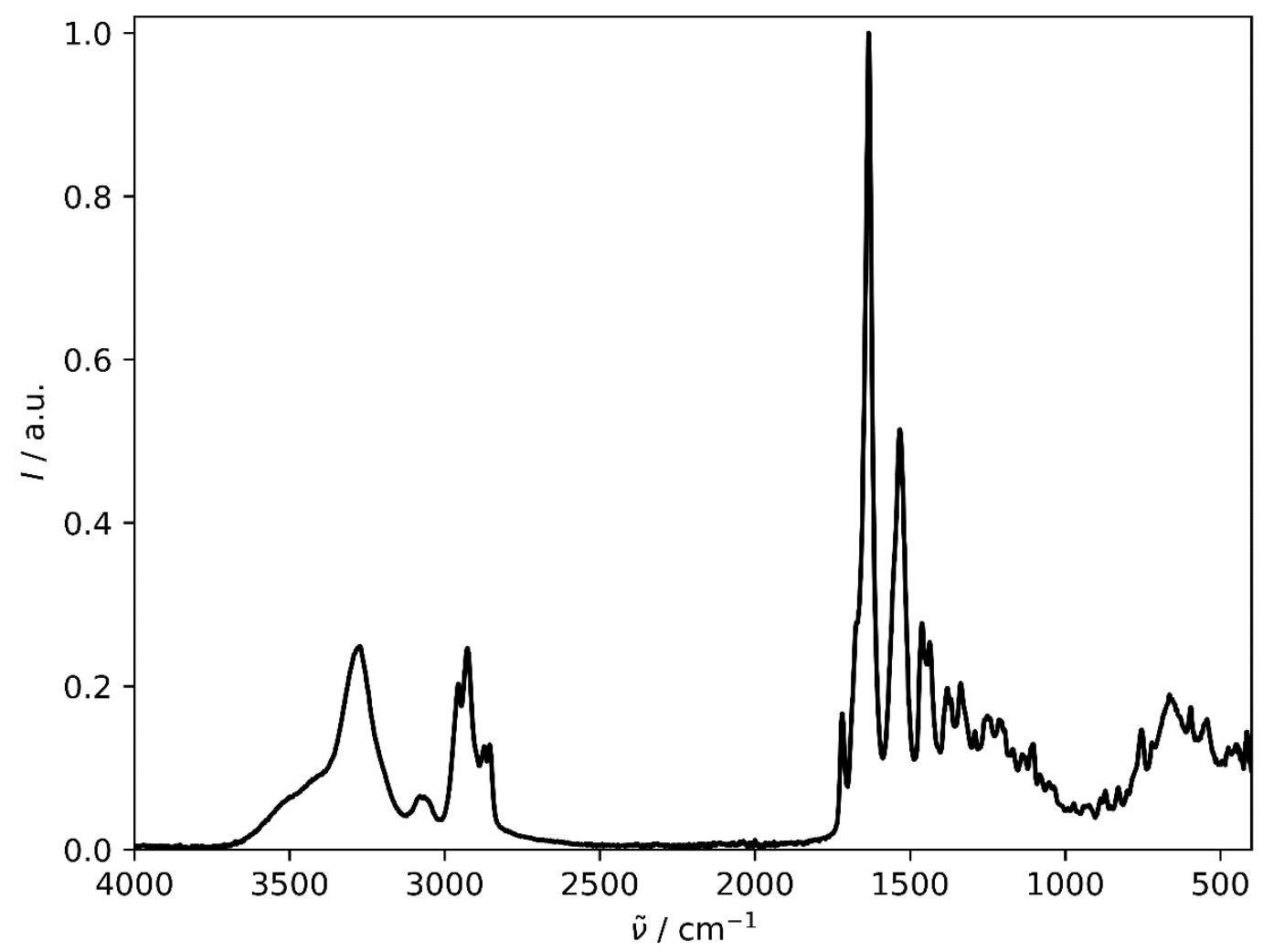

Figure 13. Experimental IR spectrum of lyophilized mutanobactin D.

\subsection{Isotopic Labelling Experiment}

In order to exclude the possibility of configurational scrambling at C-25, the ultimate step was run with isotopically labelled water (97 atom\% ${ }^{18} \mathrm{O}$, Sigma-Aldrich). The labelled oxygen content of the product was measured using LC-HRMS by comparing calculated intensities (Bruker Compass Isotope Pattern v. 5.0.37.0) and measured intensities. 


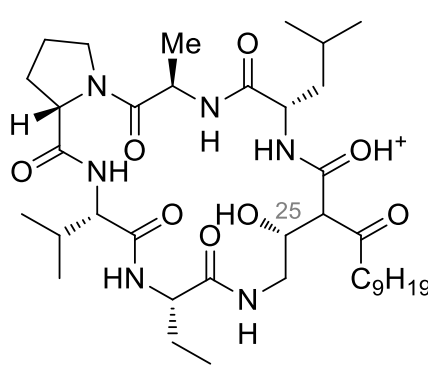

Chemical Formula: $\mathrm{C}_{37} \mathrm{H}_{65} \mathrm{~N}_{6} \mathrm{O}_{8}{ }^{+}$

Exact Mass: 721.4858 mutanobactin D

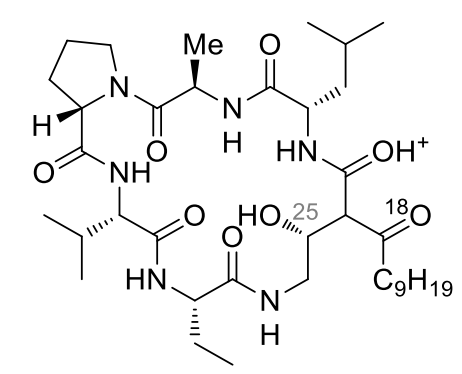

Chemical Formula: $\mathrm{C}_{37} \mathrm{H}_{65} \mathrm{~N}_{6} \mathrm{O}_{7}{ }^{18} \mathrm{O}^{+}$

Exact Mass: 723.4901

mutanobactin $D\left({ }^{18} \mathrm{O}\right)$

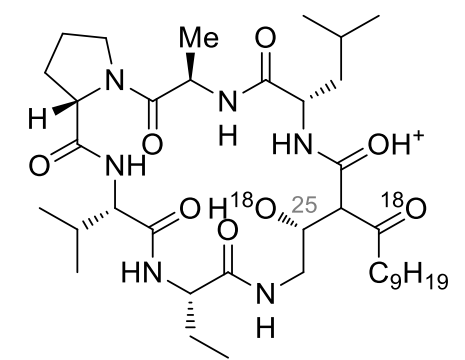

Chemical Formula: $\mathrm{C}_{37} \mathrm{H}_{65} \mathrm{~N}_{6} \mathrm{O}_{6}{ }^{18} \mathrm{O}_{2}{ }^{+}$

Exact Mass: 725.4943

mutanobactin D $\left(2 \times{ }^{18} \mathrm{O}\right)$

Two reaction conditions were investigated. Conditions 1 included $\mathrm{Pd}-\mathrm{C} / \mathrm{H}_{2}, \mathrm{H}_{2}$ (1 atm), AcOH in $\mathrm{MeOH}-\mathrm{H}_{2}{ }^{18} \mathrm{O}(5: 1)$. Conditions 2 included $\mathrm{Mo}(\mathrm{CO})_{3}(\mathrm{MeCN})_{3}$ in $\mathrm{MeCN}-\mathrm{H}_{2}{ }^{18} \mathrm{O}(5: 2)$. Both conditions gave the same mutanobactin D product (by NMR). However, the first condition gave mainly the expected product with one ${ }^{18} \mathrm{O}$ incorporated (Figure 15) while the second condition led to incorporation of two ${ }^{18} \mathrm{O}$ atoms (Figure 17). This finding is consistent with $\mathrm{Pd}-\mathrm{C}$ leading to the product with a labeled ketone whereas molybdenum seemed to have promoted exchange of the $\beta$-hydroxy group in addition. As both products are identical as judged by ${ }^{1} \mathrm{H}$ NMR spectroscopy, it was concluded that the configuration of C-25 did not change overall. For a full discussion, see main text of the paper. To confirm which position incorporated ${ }^{18} \mathrm{O}$, we compared the ${ }^{13} \mathrm{C}$ NMR spectrum of the product obtained from reduction with $\mathrm{Mo}(\mathrm{CO})_{3}(\mathrm{MeCN})_{3}$ and ${ }^{18} \mathrm{OH}_{2}$ with the ${ }^{13} \mathrm{C} \mathrm{NMR}$ spectrum of unlabeled mutanobactin $\mathrm{D}$ (Figure 20). C-28 (ketone) and C-25 (the secondary alcohol) are shifted upfield by $0.053 \mathrm{ppm}$ and $0.019 \mathrm{ppm}$, respectively, thus suggesting those positions are labeled with ${ }^{18} \mathrm{O} .{ }^{31,32}$ 


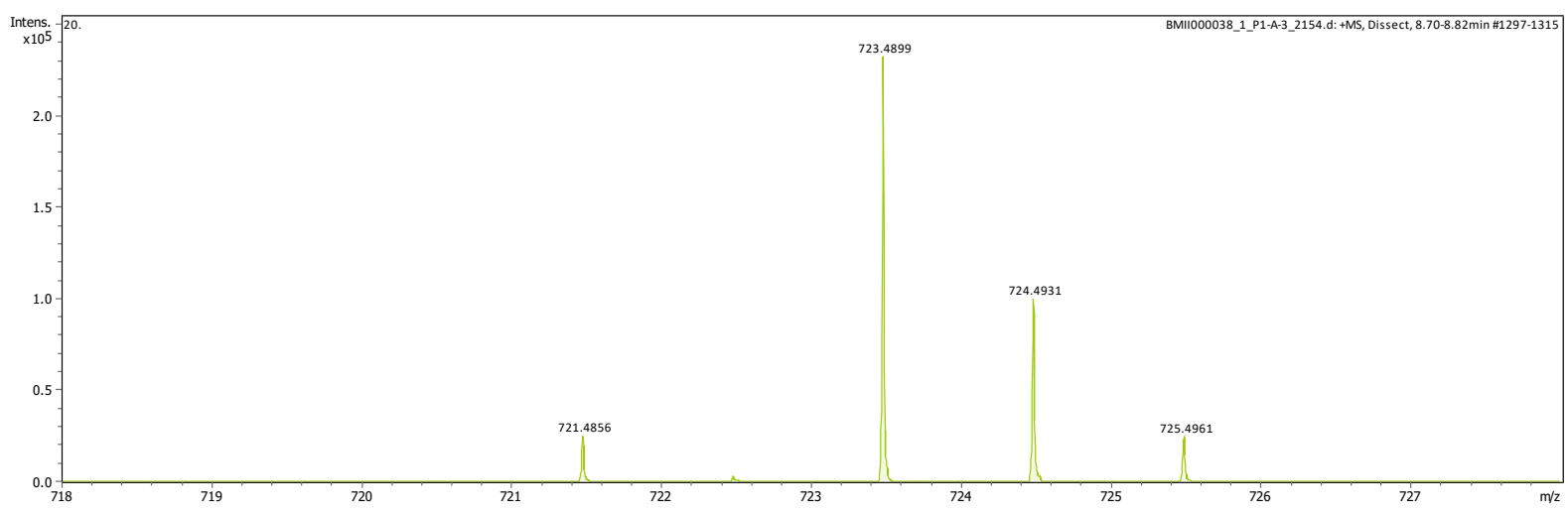

Figure 14. LC-HRMS trace of the reduction and hydrolysis of SI-13 with Pd-C, hydrogen gas (1 atm) in $\mathrm{MeOH}-\mathrm{H}_{2}{ }^{18} \mathrm{O}(5: 1)$.

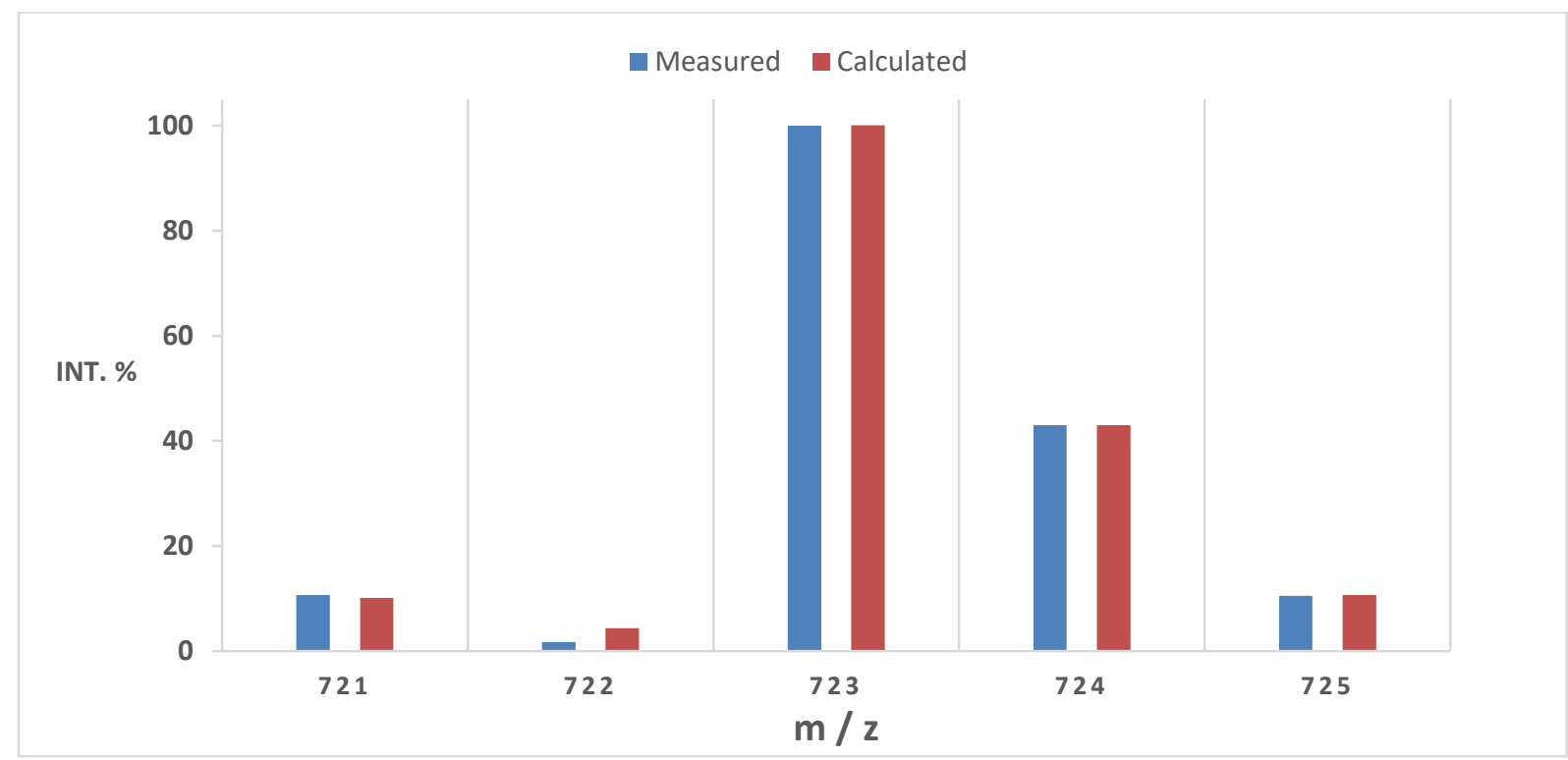

Figure 15. Measured vs. calculated HRMS intensities of the reduction and hydrolysis of SI-13 with Pd-C, hydrogen gas (1 atm) in $\mathrm{MeOH}-\mathrm{H}_{2}{ }^{18} \mathrm{O}(5: 1)$.

$\begin{array}{crr}\mathbf{m} / \mathbf{z} & \text { I \% } & \\ 721.4856 & & 10.7 \\ 722.4894 & & 1.7 \\ 723.4899 & & 100.0 \\ 724.4931 & & 43.0 \\ 725.4961 & & 10.5\end{array}$




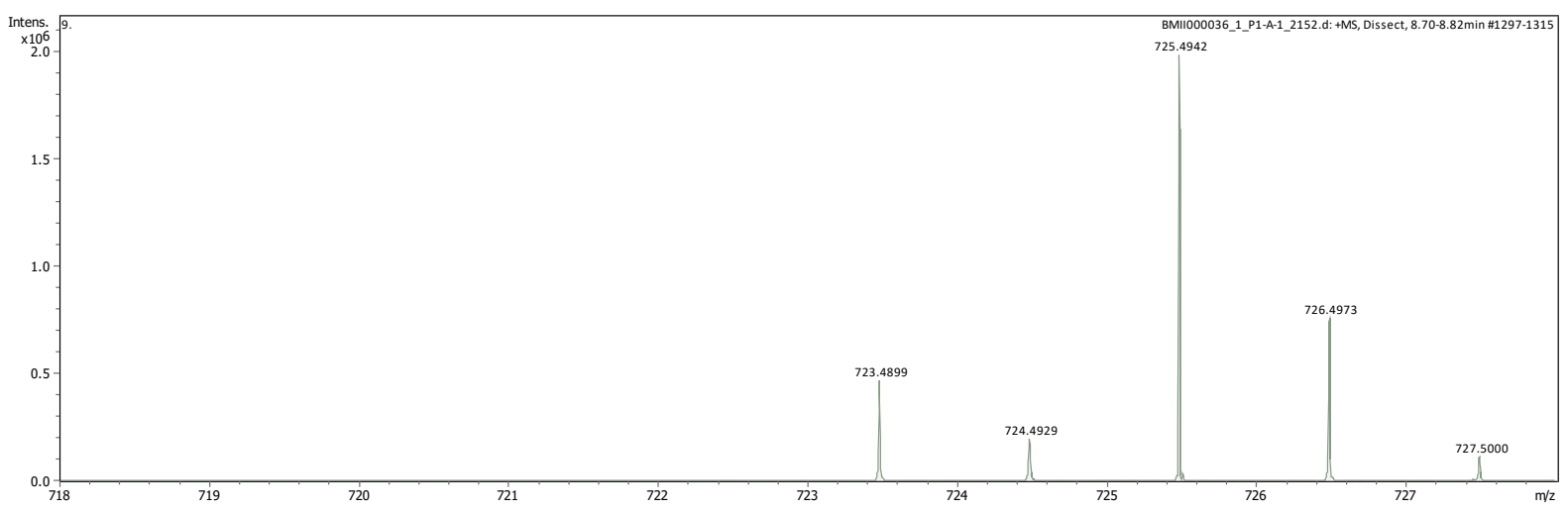

Figure 16. LC-HRMS trace of the reduction and hydrolysis of SI-13 with $\mathrm{Mo}(\mathrm{CO})_{3}(\mathrm{MeCN})_{3}$ in $\mathrm{MeCN}-\mathrm{H}_{2}{ }^{18} \mathrm{O}(5: 2)$.

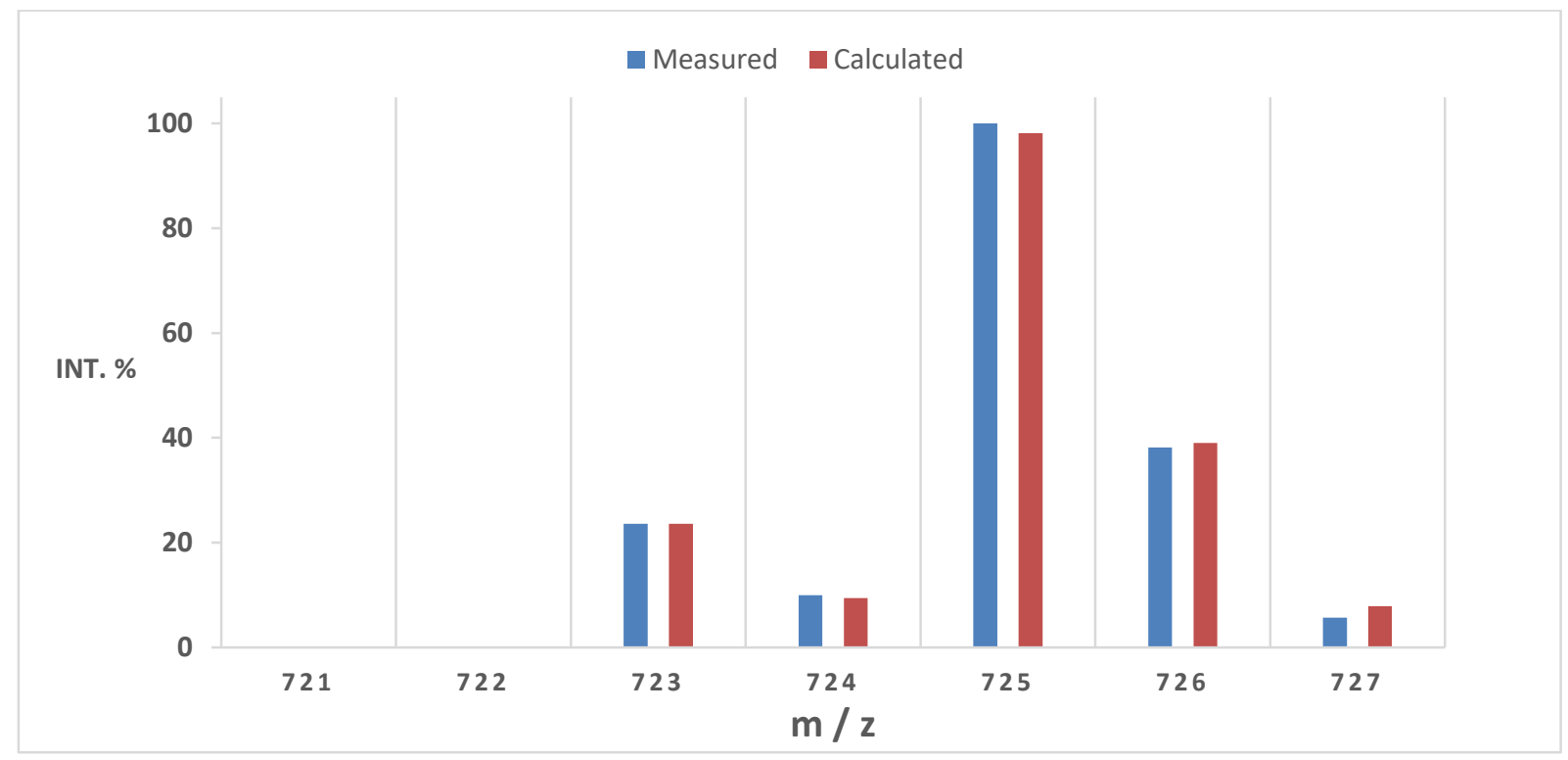

Figure 17. Measured vs. calculated HRMS intensities of the reduction and hydrolysis of SI-13 with $\mathrm{Mo}(\mathrm{CO})_{3}(\mathrm{MeCN})_{3}$ in $\mathrm{MeCN}-\mathrm{H}_{2}{ }^{18} \mathrm{O}(5: 2)$.

\begin{tabular}{|c|c|c|}
\hline $\mathrm{m} / \mathrm{z}$ & $1 \%$ & $180(0) \_\%$ \\
\hline 723.4899 & 23.6 & \\
\hline 724.4929 & 10.0 & 180(1)_\% \\
\hline 725.4942 & 100.0 & \\
\hline 726.4973 & 38.2 & 180(2)_\% \\
\hline 727.5000 & 5.7 & \\
\hline
\end{tabular}

In a second series of experiments, SI-14 was exposed to the same reaction conditions described above $\left(\mathrm{Pd}-\mathrm{C} / \mathrm{H}_{2}\right.$ and $\left.\mathrm{Mo}(\mathrm{CO})_{3}(\mathrm{MeCN})_{3}\right)$. Interestingly, exposure of SI-14 to $\mathrm{Pd}-\mathrm{C} / \mathrm{H}_{2}$ did not lead to formation of mutanobactin D but rather a complex mixture of products. On the other hand, exposure of SI-14 to $\mathrm{Mo}(\mathrm{CO})_{3}(\mathrm{MeCN})_{3}$ led to formation of mutanobactin $\mathrm{D}$ as judged by NMR and LC-HRMS using a standard. When isotopically labelled water $\left(97\right.$ atom\% ${ }^{18} \mathrm{O}$, Sigma-Aldrich) was used instead of unlabeled water in the reaction with $\operatorname{Mo}(\mathrm{CO})_{3}(\mathrm{MeCN})_{3}$, incorporation of two ${ }^{18} \mathrm{O}$ atoms was observed judged by LC-HRMS (Figure 18 and Figure 19). 
This finding is consistent with epimerization of C-25 during isoxazoline cleavage and subsequent hydrolysis of SI-14. For a full discussion, see main text.

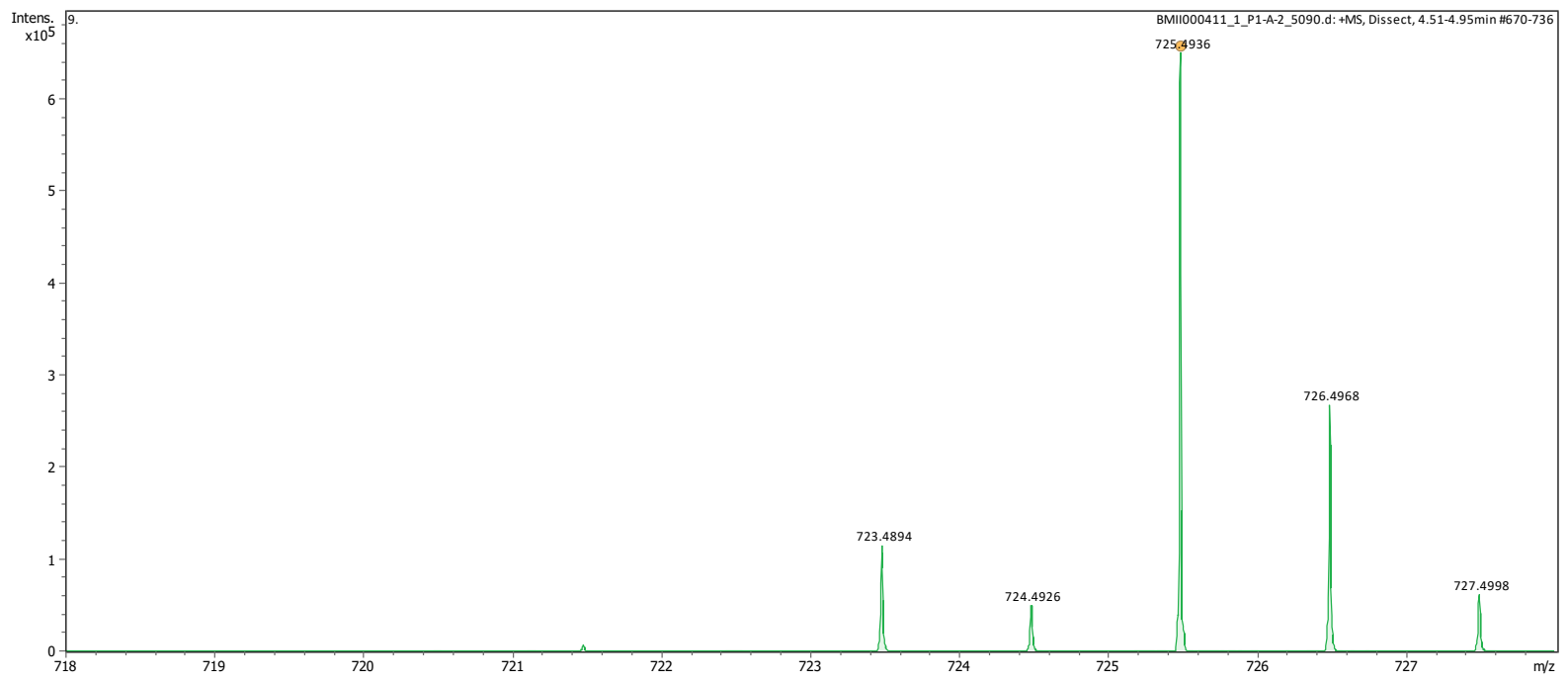

Figure 18. $\mathrm{LC}-\mathrm{HRMS}$ trace of the reduction and hydrolysis of $\mathbf{S I - 1 4}$ with $\mathrm{Mo}(\mathrm{CO})_{3}(\mathrm{MeCN})_{3}$ in $\mathrm{MeCN}-\mathrm{H}_{2}{ }^{18} \mathrm{O}(5: 2)$.

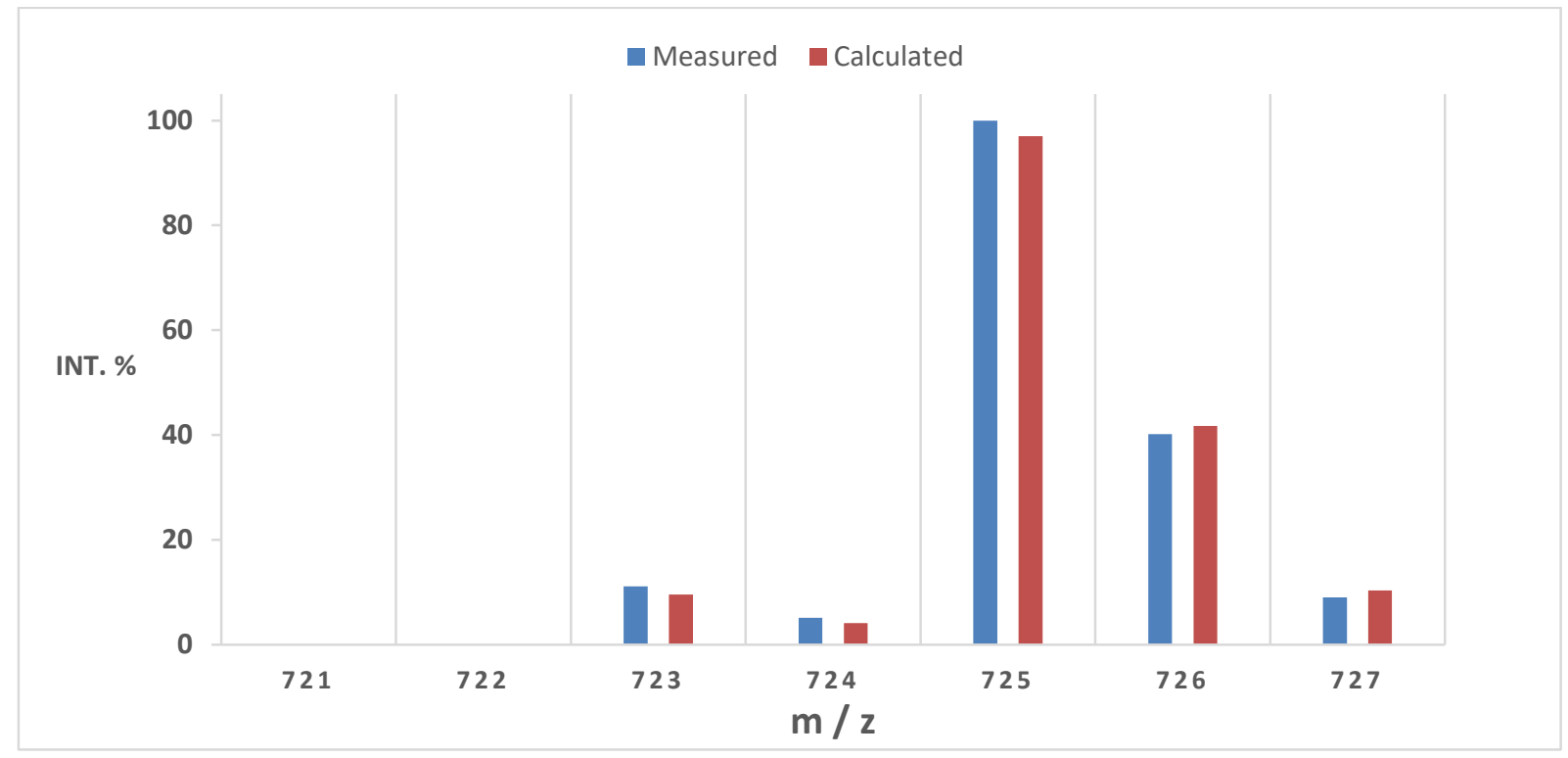

Figure 19. Measured vs. calculated HRMS intensities of the reduction and hydrolysis of SI-14 with $\mathrm{Mo}(\mathrm{CO})_{3}(\mathrm{MeCN})_{3}$ in $\mathrm{MeCN}-\mathrm{H}_{2}{ }^{18} \mathrm{O}(5: 2)$.

\begin{tabular}{|c|c|c|}
\hline $\mathrm{m} / \mathrm{z}$ & $1 \%$ & 180(0)_\% \\
\hline 723.4899 & 11.1 & \\
\hline 724.4931 & 5.1 & 180(1)_\% \\
\hline 725.4961 & 100.0 & \\
\hline 726.4969 & 40.2 & 180(2)_\% \\
\hline 727.4998 & 9.0 & \\
\hline
\end{tabular}




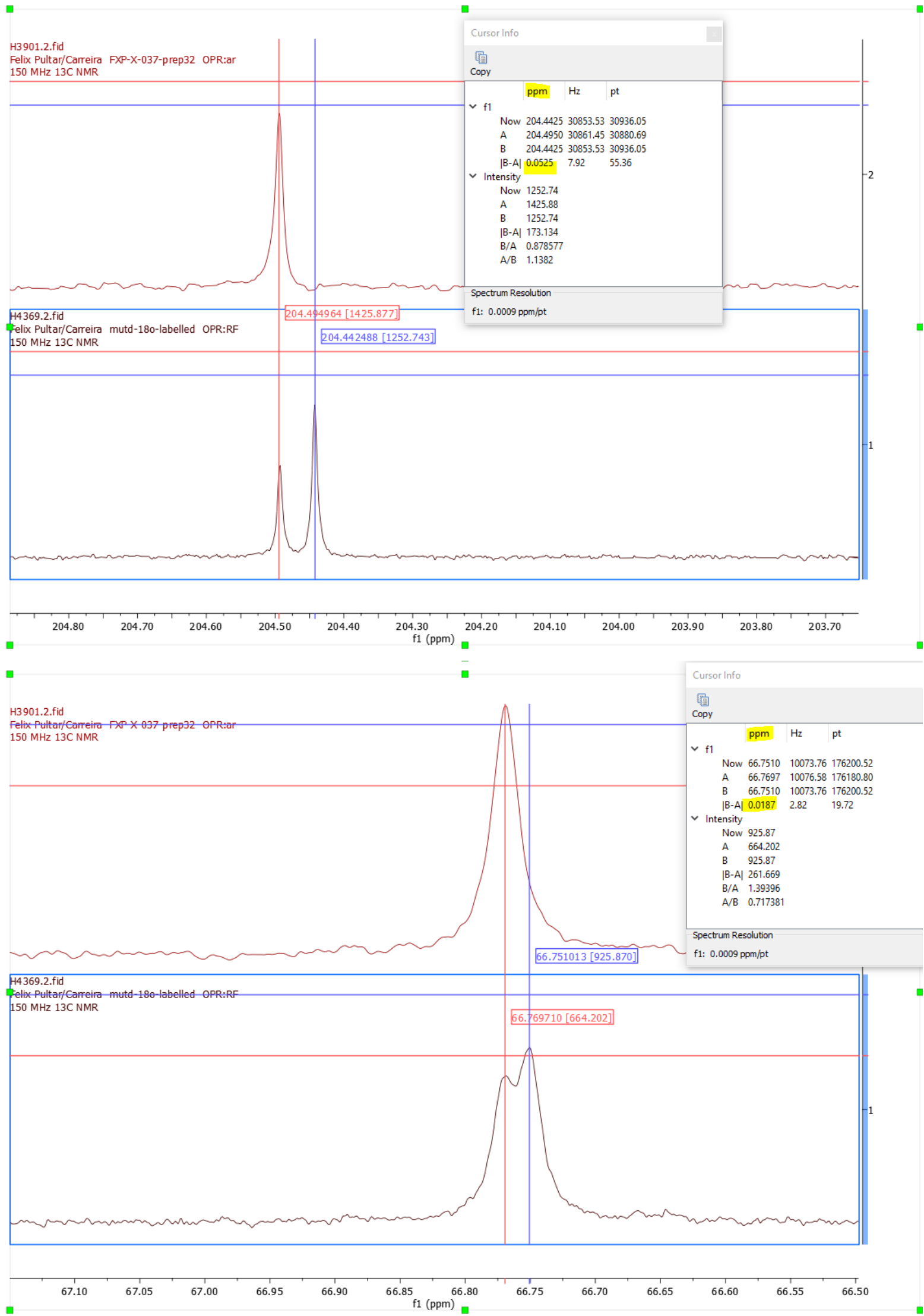

Figure 20. Overlays of ${ }^{13} \mathrm{C}$ spectra of unlabeled (top) vs ${ }^{18} \mathrm{O}$ labeled (bottom) mutanobactin D in DMSO-d 6 at $150 \mathrm{MHz}$. The labeled ketone (top) and the labeled secondary alcohol are shifted by $0.053 \mathrm{ppm}$ and $0.019 \mathrm{ppm}$, respectively. Labeling was achieved converting SI-13 to mutanobactin D using $\mathrm{Mo}(\mathrm{CO})_{3}(\mathrm{MeCN})_{3}$ in $\left.\mathrm{MeCN}-\mathrm{H}_{2} \mathrm{O}^{18}(5: 2)\right)^{31,32}$ 


\section{$3.21(3 S, 6 S, 10 R, 14 S, 17 R, 22 a S)-6-E t h y l-10-h y d r o x y-11-(1-h y d r o x y d e c y l)-14-i s o b u t y l-3-$}

isopropyl-17-methylhexadecahydropyrrolo[1,2g] $[1,4,7,10,13,16]$ hexaazacycloicosine-1,4,7,12,15,18-hexaone

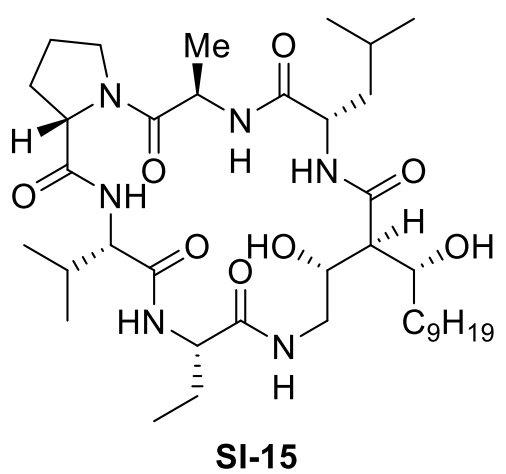

A solution of synthetic mutanobactin D (20.8 mg, $0.0290 \mathrm{mmol}, 1.0$ equiv) was dissolved in $\mathrm{MeOH}(1000 \mu \mathrm{L})$ and cooled to $-78{ }^{\circ} \mathrm{C}$ before $\mathrm{NaBH}_{4}(8.73 \mathrm{mg}, 0.231 \mathrm{mmol}$, 8.0 equiv) was added. The solution was stirred at $-78^{\circ} \mathrm{C}$ for $90 \mathrm{~min}$ before the reaction was quenched with acetic acid. The mixture was allowed to reach room temperature and was submitted directly to preparative HPLC purification (40\%

$\mathrm{MeCN}$ in water with $0.1 \%$ formic acid to $70 \% \mathrm{MeCN}$ in water with $0.1 \%$ formic acid) to yield the title compound as a colorless powder after lyophilization $(9.51 \mathrm{mg}, 0.0132 \mathrm{mmol}, 46 \%$ yield).

${ }^{1}$ H NMR (600 MHz, DMSO-d6): $\delta 8.75$ (brs, 1H), 8.32 (d, $\left.J=4.2 \mathrm{~Hz}, 1 \mathrm{H}\right), 7.97$ (d, $J=5.5 \mathrm{~Hz}$, 1H), 7.75 (brs, 1H), 7.72 (dd, $J=8.4,3.94 \mathrm{~Hz}, 1 \mathrm{H}$ ), 4.66 (brs, 1H), 4.33 (dd, $J=8.0,3.2 \mathrm{~Hz}$, $1 \mathrm{H}), 4.31-4.27(\mathrm{~m}, 1 \mathrm{H}), 4.25(\mathrm{dq}, J=6.7,3.6 \mathrm{~Hz}, 1 \mathrm{H}), 4.21(\mathrm{~d}, J=9.0 \mathrm{~Hz}, 1 \mathrm{H}), 4.01-3.96(\mathrm{~m}$, $1 \mathrm{H}), 3.96-3.92(\mathrm{~m}, 1 \mathrm{H}), 3.86-3.79(\mathrm{~m}, 1 \mathrm{H}), 3.77(\mathrm{td}, J=7.3,4.1 \mathrm{~Hz}, 1 \mathrm{H}), 3.54-3.44(\mathrm{~m}, 3 \mathrm{H})$, 2.92-2.82 (m, 1H), 2.49-2.46 (m, 1H), 2.08-1.88 (m, 4H), 1.81-1.73 (m, 3H), 1.67-1.58 (m, $2 \mathrm{H}), 1.52-1.45(\mathrm{~m}, 2 \mathrm{H}), 1.42-1.36(\mathrm{~m}, 1 \mathrm{H}), 1.29-1.13$ (brs, $14 \mathrm{H}), 1.17$ (d, $J=6.7 \mathrm{~Hz}, 3 \mathrm{H})$, $0.93(\mathrm{~d}, J=6.3 \mathrm{~Hz}, 3 \mathrm{H}), 0.91(\mathrm{t}, J=6.6 \mathrm{~Hz}, 3 \mathrm{H}), 0.89(\mathrm{~d}, J=6.6 \mathrm{~Hz}, 3 \mathrm{H}), 0.85(\mathrm{~d}, J=6.9 \mathrm{~Hz}$, $3 \mathrm{H}), 0.85(\mathrm{~m}, 3 \mathrm{H}), 0.83(\mathrm{~d}, J=6.3 \mathrm{~Hz}, 3 \mathrm{H}) \mathrm{ppm}$.

${ }^{13}$ C NMR (151 MHz, DMSO-d6): $\delta$ 173.5, 172.0, 171.7, 171.6, 170.6, 69.4, 68.0, 59.9, 58.8, 56.5, 51.8, 51.3, 47.3, 46.6, 41.6, 40.4, 35.8, 31.24, 31.23, 29.4, 29.3, 29.2, 29.1, 29.1, 28.1, 25.6, 24.4, 23.8, 23.5. 23.0, 22.1, 22.0, 19.6, 19.3, 19.2, 15.6, 13.9, 10.6 ppm.

HRMS (ESI): $\quad$ calcd. for $\mathrm{C}_{37} \mathrm{H}_{66} \mathrm{~N}_{6} \mathrm{NaO}_{8}{ }^{+} \quad 745.4834[\mathrm{M}+\mathrm{Na}]^{+}$ found: 


\section{$3.22(1 \mathrm{R}, 4 \mathrm{aR}, 8 \mathrm{8S}, 11 S, 13 \mathrm{aS}, 19 \mathrm{R}, 22 \mathrm{~S}, 24 \mathrm{aS})-8$-ethyl-22-isobutyl-11-isopropyl-3,3,19-}

trimethyl-1-nonyltetradecahydro-1H-[1,3]dioxino[4,5-r]pyrrolo[1,2-

g] $[1,4,7,10,13,16]$ hexaazacycloicosine-7,10,13,18,21,24(4aH,24aH)-hexaone ${ }^{33}$

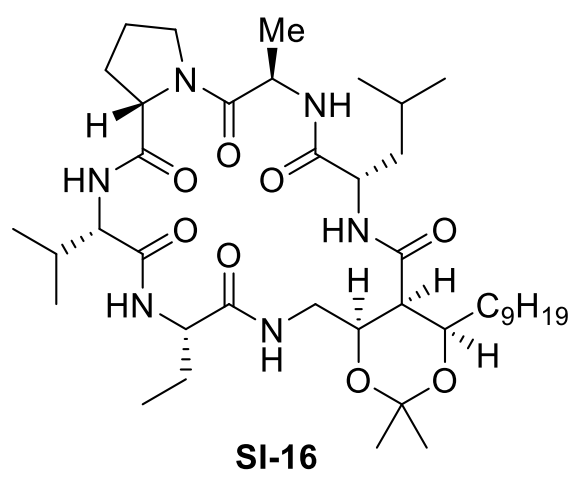

To a solution of SI-15 (5.40 mg, $7.47 \mu \mathrm{mol}, 1.0$ equiv) in $\mathrm{CH}_{2} \mathrm{Cl}_{2}(170 \mu \mathrm{L})$ was added a stock solution of 2-methoxyprop-1-ene $(4.3 \mu \mathrm{L}, \quad 0.045 \mathrm{mmol}, \quad 6.0$ equiv $)$ and pyridinium para-toluenesulfonate $(1.88 \mathrm{mg}, 7.47 \mu \mathrm{mol}$, 1.0 equiv) in $\mathrm{CH}_{2} \mathrm{Cl}_{2}(200 \mu \mathrm{L})$ at $0{ }^{\circ} \mathrm{C}$. To reaction was allowed to reach r.t over $4 \mathrm{~h}$. After completion of the reaction, $\mathrm{pH} 7$ buffer $(2 \mathrm{~mL})$ and DMSO $(2 \mathrm{~mL})$ were

added. The major part of $\mathrm{CH}_{2} \mathrm{Cl}_{2}$ was removed in vacuo and the remaining solution was filtered and submitted directly to preparative HPLC purification $(50 \% \mathrm{MeCN}$ in water with $0.1 \%$ formic acid to $70 \% \mathrm{MeCN}$ in water with $0.1 \%$ formic acid) to yield the title compound as a colorless powder after lyophilization (4.01 mg, $5.24 \mu \mathrm{mol}, 70 \%$ yield).

${ }^{1}$ H NMR (600 MHz, DMSO-d6): $\delta 8.54(\mathrm{~d}, J=7.3 \mathrm{~Hz}, 1 \mathrm{H}), 7.85(\mathrm{~d}, J=7.8 \mathrm{~Hz}, 1 \mathrm{H}), 7.82(\mathrm{~d}$, $J=8.4 \mathrm{~Hz}, 1 \mathrm{H}), 7.68(\mathrm{t}, J=6.1 \mathrm{~Hz}, 1 \mathrm{H}), 7.56(\mathrm{~d}, J=7.1 \mathrm{~Hz}, 1 \mathrm{H}), 4.45(\mathrm{p}, J=6.8 \mathrm{~Hz}, 1 \mathrm{H}), 4.26$ $(\mathrm{dd}, J=8.8,3.6 \mathrm{~Hz}, 1 \mathrm{H}), 4.22(\mathrm{ddd}, J=10.9,7.0,4.6 \mathrm{~Hz}, 1 \mathrm{H}), 4.16-4.10(\mathrm{~m}, 1 \mathrm{H}), 4.03(\mathrm{td}, J$ $=8.4,5.3 \mathrm{~Hz}, 1 \mathrm{H}), 3.90-3.86(\mathrm{~m}, 1 \mathrm{H}), 3.71-3.65(\mathrm{~m}, 1 \mathrm{H}), 3.55-3.45(\mathrm{~m}, 2 \mathrm{H}), 3.11(\mathrm{dt}, J=$ 13.5, 8.0 Hz, 1H), $2.99(\mathrm{dt}, J=13.3,4.8 \mathrm{~Hz}, 1 \mathrm{H}), 2.25-2.16(\mathrm{~m}, 1 \mathrm{H}), 2.14(\mathrm{t}, J=3.1 \mathrm{~Hz}, 1 \mathrm{H})$, $2.11-2.02(\mathrm{~m}, 1 \mathrm{H}), 1.90-1.77(\mathrm{~m}, 4 \mathrm{H}), 1.74-1.65(\mathrm{~m}, 1 \mathrm{H}), 1.61-1.53(\mathrm{~m}, 2 \mathrm{H}), 1.51-1.44$ $(\mathrm{m}, 2 \mathrm{H}), 1.35$ (s, 3H), $1.28(\mathrm{~s}, 3 \mathrm{H}), 1.26-1.21(\mathrm{~m}, 16 \mathrm{H}), 1.12(\mathrm{~d}, J=6.7 \mathrm{~Hz}, 3 \mathrm{H}), 0.94-0.89$ $(\mathrm{m}, 6 \mathrm{H}), 0.88-0.80(\mathrm{~m}, 12 \mathrm{H}) \mathrm{ppm}$.

${ }^{13}$ C NMR (151 MHz, DMSO-d6): $\delta$ 172.5, 171.8, 171.5, 170.9, 170.2, 168.7, 98.1, 69.7, 68.4, $61.4,60.2$, 54.5, 51.5, 46.9, 46.8, 44.4, 41.8, 39.6, 33.1, 31.3, 31.2, 29.5, 29.2, 29.1, 29.0, 28.9, $28.8,28.7,28.7,28.5,25.2,25.1,24.4,24.1,23.1,22.1,21.1,19.7,19.3,19.2,17.2,13.9,10.7$ ppm.

HRMS (ESI): $\quad$ calcd. for $\mathrm{C}_{40} \mathrm{H}_{70} \mathrm{~N}_{6} \mathrm{NaO}_{8}{ }^{+} \quad 785.5147[\mathrm{M}+\mathrm{Na}]^{+}$

found:

785.5140 


\section{Comparison of NMR Spectra of Natural and Synthetic Mutanobactin D}

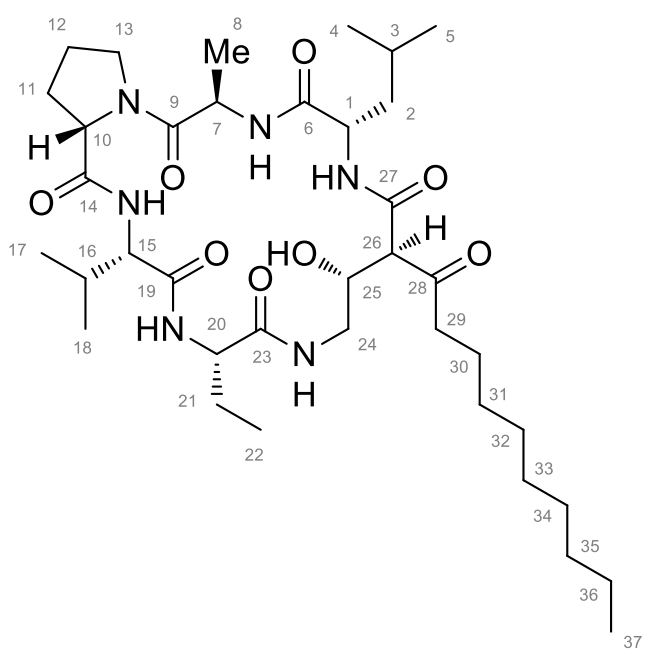

Table 3. Comparison of the chemical shifts of natural (nat) and synthetic (syn) mutanobactin D in DMSO- $d_{6} .{ }^{a}$ Extracted from ${ }^{15} \mathrm{~N}-\mathrm{HSQC}$ spectra.

\begin{tabular}{|c|c|c|c|c|c|c|}
\hline & $\delta \mathrm{c}$ (nat) & $\delta_{H}($ nat $)$ & dc (syn) & $\delta_{H}(\mathbf{s y n})$ & $\delta_{N}(\operatorname{syn})^{a}$ & $\Delta \mathbf{C}$ \\
\hline 1 & 52.3 & $4.21(\mathrm{~m})$ & 52.3 & $4.21(\mathrm{~m})$ & - & 0 \\
\hline \multirow[t]{2}{*}{2} & 40.5 & $1.45(\mathrm{~m})$ & 40.5 & $1.45(\mathrm{~m})$ & - & 0 \\
\hline & & $1.71(\mathrm{~m})$ & & $1.72(\mathrm{~m})$ & & \\
\hline 3 & 24.5 & $1.43(\mathrm{~m})$ & 24.5 & $1.44(\mathrm{~m})$ & - & 0 \\
\hline 4 & 21.6 & $0.91(\mathrm{~d}, 6.4)$ & 21.6 & $0.91(\mathrm{~d}, 6.6)$ & - & 0 \\
\hline 5 & 23.6 & $0.81(\mathrm{~d}, 6.4)$ & 23.5 & $0.82(\mathrm{~d}, 6.4)$ & - & 0.1 \\
\hline 6 & 172.0 & - & 172.0 & - & - & 0 \\
\hline 7 & 47.5 & $4.25(\mathrm{~m})$ & 47.5 & $\begin{array}{c}4.25(\mathrm{qd}, 6.7 \\
3.6)\end{array}$ & - & 0 \\
\hline 8 & 15.1 & $1.20(\mathrm{~d}, 6.9)$ & 15.1 & $1.20(\mathrm{~d}, 6.9)$ & - & 0 \\
\hline 9 & 171.1 & - & 171.0 & - & - & 0.1 \\
\hline 10 & 60.0 & $4.35(\mathrm{brd}, 7.0)$ & 59.9 & $4.36(\mathrm{brd}, 7.0)$ & - & 0.1 \\
\hline
\end{tabular}




\begin{tabular}{|c|c|c|c|c|c|c|}
\hline \multirow[t]{2}{*}{11} & \multirow[t]{2}{*}{29.4} & $1.98(\mathrm{~m})$ & \multirow[t]{2}{*}{29.3} & $1.98(\mathrm{~m})$ & \multirow[t]{2}{*}{-} & \multirow[t]{2}{*}{0.1} \\
\hline & & $2.06(\mathrm{~m})$ & & $2.05(\mathrm{~m})$ & & \\
\hline \multirow[t]{2}{*}{12} & 23.6 & $1.76(\mathrm{~m})$ & 23.5 & $1.76(\mathrm{~m})$ & - & 0.1 \\
\hline & & $1.98(\mathrm{~m})$ & & $1.98(\mathrm{~m})$ & & \\
\hline \multirow[t]{2}{*}{13} & 46.5 & $3.54(\mathrm{~m})$ & 46.5 & $3.54(\mathrm{~m})$ & - & 0 \\
\hline & & 3.91 (brt, 8.9) & & 3.91 (brt, 9.4) & & \\
\hline 14 & 170.5 & - & 170.5 & - & - & 0 \\
\hline 15 & 58.2 & 4.05 (brt, 9.9) & 58.2 & 4.05 (brt, 9.9) & - & 0 \\
\hline 16 & 29.5 & $2.13(\mathrm{~m})$ & 29.5 & $2.13(\mathrm{~m})$ & - & 0 \\
\hline 17 & 19.8 & $0.90(\mathrm{~d}, 6.5)$ & 19.8 & $0.91(\mathrm{~d}, 6.7)$ & - & 0 \\
\hline 18 & 19.4 & $0.97(\mathrm{~d}, 6.6)$ & 19.4 & $0.97(\mathrm{~d}, 6.7)$ & - & 0 \\
\hline 19 & 172.0 & - & 172.0 & - & - & 0 \\
\hline \multirow[t]{2}{*}{20} & 56.4 & $3.80(\mathrm{td}, 2.4$ & 56.5 & $3.80(\mathrm{td}, 3.0$ & - & 0.1 \\
\hline & & 7.4) & & $7.2)$ & & \\
\hline 21 & 23.8 & $1.52(\mathrm{~m})$ & 23.8 & $1.51(\mathrm{~m})$ & - & 0 \\
\hline 22 & 10.3 & $0.85(\mathrm{t}, 7.4)$ & 10.3 & $0.85(\mathrm{t}, 7.4)$ & - & 0 \\
\hline 23 & 172.5 & - & 172.5 & - & - & 0 \\
\hline \multirow[t]{2}{*}{24} & 42.1 & $2.65(\mathrm{brd}, 13.7)$ & 42.1 & $2.66(\mathrm{brd}, 9.9)$ & - & 0 \\
\hline & & $3.38(\mathrm{~m})$ & & $3.38(\mathrm{~m})$ & & \\
\hline 25 & 66.7 & $4.18(\mathrm{~m})$ & 66.8 & $4.17(\mathrm{~m})$ & - & 0.1 \\
\hline 26 & 61.7 & $3.98(\mathrm{~d}, 10.4)$ & 61.9 & $3.98(\mathrm{~d}, 10.4)$ & - & 0.2 \\
\hline 27 & 166.3 & - & 166.3 & - & - & 0 \\
\hline
\end{tabular}




\begin{tabular}{|c|c|c|c|c|c|c|}
\hline 28 & 204.5 & - & 204.5 & - & - & 0 \\
\hline \multirow[t]{2}{*}{29} & 40.1 & $2.23(\mathrm{~m})$ & 40.1 & $2.23(\mathrm{~m})$ & - & 0 \\
\hline & & $2.35(\mathrm{~m})$ & & $2.35(\mathrm{~m})$ & & \\
\hline 30 & 22.5 & $1.36(\mathrm{~m})$ & 22.5 & $1.36(\mathrm{~m})$ & - & 0 \\
\hline 31 & 28.4 & $1.16(\mathrm{~m})$ & 28.4 & $1.15(\mathrm{~m})$ & - & 0 \\
\hline 32 & 28.6 & $1.20(\mathrm{~m})$ & 28.6 & $1.21(\mathrm{~m})$ & - & 0 \\
\hline 33 & 29.0 & $1.21(\mathrm{~m})$ & 28.9 & $1.21(\mathrm{~m})$ & - & 0.1 \\
\hline 34 & 28.7 & $1.22(\mathrm{~m})$ & 28.6 & $1.21(\mathrm{~m})$ & - & 0.1 \\
\hline 35 & 31.2 & $1.22(\mathrm{~m})$ & 31.2 & $1.22(\mathrm{~m})$ & - & 0 \\
\hline 36 & 22.1 & $1.22(\mathrm{~m})$ & 22.1 & $1.24(\mathrm{~m})$ & - & 0 \\
\hline 37 & 13.9 & $0.84(\mathrm{t}, 6.8)$ & 13.9 & $0.84(\mathrm{t}, 6.9)$ & - & 0 \\
\hline $1-\mathrm{NH}$ & - & $8.12(\mathrm{~d}, 4.5)$ & - & $8.12(\mathrm{~d}, 4.7)$ & 126.5 & - \\
\hline 7-NH & - & 9.05 (brs) & - & 9.03 (brs) & 133.0 & - \\
\hline $15-\mathrm{NH}$ & - & $7.63(\mathrm{~d}, 9.3)$ & - & $7.63(\mathrm{~d}, 9.2)$ & 118.6 & - \\
\hline 20-NH & - & $8.46(\mathrm{~d}, 2.6)$ & - & $8.45(\mathrm{~d}, 3.1)$ & 128.0 & - \\
\hline 24-NH & - & $7.81(\mathrm{dd}, 14.1$ & - & $7.80(\mathrm{dd}, 9.1$ & 110.0 & - \\
\hline $25-\mathrm{OH}$ & - & 4.70 (brs) & - & 4.67 (brs) & - & - \\
\hline
\end{tabular}




\section{Configurational Assignment of C-26}

\subsection{Derivatization, Rychnovky's Correlation, and $J$-Coupling Analysis}

Scheme 3. Configurational Assignment of C-26 in SI-16.

A. Transformation of 1 to Cyclic Acetal 12

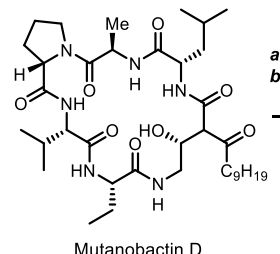

Mutanobactin D a. $\mathrm{NaBH}_{4}, \mathrm{CH}_{3} \mathrm{OH},-78^{\circ} \mathrm{C}$ 2-methoxypropene,

$32 \%$ yield

(c)

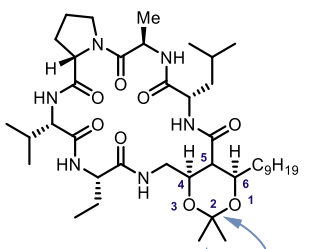

SI-16 $98.1 \mathrm{ppm}$

B. Conformation and Typical ${ }^{13} \mathrm{C}$ NMR Chemical Shifts of Generic Diol Acetonides

$$
19.2 \text { and } 29.5 \mathrm{ppm}
$$
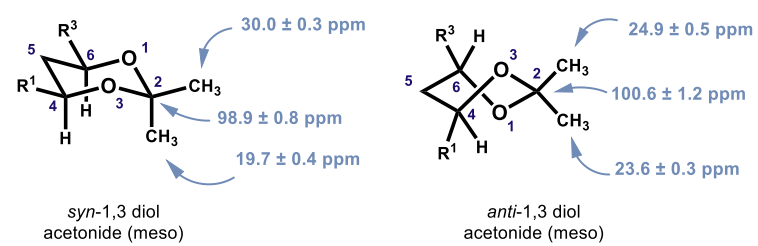

anti-1,3 diol acetonide (meso)

C. Conformational and J-Coupling Analysis of Candidate I

D. Conformational and J-Coupling Analysis of Candidate II
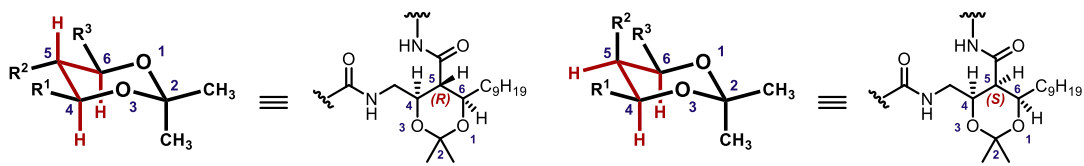

Candidate I

Candidate II

$\theta$ (H4-C4-C5-H5): $180^{\circ}$ (anti)

$\theta$ (H5-C5-C6-H6): $180^{\circ}$ (anti)

${ }^{3} J_{H 4-H 5}$ and ${ }^{3} J_{H 5-H 6}$ expected large $(9-10 \mathrm{~Hz})$

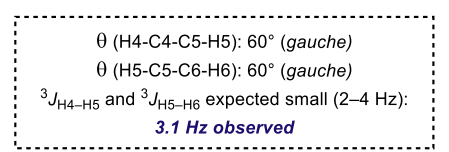

${ }^{a}$ Reagents and conditions: (a) $\mathrm{NaBH}_{4}, \mathrm{MeOH},-78{ }^{\circ} \mathrm{C}$ to r.t., $46 \%$; (b) 2-methoxy-1-propene, PPTS, $\mathrm{CH}_{2} \mathrm{Cl}_{2}, 70 \%$; (c) $\mathrm{NaBH}_{4}$, methanol- $\mathrm{d}_{4},-78{ }^{\circ} \mathrm{C}$ to r.t.; PPTS = pyridinium para-toluenesolfonate; (A.) Transformation of mutanobactin D to cyclic acetal SI-16 and ${ }^{13} \mathrm{C}$ NMR chemical shifts of the acetal. (B.) Generic acetonides with their corresponding average ${ }^{13} \mathrm{C}$ NMR chemical shifts \pm standard deviation; (C.) $J$-coupling analysis of acetonide I. (D.) $J$-coupling analysis of acetonide II. Because of change of priorities using the CIP nomenclature, it follows that C-26 in mutanobactin D is $(R)$-configured even though C-26 in II is assigned $(S)$. 


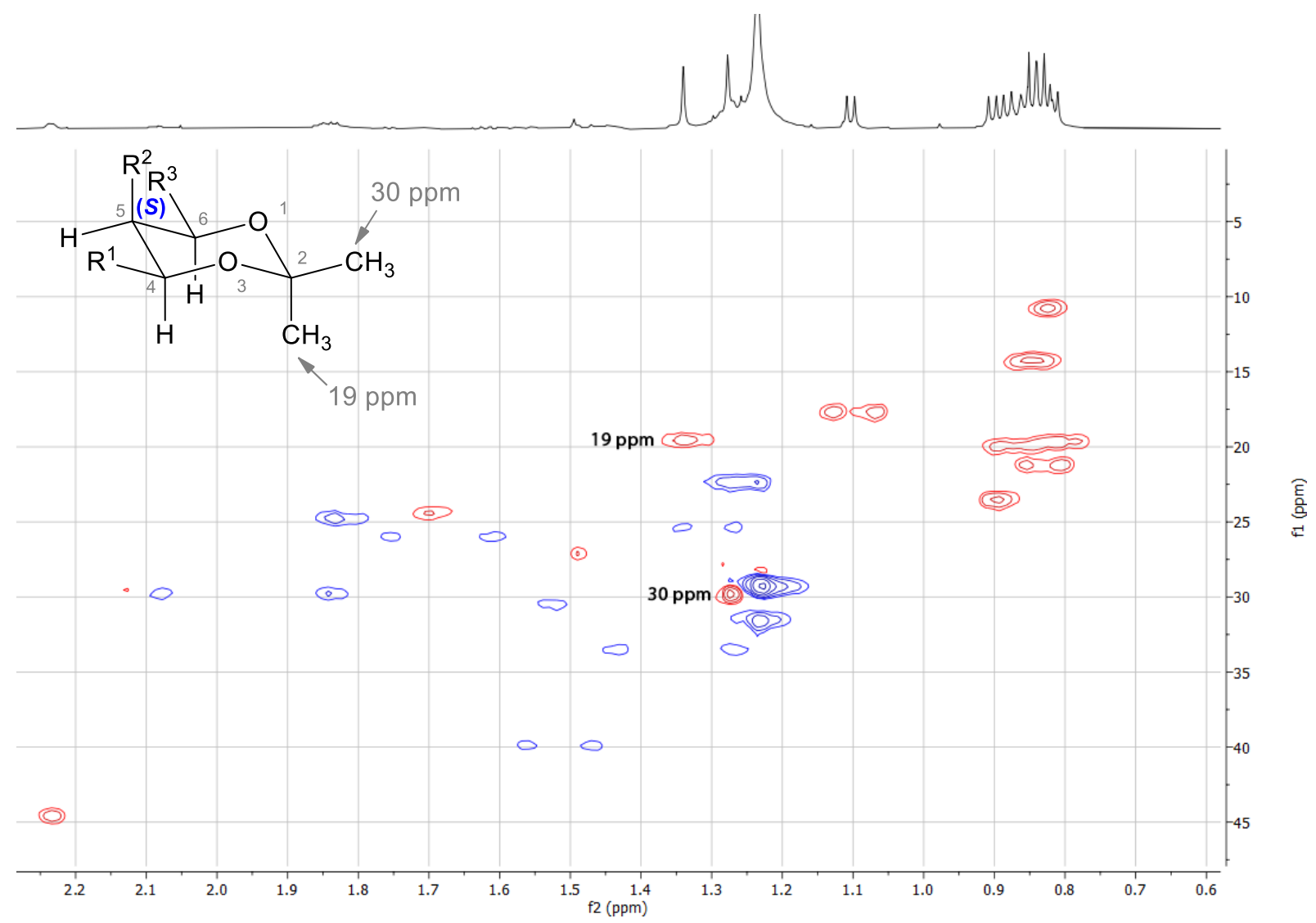

Figure 21. HSQC spectrum of SI-16. The two labelled methyl groups of the acetal at 19 and $30 \mathrm{ppm}$ indicate a syn geometry of the diol. 

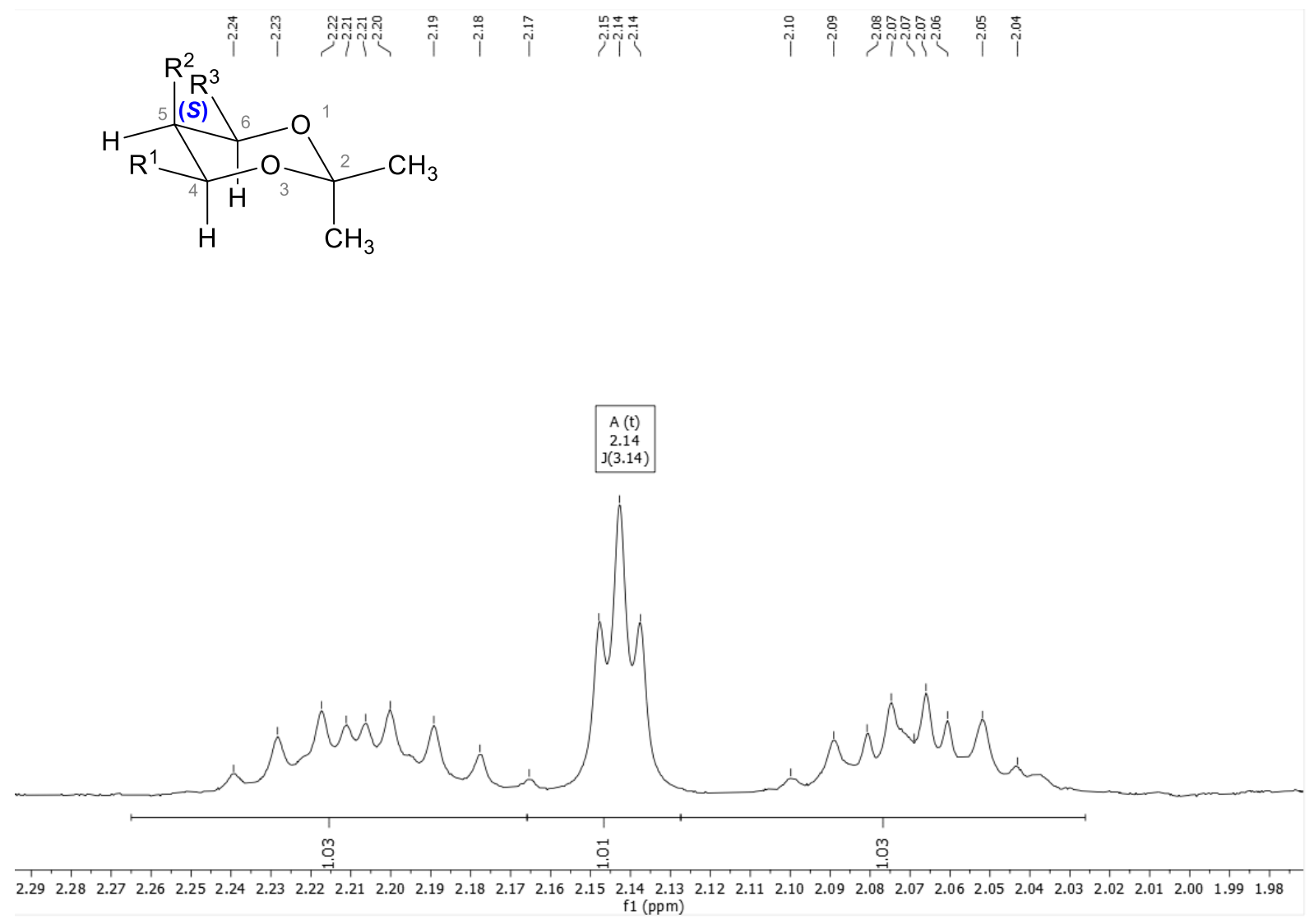

Figure 22. Analysis of the coupling pattern of H-5 of SI-16. The multiplet appears as a doublet of doublet with both coupling constants in the range of $3 \mathrm{~Hz}$. 


\section{NMR Solution-State Structure of Mutanobactin D}

\subsection{Conformational Homogeneity}

Conformational homogeneity of peptides in solution was assumed due to the fulfillment of the following criteria defined by KESSLER: ${ }^{34}$

\begin{tabular}{|c|c|}
\hline Indicator & Observation \\
\hline $\begin{array}{l}\text { Strong differentiation of temperature gradients of } \\
\text { the NH signals between separate amino acid } \\
\text { units; linear within the observed temperature } \\
\text { range }\end{array}$ & $\begin{array}{l}\text { Values between } 1.3 \text { and } 6.2 \mathrm{ppb} \mathrm{K}^{-1} \\
\text { observed; all coefficients follow linear } \\
\text { relationships. }\end{array}$ \\
\hline $\begin{array}{l}\text { Similarly strong differentiation of the chemical } \\
\text { shifts of the NH signals }\end{array}$ & $\begin{array}{l}\text { Values between } 9.03 \text { and } 7.63 \mathrm{ppm} \\
\text { observed. }\end{array}$ \\
\hline $\begin{array}{l}\text { Large chemical shift differences between } \\
\text { germinal diastereotopic glycine or } \beta \text {-amino acid } \\
\text { protons }\end{array}$ & H-24 and H-24' separated by 0.72 ppm. \\
\hline $\begin{array}{l}\text { Strong differentiation between vicinal coupling } \\
\text { constants of diastereotopic protons }\end{array}$ & $\begin{array}{l}{ }^{3} J(\mathrm{NH}, \mathrm{H}-24)=9.9 \mathrm{~Hz} \\
{ }^{3} J\left(\mathrm{NH}, \mathrm{H}-24^{\prime}\right)=3.1 \mathrm{~Hz}\end{array}$ \\
\hline $\begin{array}{l}\text { Large differences between } \mathrm{NHC}_{\alpha} H \text { coupling } \\
\text { constants }\end{array}$ & $\begin{array}{l}\text { Values between } 9.2 \mathrm{~Hz} \text { and } 3.0 \mathrm{~Hz} \\
\text { observed. }\end{array}$ \\
\hline
\end{tabular}

\subsection{Determination of the Dihedral Angle between H-25 and H-26}

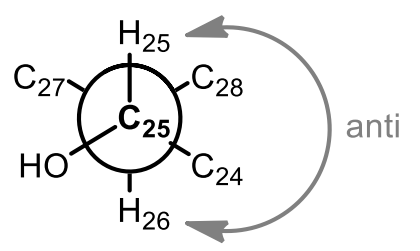

The Haasnot equation was used to quantify the dihedral angle between $\mathrm{H}-25$ and $\mathrm{H}-26:^{35}$

$$
\begin{aligned}
& { }^{3} J(H, H)=14.64 \cos ^{2}(\varphi)-0.78 \cos (\varphi)+0.58 \\
& +\sum_{i} \lambda_{i}\left[0.34-2.31 \cos ^{2}\left(s_{i}(\varphi)+16.9\left|\lambda_{i}\right|\right)\right]
\end{aligned}
$$

Empirical parameters accounting for the group electronegativity $\lambda_{\mathrm{i}}$ were taken from the literature (Table 4). The resulting calculated coupling constants ranged from $0.9 \mathrm{~Hz}\left(90^{\circ}\right)$ to 
$10.9 \mathrm{~Hz}\left(180^{\circ}\right)$. Thus, the observed vicinal coupling constant $(10.4 \mathrm{~Hz})$ corresponds to dihedral an anti-relationship.

Table 4. Coefficients for the Haasnot equation. ${ }^{36}$

\begin{tabular}{|c|c|c|}
\hline Substituent & $\boldsymbol{s}_{\mathbf{i}}$ & $\boldsymbol{\lambda}_{\mathbf{i}}$ \\
\hline $\mathrm{C}_{24}$ & +1 & 0.68 \\
\hline $\mathrm{OH}$ & -1 & 1.33 \\
\hline $\mathrm{C}_{28}$ & +1 & 0.50 \\
\hline $\mathrm{C}_{27}$ & -1 & 0.42 \\
\hline
\end{tabular}

\subsection{Analysis of the Amide Bond Geometry}

In addition to the quantification of NOE data from $\mathrm{NH}$ to $\mathrm{H}_{\alpha}$ of the next amino acid unit (Section 6.8 ), the geometry of secondary amide bonds was assigned by comparing the respective ${ }^{1} J_{\mathrm{NH}}$ coupling constants with published values. ${ }^{37}$ All couplings constants are in excellent agreement to amides with a trans-geometry.

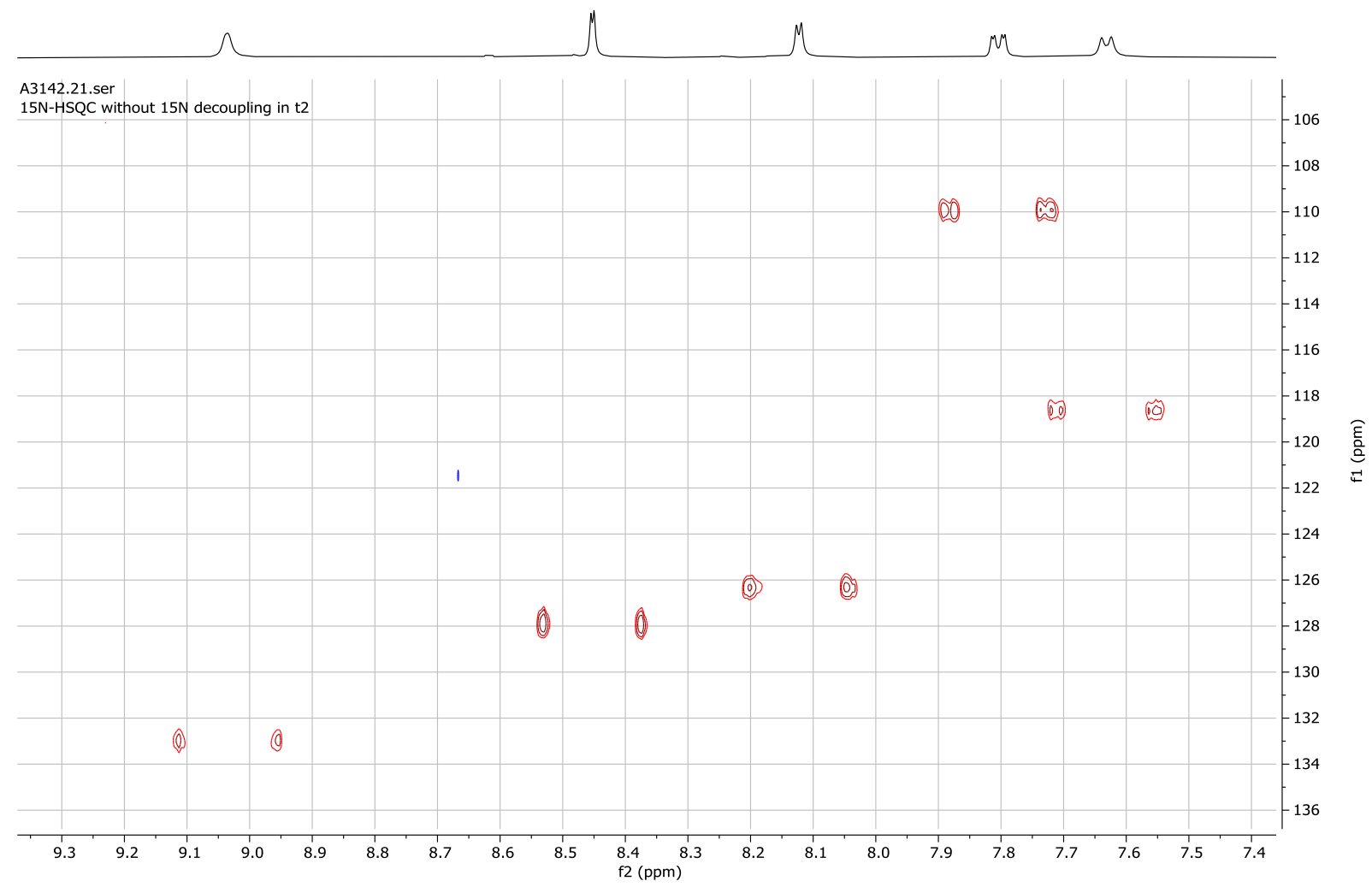


Table 5. N-H chemical shifts (ppm) and backbone amide ${ }^{1} J_{\mathrm{NH}}$ coupling constants for mutanobactin D in DMSO-d6.

\begin{tabular}{cccc}
\hline Residue & $\boldsymbol{\delta}_{\mathbf{N H}}(\mathbf{p p m})$ & $\boldsymbol{\delta}_{\mathbf{N H}}(\mathbf{p p m})$ & $\boldsymbol{1}_{\mathbf{N H}} \mathbf{a}^{\mathbf{a}}$ \\
\hline Abu & 8.46 & 128.0 & 93.8 \\
Val & 7.63 & 118.6 & 92.3 \\
Ala & 9.05 & 133.0 & 95.7 \\
Leu & 8.12 & 126.5 & 93.2 \\
PK & 7.81 & 110.0 & 92.8 \\
\hline
\end{tabular}

${ }^{a}$ From ${ }^{1} \mathrm{H}$-coupled ${ }^{15} \mathrm{~N}$-HSQC.

\subsection{Analysis of the Proline Amide Bond Geometry}

It has been shown that the ${ }^{13} \mathrm{C}$ chemical shifts of $\mathrm{C}_{\beta}$ and $\mathrm{C}_{\gamma}$ of proline correlate with the $\mathrm{XXX}$ Pro amide bond geometry. Values around $31.3 \pm 1.2 \mathrm{ppm}$ for $\mathrm{C}_{\beta}$ and $22.5 \pm 0.3 \mathrm{ppm}$ for $\mathrm{C}_{\gamma}$ are typical for a cis-geometry, whereas values around $29.5 \pm 0.6 \mathrm{ppm}$ for $\mathrm{C}_{\beta}$ and $24.2 \pm 0.5 \mathrm{ppm}$ for $\mathrm{C}_{\gamma}$ are usually observed for a trans-geometry. ${ }^{38}$ We observed 29.3 and $23.5 \mathrm{ppm}$, respectively, indicating a trans-geometry.

\subsection{Determination of Temperature Coefficients}

${ }^{1} \mathrm{H}$ NMR spectra of a $3.9 \mathrm{mM}$ solution of mutanobactin D in DMSO-d 6 were measured between 25 and $65{ }^{\circ} \mathrm{C}$ in $10{ }^{\circ} \mathrm{C}$ increments (Figure 23). The temperature was controlled with an external thermometer and the sample was allowed to equilibrate for $15 \mathrm{~min}$ before the spectrum was recorded. All shifts were referenced to TMS (0 ppm). Temperature coefficients of the amide protons were determined by linear regression from 25 to $65{ }^{\circ} \mathrm{C}$ using Microsoft Excel (Table 6). 


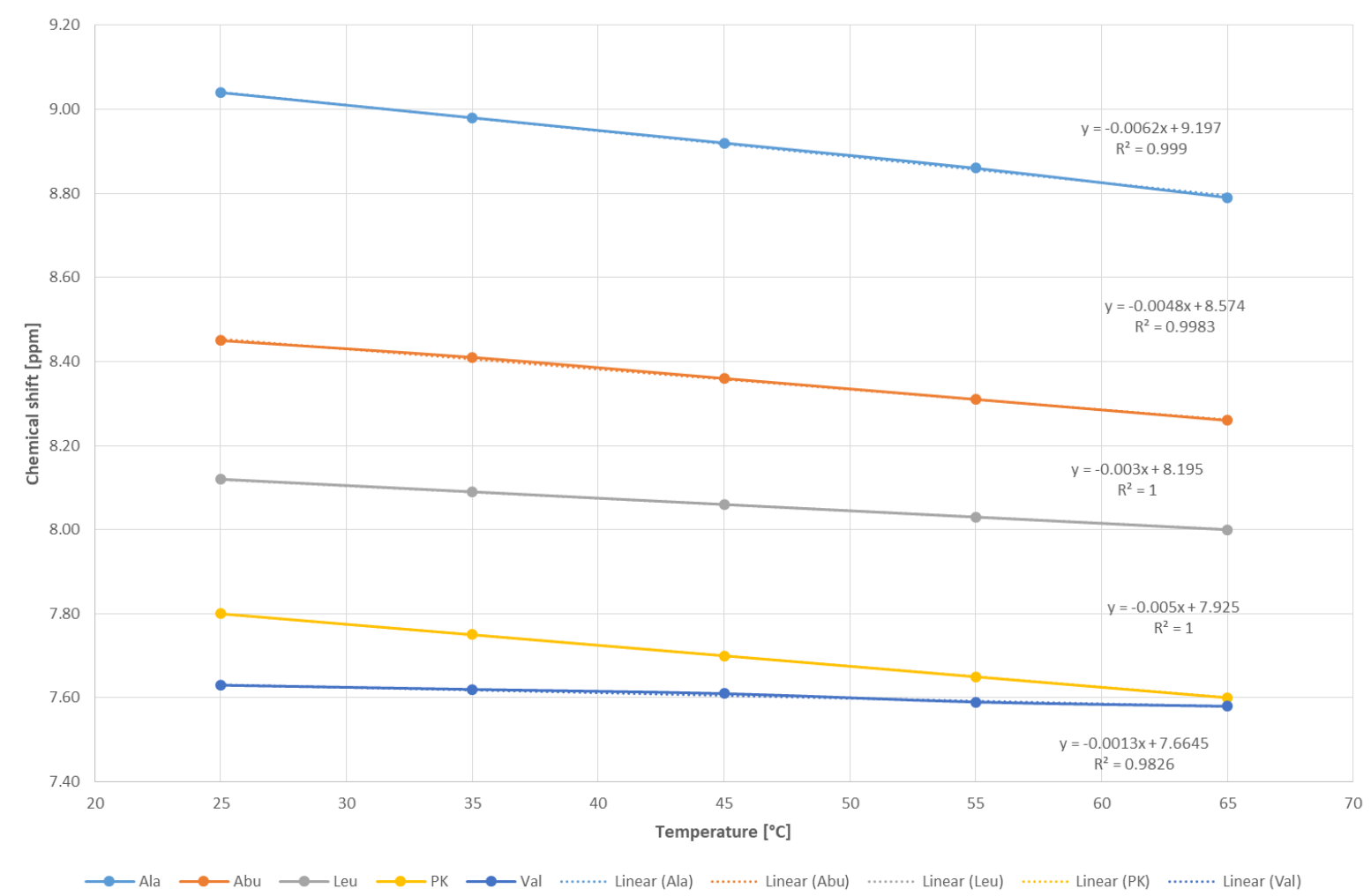

Figure 23. Dependence of ${ }^{1} \mathrm{H}$ chemical shifts of the $\mathrm{N}-\mathrm{H}$ protons and linear regression analysis between 25 and $65{ }^{\circ} \mathrm{C}$ in DMSO-d6. Samples were allowed to reach temperature for $15 \mathrm{~min}$ before spectra were recorded. All shifts were referred to TMS (0 ppm).

It can be concluded that the amide protons corresponding to valine and leucine are engaged in an intramolecular hydrogen bond, whereas the amide protons of $\alpha$-aminobutyric acid, alanine, and the polyketide part of mutanobactin D are solvent-exposed. ${ }^{39}$

Table 6. $\mathrm{N}-\mathrm{H}$ chemical shifts (ppm) in DMSO-d6 and backbone amide temperature $\Delta \delta_{\mathrm{NH}} / \Delta \mathrm{T}\left(\mathrm{ppb} \mathrm{K}^{-1}\right.$ ) coefficients for mutanobactin D in DMSO-d6.

\section{Residue \\ $\delta_{\mathrm{NH}}(\mathbf{p p m})$ in DMSO-d6 \\ $\Delta \delta_{\mathrm{NH}} / \Delta \mathrm{T}\left(\mathrm{ppb} \mathrm{K}^{-1}\right)^{\mathrm{a}}$}

$\begin{array}{lcc}\text { Abu } & 8.46 & 4.8 \\ \text { Val } & 7.63 & 1.3 \\ \text { Ala } & 9.05 & 6.2 \\ \text { Leu } & 8.12 & 3.0 \\ \text { PK } & 7.81 & 5.0\end{array}$

a Amide temperature coefficients are obtained from linear regression as negative numbers but are reported as positive values in this table. In accordance with literature data, values below 3.0 are assumed to indicate a strong intramolecular hydrogen 
bond and solvent shielding, values between 3.0 and 5.0 indicate that the proton is in equilibrium between an intramolecular and a solvent hydrogen bond, and values above 5.0 indicate that the proton is in a hydrogen bond with solvent molecules. ${ }^{39}$

\subsection{Titration of $\mathrm{N}-\mathrm{H}$ Protons}

Mutanobactin D was dissolved in a mixture of $\mathrm{D}_{2} \mathrm{O}$ and DMSO- $\mathrm{d}_{6}(1: 5) .{ }^{1} \mathrm{H}$ NMR spectra were recorded after 5 min and after $2 \mathrm{~h}$. Subsequently, TFA-d $\mathrm{d}_{1}$ was added and ${ }^{1} \mathrm{H}$ NMR spectra were recorded after $15 \mathrm{~min}, 2 \mathrm{~h}, 6 \mathrm{~h}$, and $12 \mathrm{~h}$.

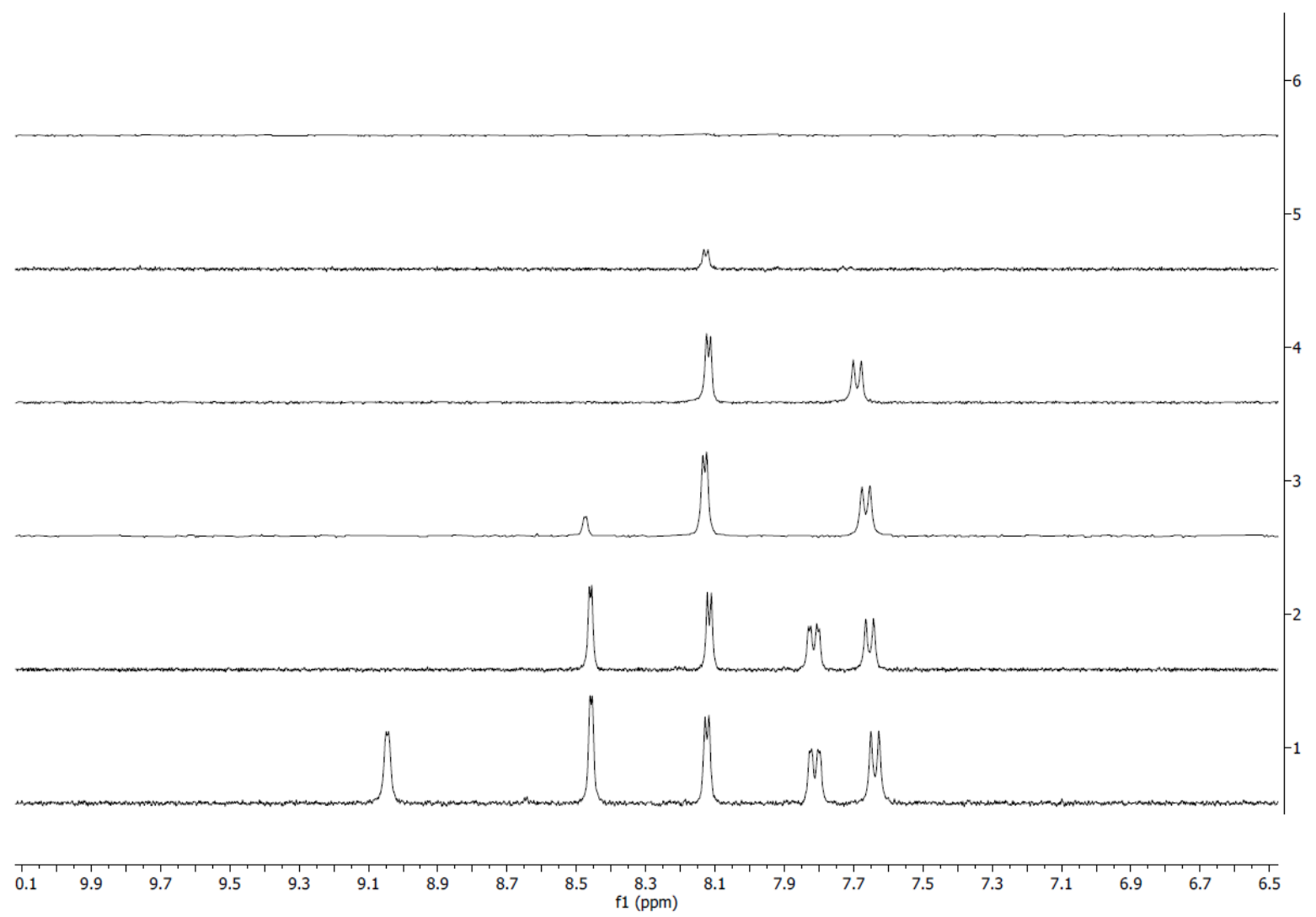

Figure 24. Spectrum of mutanobactin $\mathrm{D}$ in a in a mixture of $\mathrm{D}_{2} \mathrm{O}$ and DMSO- $\mathrm{d}_{6}$ (1:5) (1) after 5 min; (2) after $2 \mathrm{~h}$; and with additional 5\% (v/v) TFA-d $d_{1}$ after (3) 15 min (4) $2 \mathrm{~h}$; (5) $6 \mathrm{~h}$; (6) $12 \mathrm{~h}$.

$\mathrm{N}-\mathrm{H}$ (Ala) underwent rapid exchange even without the addition of TFA- $\mathrm{d}_{1}$. N-H (Abu) and $\mathrm{N}-$ $\mathrm{H}$ (PK) underwent nearly quantitative exchange with deuterium 15 min after addition of TFA$\mathrm{d}_{1}$. In contrast, $\mathrm{N}-\mathrm{H}(\mathrm{Val})$ and eventually $\mathrm{N}-\mathrm{H}(\mathrm{Leu})$ required more than $6 \mathrm{~h}$ of reaction time before exchange was complete.

These observations corroborate our findings from section 6.5 that $\mathrm{N}-\mathrm{H}$ (Val) and $\mathrm{N}-\mathrm{H}$ (Leu) are engaged in intramolecular hydrogen bonds while $\mathrm{N}-\mathrm{H}(\mathrm{Ala}), \mathrm{N}-\mathrm{H}(\mathrm{Abu})$, and $\mathrm{N}-\mathrm{H}(\mathrm{PK})$ are solvent exposed.

Interestingly, $\mathrm{H}-26$ (the $\alpha-\mathrm{H}$ of the $\beta$-ketoamide in mutanobactin $\mathrm{D}$ ) did not undergo exchange with deuterium (data not shown). 


\subsection{Analysis of Scalar Coupling Constants and the Dihedral Angles $\theta$ and $\varphi$}<smiles>[Y]C(=O)NC([R])([2H])C([Y])=O</smiles>

Proton-proton ${ }^{3} J$ coupling constants were directly extracted from nonoverlapping signals in the ${ }^{1} \mathrm{H}$ NMR spectrum using the multiplet analysis tool in MestReNova. Dihedral angles are obtained as the up to four solutions of the corresponding Karplus equation (Table 7): ${ }^{40}$

$$
J(\theta)=6.98 \cos ^{2}(\theta)-1.38 \cos (\theta)+1.72
$$

Table 7. Chemical shifts and vicinal coupling constants of mutanobactin D in DMSO- $\mathrm{d}_{6}$ with the corresponding dihedral angles as solutions of the Karplus equation. All chemical shifts are reported in ppm and all coupling constants in Hz. Dihedral Angles $\theta$ and $\varphi$ are reported in degrees as solutions of the Karplus equation. By convention, $\theta$ is defined from 0 to $180^{\circ}$ whereas $\varphi$ is defined from $-180^{\circ}$ to $180^{\circ}$.

\begin{tabular}{|c|c|c|c|c|c|c|c|c|c|}
\hline Residue & $\delta_{H a}$ & $\delta_{\mathrm{NH}}$ & ${ }^{3} J_{\mathrm{HNCaHa}}$ & $\theta_{1}$ & $\theta_{2}$ & $\varphi 1$ & $\varphi 2$ & $\varphi 3$ & $\varphi 4$ \\
\hline $\mathrm{Abu}$ & 3.80 & 8.46 & 3.0 & 57 & 110 & +117 & +3 & +170 & -50 \\
\hline Val & 4.05 & 7.63 & 9.2 & - & 160 & - & - & -140 & -100 \\
\hline Pro & 4.35 & - & - & - & - & - & - & - & - \\
\hline Ala & 4.25 & 9.05 & 3.5 & 52 & 115 & -8 & -112 & +55 & -175 \\
\hline Leu & 4.21 & 8.12 & 3.1 & 56 & 111 & +116 & +4 & +171 & -51 \\
\hline
\end{tabular}

\subsection{Determination of NOE-Derived Distances}

ROESY spectra were recorded on a $600 \mathrm{MHz}$ spectrometer with a mixing time of $300 \mathrm{~ms}$. Peak integration was performed with MestReNova. Cross-peak volumes were then converted into distances according to the following equation:

$$
r_{i j}=r_{c a l} \sqrt[6]{\frac{V_{c a l}}{V_{i j}}}
$$

Where $\mathrm{r}_{i j}$ is the distance between protons $i$ and $j, \mathrm{r}_{c a l}$ a known calibration distance, $\mathrm{V}_{c a l}$ the crosspeak volume of the two protons used for calibration and $\mathrm{V}_{i j}$ the cross-peak volume of the two protons $i$ and $j$. The distances between the two germinal protons $\mathrm{H} \gamma 2$ and $\mathrm{H} \gamma 1$ as well as $\mathrm{H} \delta 2$ and $\mathrm{H} \delta 1$ of the proline residue were assumed to be $1.78 \AA$ and averaged values were used for 
calibration. If possible, cross peaks from both sides of the diagonal were independently integrated and converted into distances and averaged.

Table 8. Interproton distances derived from the the procedure described above. Diastereotopic germinal protons in the proline residue were labelled as follows: $\mathrm{H} \beta 2, \mathrm{H} \gamma 2$, and $\mathrm{H} \delta 2$ are syn with the proline $\mathrm{H} \alpha$ protons whereas $\mathrm{H} \beta 1, \mathrm{H} \gamma 1$, and $\mathrm{H} \delta 1$ are anti.

\begin{tabular}{|c|c|c|c|c|}
\hline Residue 1 & Atom 1 & Residue 2 & Atom 2 & $\mathbf{r}[\AA]$ \\
\hline \multirow[t]{4}{*}{ Ala } & $\mathrm{NH}$ & Ala & $\mathrm{H} \alpha$ & 3.1 \\
\hline & & Leu & $\mathrm{H} \alpha$ & 2.4 \\
\hline & $\mathrm{H} \alpha$ & Pro & $\mathrm{H} \delta 1$ & 2.1 \\
\hline & & Pro & $\mathrm{H} \delta 2$ & 2.2 \\
\hline \multirow[t]{3}{*}{$\mathrm{Abu}$} & $\mathrm{NH}$ & Val & $\mathrm{H} \alpha$ & 2.1 \\
\hline & & $\mathrm{Abu}$ & $\mathrm{H} \alpha$ & 2.6 \\
\hline & & Val & $\mathrm{H} \beta$ & 4.6 \\
\hline \multirow[t]{4}{*}{ Leu } & $\mathrm{NH}$ & Leu & $\mathrm{H} \alpha$ & 2.6 \\
\hline & & PK & $\mathrm{H} \beta$ & 2.8 \\
\hline & & $\mathrm{PK}$ & $\mathrm{H} \alpha$ & 2.1 \\
\hline & & Val & $\mathrm{H} \beta$ & 2.7 \\
\hline \multirow[t]{5}{*}{ PK } & $\mathrm{NH}$ & PK & $\mathrm{H} \alpha$ & 3.1 \\
\hline & & PK & $\mathrm{H} \beta$ & 3.7 \\
\hline & & $\mathrm{Abu}$ & $\mathrm{H} \alpha$ & 2.0 \\
\hline & $\mathrm{H} \alpha$ & $\mathrm{Abu}$ & $\mathrm{H} \alpha$ & 3.7 \\
\hline & & PK & $\mathrm{H} \gamma 1$ & 2.8 \\
\hline
\end{tabular}




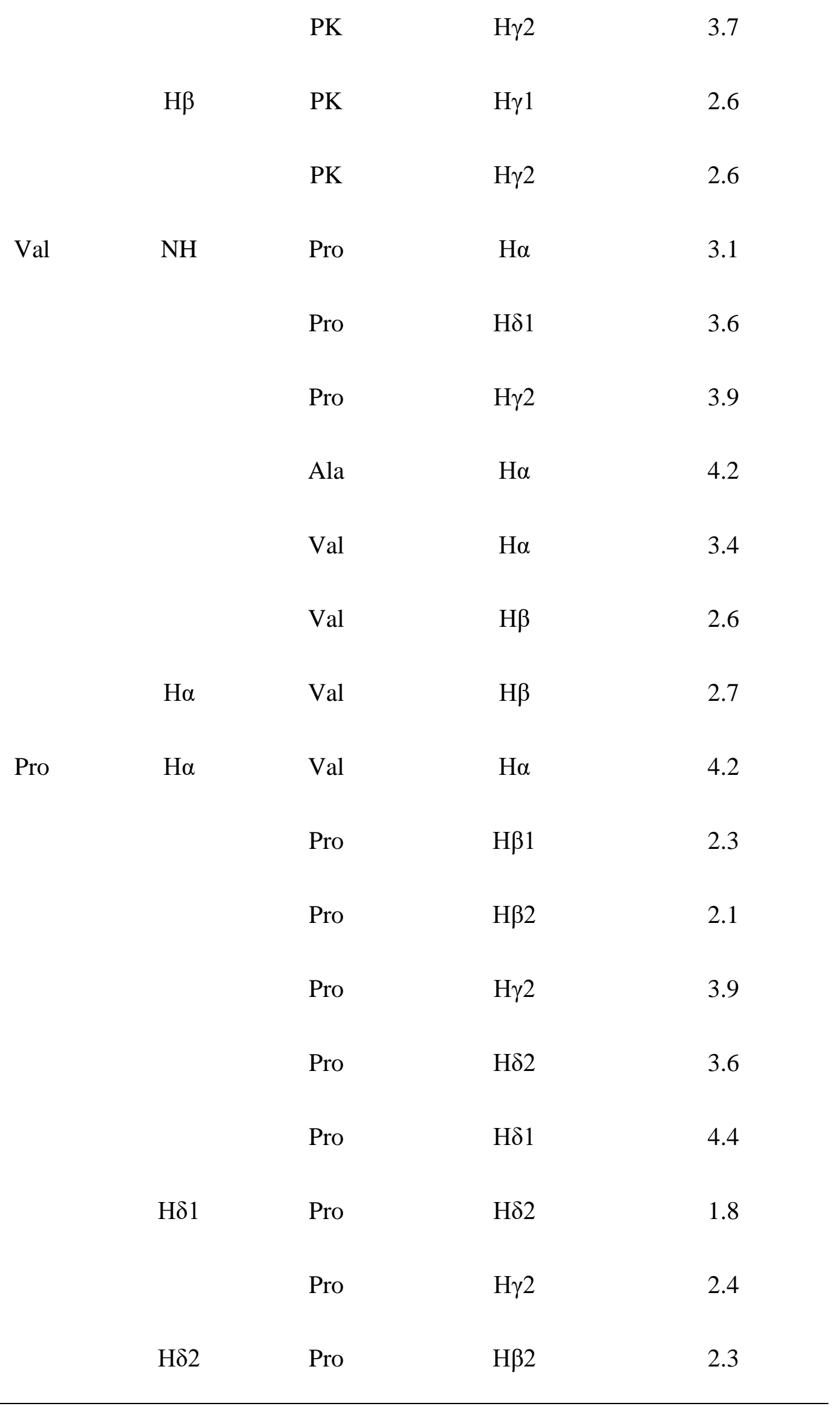




\subsection{Proposed Solution-State Structure}

The data obtained from sections 6.1 to 6.8 was visualized using a constrained conformational search using the Monte Carlo algorithm (intermediate torsional sampling MCMM) implemented in MacroModel v12.6 (Schrödinger 2019-4 release). The following constraints were implemented in the search:

Table 9. Constraints used in the conformational search.

\begin{tabular}{|c|c|c|}
\hline Constraint & Value & Error \\
\hline$\theta(\mathrm{Val})$ & $160^{\circ}$ & $\pm 15^{\circ}$ \\
\hline$\theta(\mathrm{H}-25, \mathrm{H}-26)$ & $180^{\circ}$ & $\pm 15^{\circ}$ \\
\hline $\mathrm{d}\left(\mathrm{NH} \mathrm{PK}, \mathrm{H} \alpha_{\mathrm{Abu}}\right)$ & $2.0 \AA$ & $\pm 0.2 \AA$ \\
\hline $\mathrm{d}\left(\mathrm{NH}_{\mathrm{Abu}}, \mathrm{H} \alpha_{\mathrm{Val}}\right)$ & $2.1 \AA$ & $\pm 0.2 \AA$ \\
\hline $\mathrm{d}\left(\mathrm{NH}_{\mathrm{Val}}, \mathrm{H} \alpha_{\mathrm{Pro}}\right)$ & $3.1 \AA$ & $\pm 0.3 \AA$ \\
\hline $\mathrm{d}\left(\mathrm{NH}_{\mathrm{Ala}}, \mathrm{H} \alpha_{\mathrm{Leu}}\right)$ & $2.4 \AA$ & $\pm 0.3 \AA$ \\
\hline $\mathrm{d}\left(\mathrm{NH}_{\mathrm{Leu}}, \mathrm{H} \alpha_{\mathrm{PK}}\right)$ & $2.1 \AA$ & $\pm 0.2 \AA$ \\
\hline $\mathrm{d}\left(\mathrm{NH}_{\mathrm{Leu}}, \mathrm{H} \beta_{\mathrm{PK}}\right)$ & $2.8 \AA$ & $\pm 0.3 \AA$ \\
\hline $\mathrm{d}\left(\mathrm{H} \alpha_{\mathrm{Ala}}, \mathrm{H} \delta 2_{\mathrm{Pro}}\right)$ & $2.2 \AA$ & $\pm 0.2 \AA$ \\
\hline $\mathrm{d}\left(\mathrm{H} \alpha_{\mathrm{Ala}}, \mathrm{H} \delta 1_{\mathrm{Pro}}\right)$ & $2.1 \AA$ & $\pm 0.2 \AA$ \\
\hline $\mathrm{d}\left(\mathrm{NH}_{\mathrm{Leu}}, \mathrm{H} \beta_{\mathrm{Val}}\right)$ & $2.7 \AA$ & $\pm 0.3 \AA$ \\
\hline
\end{tabular}

The fatty acid side chain was truncated from a nonyl unit to an ethyl unit to simplify selection and later modelled as a linear chain. 50000 Monte Carlo (MCMM) steps were followed by a maximum of 5000 energy minimization steps using the Polak-Ribiere conjugate gradient (PRCG) algorithm. Redundant structures were removed according to a maximum atom deviation of $0.5 \AA$ in respect to all heavy atoms. Remaining conformers were minimized with 
the same software using the OPLS3e force field with the dielectric constant for DMSO $\varepsilon_{r}=$ 46.7. All conformers within $42 \mathrm{~kJ} \mathrm{~mol}^{-1}$ from the global minimum were retained. Obtained structures showed excellent agreement with the criteria discussed in sections 6.1 to 6.8 and we can thus propose the major solution-state structure of mutanobactin D as shown below (Figure 25).

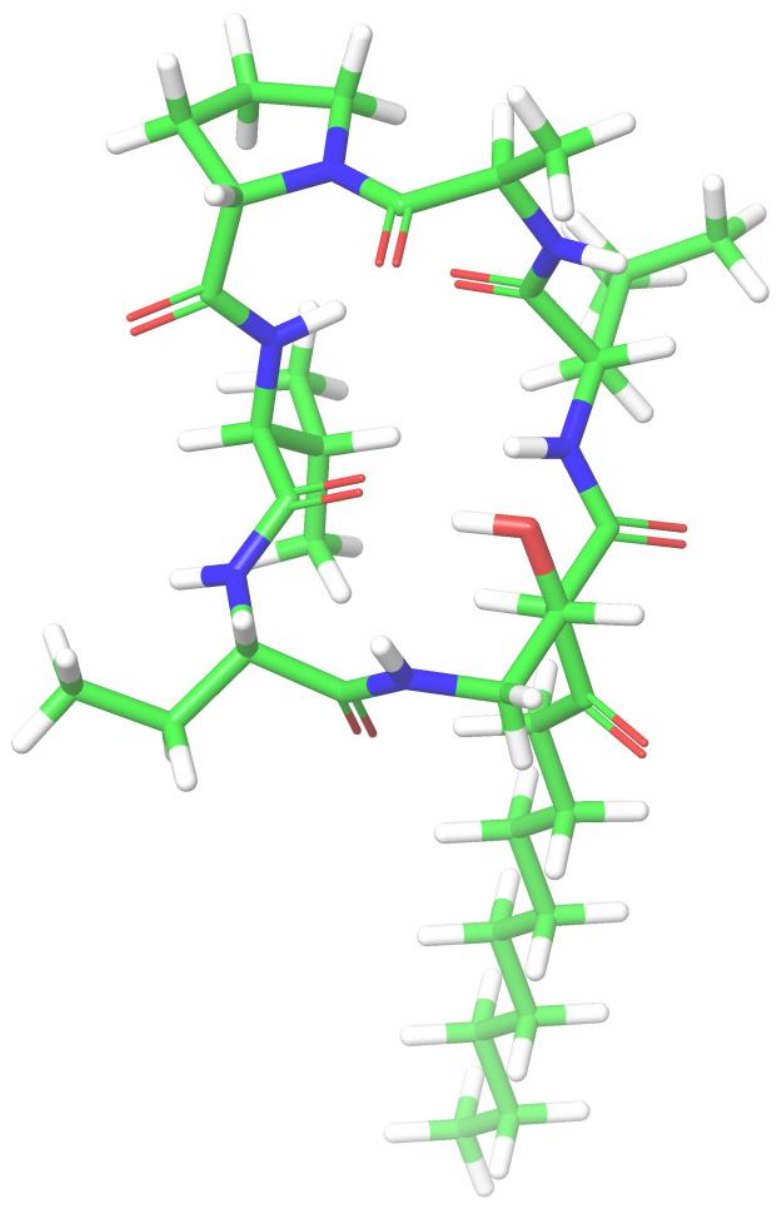

Figure 25. Major solution-state structure of mutanobactin D as obtained from NMR data. 


\subsection{Cartesian Coordinates for the NMR Solution-State Structure}

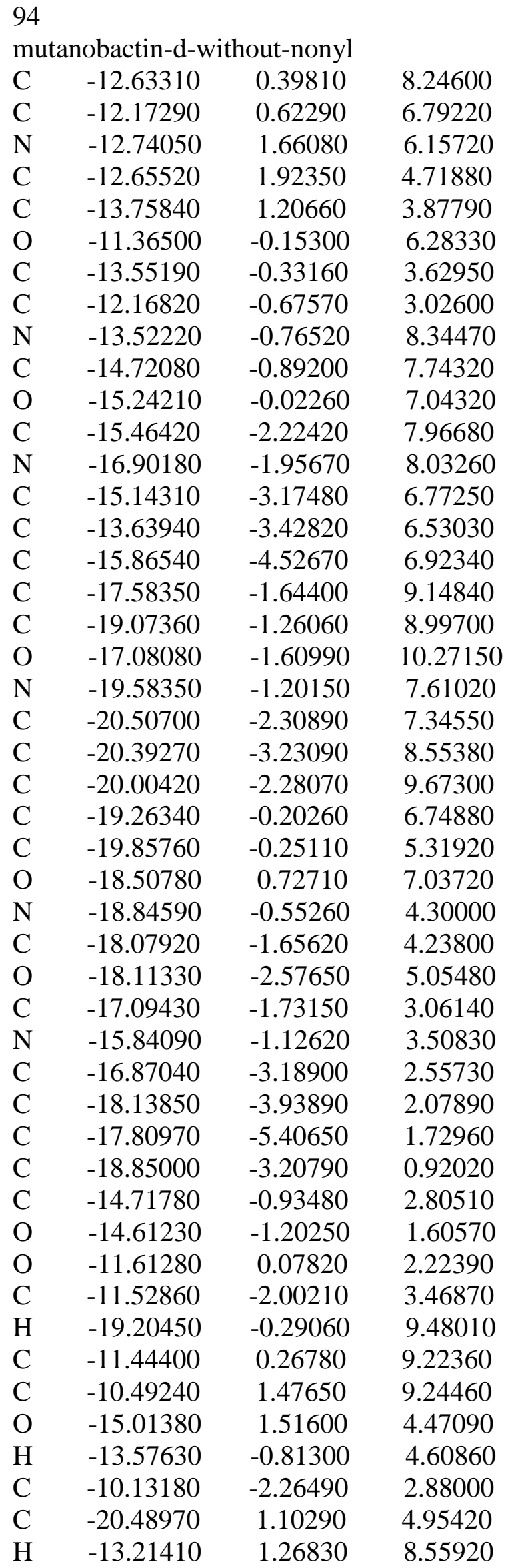




\begin{tabular}{|c|c|c|c|}
\hline $\mathrm{H}$ & -13.36270 & 2.26110 & 6.67920 \\
\hline $\mathrm{H}$ & -12.79040 & 3.00100 & 4.61670 \\
\hline $\mathrm{H}$ & -11.65070 & 1.71890 & 4.34640 \\
\hline $\mathrm{H}$ & -13.83210 & 1.66590 & 2.89910 \\
\hline $\mathrm{H}$ & -13.17430 & -1.52970 & 8.90530 \\
\hline $\mathrm{H}$ & -15.12340 & -2.68390 & 8.89680 \\
\hline $\mathrm{H}$ & -17.38650 & -1.96110 & 7.14650 \\
\hline $\mathrm{H}$ & -15.52750 & -2.71560 & 5.86140 \\
\hline $\mathrm{H}$ & -13.48850 & -4.16080 & 5.73710 \\
\hline $\mathrm{H}$ & -13.11130 & -2.52760 & 6.22120 \\
\hline $\mathrm{H}$ & -13.15430 & -3.80950 & 7.42920 \\
\hline $\mathrm{H}$ & -15.64830 & -5.18540 & 6.08210 \\
\hline $\mathrm{H}$ & -16.94820 & -4.40590 & 6.96010 \\
\hline $\mathrm{H}$ & -15.55700 & -5.03880 & 7.83520 \\
\hline $\mathrm{H}$ & -20.28250 & -2.85020 & 6.42730 \\
\hline $\mathrm{H}$ & -21.51480 & -1.90150 & 7.25660 \\
\hline $\mathrm{H}$ & -21.30390 & -3.79420 & 8.75620 \\
\hline $\mathrm{H}$ & -19.58420 & -3.94510 & 8.39020 \\
\hline $\mathrm{H}$ & -19.55600 & -2.80090 & 10.52070 \\
\hline $\mathrm{H}$ & -20.89350 & -1.76800 & 10.04240 \\
\hline $\mathrm{H}$ & -20.64690 & -0.99750 & 5.23800 \\
\hline $\mathrm{H}$ & -18.73620 & 0.15180 & 3.58460 \\
\hline $\mathrm{H}$ & -17.48130 & -1.12060 & 2.24450 \\
\hline $\mathrm{H}$ & -15.83890 & -0.70350 & 4.42460 \\
\hline $\mathrm{H}$ & -16.39530 & -3.76540 & 3.35330 \\
\hline $\mathrm{H}$ & -16.15920 & -3.19460 & 1.73210 \\
\hline $\mathrm{H}$ & -18.84380 & -3.98390 & 2.90870 \\
\hline $\mathrm{H}$ & -17.92990 & -5.62440 & 0.66840 \\
\hline $\mathrm{H}$ & -18.46060 & -6.08910 & 2.27670 \\
\hline $\mathrm{H}$ & -16.78330 & -5.66840 & 1.98830 \\
\hline $\mathrm{H}$ & -18.20220 & -2.47290 & 0.44200 \\
\hline $\mathrm{H}$ & -19.19160 & -3.88770 & 0.13970 \\
\hline $\mathrm{H}$ & -19.73020 & -2.67790 & 1.28550 \\
\hline $\mathrm{H}$ & -12.19510 & -2.81400 & 3.17680 \\
\hline $\mathrm{H}$ & -11.46350 & -2.01750 & 4.55560 \\
\hline $\mathrm{H}$ & -10.87490 & -0.63550 & 8.99810 \\
\hline $\mathrm{H}$ & -11.83690 & 0.12540 & 10.23120 \\
\hline $\mathrm{H}$ & -9.72370 & 1.34810 & 10.00700 \\
\hline $\mathrm{H}$ & -11.02980 & 2.39790 & 9.47090 \\
\hline $\mathrm{H}$ & -9.98200 & 1.61090 & 8.29060 \\
\hline $\mathrm{H}$ & -15.08750 & 2.47000 & 4.54870 \\
\hline $\mathrm{H}$ & -9.74180 & -3.21980 & 3.23270 \\
\hline $\mathrm{H}$ & -9.42120 & -1.49180 & 3.17560 \\
\hline $\mathrm{H}$ & -10.15590 & -2.30360 & 1.79010 \\
\hline $\mathrm{H}$ & -21.25150 & 1.39110 & 5.67960 \\
\hline $\mathrm{H}$ & -19.74770 & 1.90180 & 4.91430 \\
\hline $\mathrm{H}$ & -20.97340 & 1.05630 & 3.97790 \\
\hline
\end{tabular}




\section{Computational Details}

\subsection{General Considerations}

All DFT computations were performed in the ORCA/4.2.0 software package ${ }^{41}$ using the gradient corrected BP86 functional on the Euler cluster at ETH Zurich. All computations utilized density fitting, also known as the resolution of identity (RI) approximation. All results reported are based on tightly convergence SCF and tightly optimized geometries. An implementation of the IRSA algorithm is available online under https://github.com/rinikerlab/irsa. All computations are accessible under https://github.com/rinikerlab/irsa.

\subsection{Sampling and Optimization Protocol}

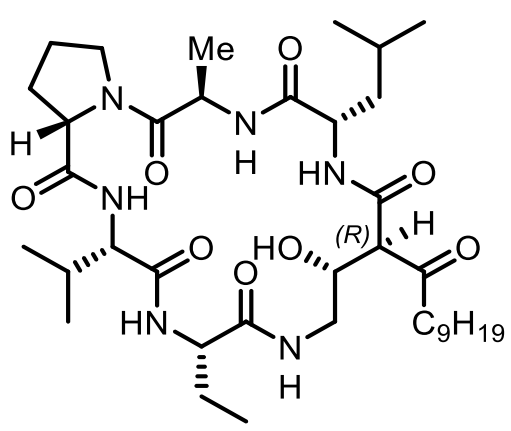

Isomer I mutanobactin $\mathrm{D}$

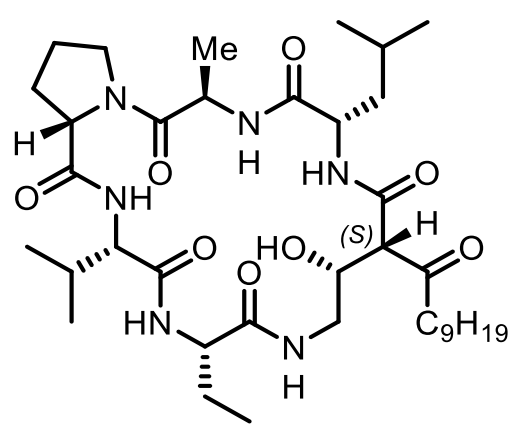

Isomer II epi-mutanobactin D

Conformers for isomers I and II were generated using the OMEGA software package. ${ }^{42}$ An initial set of conformers for both isomers I and II were generated using the OMEGA Toolkit, which offers an algorithm specifically designed for sampling conformations of macrocycles.

For both isomers, the maximum number of conformers $N$ was set to 400 . Resulting conformers are minimized using the MMFF94 force field (convergence threshold $=1 \times 10^{-3} \mathrm{kcal} \mathrm{mol}^{-1}$ ). Two conformers were considered identical, if the RMSD between those conformers was below $0.5 \AA$ in respect to all heavy atoms. The number of attempts to find a new conformation was set to 2000. All conformers within $10 \mathrm{kcal} \mathrm{mol}^{-1}$ from the global minimum were retained and summarized to clusters with a RMSD below $0.5 \AA$. We found 84 and 36 unique clusters for isomer I and II, respectively.

All conformers were pre-optimized in vacuum on the $\mathrm{RI}^{43}-\mathrm{BP} 86^{44} / \mathrm{def} 2-\mathrm{SVP}^{45}-\mathrm{D} 3 \mathrm{BJ}{ }^{46}$ level of theory, followed by an optimization on the RI-BP86/def2-TZVP ${ }^{45}$-D3BJ level of theory with an integration Grid 5 (FinalGrid6). We subsequently performed frequency calculations on the 
converged structures on the same level of theory and confirmed true minima (no imaginary frequencies). A comprehensive list of conformers and their respective ZPE is given in Table 10 and Table 11. ${ }^{47}$ Interestingly, we found that for both isomers the global minimum was energetically favorable by more than $5 \mathrm{kcal} \mathrm{mol}^{-1}$ compared to the next ranked cluster. Consequently, we deemed only the global minimum relevant for its contribution to the theoretical IR spectra.

Table 10. Conformers and Gibbs energies of isomer I on the RI-BP86/def2-TZVP level. Dispersion interactions modelled with D3BJ.

\begin{tabular}{|c|c|}
\hline Conformer Number for Isomer I & Relative Gibbs energy / kcal mol ${ }^{-1}$ \\
\hline 1 & 0 \\
\hline 2 & 5.73 \\
\hline 3 & 6.07 \\
\hline 4 & 8.40 \\
\hline 5 & 8.75 \\
\hline 6 & 9.23 \\
\hline 7 & 10.07 \\
\hline 8 & 10.41 \\
\hline 9 & 10.52 \\
\hline 10 & 10.65 \\
\hline 11 & 10.87 \\
\hline 12 & 11.40 \\
\hline 13 & 11.85 \\
\hline 14 & 11.96 \\
\hline 15 & 12.05 \\
\hline 16 & 12.07 \\
\hline 17 & 12.21 \\
\hline 18 & 12.61 \\
\hline 19 & 13.18 \\
\hline 20 & 13.80 \\
\hline 21 & 13.85 \\
\hline 22 & 13.88 \\
\hline 23 & 14.07 \\
\hline 24 & 14.23 \\
\hline 25 & 14.66 \\
\hline 26 & 14.72 \\
\hline 27 & 14.80 \\
\hline 28 & 14.83 \\
\hline 29 & 15.02 \\
\hline
\end{tabular}




\begin{tabular}{|c|c|}
\hline 30 & 15.07 \\
\hline 31 & 15.26 \\
\hline 32 & 15.28 \\
\hline 33 & 15.50 \\
\hline 34 & 15.56 \\
\hline 35 & 16.09 \\
\hline 36 & 16.27 \\
\hline 37 & 16.44 \\
\hline 38 & 16.44 \\
\hline 39 & 16.47 \\
\hline 40 & 16.62 \\
\hline 41 & 16.64 \\
\hline 42 & 16.72 \\
\hline 43 & 16.94 \\
\hline 44 & 17.15 \\
\hline 45 & 17.44 \\
\hline 46 & 17.51 \\
\hline 47 & 17.64 \\
\hline 48 & 18.08 \\
\hline 49 & 18.39 \\
\hline 50 & 18.88 \\
\hline 51 & 19.08 \\
\hline 52 & 19.10 \\
\hline 53 & 19.37 \\
\hline 54 & 19.39 \\
\hline 55 & 19.44 \\
\hline 56 & 19.53 \\
\hline 57 & 19.54 \\
\hline 58 & 19.55 \\
\hline 59 & 19.67 \\
\hline 60 & 19.69 \\
\hline 61 & 19.82 \\
\hline 62 & 20.04 \\
\hline 63 & 20.16 \\
\hline 64 & 20.51 \\
\hline 65 & 20.79 \\
\hline 66 & 22.03 \\
\hline 67 & 22.08 \\
\hline 68 & 22.20 \\
\hline
\end{tabular}




\begin{tabular}{ll}
69 & 22.40 \\
70 & 22.43 \\
71 & 22.51 \\
72 & 22.92 \\
73 & 23.05 \\
74 & 23.40 \\
75 & 24.01 \\
76 & 24.46 \\
77 & 24.48 \\
78 & 25.15 \\
79 & 25.17 \\
80 & 25.81 \\
81 & 25.88 \\
82 & 27.71 \\
83 & 28.86 \\
84 & 31.19 \\
\hline
\end{tabular}

Table 11. Conformers and Gibbs energies of isomer II on the RI-BP86/def2-TZVP level. Dispersion interactions modelled with D3BJ.

\begin{tabular}{cc}
\hline Conformer Number for Isomer II & Relative Gibbs Energy / kcal mol $^{-1}$ \\
\hline 1 & 0 \\
2 & 7.32 \\
3 & 8.16 \\
4 & 8.62 \\
5 & 9.36 \\
6 & 9.58 \\
7 & 9.60 \\
8 & 9.76 \\
9 & 10.97 \\
10 & 10.12 \\
11 & 10.52 \\
12 & 10.67 \\
13 & 10.87 \\
14 & 11.01 \\
15 & 11.72 \\
16 & 12.24 \\
17 & 12.34 \\
18 & 12.46
\end{tabular}




\subsection{Unaligned IR Spectra}

In Figure 26, the experimental IR spectra (black) and the unaligned theoretical spectra of isomer I (blue, left panel) and isomer II (green, right panel) are shown.
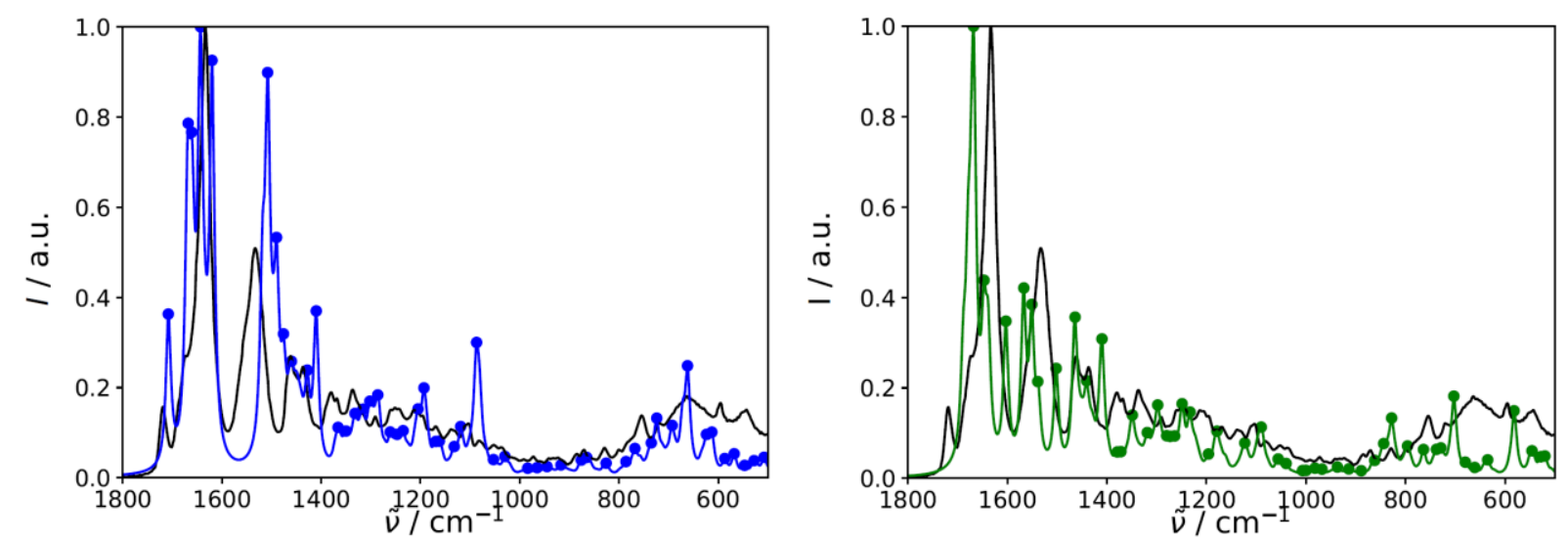

Figure 26. Experimental (black) and unaligned theoretical spectra of isomer I (blue, left) and isomer II (green, right). The theoretical spectra were broadened assuming a Lorentz band shape with a bandwidth of $12 \mathrm{~cm}^{-1}$. Theoretical peaks, which were automatically selected for the alignment with the IRSA algorithm, are marked with circles. 


\subsection{Alignment with the IRSA Algorithm ${ }^{48,49}$}

The experimental IR spectrum was sliced from $500-1000 \mathrm{~cm}^{-1}$ and from $500-1800 \mathrm{~cm}^{-1}$, respectively. For each slice, a constant baseline was computed and subtracted from the experimental spectrum. All peaks were manually selected. The scoring function used in this work is a product of two Gaussian functions,

$$
S_{i j}=e^{-0.5\left(\min \left(\frac{I_{i}}{I_{j}}, \frac{I_{j}}{I_{i}}\right)-1\right)^{2} / \sigma_{1}^{2}} \cdot e^{-0.5\left(\frac{\tilde{v}_{i}}{\tilde{\mathrm{v}}_{j}}-\mu\right)^{2} / \sigma_{2}^{2}},
$$

where $s$ is the score of matching the experimental peak $i$ with the theoretical peak $j . I_{i}$ and $I_{j}$ are the intensities of the experimental and theoretical intensities, respectively, and $\tilde{v}_{i}$ and $\tilde{v}_{j}$ their respective wavenumbers. $\mu$ is a constant scaling factor, and $\sigma_{1}=0.1$ and $\sigma_{2}=0.0192$ are parameters. A cutoff of $30 \mathrm{~cm}^{-1}$ was employed. $\mu$ was varied between 1.00 and 1.014 in steps of 0.001 . For the computation of the Pearson and the Spearman coefficients, 150 bins were created for each slice. The numerical results are available at https://github.com/rinikerlab/irsa.

\subsection{Application of a Constant Scaling Factor}

In the past, constant scaling factors have typically been applied in order to shift the theoretical spectrum to account for the red-shift and to obtain a better match between theoretical and experimental spectra as an alternative to the IRSA algorithm. In Figure 27, the values of the coefficients are shown as a function of the constant scaling factor $\mu$. The computational results suggest that the traditional method would equally predict isomer $\mathbf{I}$ as the correct isomer. 

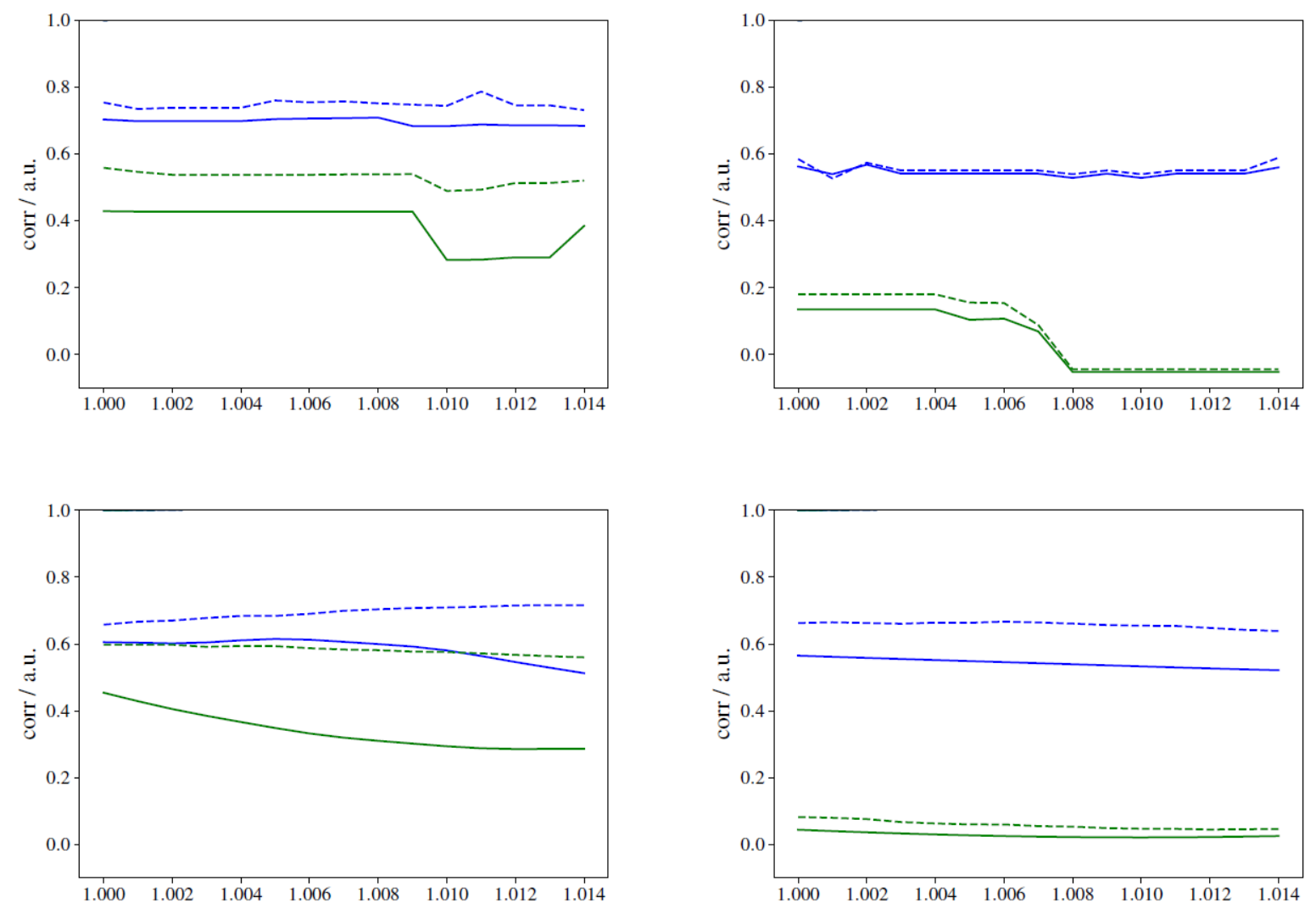

Figure 27. Pearson (solid lines) and the Spearman (dashed lines) coefficients for isomer I (blue) and II (green) for the alignment between the theoretical and experimental IR spectra as a function of the scaling factor $\mu$. The alignment was either performed with IRSA (top) or with a constant scaling factor (bottom). (Left): spectral region 500-1800 $\mathrm{cm}^{-1}$. (Right): spectral region 500$1000 \mathrm{~cm}^{-1}$. Note that for BP86/def2-TZVP, theoretical peaks are red-shifted, i.e. only slightly positive values for $\mu$ are reasonable (1.00 to 1.014$)$.

\subsection{Validation of the Lowest-Energy Conformer of Isomer II}

The frequency analysis depends on the lowest-energy conformer. Whether the correct lowestenergy conformer is determined depends in turn on the quality and exhaustiveness of the conformational search. To rule out that the lowest-energy structure of isomer I exists also for isomer II (with an inverted stereocenter), we inverted the stereocenter manually for the lowestenergy structure of I and subjected it to DFT re-optimization. This process resulted in a structure with an energy that is $16 \mathrm{~kJ} \mathrm{~mol}^{-1}$ above the lowest-energy structure initially determined for isomer II which we deemed negligible for the computation of a theoretical IR spectrum.

\subsection{Contribution of the Decanoyl Side Chain to Theoretical IR Spectra}

The contribution of the carbonyl group to the normal modes was computed via

$$
C_{i}=\left|\vec{D}_{i}\right| \cdot\left|\vec{Q}_{i, 0}\right|,
$$


where $C_{i}$ is the contribution, $\vec{D}_{i}$ is the transition dipole moment, $\vec{Q}_{i, \mathrm{O}}$ is a mass-weighted normal mode of the carbonyl group. $i$ refers to the $i^{\text {th }}$ normal mode. All theoretical spectra were convoluted using Lorentz-broadening with a bandwidth of $12 \mathrm{~cm}^{-1}$.

\subsection{Comparison NMR Solution-State Structure and DFT Optimized Structure in DMSO}

In order to gain additional confidence in the obtained NMR solution-state structure in DMSO (Figure 25), we performed a DFT geometry optimization of mutanobactin D using the conductor-like polarizable continuum model of DMSO. The nonyl chain of was truncated to an ethyl group in order to avoid dispersion interactions of the long alkyl chain with the solvent. Conformers were generated using the OMEGA software package and DFT geometry optimized using the same protocol as for the unmodified isomers (see 7.2). The obtained minimum structure was very similar to the NMR solution-state structure. Visual comparison is given in Figure 28 followed by numerical comparison of torsional angles and intramolecular distances (Table 12 and Table 13).

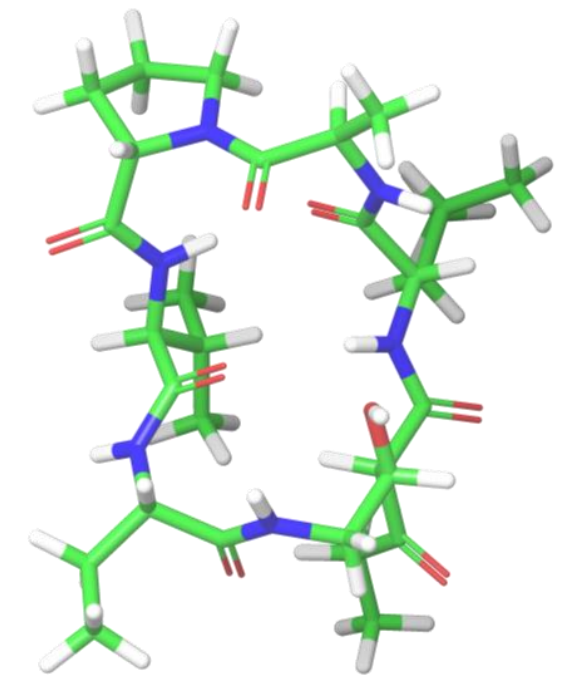

(a) NMR major solution-state structure in DMSO

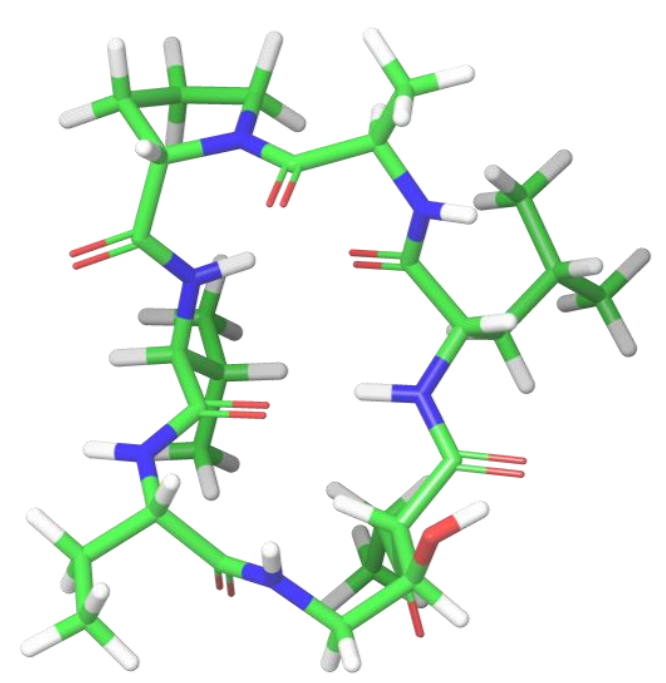

(b) DFT optimized structure in DMSO

Figure 28. Comparison of the NMR major solution-state structure (left) with the DFT optimized structure in DMSO (right). The fatty acid chain was truncated for clarity. 
Table 12. Comparison of dihedrals $\varphi$ and $\theta$ obtained from raw NMR data (NMR), the major solution-state structure from MacroModel (Model) and DFT calculations (DFT).

\begin{tabular}{ccccccc}
\hline Residue & $\boldsymbol{\varphi}$ (NMR) & $\boldsymbol{\varphi}$ (Model) & $\boldsymbol{\varphi}$ (DFT) & $\boldsymbol{\theta}$ (NMR) & $\boldsymbol{\theta}$ (Model) & $\boldsymbol{\theta}$ (DFT) \\
\hline Abu & -50 & -55 & -55 & +110 & +118 & +116 \\
Val & -100 & -86 & -90 & +160 & +151 & +163 \\
Pro & - & -73 & -76 & - & - & - \\
Ala & +55 & +52 & +59 & +115 & +110 & +119 \\
Leu & -189 & -174 & -161 & +111 & +114 & +135 \\
\hline
\end{tabular}

Table 13. Comparison of distances $r$ obtained from raw NMR data (NMR), the major solution-state structure from MacroModel (Model) and DFT calculations (DFT).

\begin{tabular}{|c|c|c|c|c|c|c|}
\hline Residue 1 & Atom 1 & Residue 2 & Atom 2 & $\begin{array}{c}\mathbf{r}[\AA] \\
\text { (NMR) }\end{array}$ & $\begin{array}{c}\text { r [̊̊] } \\
\text { (Model) }\end{array}$ & $\begin{array}{c}\mathbf{r}[\AA] \\
(\mathbf{D F T})\end{array}$ \\
\hline \multirow[t]{4}{*}{ Ala } & $\mathrm{NH}$ & Ala & $\mathrm{H} \alpha$ & 3.1 & 2.8 & 2.8 \\
\hline & & Leu & $\mathrm{H} \alpha$ & 2.4 & 2.2 & 2.2 \\
\hline & $\mathrm{H} \alpha$ & Pro & $\mathrm{H} \delta 1$ & 2.1 & 2.2 & 2.1 \\
\hline & & Pro & $\mathrm{H} \delta 2$ & 2.2 & 2.4 & 2.4 \\
\hline \multirow[t]{3}{*}{$\mathrm{Abu}$} & $\mathrm{NH}$ & Val & $\mathrm{H} \alpha$ & 2.1 & 2.2 & 2.2 \\
\hline & & $\mathrm{Abu}$ & $\mathrm{H} \alpha$ & 2.6 & 2.8 & 2.8 \\
\hline & & Val & $\mathrm{H} \beta$ & 4.6 & 4.1 & 4.3 \\
\hline \multirow[t]{3}{*}{ Leu } & $\mathrm{NH}$ & Leu & $\mathrm{H} \alpha$ & 2.6 & 2.8 & 2.9 \\
\hline & & PK & $\mathrm{H} \beta$ & 2.8 & 3.5 & 4.6 \\
\hline & & PK & $\mathrm{H} \alpha$ & 2.1 & 2.3 & 2.1 \\
\hline
\end{tabular}




\begin{tabular}{|c|c|c|c|c|c|c|}
\hline & & Val & $\mathrm{H} \beta$ & 2.7 & 2.6 & 2.6 \\
\hline \multirow[t]{6}{*}{ PK } & $\mathrm{NH}$ & PK & $\mathrm{H} \alpha$ & 3.1 & 3.7 & 3.0 \\
\hline & & PK & $\mathrm{H} \beta$ & 3.7 & 3.9 & 3.9 \\
\hline & & $\mathrm{Abu}$ & $\mathrm{H} \alpha$ & 2.0 & 2.1 & 2.1 \\
\hline & $\mathrm{H} \alpha$ & $\mathrm{Abu}$ & $\mathrm{H} \alpha$ & 3.7 & 4.5 & 3.7 \\
\hline & $\mathrm{H} \beta$ & PK & $\mathrm{H} \gamma 1$ & 2.6 & 2.4 & 2.4 \\
\hline & & PK & $\mathrm{H} \gamma 2$ & 2.6 & 2.6 & 2.5 \\
\hline \multirow[t]{7}{*}{ Val } & $\mathrm{NH}$ & Pro & $\mathrm{H} \alpha$ & 3.1 & 3.4 & 3.4 \\
\hline & & Pro & $\mathrm{H} \delta 1$ & 3.6 & 3.1 & 2.8 \\
\hline & & Pro & $\mathrm{H} \gamma 2$ & 3.9 & 4.1 & 4.5 \\
\hline & & Ala & $\mathrm{H} \alpha$ & 4.2 & 3.9 & 3.6 \\
\hline & & Val & $\mathrm{H} \alpha$ & 3.4 & 3.2 & 3.0 \\
\hline & & Val & $\mathrm{H} \beta$ & 2.6 & 2.4 & 2.5 \\
\hline & $\mathrm{H} \alpha$ & Val & $\mathrm{H} \beta$ & 2.7 & 3.1 & 3.1 \\
\hline \multirow[t]{6}{*}{ Pro } & $\mathrm{H} \alpha$ & Val & $\mathrm{H} \alpha$ & 4.2 & 4.8 & 4.6 \\
\hline & & Pro & $\mathrm{H} \beta 1$ & 2.3 & 2.7 & 2.7 \\
\hline & & Pro & $\mathrm{H} \beta 2$ & 2.1 & 2.3 & 2.4 \\
\hline & & Pro & $\mathrm{H} \gamma 2$ & 3.9 & 4.2 & 4.2 \\
\hline & & Pro & $\mathrm{H} \delta 2$ & 3.6 & 3.6 & 3.7 \\
\hline & & Pro & $\mathrm{H} \delta 1$ & 4.4 & 4.1 & \\
\hline
\end{tabular}




$\begin{array}{lccccc}\text { H } \delta 1 & \text { Pro } & \mathrm{H} \delta 2 & 1.8 & 1.8 & 1.8 \\ & \text { Pro } & \mathrm{H} \gamma 2 & 2.4 & 2.4 & 2.8 \\ \mathrm{H} \delta 2 & \text { Pro } & \mathrm{H} \beta 2 & 2.3 & 2.9 & 2.9\end{array}$

\subsection{Comparison of Zero-Point Corrected Energies for Isomers I and II}

Table 14 gives a comparison of ZPE corrected free energies of isomer I compared to isomer II. We found that isomer I is favored by $2.70 \mathrm{kcal} \mathrm{mol}^{-1}$ relative to isomer II. This finding may explain why C-26 epimerizes spontaneously during the isoxazoline reduction. ${ }^{47}$

Table 14. Zero-point corrected energies for lowest energy conformers of isomers I and II on the RI-BP86/def2-TZVP level of theory.

\begin{tabular}{ccc}
\hline Isomer & Gibbs energy / Hartree & Gibbs energy / kcal mol \\
\hline I \\
\hline I & -2379.19391355 & -1492967.0401 \\
II & -2379.18960842 & -1492964.3386 \\
Difference & -0.00430 & -2.70 \\
\hline
\end{tabular}


8 NMR Spectra 


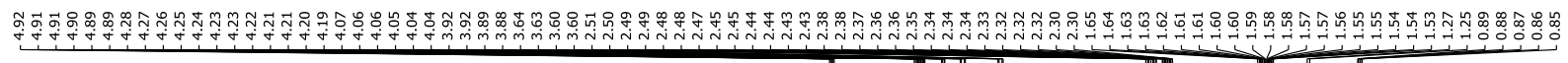<smiles>CCCCCC1=NO[C@H](CO)[C@H]1C(=O)OCC</smiles>
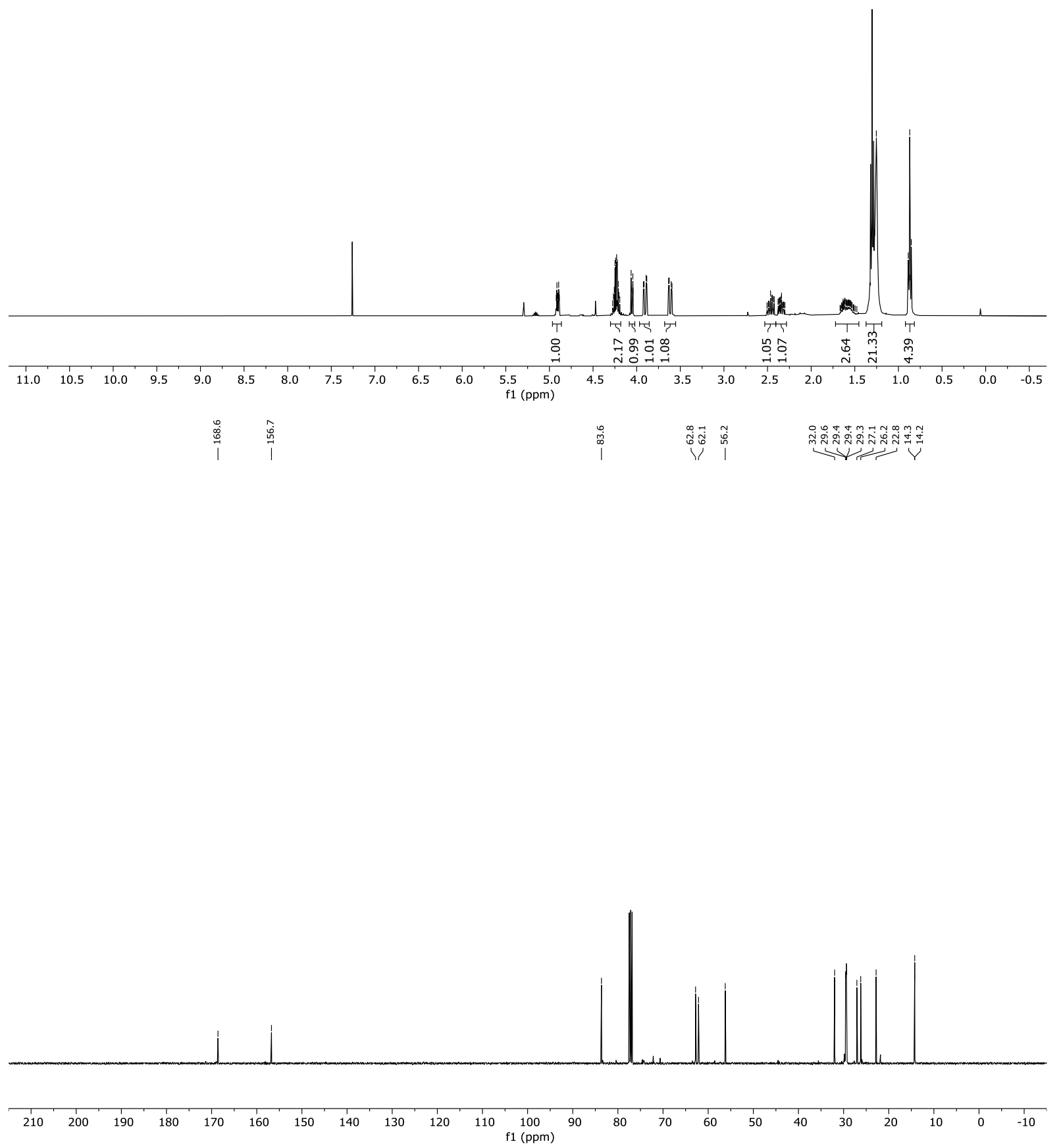

79 


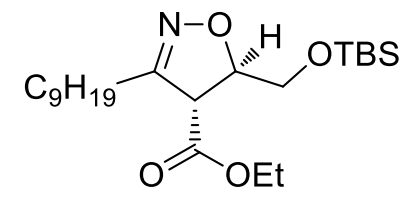
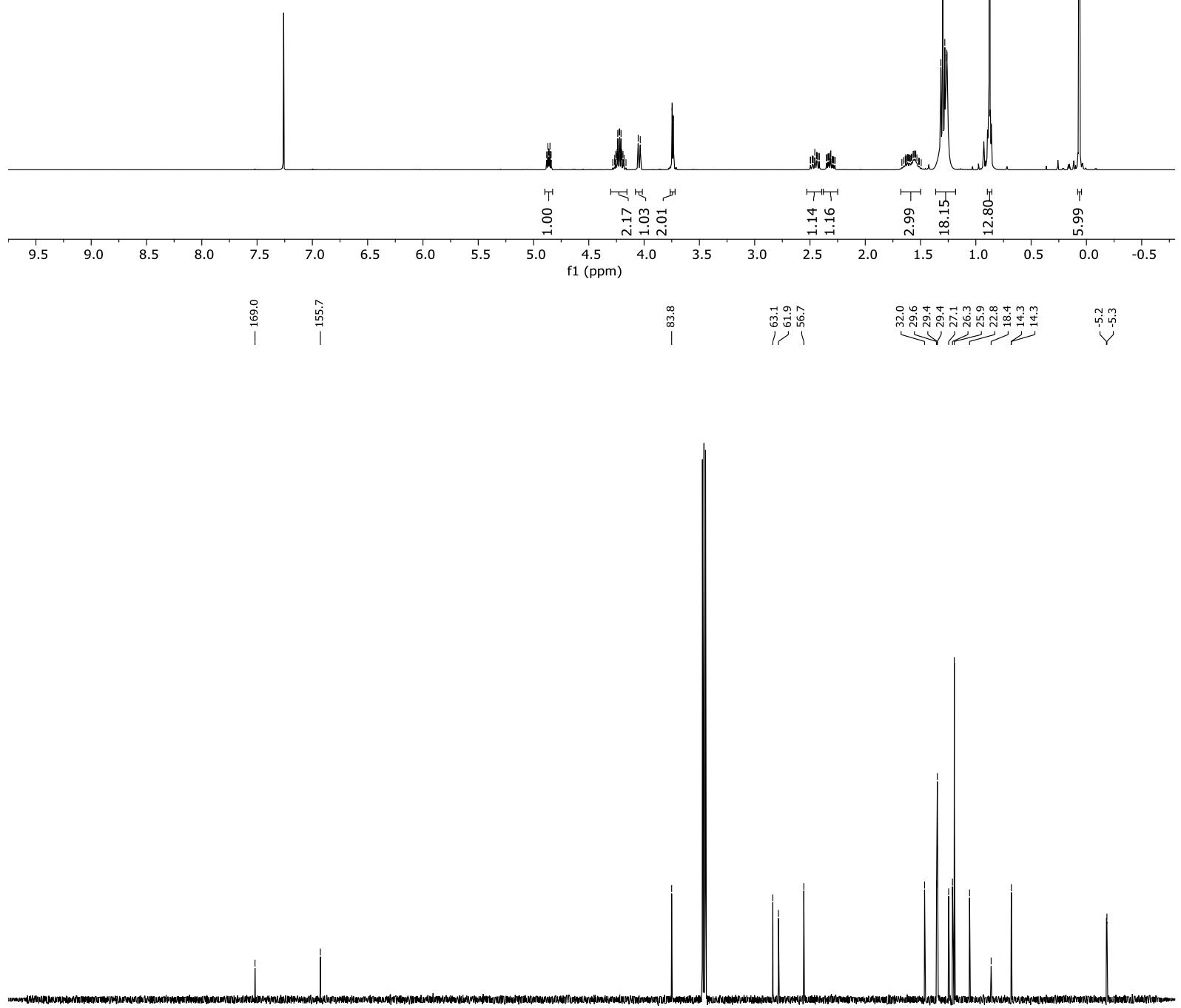

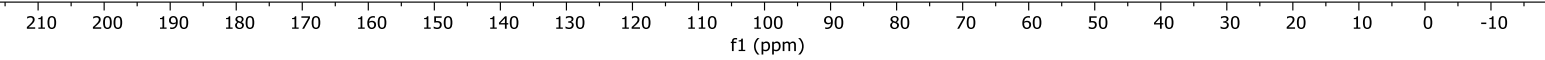


<smiles>CCCCCC1=NO[C@H](CO[SbH2])[C@H]1CO</smiles>
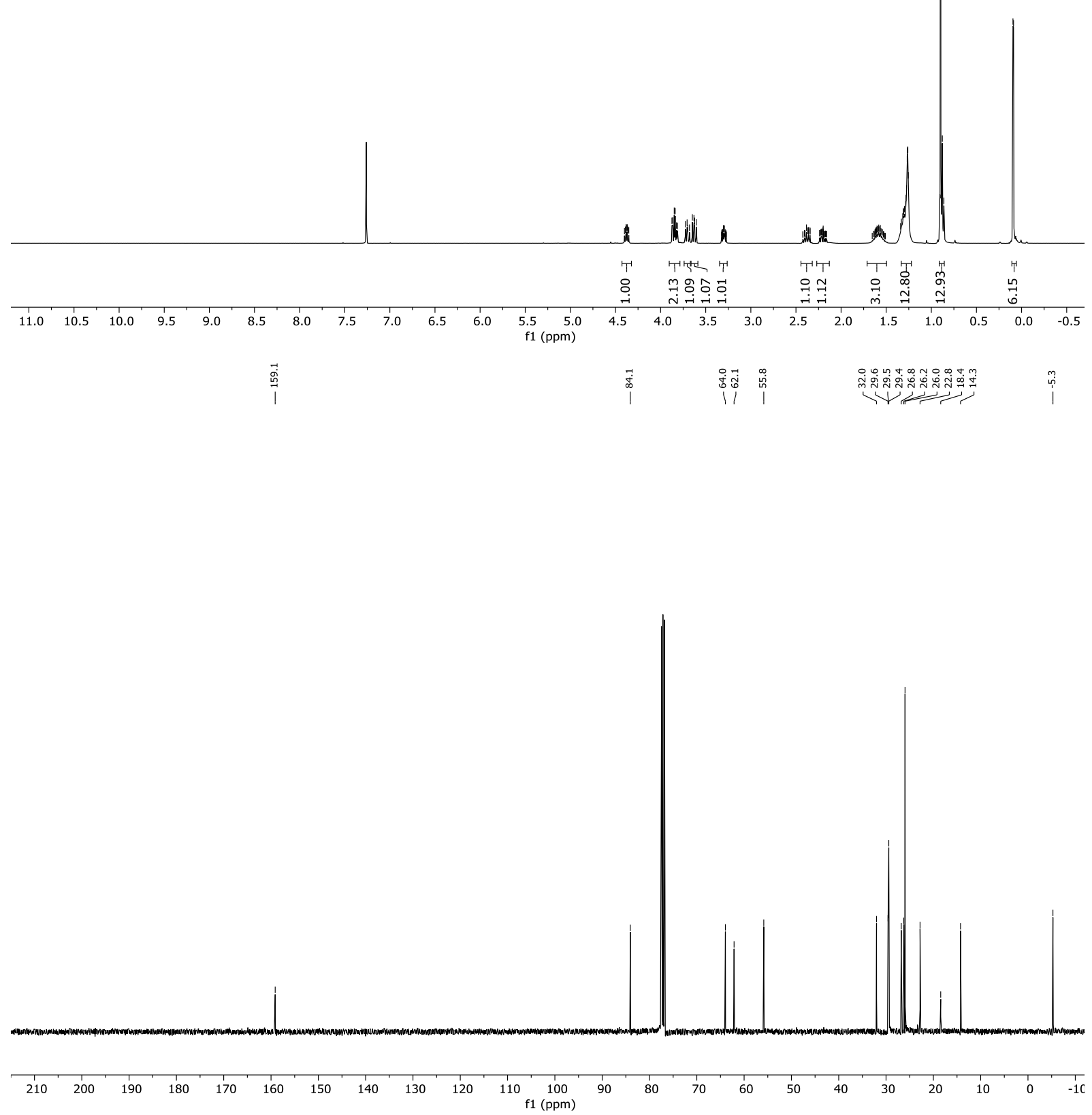
<smiles>CC(=O)OC[C@H]1C(c2ccccc2)=NO[C@@H]1CO[SbH2]</smiles>
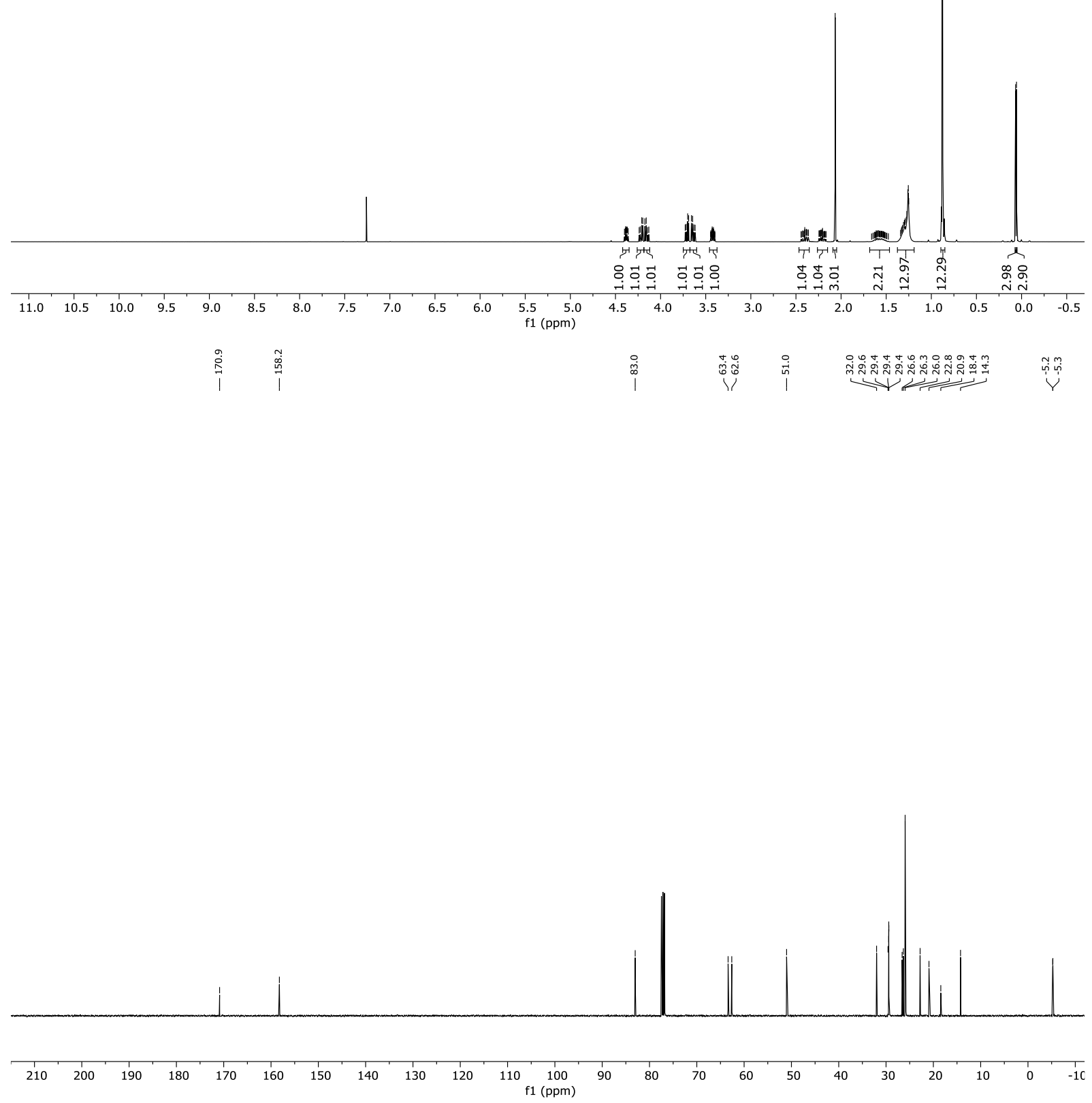
<smiles>CC(=O)OC[C@H]1C(Cc2ccccc2)=NO[C@@H]1CO</smiles>

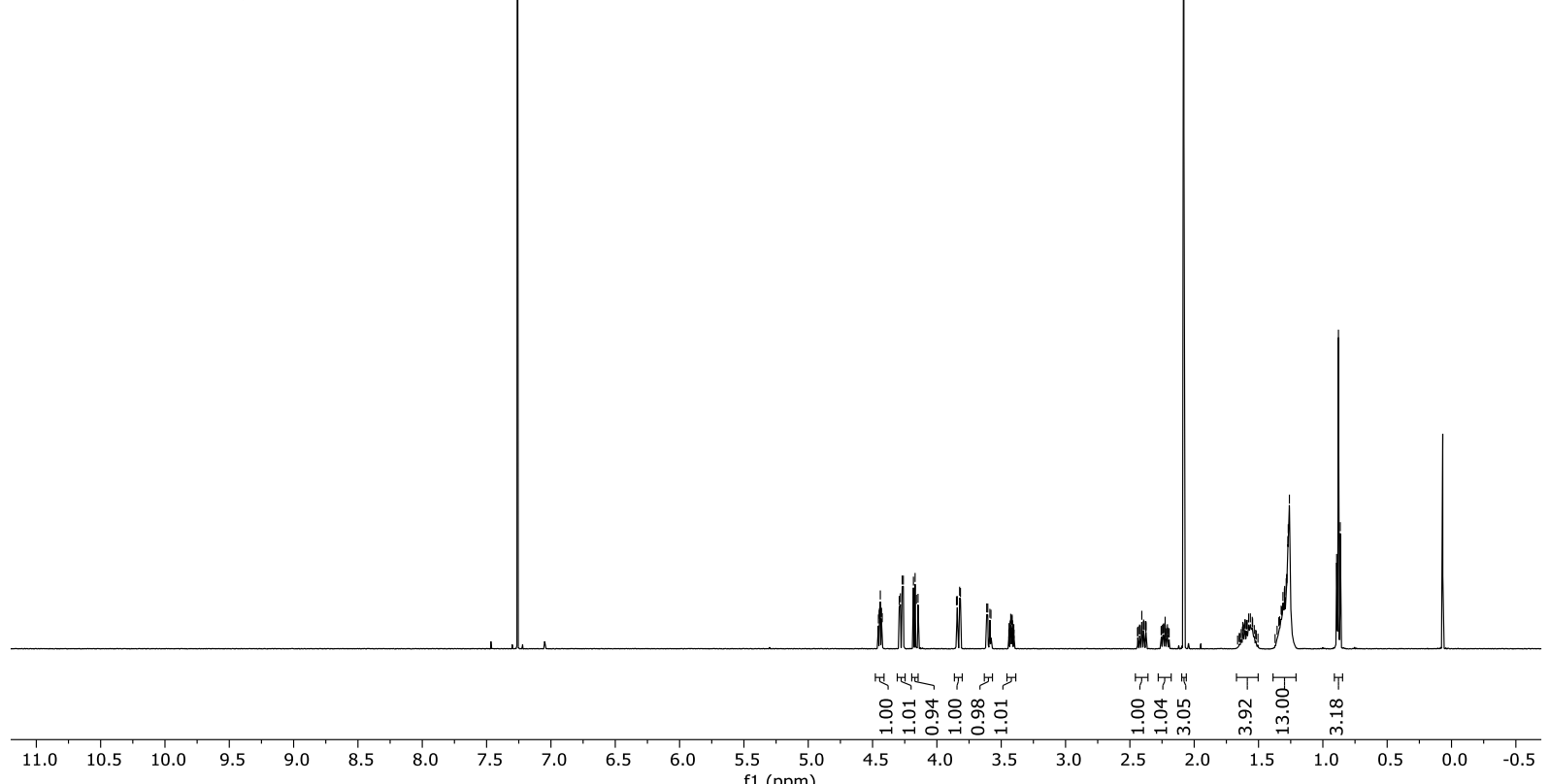

$$
\text { i }
$$

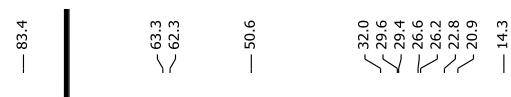

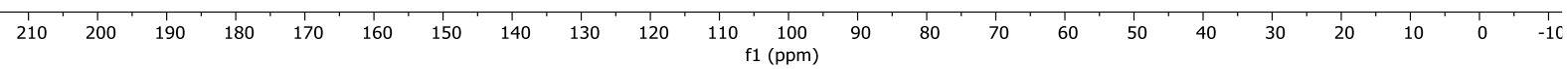


<smiles>COC[C@H]1ON=C(c2ccccc2)[C@H]1COC(C)=O</smiles>

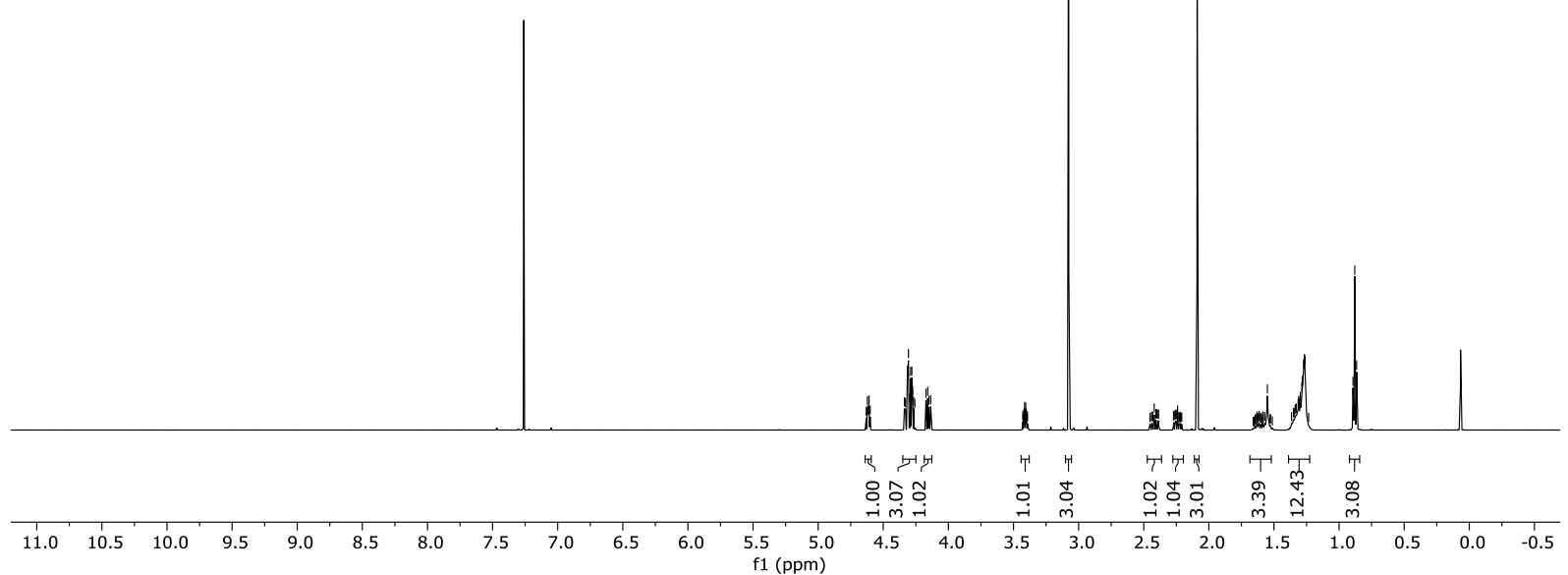

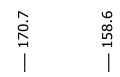

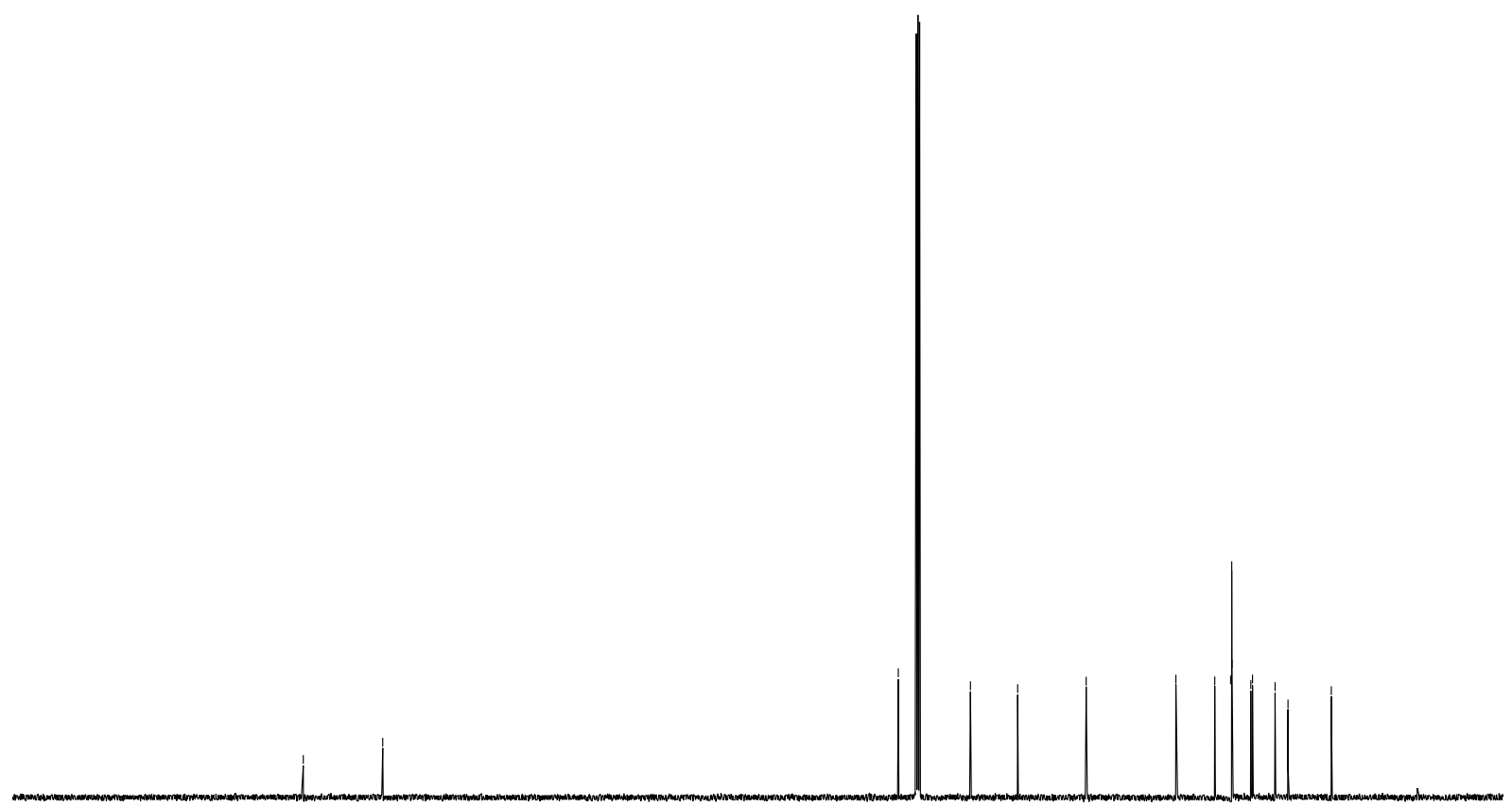

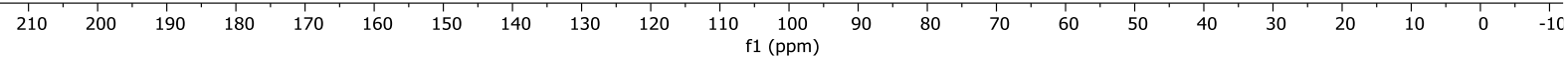


<smiles>CC(=O)OC[C@H]1C(c2ccccc2)=NO[C@@H]1CN</smiles>

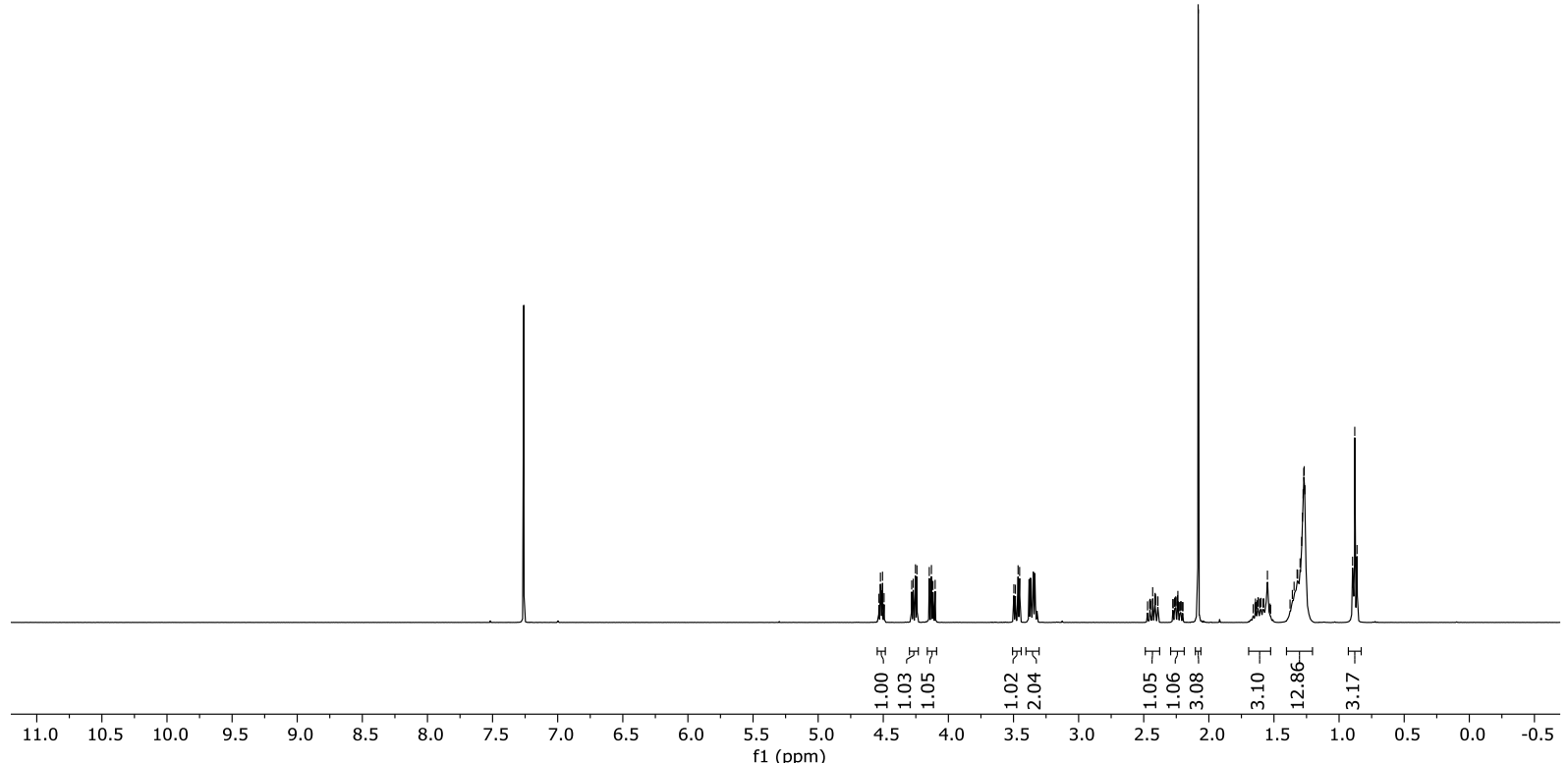

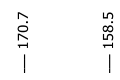
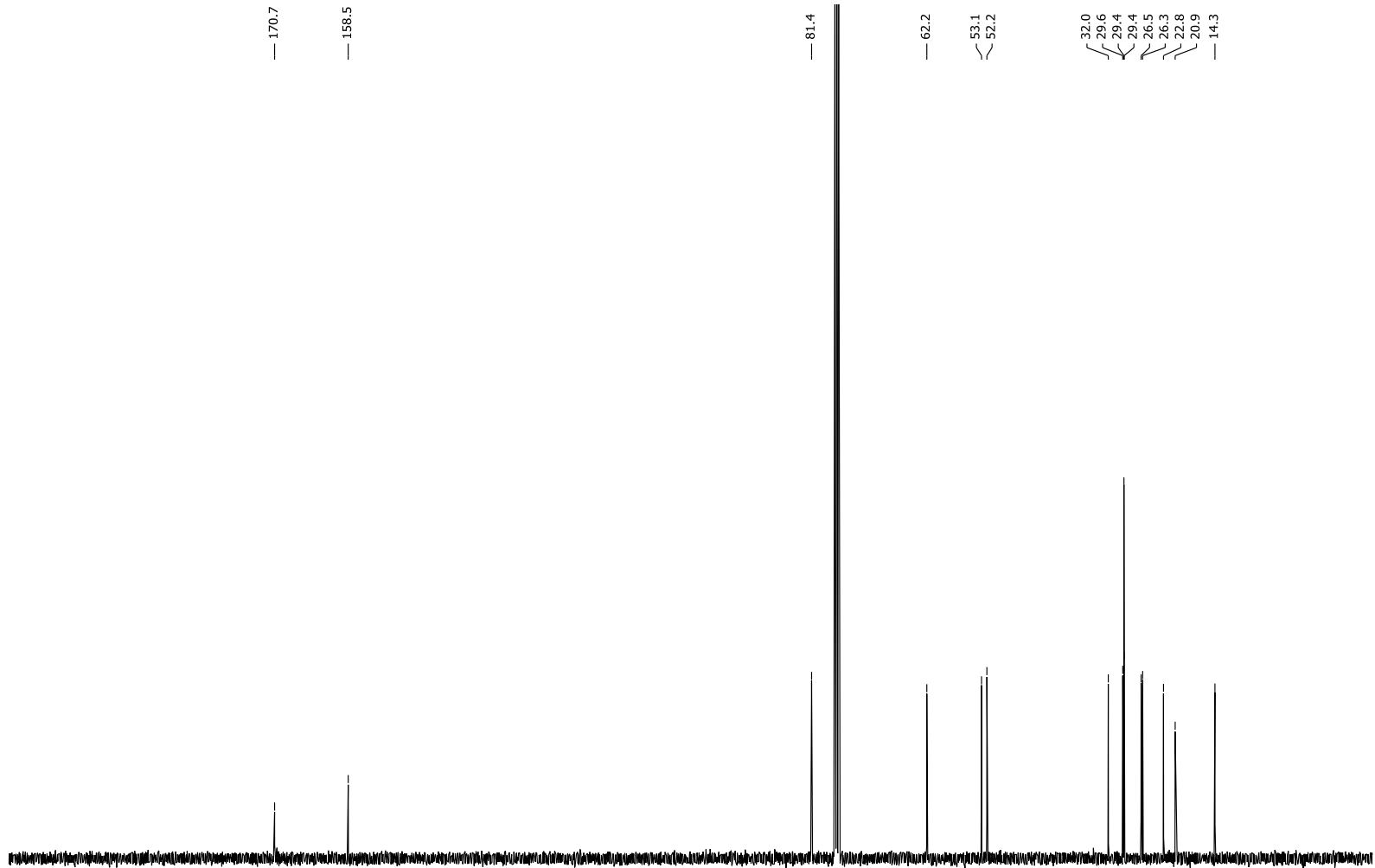

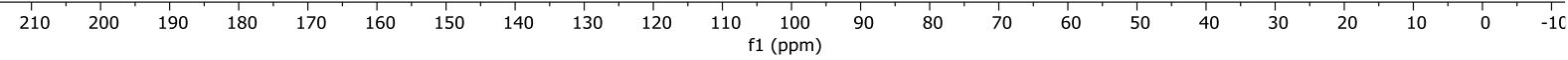


<smiles>NC[C@H]1ON=C(Cc2ccccc2)[C@@H]1CO</smiles>

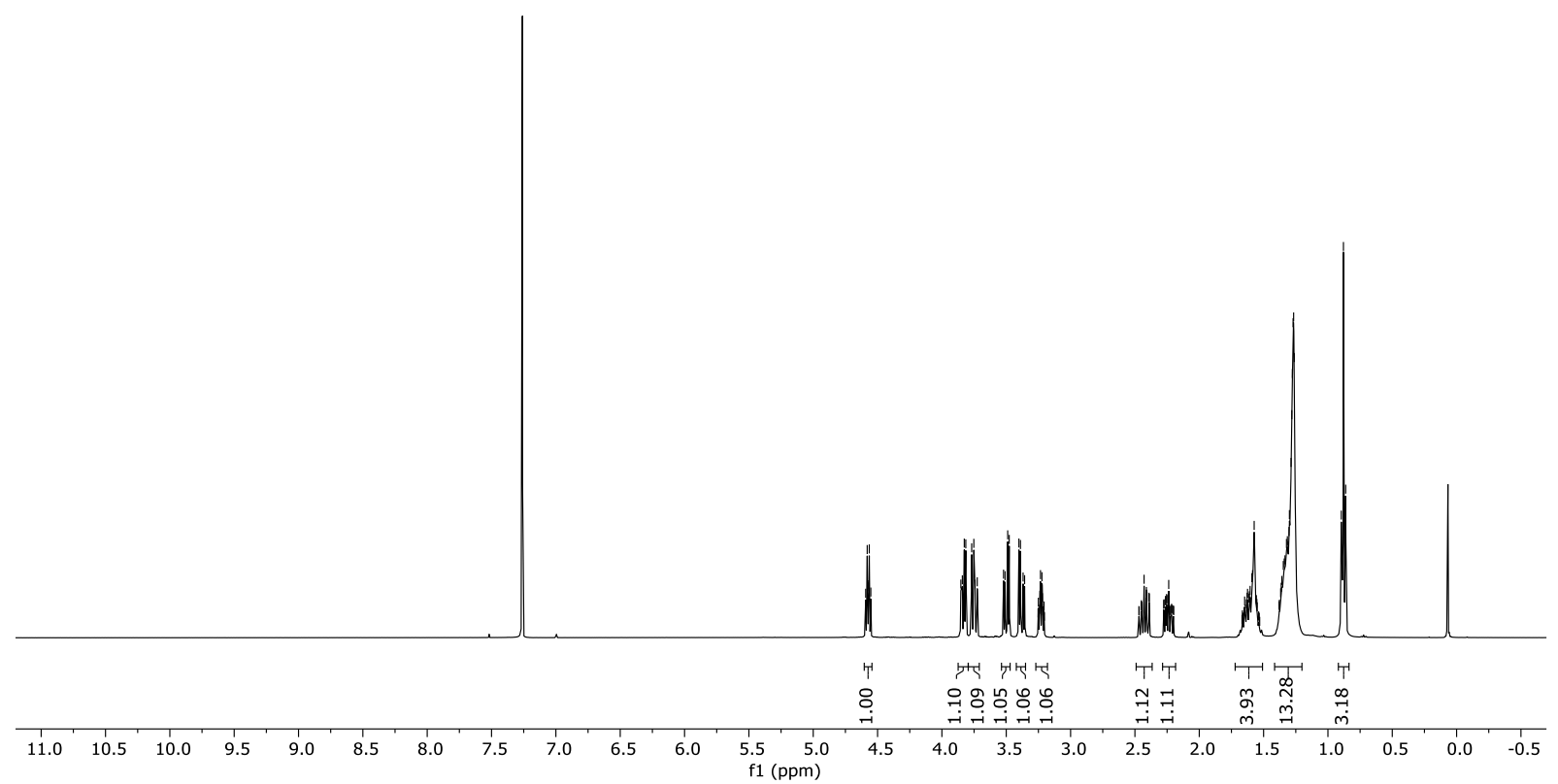
总

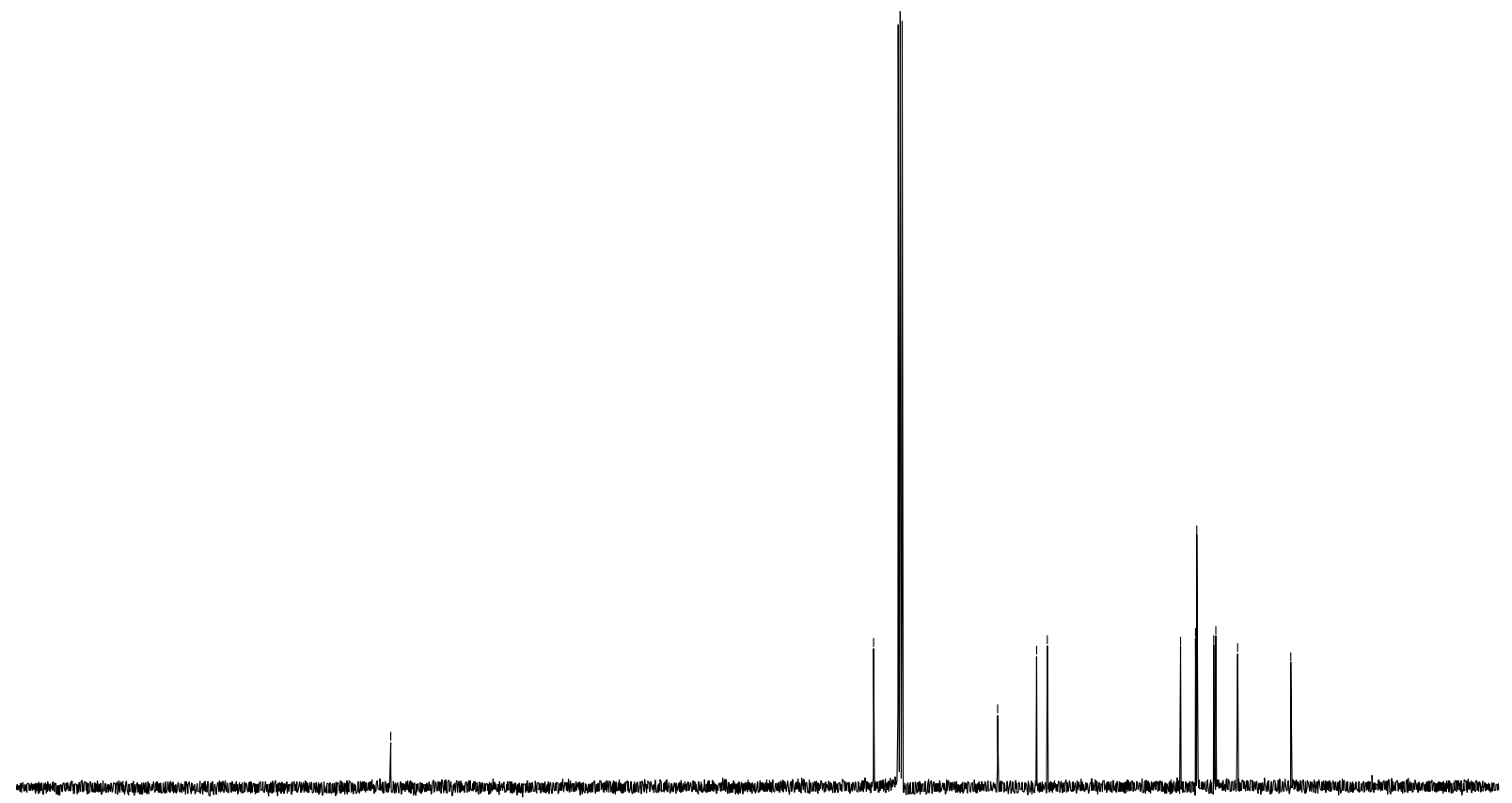

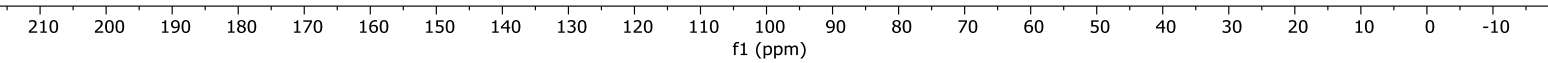


<smiles>O=C1OC[C@H]2ON=C([Hg])[C@H]12</smiles>
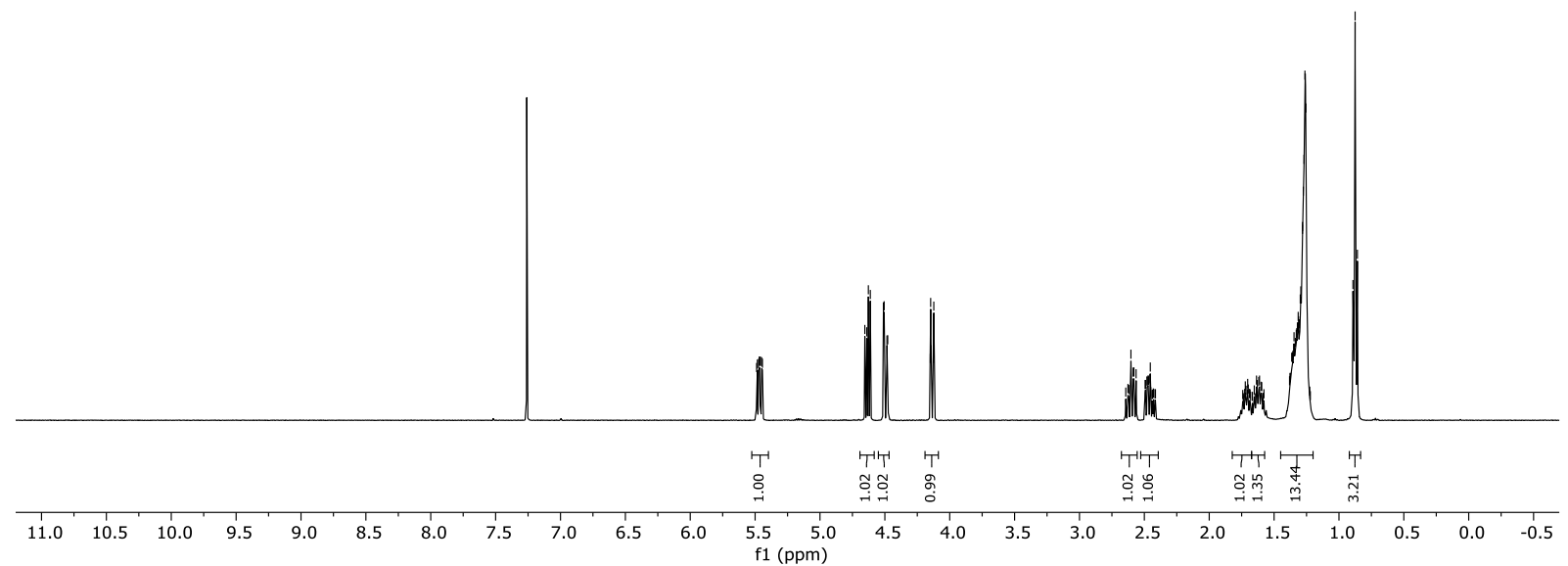

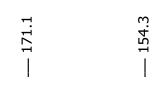

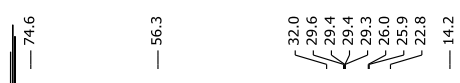

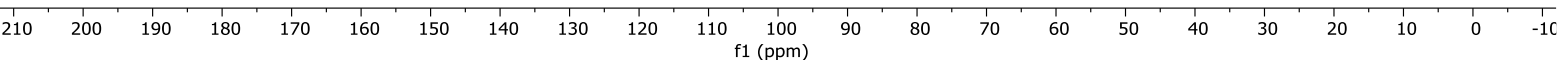




$$
\bar{I}
$$




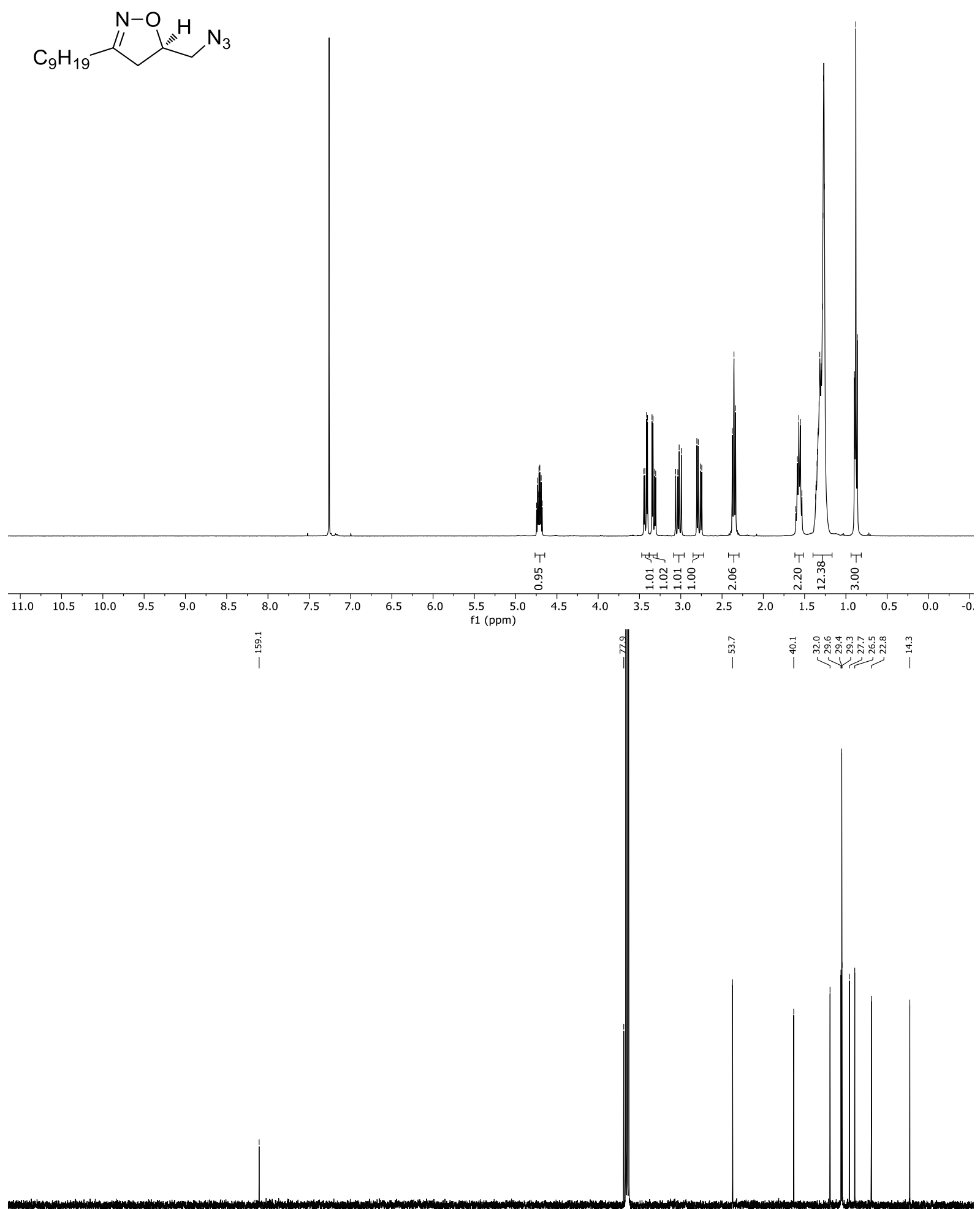

$\begin{array}{lllllllllllllllllllllll}210 & 200 & 190 & 180 & 170 & 160 & 150 & 140 & 130 & 120 & 110 & 100 & 90 & 80 & 70 & 60 & 50 & 40 & 30 & 20 & 10 & 1\end{array}$ 
<smiles>CCCCCCCCCC(=O)N1CCC[C@H]1C(=O)N[C@@H](CC(C)C)C(=O)N[C@@H](CC(C)C)C(=O)N[C@@H](CC)C(=O)O</smiles>

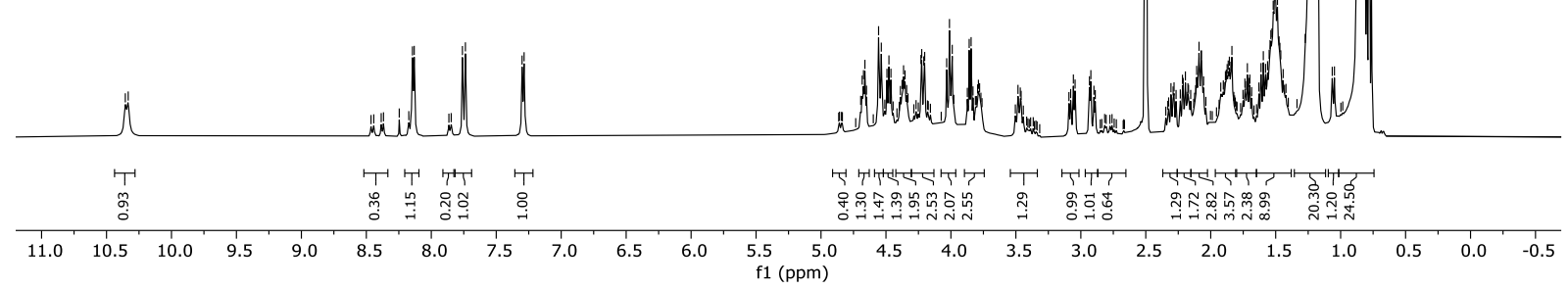

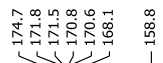




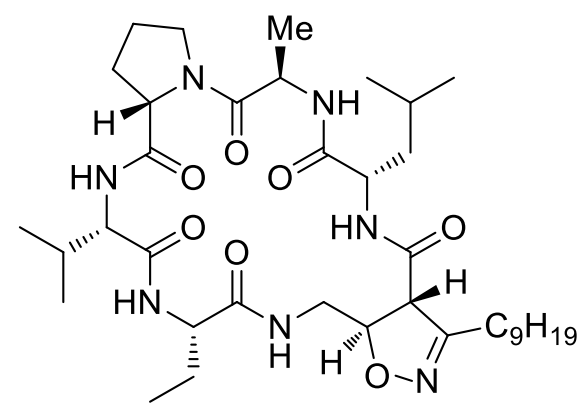

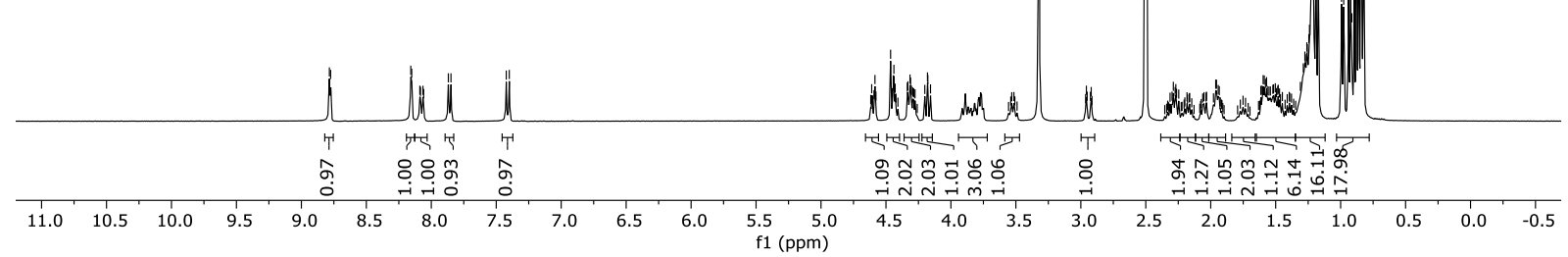

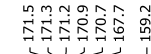

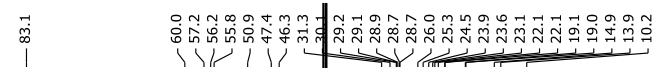

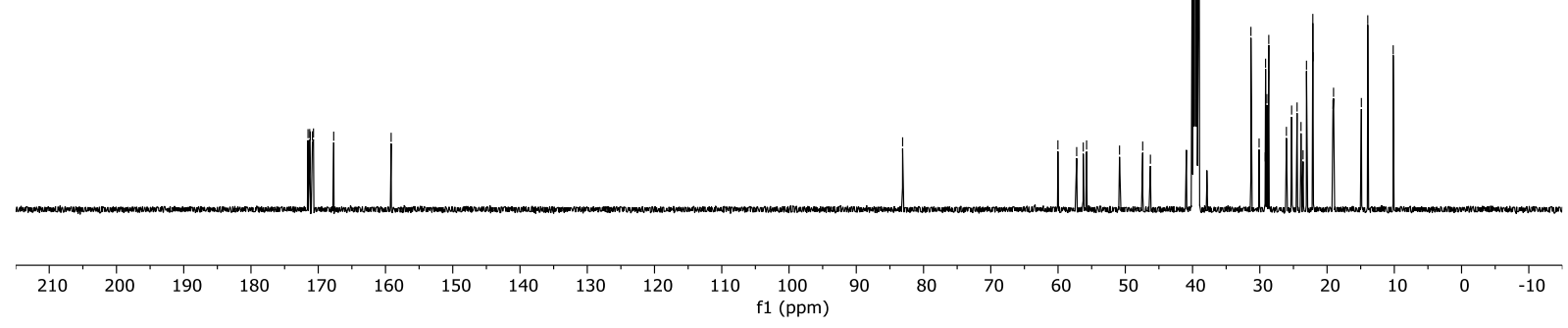




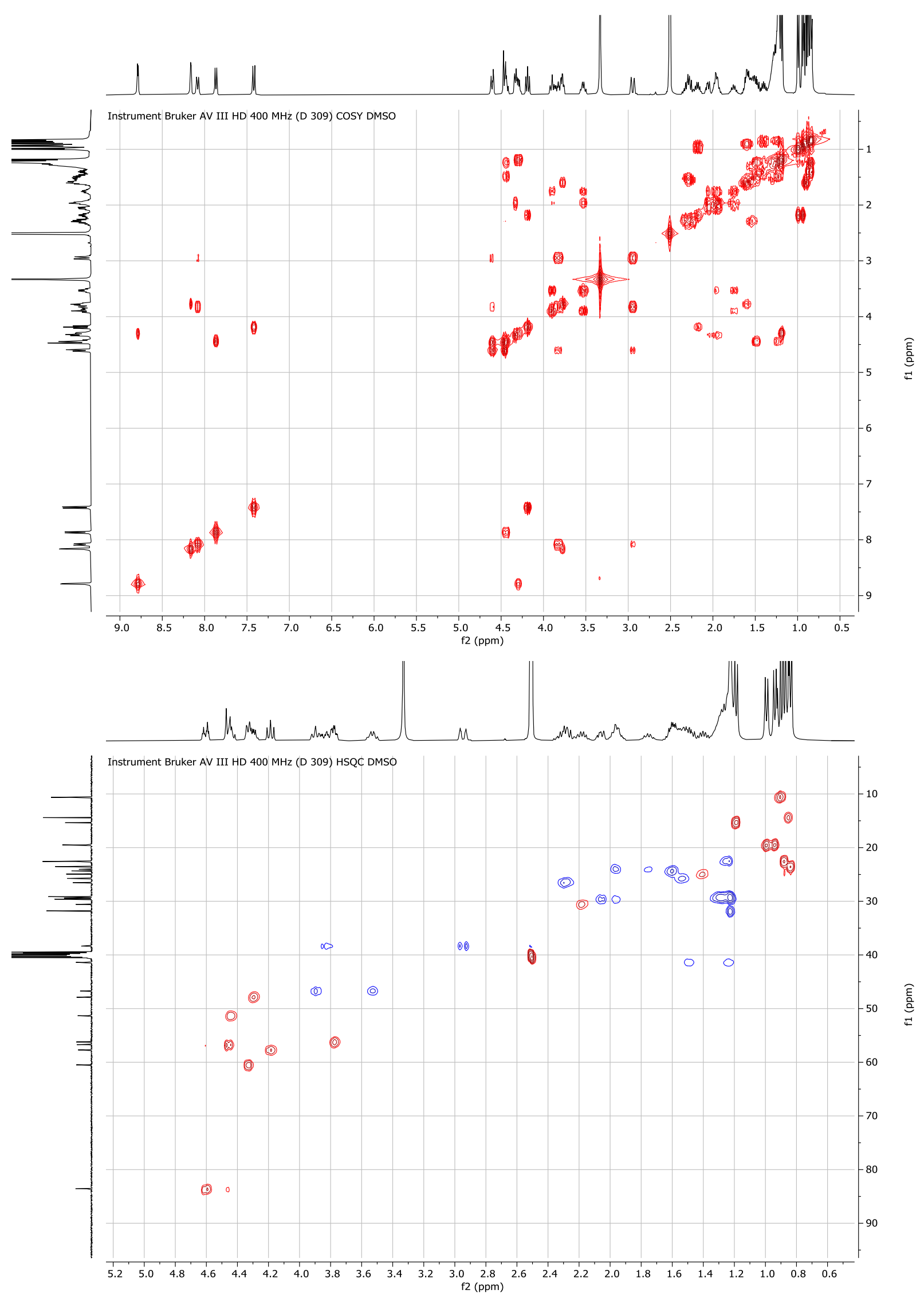




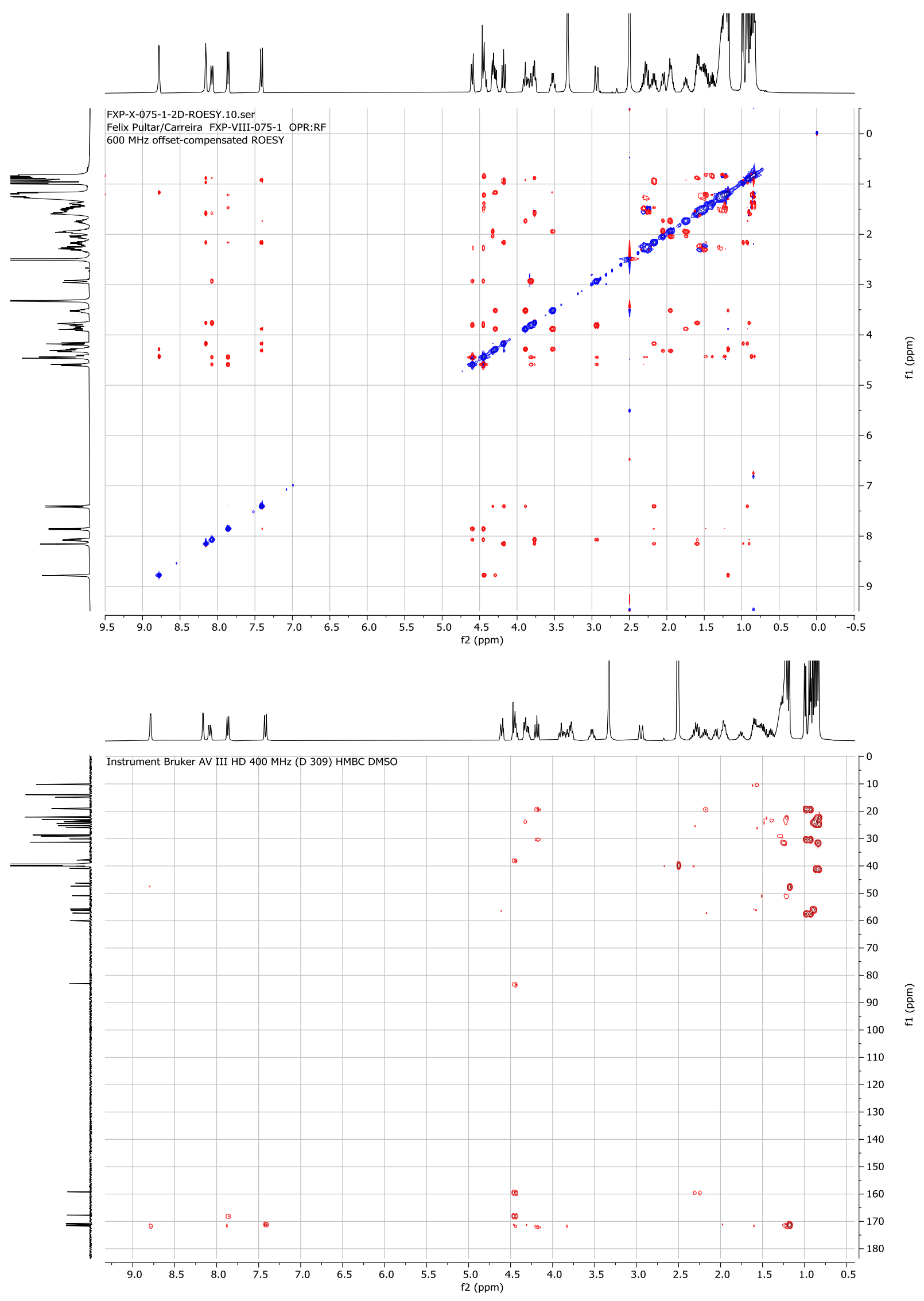




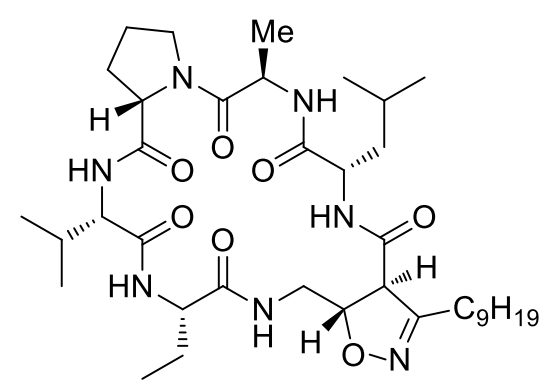

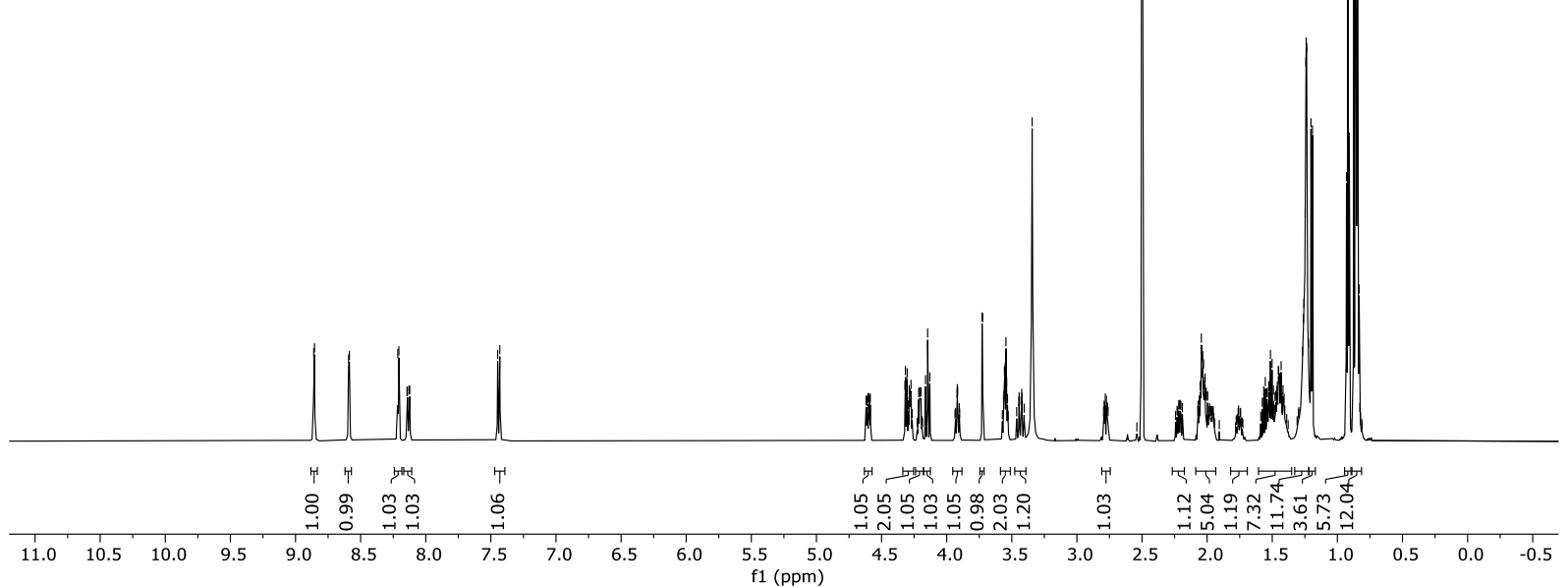

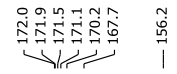

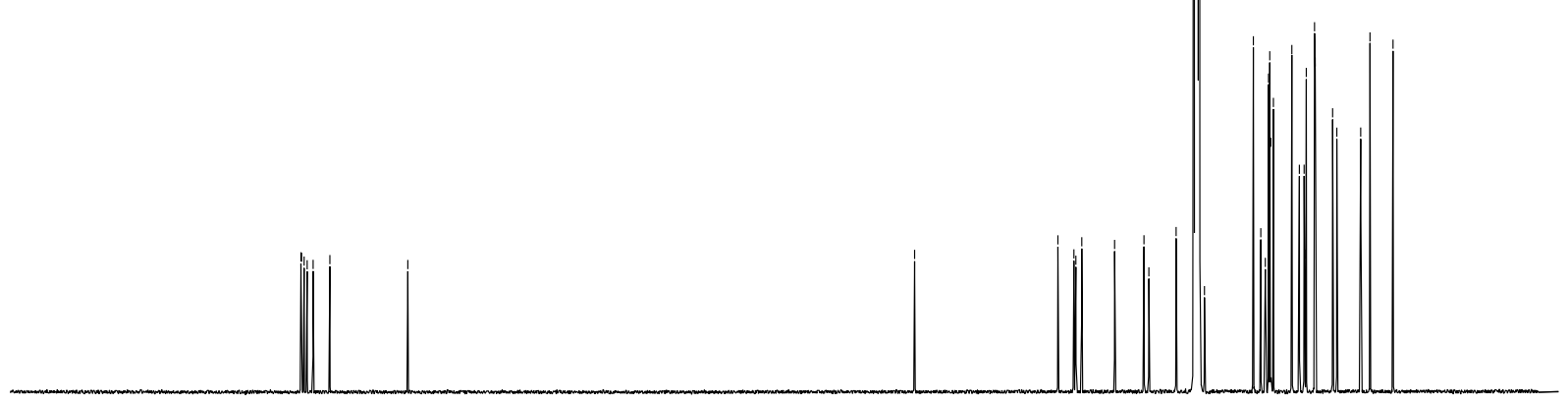

$\begin{array}{llllllllllllllllllllllllll}1 & 10 & 200 & 190 & 180 & 170 & 160 & 150 & 140 & 130 & 120 & 110 & 100 & 10 & 80 & 70 & 60 & 50 & 40 & 30 & 20 & 10 & 0 & -10\end{array}$ 


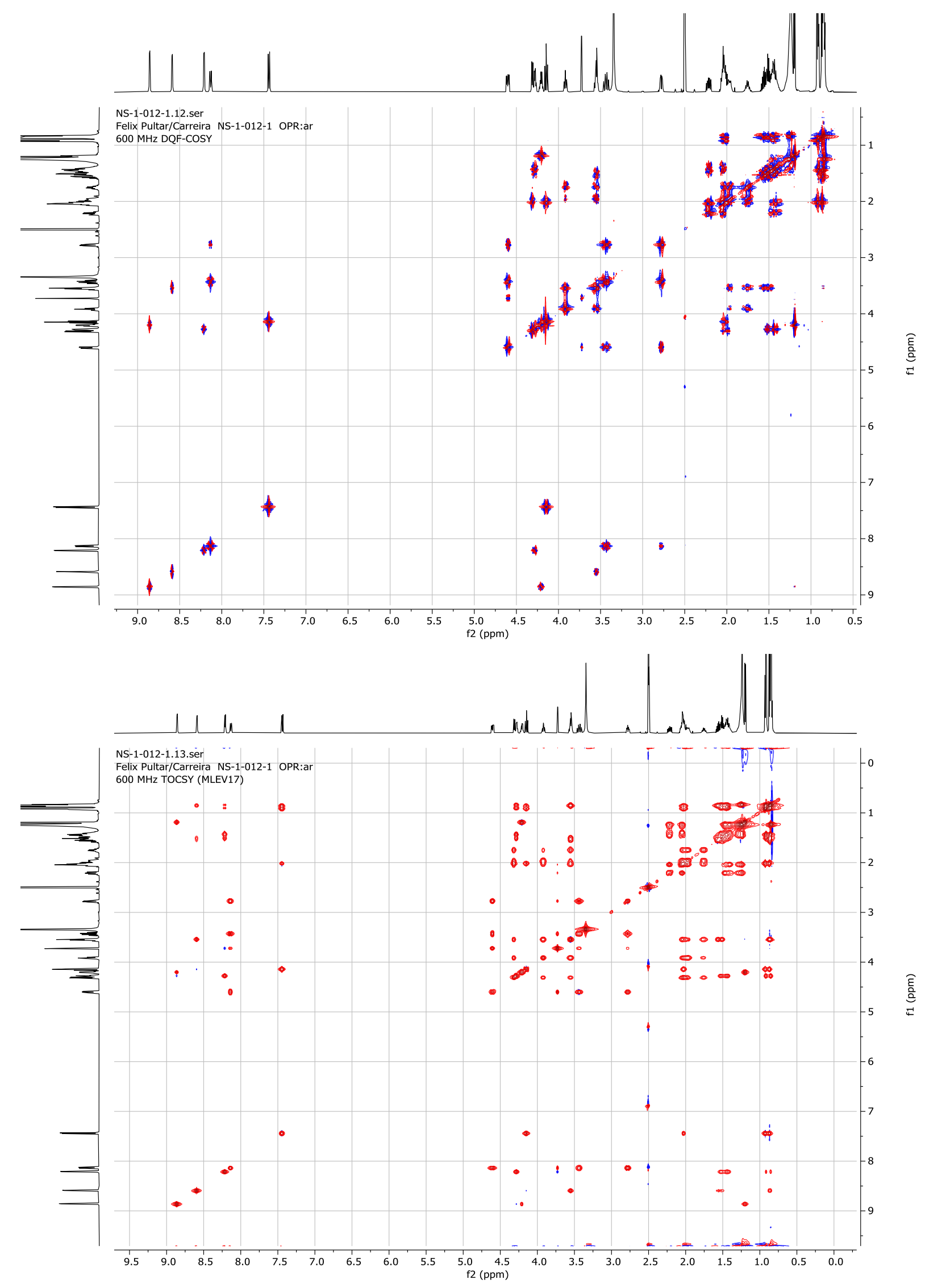




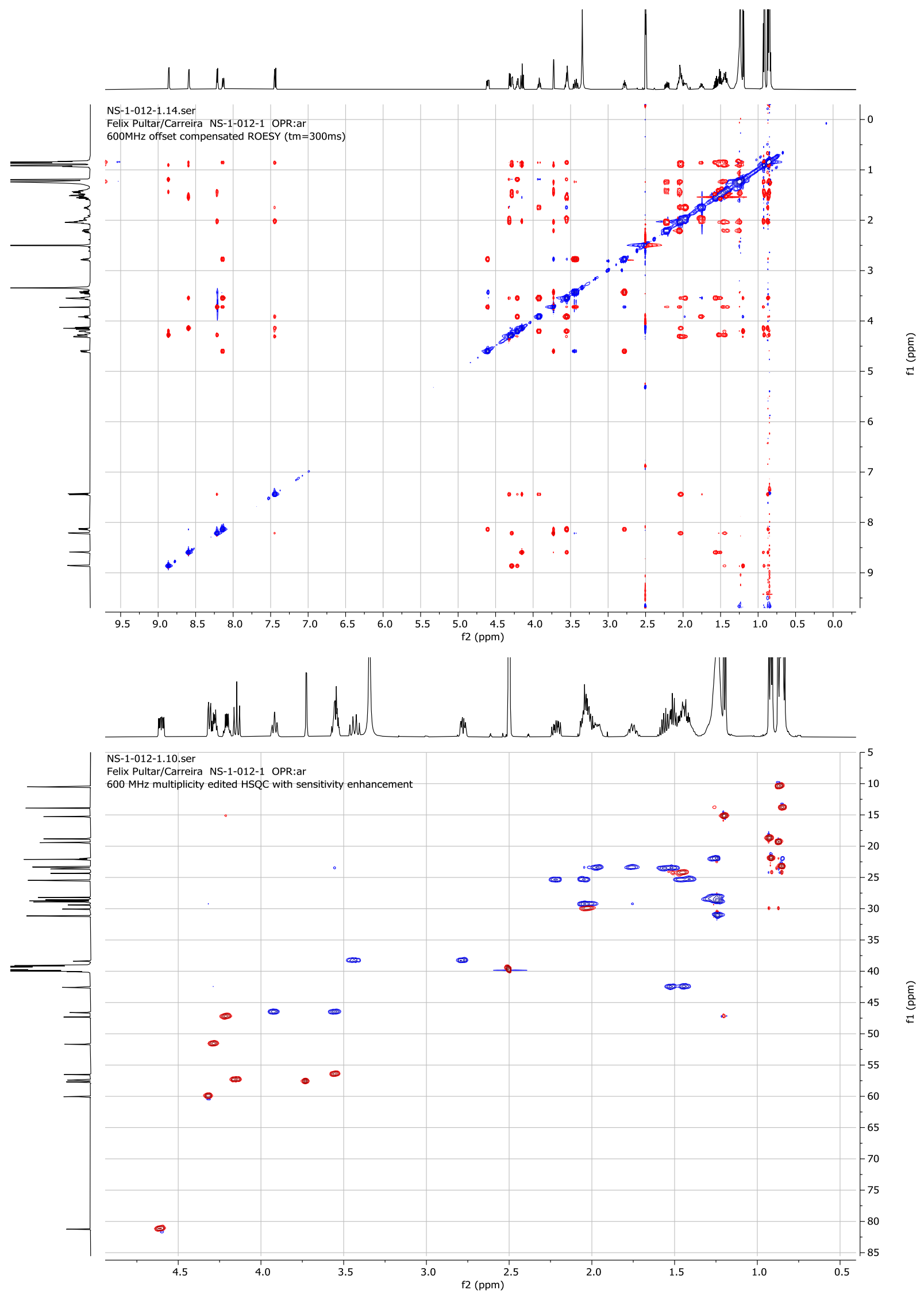




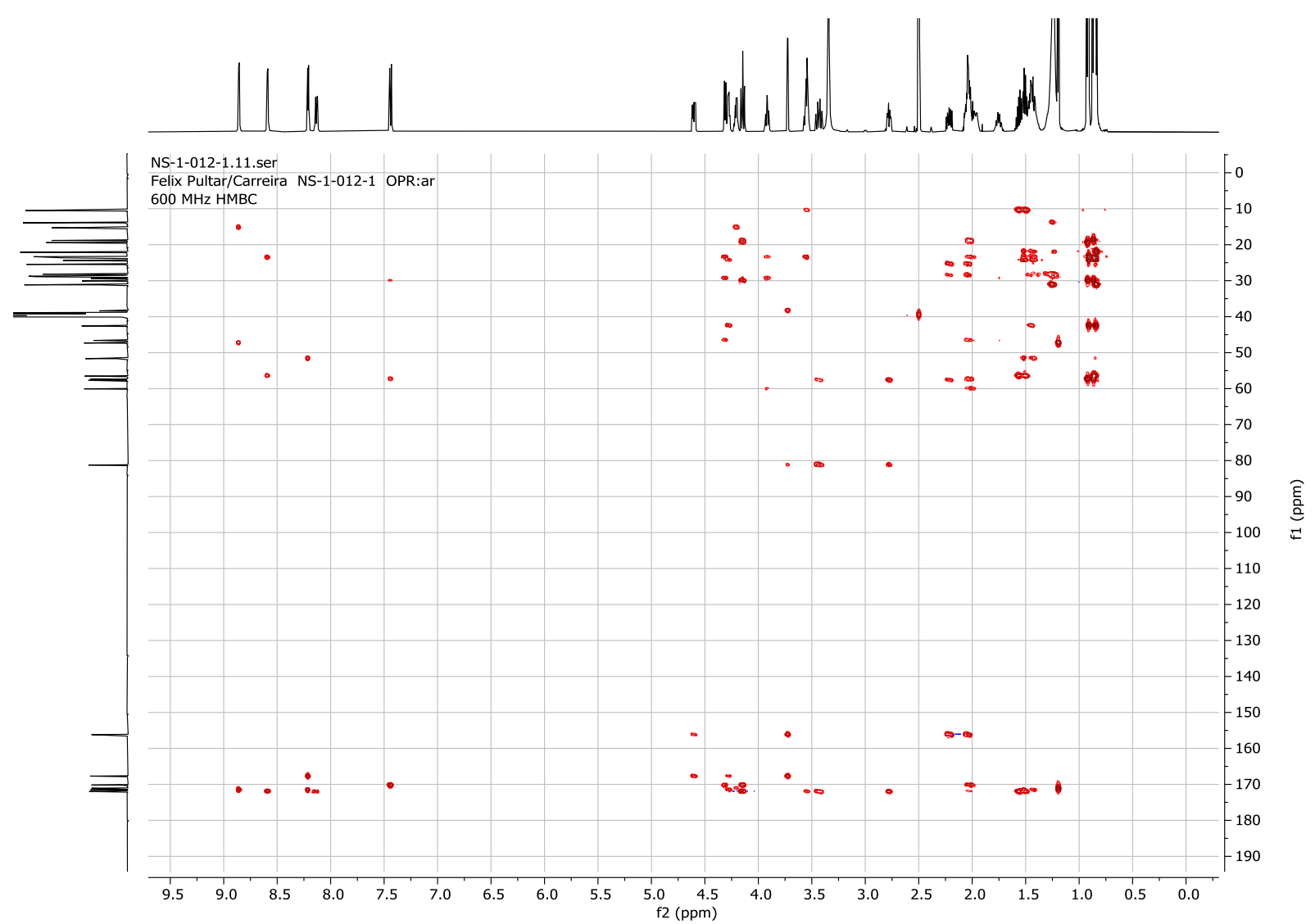




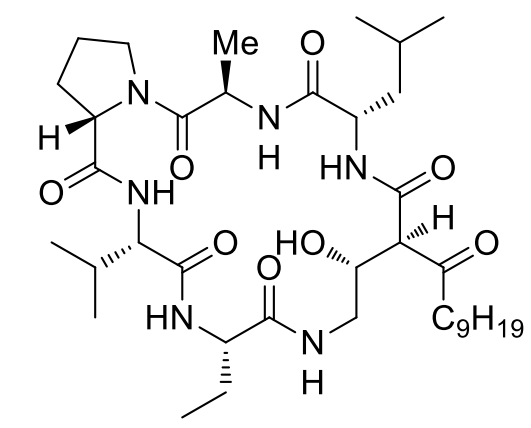
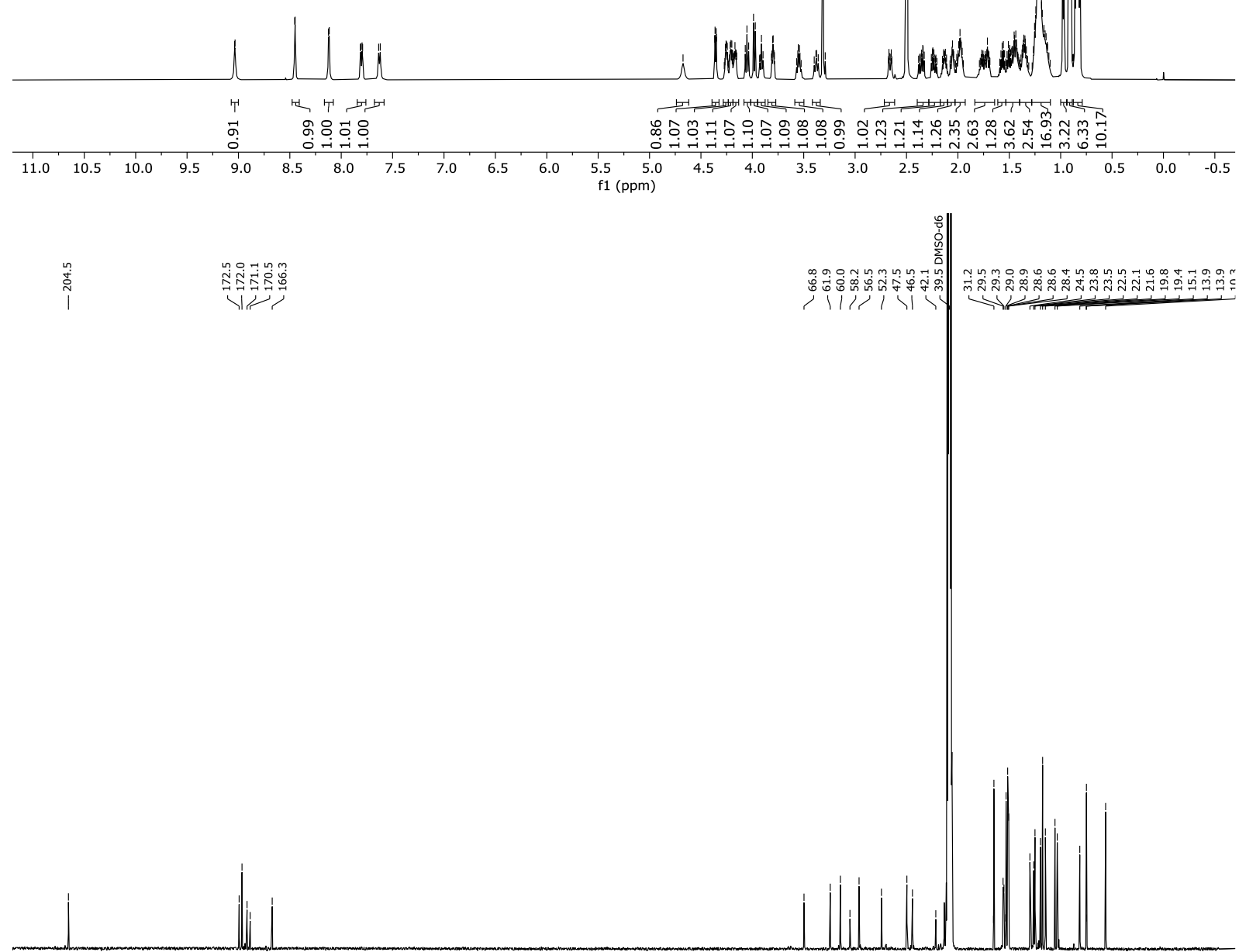

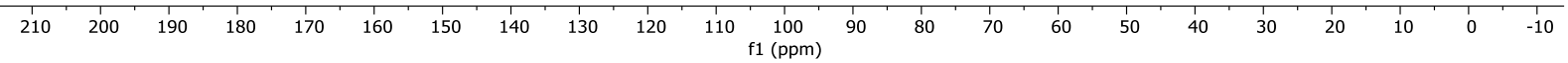



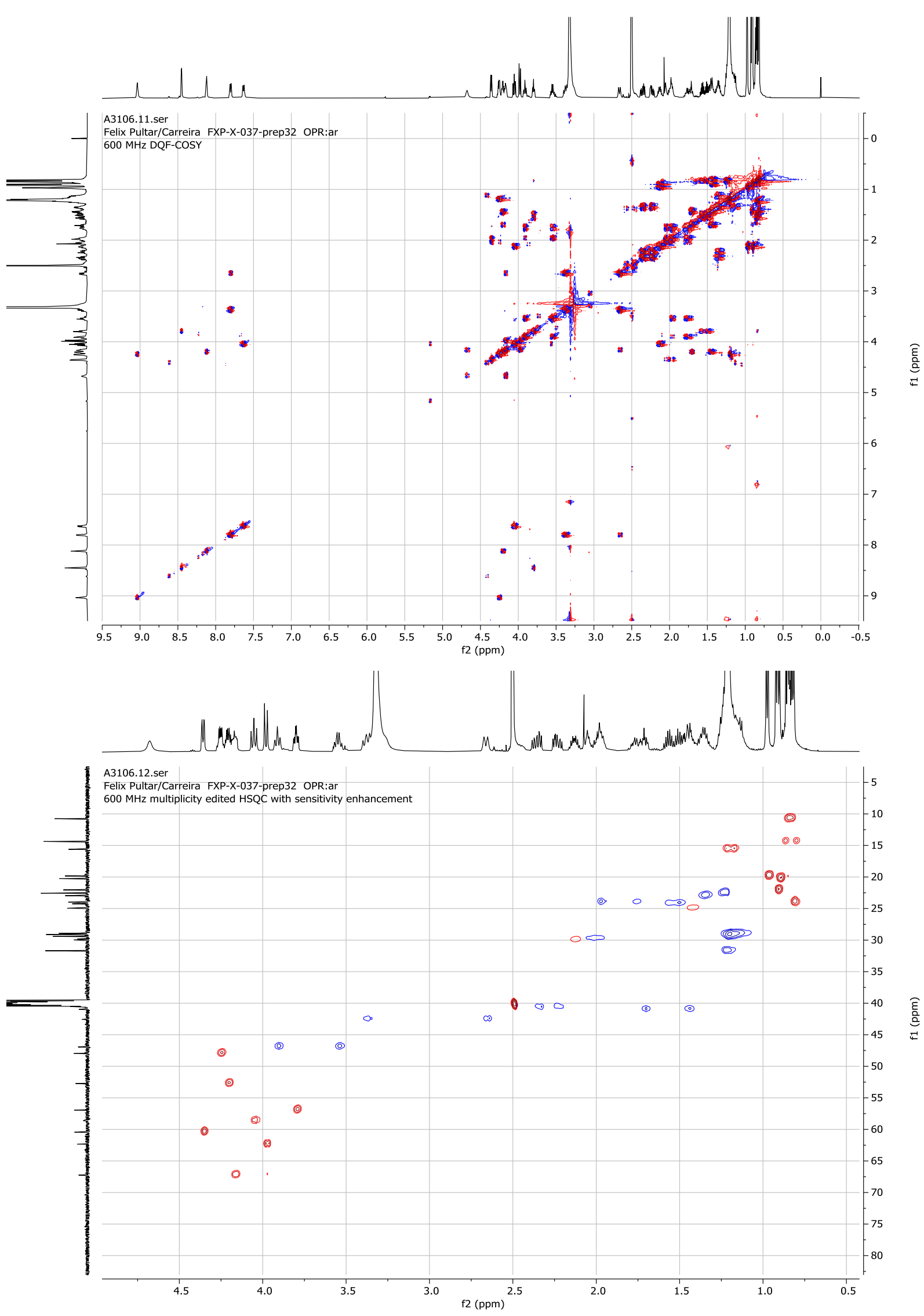

99 

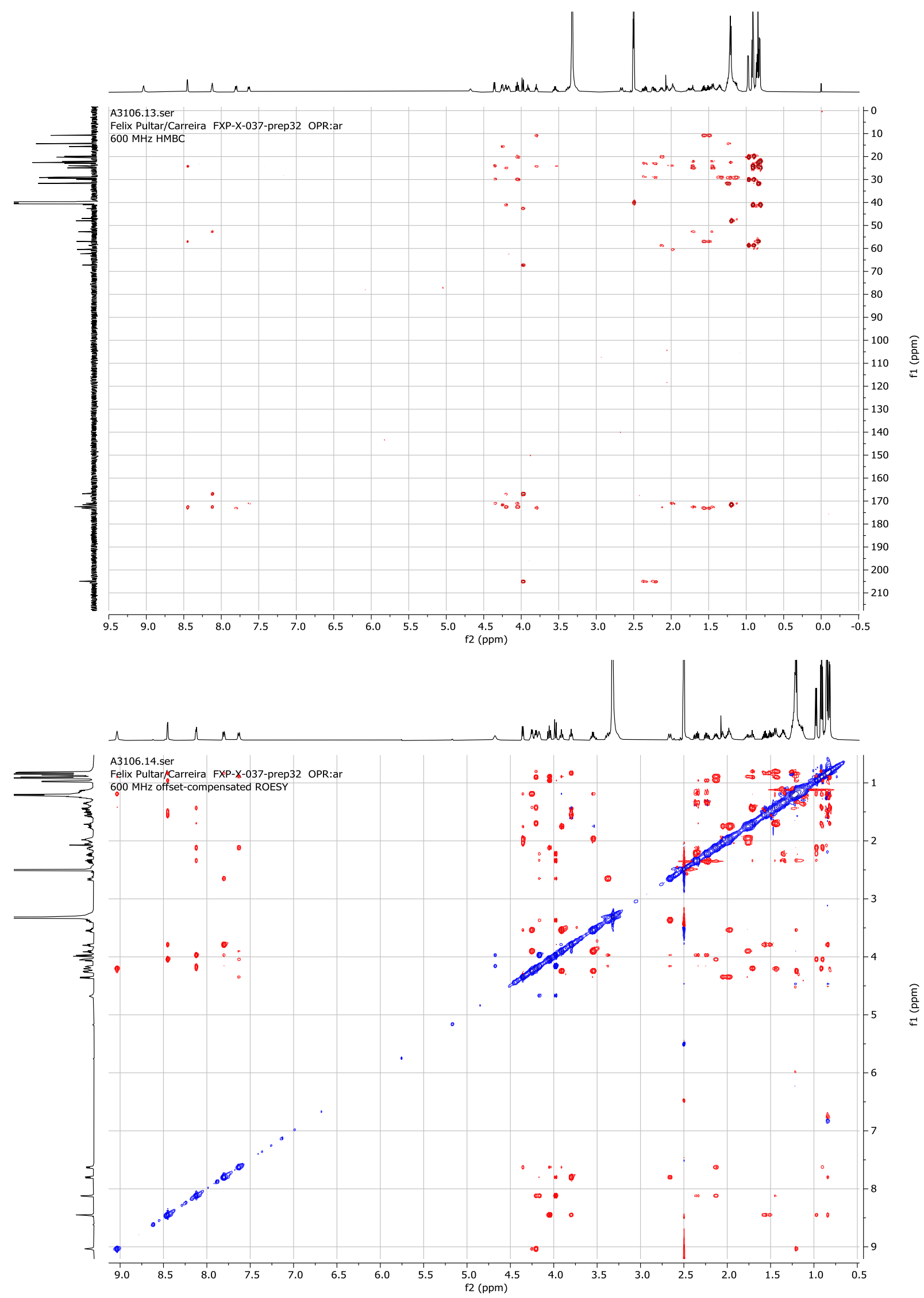

100 

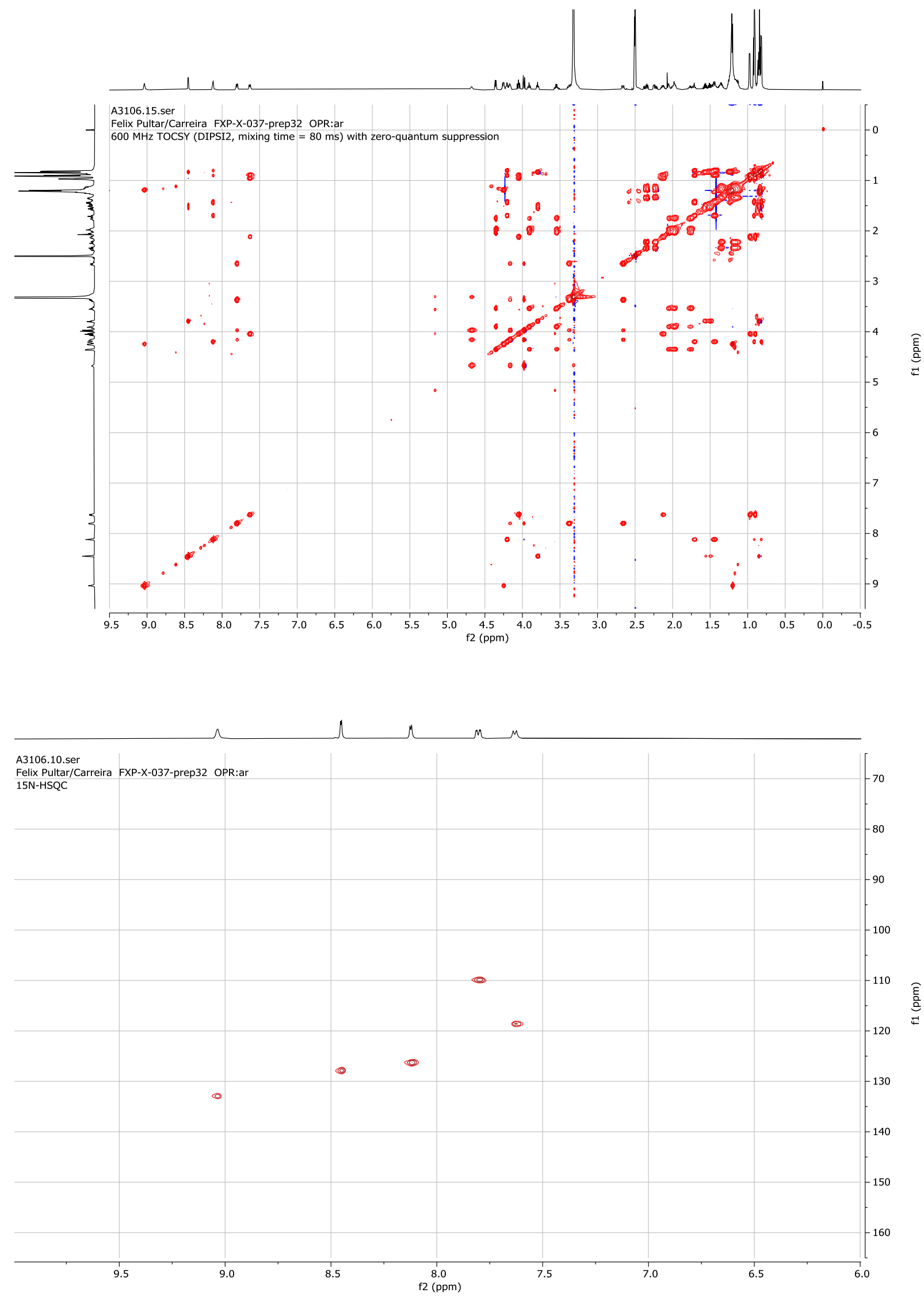


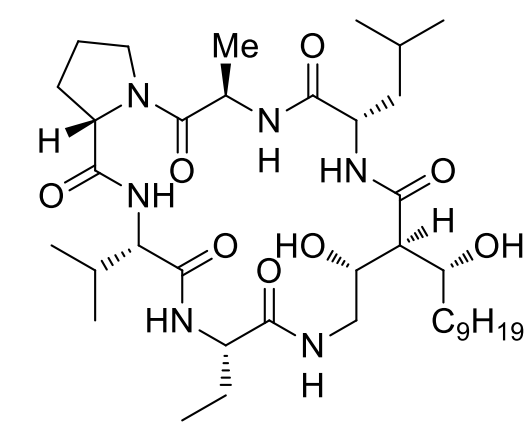

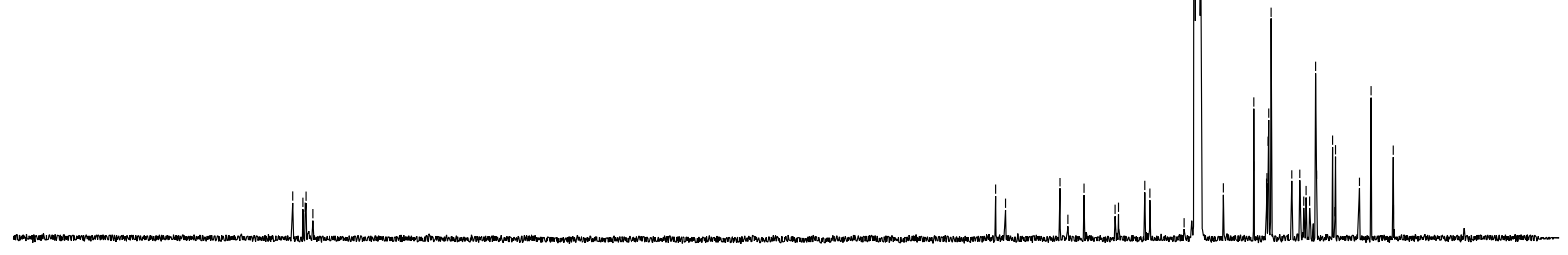

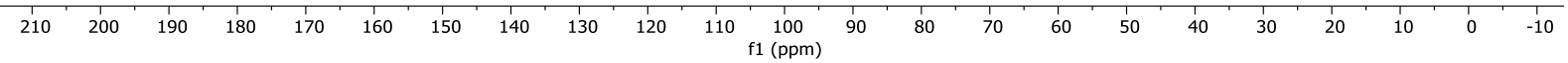




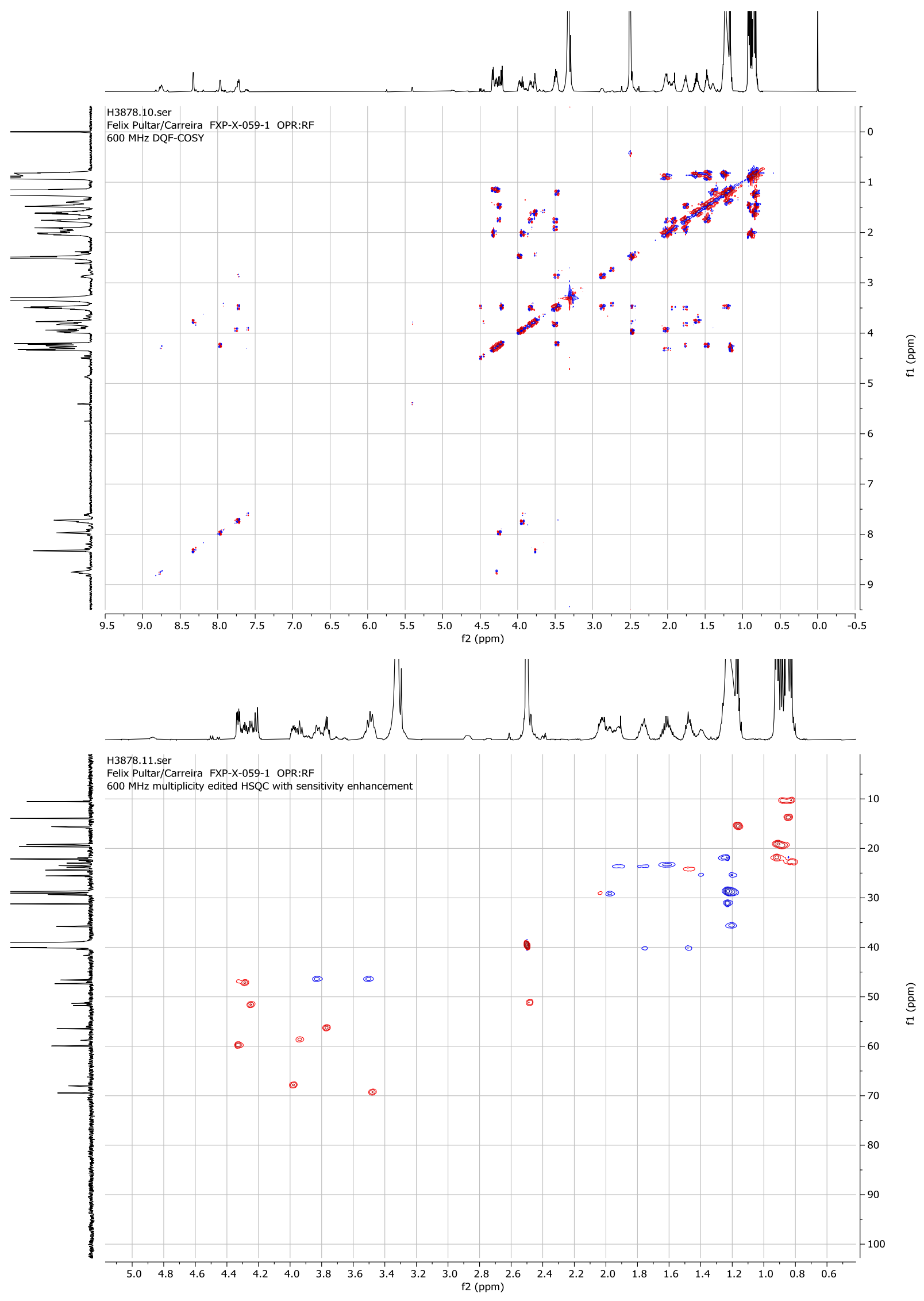



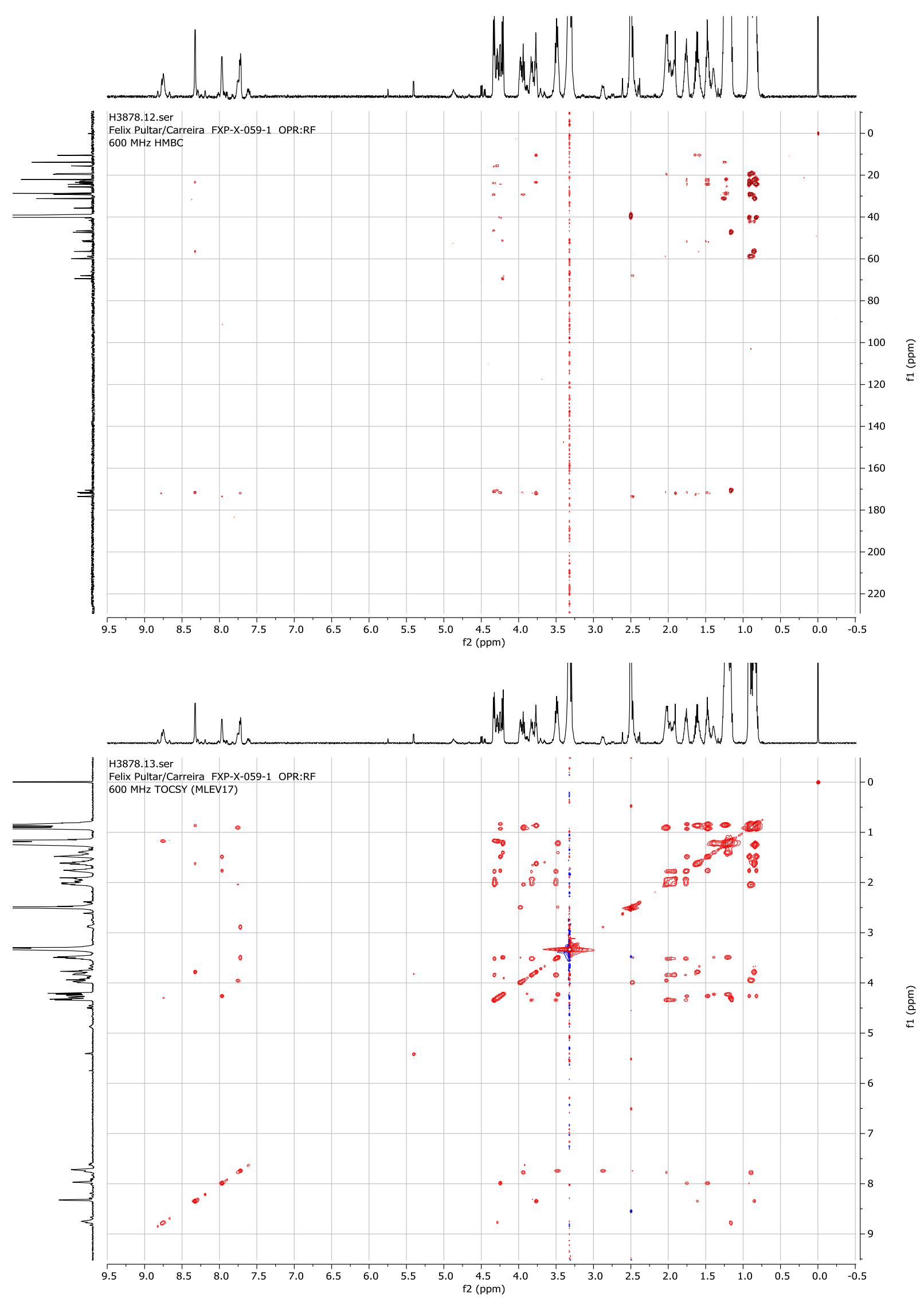

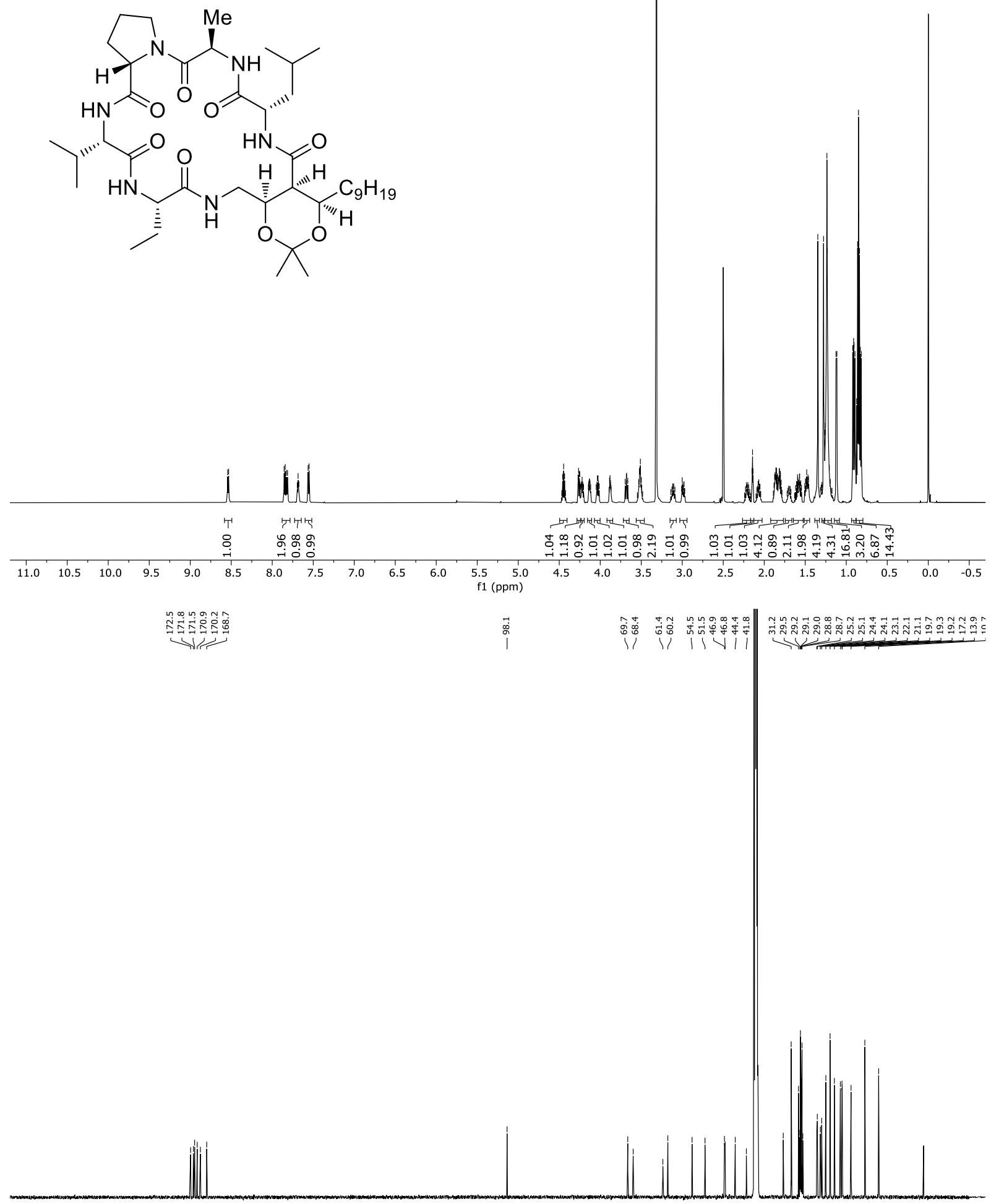

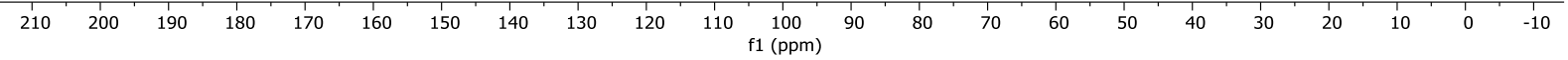




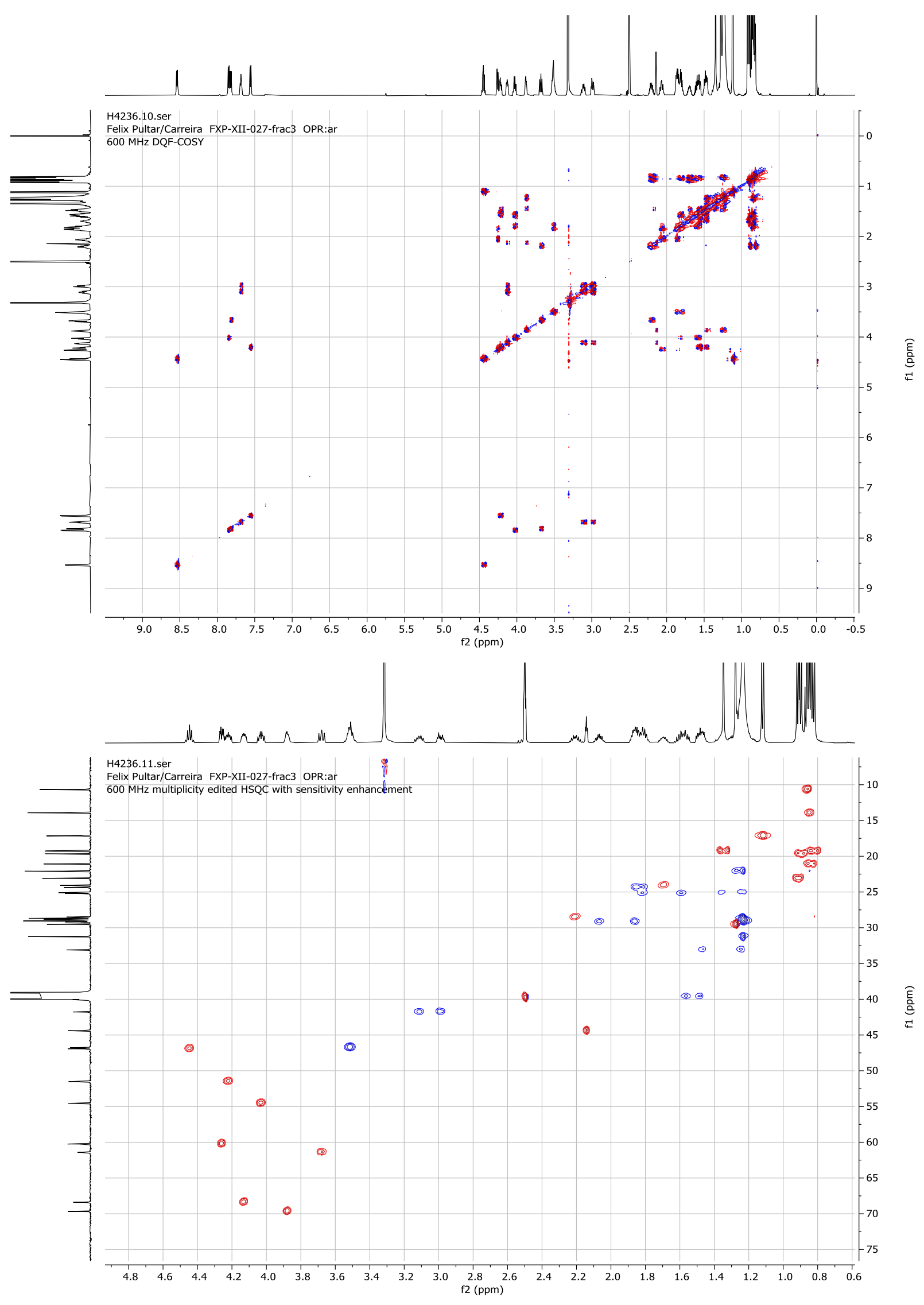



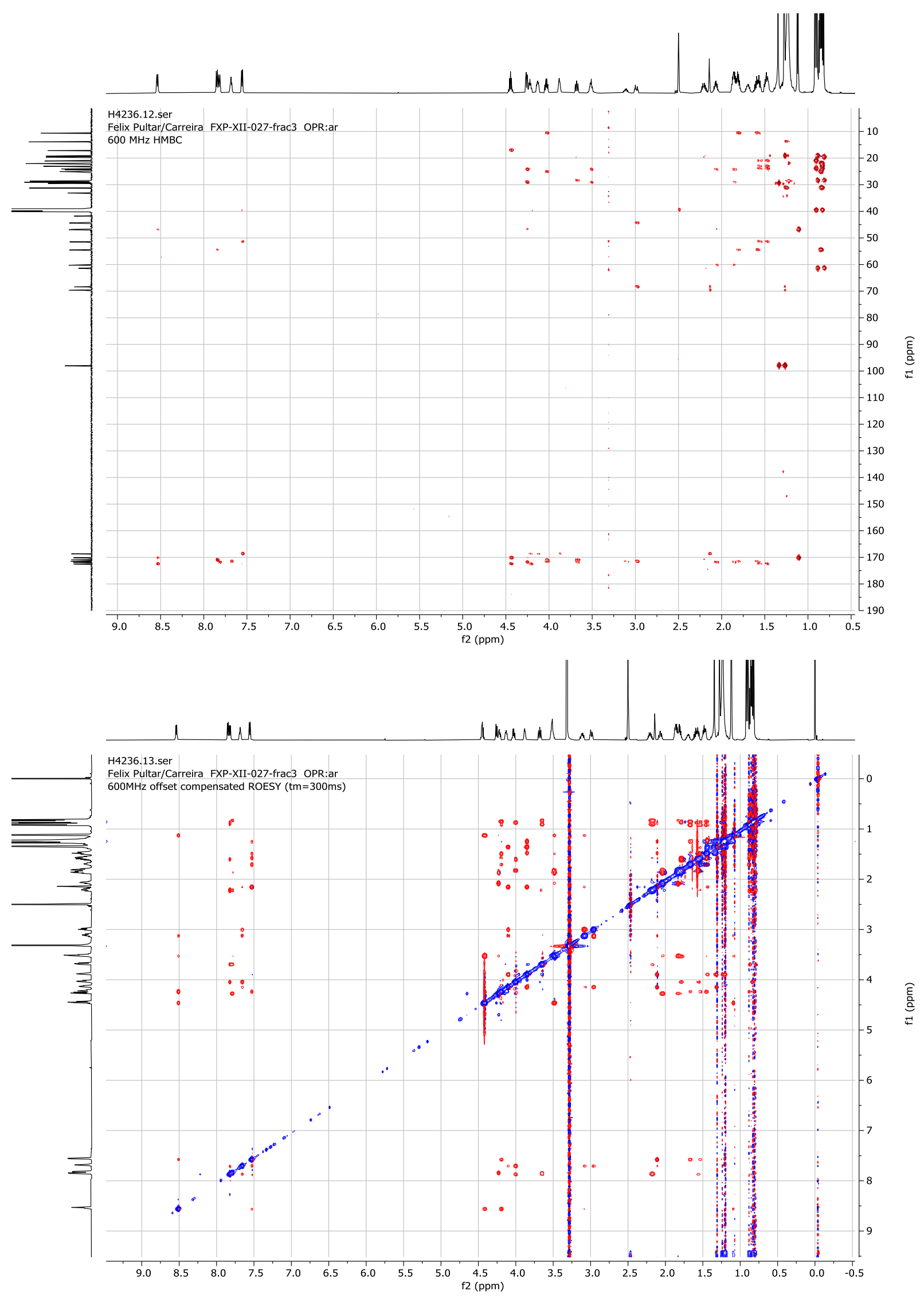


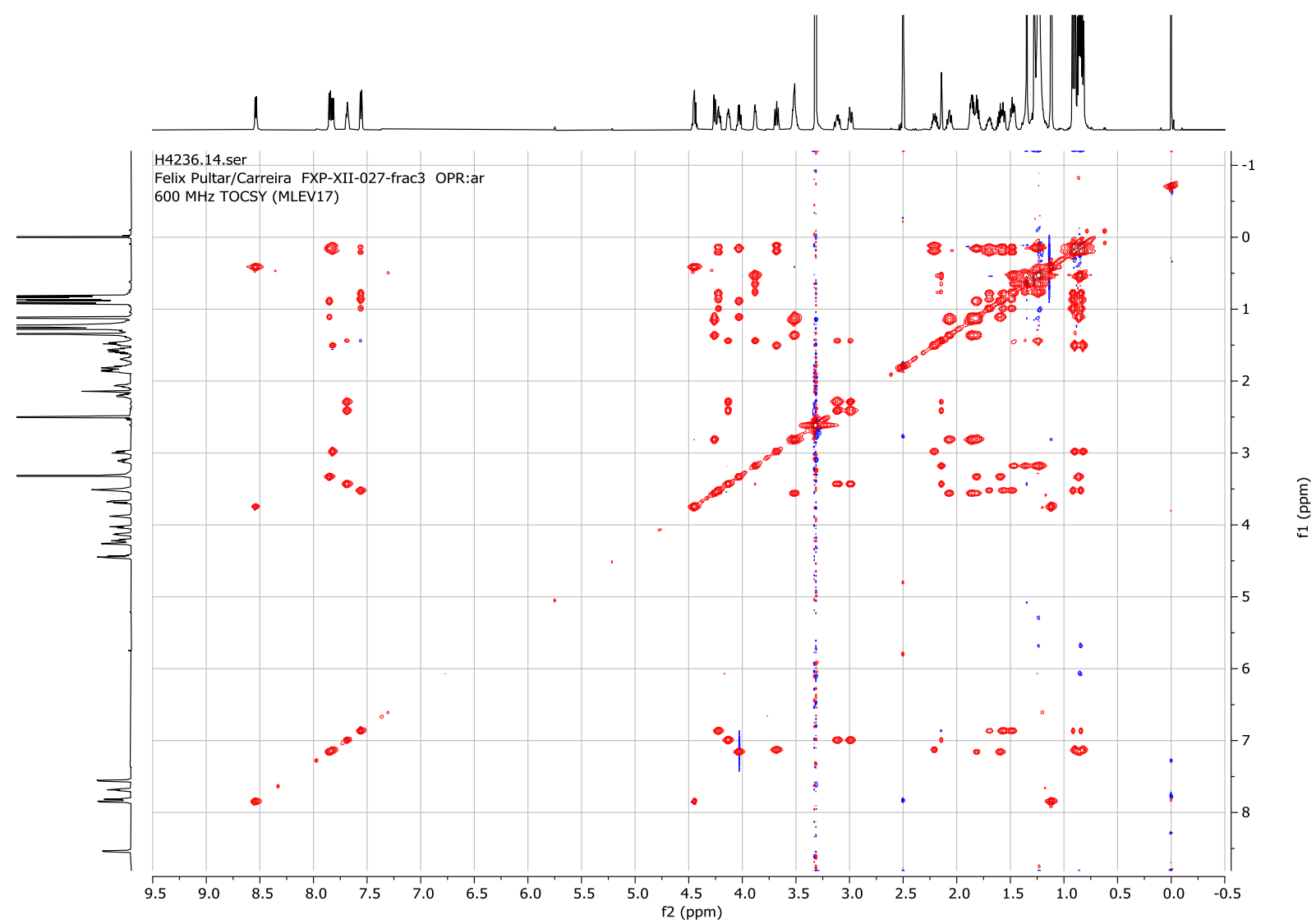




\section{Crystallographic Data}

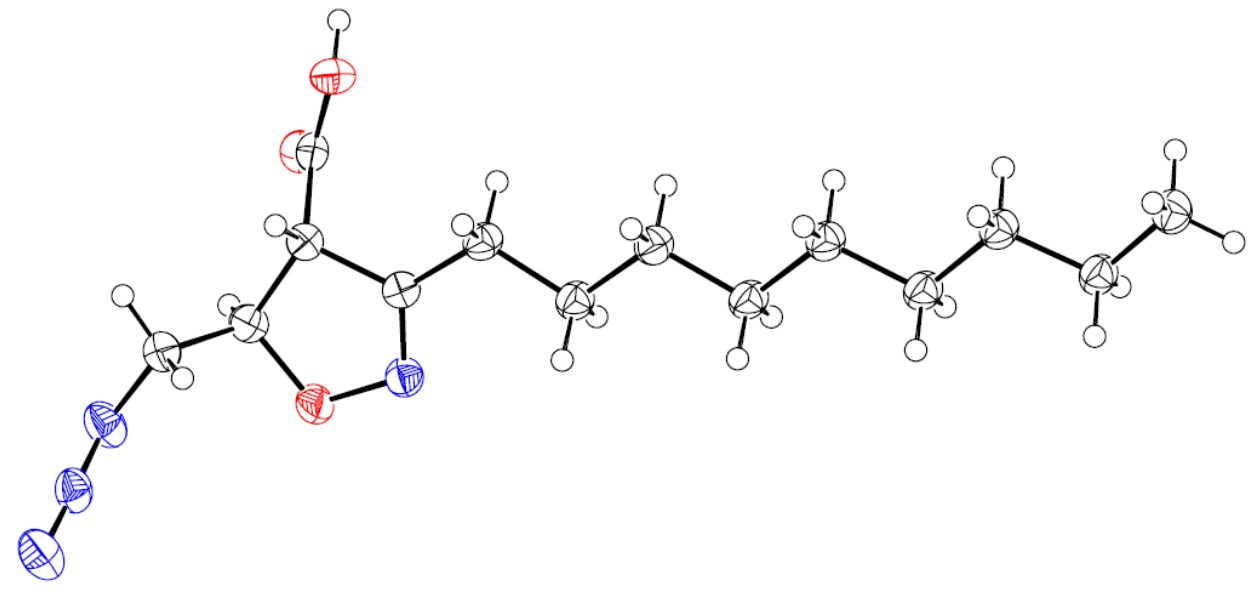

Table 15. Crystal data and structure refinement for ca180119_1_1.

Empirical formula

Formula weight

Temperature/K

Crystal system

Space group

$\mathrm{a} / \AA$

$\mathrm{b} / \AA$

$\mathrm{c} / \AA$

$\alpha /^{\circ}$

$\beta /{ }^{\circ}$

$\gamma /{ }^{\circ}$

Volume $/ \AA^{3}$

$\mathrm{Z}$

$\rho_{\text {calc }} \mathrm{g} / \mathrm{cm}^{3}$

$\mu / \mathrm{mm}^{-1}$

$\mathrm{F}(000)$

Crystal size $/ \mathrm{mm}^{3}$

Radiation

$2 \Theta$ range for data collection ${ }^{\circ}$

Index ranges

Reflections collected

Independent reflections

Data/restraints/parameters

Goodness-of-fit on $\mathrm{F}^{2}$
$\mathrm{C}_{14} \mathrm{H}_{24} \mathrm{~N}_{4} \mathrm{O}_{3}$

296.37

100.0(1)

monoclinic

$\mathrm{P} 21$

$9.5580(2)$

4.85780(10)

17.1177(3)

90

$94.749(2)$

90

$792.06(3)$

2

1.243

0.727

320.0

$0.129 \times 0.072 \times 0.038$

$\operatorname{CuK} \alpha(\lambda=1.54184)$

9.284 to 159.104

$-12 \leq \mathrm{h} \leq 12,-6 \leq \mathrm{k} \leq 6,-21 \leq 1 \leq 21$

16508

$3331\left[\mathrm{R}_{\text {int }}=0.0526, \mathrm{R}_{\text {sigma }}=0.0318\right]$

$3331 / 2 / 194$

1.073 
Final $\mathrm{R}$ indexes $[\mathrm{I}>=2 \sigma(\mathrm{I})]$

Final $\mathrm{R}$ indexes [all data]

Largest diff. peak/hole / e $\AA^{-3}$

Flack parameter
$\mathrm{R}_{1}=0.0372, \mathrm{wR}_{2}=0.1004$

$\mathrm{R}_{1}=0.0394, \mathrm{wR}_{2}=0.1021$

$0.24 /-0.19$

$-0.33(13)$ 
Table 16. Fractional Atomic Coordinates $\left(\times 10^{4}\right)$ and Equivalent Isotropic Displacement Parameters $\left(\AA^{2} \times 10^{3}\right)$ for ca180119_1_1. U U is defined as $1 / 3$ of of the trace of the orthogonalised $U_{\text {IJ }}$ tensor.

\begin{tabular}{|c|c|c|c|c|}
\hline Atom & $x$ & $y$ & $z$ & $\mathbf{U}(\mathbf{e q})$ \\
\hline $\mathrm{O} 1$ & $3719.4(14)$ & $4319(3)$ & $181.6(8)$ & $31.7(3)$ \\
\hline $\mathrm{O} 2$ & $4328.0(15)$ & $8260(3)$ & $810.0(8)$ & $34.3(3)$ \\
\hline $\mathrm{O} 3$ & $1299.3(14)$ & $1739(3)$ & $1650.2(9)$ & $34.0(3)$ \\
\hline N1 & $-1226.2(18)$ & $3367(5)$ & $670.1(11)$ & $39.0(4)$ \\
\hline $\mathrm{N} 2$ & $-2327.1(18)$ & $3515(4)$ & $993.9(10)$ & $34.8(4)$ \\
\hline N3 & $-3385(2)$ & $3453(5)$ & $1244.2(12)$ & $46.2(5)$ \\
\hline N4 & 2403.3(18) & 2299(4) & $2237.9(10)$ & $30.7(4)$ \\
\hline $\mathrm{C} 1$ & $3073(2)$ & $4429(4)$ & 2053.7(11) & $27.0(4)$ \\
\hline $\mathrm{C} 2$ & 2498.8(19) & $5742(4)$ & $1287.7(11)$ & $27.3(4)$ \\
\hline $\mathrm{C} 3$ & $1286(2)$ & $3822(4)$ & $1041.8(11)$ & $29.8(4)$ \\
\hline $\mathrm{C} 4$ & $-109(2)$ & $5279(5)$ & $988.2(12)$ & $33.1(4)$ \\
\hline C5 & $3583.8(19)$ & $6000(4)$ & $696.8(11)$ & $28.4(4)$ \\
\hline C6 & $4256(2)$ & $5623(4)$ & $2568.9(11)$ & $30.2(4)$ \\
\hline $\mathrm{C} 7$ & $4719(2)$ & 3911(4) & $3292.6(11)$ & 31.1(4) \\
\hline $\mathrm{C} 8$ & $5925(2)$ & $5294(5)$ & $3780.8(11)$ & $31.1(4)$ \\
\hline C9 & $6449(2)$ & $3712(5)$ & $4517.3(11)$ & $32.0(4)$ \\
\hline $\mathrm{C} 10$ & $7668(2)$ & $5146(5)$ & $4980.4(11)$ & $32.3(5)$ \\
\hline C11 & $8274(2)$ & $3582(5)$ & $5702.2(11)$ & $32.5(4)$ \\
\hline C12 & $9513(2)$ & $5037(5)$ & $6138.0(12)$ & $32.1(4)$ \\
\hline C13 & 10191(2) & $3429(5)$ & $6833.8(12)$ & $33.0(4)$ \\
\hline C14 & $11410(2)$ & $4965(5)$ & $7259.1(13)$ & $37.9(5)$ \\
\hline
\end{tabular}

Table 17. Anisotropic Displacement Parameters $\left(\AA^{2} \times 10^{3}\right)$ for ca180119_1_1. The Anisotropic displacement factor exponent takes the form: $-2 \pi^{2}\left[h^{2} a^{* 2} U_{11}+2 h k a * b * U_{12}+\ldots\right]$.

\begin{tabular}{lrrrrrr} 
Atom & \multicolumn{1}{l}{$\mathbf{U}_{\mathbf{1 1}}$} & \multicolumn{1}{c}{$\mathbf{U}_{\mathbf{2 2}}$} & \multicolumn{1}{l}{$\mathbf{U}_{\mathbf{3 3}}$} & \multicolumn{1}{c}{$\mathbf{U}_{\mathbf{1 3}}$} & $\mathbf{U}_{\mathbf{1 2}}$ \\
O1 & $31.6(7)$ & $35.6(8)$ & $28.1(7)$ & $-2.3(6)$ & $3.9(5)$ & $4.3(6)$ \\
O2 & $37.2(7)$ & $33.8(8)$ & $32.9(7)$ & $0.5(6)$ & $8.5(6)$ & $-6.6(6)$ \\
O3 & $30.8(7)$ & $28.6(7)$ & $41.4(8)$ & $2.6(6)$ & $-4.8(6)$ & $-4.4(6)$ \\
N1 & $30.2(9)$ & $52.9(12)$ & $33.6(9)$ & $-9.0(9)$ & $1.4(7)$ & $-3.3(8)$ \\
N2 & $33.0(9)$ & $41.7(10)$ & $28.6(8)$ & $-3.2(8)$ & $-4.0(7)$ & $-0.3(8)$ \\
N3 & $32.6(9)$ & $63.7(14)$ & $42.1(10)$ & $-10.1(10)$ & $2.4(8)$ & $-1.3(9)$ \\
N4 & $30.9(8)$ & $28.3(9)$ & $32.4(8)$ & $-0.1(7)$ & $0.3(7)$ & $0.2(7)$ \\
C1 & $28.9(9)$ & $26.0(10)$ & $26.5(9)$ & $-1.0(8)$ & $3.9(7)$ & $0.5(8)$ \\
C2 & $28.0(9)$ & $27.1(9)$ & $26.8(9)$ & $-1.8(8)$ & $2.3(7)$ & $-0.1(8)$ \\
C3 & $30.5(9)$ & $34.1(11)$ & $24.9(9)$ & $-3.3(8)$ & $3.3(7)$ & $-3.0(8)$ \\
C4 & $30.2(10)$ & $36.4(11)$ & $32.2(9)$ & $1.3(8)$ & $-0.7(8)$ & $-2.1(8)$ \\
C5 & $26.3(9)$ & $30.9(10)$ & $27.2(9)$ & $4.4(8)$ & $-1.6(7)$ & $2.8(8)$ \\
C6 & $35.9(10)$ & $28.9(10)$ & $25.8(9)$ & $-0.1(8)$ & $2.1(7)$ & $-3.0(8)$ \\
C7 & $34.8(10)$ & $30.2(11)$ & $27.9(9)$ & $1.1(8)$ & $0.2(7)$ & $-1.9(8)$ \\
C8 & $35.5(10)$ & $30.0(10)$ & $27.6(9)$ & $-0.8(8)$ & $0.3(8)$ & $-2.7(8)$ \\
C9 & $37.8(10)$ & $31.2(10)$ & $26.6(9)$ & $1.8(8)$ & $0.3(7)$ & $-3.6(8)$ \\
C10 & $36.8(10)$ & $32.2(11)$ & $27.4(9)$ & $0.6(8)$ & $0.0(8)$ & $-2.8(8)$ \\
C11 & $37.6(10)$ & $33.0(11)$ & $26.5(9)$ & $2.5(8)$ & $0.2(8)$ & $-3.1(9)$ \\
C12 & $36.6(10)$ & $32.0(11)$ & $27.4(9)$ & $0.4(8)$ & $0.6(8)$ & $-1.3(8)$ \\
C13 & $35.5(10)$ & $35.8(11)$ & $27.5(9)$ & $3.0(9)$ & $2.2(7)$ & $1.3(9)$ \\
C14 & $37.8(11)$ & $43.2(13)$ & $32.1(10)$ & $1.0(9)$ & $-0.5(8)$ & $0.2(9)$
\end{tabular}


Table 18. Bond Lengths for ca180119_1_1.

\begin{tabular}{|c|c|c|c|c|c|}
\hline \multicolumn{2}{|c|}{ Atom Atom } & \multirow{2}{*}{$\begin{array}{c}\text { Length/Å } \\
1.217(2)\end{array}$} & \multicolumn{2}{|c|}{ Atom Atom } & \multirow{2}{*}{$\begin{array}{r}\text { Length/Å } \\
1.513(3)\end{array}$} \\
\hline $\mathrm{O} 1$ & $\mathrm{C} 5$ & & $\mathrm{C} 2$ & C5 & \\
\hline $\mathrm{O} 2$ & $\mathrm{C} 5$ & $1.314(3)$ & $\mathrm{C} 3$ & $\mathrm{C} 4$ & $1.507(3)$ \\
\hline $\mathrm{O} 3$ & $\mathrm{~N} 4$ & $1.423(2)$ & C6 & $\mathrm{C} 7$ & $1.527(3)$ \\
\hline $\mathrm{O} 3$ & $\mathrm{C} 3$ & $1.451(2)$ & $\mathrm{C} 7$ & $\mathrm{C} 8$ & $1.523(3)$ \\
\hline $\mathrm{N} 1$ & $\mathrm{~N} 2$ & $1.231(2)$ & $\mathrm{C} 8$ & C9 & $1.525(3)$ \\
\hline $\mathrm{N} 1$ & $\mathrm{C} 4$ & $1.484(3)$ & C9 & $\mathrm{C} 10$ & $1.523(3)$ \\
\hline $\mathrm{N} 2$ & N3 & $1.130(3)$ & $\mathrm{C} 10$ & $\mathrm{C} 11$ & $1.524(3)$ \\
\hline N4 & $\mathrm{C} 1$ & $1.270(3)$ & C11 & $\mathrm{C} 12$ & $1.521(3)$ \\
\hline $\mathrm{C} 1$ & $\mathrm{C} 2$ & $1.519(3)$ & $\mathrm{C} 12$ & $\mathrm{C} 13$ & $1.523(3)$ \\
\hline $\mathrm{C} 1$ & C6 & $1.492(3)$ & C13 & $\mathrm{C} 14$ & $1.518(3)$ \\
\hline $\mathrm{C} 2$ & C3 & $1.520(3)$ & & & \\
\hline
\end{tabular}

Table 19. Bond Angles for ca180119_1_1.

\begin{tabular}{lllrlllr} 
Atom Atom Atom & \multicolumn{1}{c}{ Angle $^{\circ}$} & \multicolumn{3}{c}{ Atom Atom Atom } & Angle $^{\circ}$ \\
N4 & O3 & C3 & $109.62(14)$ & N1 & C4 & C3 & $109.55(19)$ \\
N2 & N1 & C4 & $114.44(18)$ & O1 & C5 & O2 & $125.37(18)$ \\
N3 & N2 & N1 & $173.4(2)$ & O1 & C5 & C2 & $123.32(18)$ \\
C1 & N4 & O3 & $109.86(16)$ & O2 & C5 & C2 & $111.31(17)$ \\
N4 & C1 & C2 & $113.75(17)$ & C1 & C6 & C7 & $115.00(17)$ \\
N4 & C1 & C6 & $122.85(18)$ & C8 & C7 & C6 & $111.14(17)$ \\
C6 & C1 & C2 & $123.29(17)$ & C7 & C8 & C9 & $114.40(17)$ \\
C1 & C2 & C3 & $101.19(16)$ & C10 & C9 & C8 & $112.61(17)$ \\
C5 & C2 & C1 & $113.16(16)$ & C9 & C10 & C11 & $114.66(18)$ \\
C5 & C2 & C3 & $114.52(16)$ & C12 & C11 & C10 & $113.23(18)$ \\
O3 & C3 & C2 & $105.56(15)$ & C11 & C12 & C13 & $114.12(18)$ \\
O3 & C3 & C4 & $109.04(15)$ & C14 & C13 & C12 & $112.5(2)$ \\
C4 & C3 & C2 & $112.31(19)$ & & & &
\end{tabular}

Table 20. Hydrogen Atom Coordinates $(\AA ̊ \times 104)$ and Isotropic Displacement Parameters $\left(\AA^{2} \times 10^{3}\right)$ for ca180119_1_1.

\begin{tabular}{lrrrr} 
Atom & \multicolumn{1}{l}{$\boldsymbol{x}$} & \multicolumn{1}{l}{$\boldsymbol{z}$} & $\boldsymbol{U}(\mathbf{e q})$ & \\
H2 & $5010(30)$ & $8470(70)$ & $467(15)$ & 51 \\
H2A & 2127.71 & 7571.19 & 1395.12 & 33 \\
H3 & 1437.47 & 2960.9 & 537.88 & 36 \\
H4A & -314.92 & 5910.4 & 1503.99 & 40 \\
H4B & -75.54 & 6872.03 & 648.54 & 40 \\
H6A & 3979.02 & 7432.52 & 2739.28 & 36 \\
H6B & 5054.84 & 5862.45 & 2261.14 & 36 \\
H7A & 3932.19 & 3673.84 & 3609.47 & 37 \\
H7B & 5013.71 & 2103.2 & 3130.31 & 37 \\
H8A & 5622.67 & 7108.58 & 3933.34 & 37 \\
H8B & 6701.36 & 5537.46 & 3456.61 & 37 \\
H9A & 5681.64 & 3497.67 & 4849.67 & 38 \\
H9B & 6744.4 & 1888.71 & 4369.07 & 39 \\
H10A & 7353.4 & 6938.09 & 5144.54 & 39 \\
H10B & 8410.4 & 5444.73 & 4636.19 & 39 \\
H11A & 7543.05 & 3329.36 & 6056.27 &
\end{tabular}




$\begin{array}{lrrrr}\text { H11B } & 8572.13 & 1772.65 & 5542.69 & 39 \\ \text { H12A } & 9198.8 & 6800.9 & 6323 & 39 \\ \text { H12B } & 10217.46 & 5391.66 & 5773.84 & 39 \\ \text { H13A } & 9489.42 & 3056.03 & 7198.38 & 40 \\ \text { H13B } & 10523.39 & 1675.85 & 6650.76 & 40 \\ \text { H14A } & 12100.4 & 5367.81 & 6898.76 & 57 \\ \text { H14B } & 11824.6 & 3844.88 & 7678.72 & 57 \\ \text { H14C } & 11076.36 & 6652.05 & 7468.83 & 57\end{array}$




\section{Biofilm Inhibition, Surface Area Reduction Assays, and Planktonic Growth Curves}

\subsection{General Consideration}

All reagents were obtained from Fisher Thermo Scientific or Sigma Aldrich/Merck. Candida albicans strain ATCC 90028 was purchased from ATCC. Strains SC5314 and 101 were described previously. ${ }^{50,51}$

RPMI 1640 medium was from Gibco/Thermo Fisher Scientific.

Relative surface area reduction: Black, clear bottom microtiter plates were purchased from Greiner Bio-One International (cat. Number: 655090). Hoechst, Cell Mask Deep Red and Concanavalin A dyes were purchased from Molecular Probes/Thermo Fisher Scientific.

XTT assay: Flat-bottomed, clear, 96 well plates were purchased from Nunc. The Cell Proliferation Kit II (XTT) originally developed by Roche and now distributed by Merck (cat. Number: 11465015001) was used for the actual measurement.

Microscopy/Spectrophotometry: Fluorescence photographs and quantification of fluorescence intensity was performed using an Operetta system and the Harmony software (Perkin Elmer). Spectrophotometry was performed using a Biotek Synergy Mx spectrophotometer.

Software: Cell viability (biofilm growth) and relative surface area covered by yeast calculations were done using Microsoft Excel. All graphs as well as non-linear regression analysis was performed using Graph Pad Prism 8.0. 


\subsection{Experimental Procedures for Biofilm Inhibition, Surface Area Reduction Assays and Planktonic Growth Curves}

Culturing of yeast cells: C. albicans strains were cultured in autoclaved Yeast Nitrogen Base medium (YNB) without amino acids but with $\left(\mathrm{NH}_{4}\right)_{2} \mathrm{SO}_{4}$ containing $0.1 \%$ maltose and 0.2\% glucose (ATCC 90028) or Yeast Extract-Peptone-Dextrose (YPD) (SC5314 and 101). The cultures were inoculated with a glycerol stock of the respective yeast strain and then incubated at $30{ }^{\circ} \mathrm{C}, 200 \mathrm{rpm}$ in a shaking incubator. Following $16 \mathrm{~h}$ of incubation, these pre-cultures were centrifuged (1000 rpm, RT, $5 \mathrm{~min}$ ), washed twice with PBS to remove any debris from the yeast cells and re-suspended in RPMI 1640 buffered with MOPS to $\mathrm{pH}$ 7.0. The number of cells per $\mathrm{mL}$ was determined after counting the number of yeast cells with help of a hemocytometer (Neubauer chamber).

Compound preparation: Stock solutions of mutanobactin D 1 were prepared in DMSO at concentrations of $20 \mathrm{mM}, 15 \mathrm{mM}, 10 \mathrm{mM}, 7.5 \mathrm{mM}, 5 \mathrm{mM} 2.5 \mathrm{mM}, 1 \mathrm{mM}, 0.5 \mathrm{mM}$, $0.1 \mathrm{mM}$ and $50 \mu \mathrm{M}$. Diluting these stocks $(1: 100)$ in RPMI 1640 containing the desired number of yeast cells yielded a range of final concentrations $(200 \mu \mathrm{M}, 150 \mu \mathrm{M}, 100 \mu \mathrm{M}$, $75 \mu \mathrm{M}, 50 \mu \mathrm{M}, 25 \mu \mathrm{M}, 10 \mu \mathrm{M}, 5 \mu \mathrm{M}, 1 \mu \mathrm{M}$ and $0.5 \mu \mathrm{M})$ suitable for experiments aimed at determining the dose response and the IC-50 of a specific compound. This dilution strategy yielded a final DMSO concentration of $1 \%$ which did not interfere with hyphae or biofilm formation in C. albicans based on our results (data not shown).

\section{Assessing yeast planktonic growth:}

To monitor C. albicans growth, yeast pre-cultures were grown as described above, diluted to a final concentration of $1 * 10^{6}$ cells $\mathrm{mL}^{-1}$ in YNB (ATCC 90028) or YPD (SC5314 and 101) medium. Small amounts of stock solutions of substance 1 (see above: Compound preparation) were added to the yeast culture aliquots at a dilution of 1:100 yielding a final volume of $650 \mu \mathrm{L}$ for ten different concentrations ranging from $200 \mu \mathrm{M}$ to $0.5 \mu \mathrm{M}$. Subsequently $3 \times 200 \mu \mathrm{L}$ (= 20000 cells) of $C$. albicans per condition were pipetted into a well of a flat bottom microplate. Three wells of yeast culture medium plated with no additive and three wells treated with 1\% DMSO served as untreated/growth and solvent controls, respectively while three wells treated with $100 \mu \mathrm{M}$ farnesol and $10 \mu \mathrm{g} / \mathrm{mL}$ amphotericin B served as positive (no growth) controls. Controls were included on every plate. OD 600 was measured every 10 minutes, following a 30 second shaking period for $24 \mathrm{~h}$ while the plates were incubated at $30^{\circ} \mathrm{C}$. Six wells containing YNB or YPD without 
C. albicans were used to determine the background and subtracted from all the other data obtained per time point. The resulting three values per condition were averaged and subsequently plotted against the time passed from the start of the incubation using Graph Pad Prism 8.0. The resulting figures are presented in section 10.3 as Figure 29 (mutanobactin D; strain ATCC 90028), Figure 30 (mutanobactin D; strain SC5314), and Figure 31 (mutanobactin D; strain 101).

\section{Principle of the cell viability testing:}

The XTT assay is a colorimetric assay that determines cell viability by measuring $\mathrm{NAD}(\mathrm{P}) \mathrm{H}-\mathrm{dependent} \mathrm{metabolic} \mathrm{activity} \mathrm{of} \mathrm{cellular} \mathrm{oxidoreductases.} \mathrm{XTT} \mathrm{(sodium} \mathrm{3'-[1-}$ (phenylaminocarbonyl)- 3,4- tetrazolium]-bis (4-methoxy6-nitro) benzene sulfonic acid hydrate) readily enters the cells where it is reduced to an orange formazan dye which can be directly quantified using a scanning multiwell spectrophotometer (ELISA reader). A higher number of living cells results in a higher overall activity of mitochondrial dehydrogenases in the sample which directly correlates to the amount of orange formazan formed, as monitored by absorbance.

Testing of cell viability via XTT assay to determine biofilm growth: To determine if mutanobactin D (1) and farnesol alter the proliferation rate of C. albicans, yeast pre-cultures were grown as described above, diluted to a final concentration of $2.5 . * 10^{5}$ cells $/ \mathrm{mL}$ in RPMI 1640, buffered to pH 7 with MOPS, and aliquoted into Eppendorf tubes at a volume of $500 \mu \mathrm{L}$. Small amounts ( $5 \mu \mathrm{L}$ ) of stock solutions of substance 1 or farnesol (see above: Compound preparation) were added to the yeast culture aliquots (1:100 dilution) resulting in ten different final concentrations ranging from $200 \mu \mathrm{M}$ to $0.5 \mu \mathrm{M}$. Subsequently $3 \mathrm{x}$ $100 \mu \mathrm{L}$ (= 2500 cells) of $C$. albicans admixed with compound were given into a well of a flat bottom microplate per concentration. The plate was incubated for $48 \mathrm{~h}$ at $37^{\circ} \mathrm{C}, 60 \mathrm{rpm}$, in a humidified chamber. Six wells of yeast culture plated with no additive and six wells treated with $1 \%$ DMSO served as untreated/growth and solvent controls, respectively while three wells treated with $100 \mu \mathrm{M}$ farnesol served as positive (no growth) control when experiments with mutanobactin D (1) were conducted. Controls were included on every plate. Biofilm formation was triggered by the switch of medium (YNB or YPD to RPMI 1640) and rise in temperature to $37^{\circ} \mathrm{C}$. In the course of the incubation period, the plates were evaluated under the microscope $6,12,24$ and $46 \mathrm{~h}$ after initiation of biofilm formation. The actual XTT measurement was performed according to the instructions given bythe manufacturer (Roche/Merck) during the last hour of the $48 \mathrm{~h}$ incubation period. 
Formation of the orange formazan dye was quantified by reading the absorbance at $490 \mathrm{~nm}$ (test wavelength) and $660 \mathrm{~nm}$ (reference wavelength). Cell viability was calculated by analyzing the raw absorbance values using Microsoft Excel with the formula:

Cell viability $(\%)=$

[(OD value of treated wells at $490 \mathrm{~nm}$ - OD value of treated wells at $660 \mathrm{~nm}) \times 100 \%$ ] / [average of (OD values of solvent wells at $490 \mathrm{~nm}$ - OD values of solvent wells at $660 \mathrm{~nm})]$.

The $\mathrm{IC}_{50}$ of each compound was determined by non-linear regression curve fitting of graphs plotting the average percent of viable cells per condition $(n=3) \pm$ standard deviation versus the dose of the respective compound. The resulting graphs from this analysis were acquired using Graph Pad Prism 8.0 and are presented as Figure 32 and Figure 33 (mutanobactin D or farnesol; strain ATCC 90028), Figure 34 (mutanobactin D; strain SC5314), and Figure 35 (mutanobactin D; strain 101) in section 10.4. The $\mathrm{IC}_{50}$ 's obtained via this method per experiment were subsequently averaged for each compound giving rise to the values presented in Table 4, third column (in the body of the paper), namely the $\mathrm{IC}_{50} \pm$ standard variation values for $\mathbf{1}$ and farnesol with an $\mathrm{n}$ of 5-6. The statistical significance of differences in the accumulation of orange formazan was assessed via ANOVA (Bonferroni's multiple comparison test) by comparing all values obtained per compound and condition against the solvent controls (all values). The no growth controls did not form orange formazan while solvent and untreated cells used as positive controls proliferated the most and thus showed the highest absorbance.

\section{Testing of hyphae formation / reduction of cell surface area by fluorescent high content imaging}

To determine if $\mathbf{1}$ or farnesol prevent the induction of hyphae formation and reduce the surface area covered by yeast, yeast pre-cultures were grown as described above, diluted to a final concentration of 7.5 . $* 10^{5}$ cells/mL in RPMI 1640 buffered, to $\mathrm{pH} 7$ with MOPS and aliquoted into Eppendorf tubes at a volume of $500 \mu \mathrm{L}$. Small amounts $(5 \mu \mathrm{L})$ of stock solutions of substance $\mathbf{1}$ and farnesol (see above: Compound preparation) were added to the yeast culture aliquots (1:100 dilution) resulting in a maximum of ten different final concentrations ranging from $200 \mu \mathrm{M}$ to $0.5 \mu \mathrm{M}$. Subsequently, $100 \mu \mathrm{L}$ (= 7500 cells) of $C$. albicans admixed with compound were given into wells of a black, clear bottom microtiter plate. The plate was incubated for $5 \mathrm{~h}$ at $37^{\circ} \mathrm{C}$ in a humidified chamber. Six negative (no inhibition of hyphae formation, $3 x$ untreated and $3 x$ 1\% DMSO) and three positive (full 
inhibition of hyphae formation) controls (100 $\mu \mathrm{M}$ farnesol) were always run on the same plate. Hyphal growth was triggered by the described media switch (YNB or YPD to RPMI 1640) and rise in temperature to $37^{\circ} \mathrm{C}$.

To quantify the number of yeast cells and the amount of cell surface area the plates were washed twice with PBS to remove non adherent cells and debris prior to fixation with $4 \%$ paraformaldehyde in PBS for 20 min at room temperature. Following two more washing steps with PBS, the fixed yeast cultures were double-stained with either a) Hoechst 33342 ((bis-benzimide)trihydrochloride) and Cell Mask Deep Red (CMR) or b) Hoechst 33342 and Concanavalin A (ConA) diluted in PBS as indicated in Table 21 for 30 min at room temperature. After two final washing steps with PBS, the plates were assayed via confocal fluorescent high-content imaging on an Operetta system at 20x magnification using the excitation/emission wavelengths shown in Table 21:

Table 21. Absorption and emission wavelengths of dyes used for quantification of yeast surface area.

\begin{tabular}{cccc}
\hline Dye & $\boldsymbol{\Lambda \text { Abs }}$ & $\boldsymbol{\lambda}$ Em & Dilution \\
\hline Höchst 33342 & $350 \mathrm{~nm}$ & $461 \mathrm{~nm}$ & $1: 1000$ \\
\hline $\begin{array}{c}\text { Alexa Fluor 488 } \\
\text { (Concanavalin- ConA) }\end{array}$ & $495 \mathrm{~nm}$ & $519 \mathrm{~nm}$ & $1: 1000$ \\
\hline Cell Mask Deep Red & $649 \mathrm{~nm}$ & $666 \mathrm{~nm}$ & $1: 2000$ \\
\hline
\end{tabular}

Fluorescent pictures were taken from 23 different fields per 96 well yielding a total of 69 images per condition. To avoid background fluorescence being rated as positive staining, each channel was manually adjusted to a minimal intensity (above the background) that was considered as positive staining signal for each experiment prior to analysis of the obtained pictures with the Harmony software (PerkinElmer) as follows: Nuclei were identified based on positive Hoechst 33342 staining - their number, indicating the proliferation potential of the cells, as well as the area they covered were determined. The second stain (CMR or ConA) which intercalates and thus visualizes cell membranes defined the area that is covered by yeast aside from the nucleus and was used to quantify the yeast surface area. The area stained positive for either Hoechst or CMR/ConA was averaged over the 23 images analyzed per well and subsequently the three values obtained per condition (compound and concentration) were averaged again. The final number represented the average \pm standard deviation in $\mu \mathrm{m}^{2}$ of the $3 \times 23$ areas analyzed.

Visual assessment of the pictures allowed us to determine any potential morphological changes as well as to confirm that the results of the software based area quantification were 
correct. As the actual analysis was performed by a computer program, this setting provided an unbiased quantification of cell surface area. Overall, little variation was seen in both Hoechst and CMR/ConA positive area across the 69 images analyzed per condition suggesting that the assay format is reliable and robust. This was further corroborated by the fact that the results obtained by quantification of the area stained positive with CMR which uniformly visualizes cell membranes matched the ones obtained by quantification of the area stained positive with ConA which binds to $\alpha$-mannopyranosyl and $\alpha$-glucopyranosyl residues, found in the cell wall of yeast and fungi.

The potential of a compound to reduce surface area covered by yeast was determined by comparing the CMR/ConA positive area (membranes) or the total area covered by yeast (Hoechst positive staining area plus CMR/ConA positive staining area) of a specific condition to the respective area of the solvent control in Excel with the following formulas:

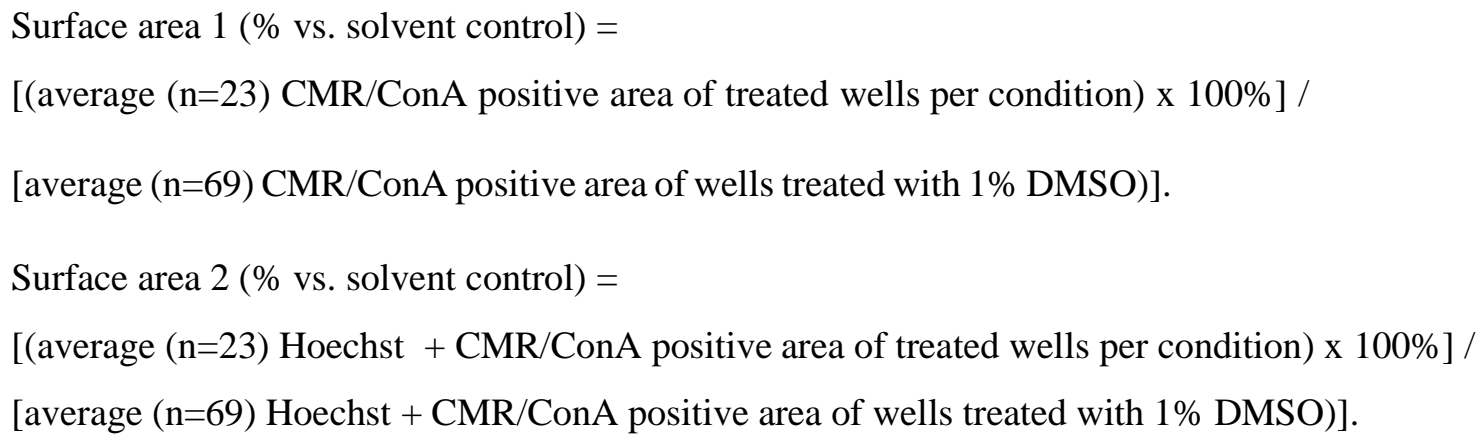

This approach yielded three values per concentration each representing 23 images per 96 well. Differences between the results obtained from the two formulae were negligible. No difference in Höchst or Cell Mask Red staining was seen between untreated cells and the ones exposed to $1 \%$ DMSO indicating that the solvent has no effect on the surface area. The IC50 of each compound was determined by non-linear regression curve fitting of graphs plotting the average percent of surface area covered by yeast per condition $(n=3) \pm$ standard deviation versus the dose of the respective compound. The resulting graphs from this analysis were acquired using Graph Pad Prism 8.0 and are presented as Figure 36 and Figure 37 (mutanobactin D and farnesol; strain ATCC 90028), Figure 38 (mutanobactin D; strain SC5314), and Figure 39 (mutanobactin D; strain 101) in section 10.5 for surface area 1 and as Figure 40 and Figure 41 (mutanobactin D and farnesol; strain ATCC 90028), Figure 42 (mutanobactin D; strain SC5314), and Figure 43 (mutanobactin D; strain 101) in section 10.6 for surface area 2 .

The IC50's obtained with this method per experiment were subsequently averaged for each 
compound giving rise to the values presented in the main text in Table 4, fourth column, namely the IC50 \pm standard deviation values of surface area covered relative to control for mutanobactin D treated yeast of the ATCC 90028, SC5314 and 101 strains, respectively. The statistical significance of differences in the area covered by yeast was assessed via ANOVA (Bonferroni's multiple comparison test) by comparing all values obtained per compound and condition against the solvent and untreated controls (values combined) for each experiment. The no growth controls $(100 \mu \mathrm{M}$ farnesol) did not filament while treatment with solvent or no treatment used as positive controls did not inhibit filamentation which is why the area covered by yeast in these wells was considered maximal. Example pictures for yeast cells stained with Hoechst 33342 and Concanavalin A (ConA) following a $5 \mathrm{~h}$ treatment with $1 \%$ DMSO, $100 \mu \mathrm{M}$ farnesol or $200,100,75,50,25,10$ and $1 \mu \mathrm{M}$ mutanobactin D for all three strains are shown in section 10.7. 


\subsection{C. albicans Planktonic Growth Curves}

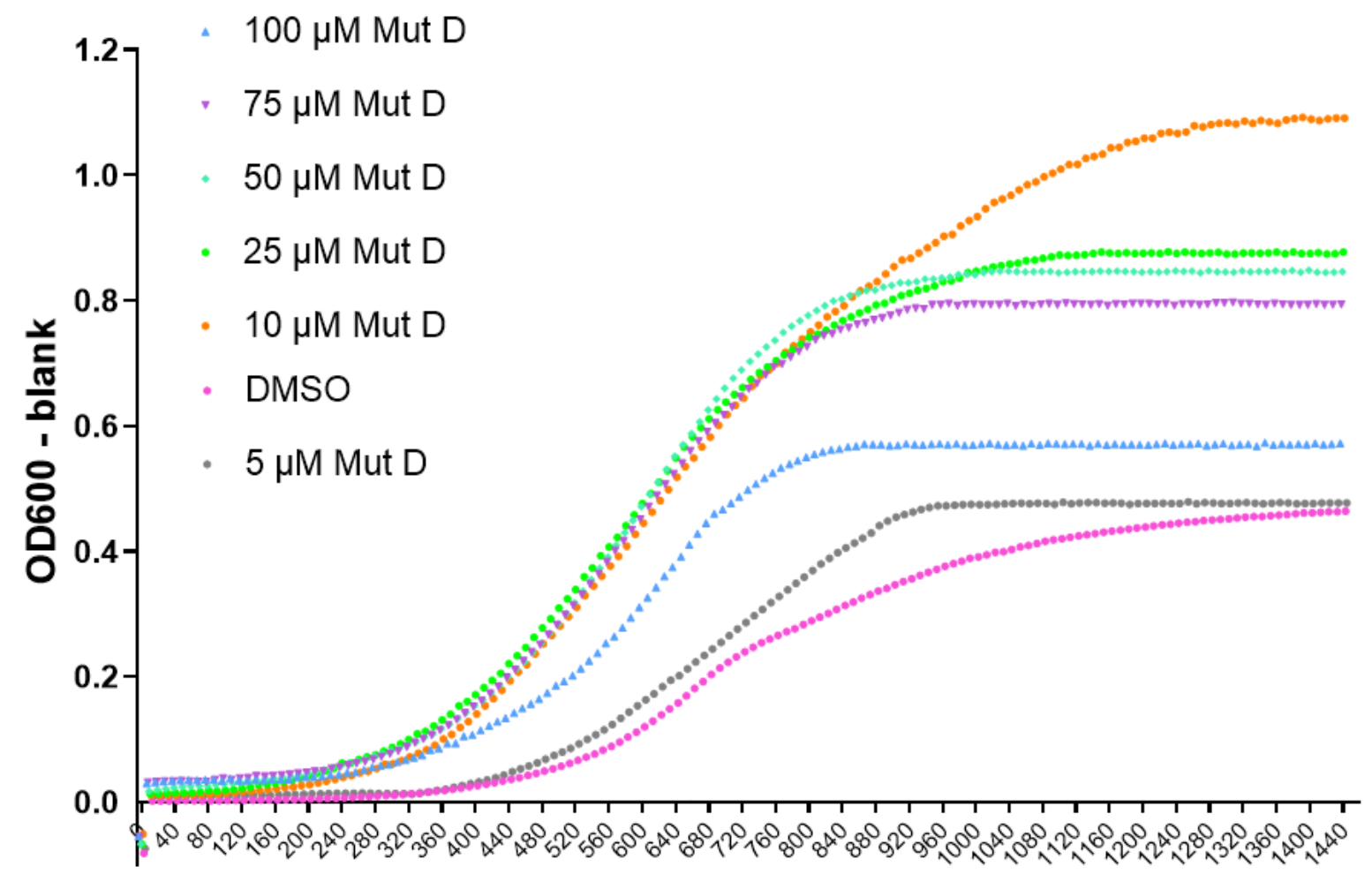

[min]

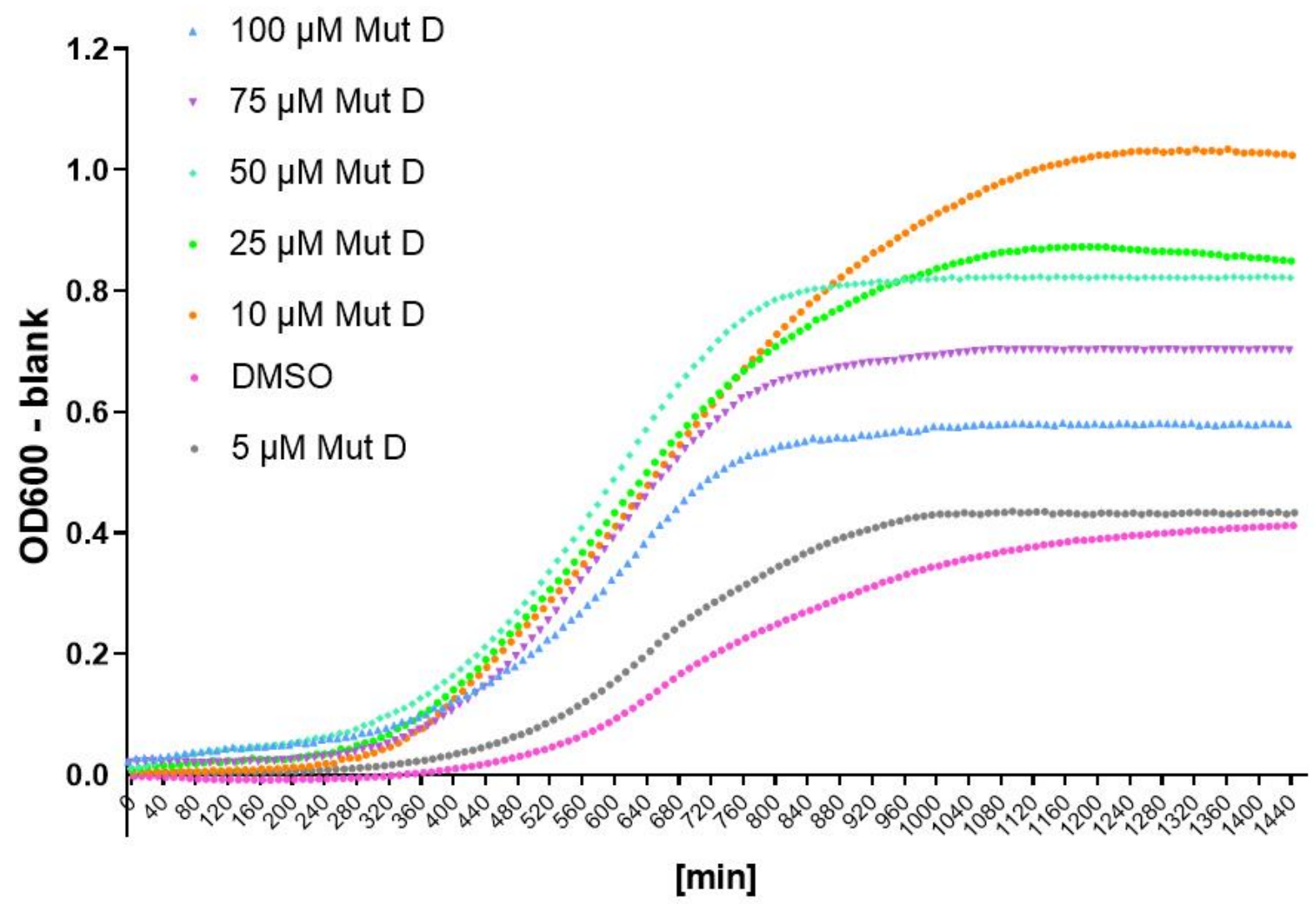

Figure 29. Growth enhancing effect of mutanobactin D (Mut D) on C. albicans strain ATCC 90028. Experiment 1 (top) and experiment 2 (bottom). 


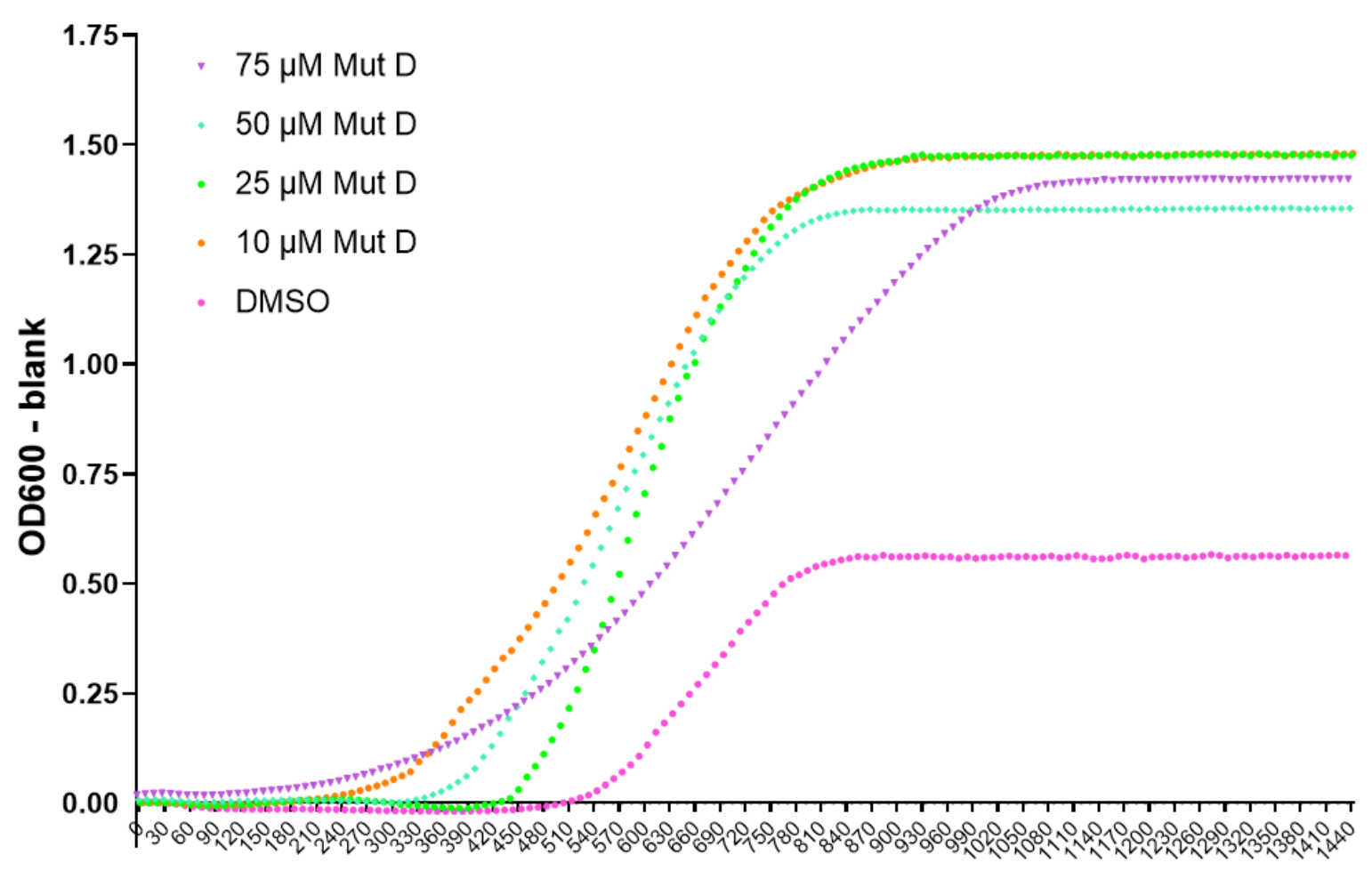

[min]

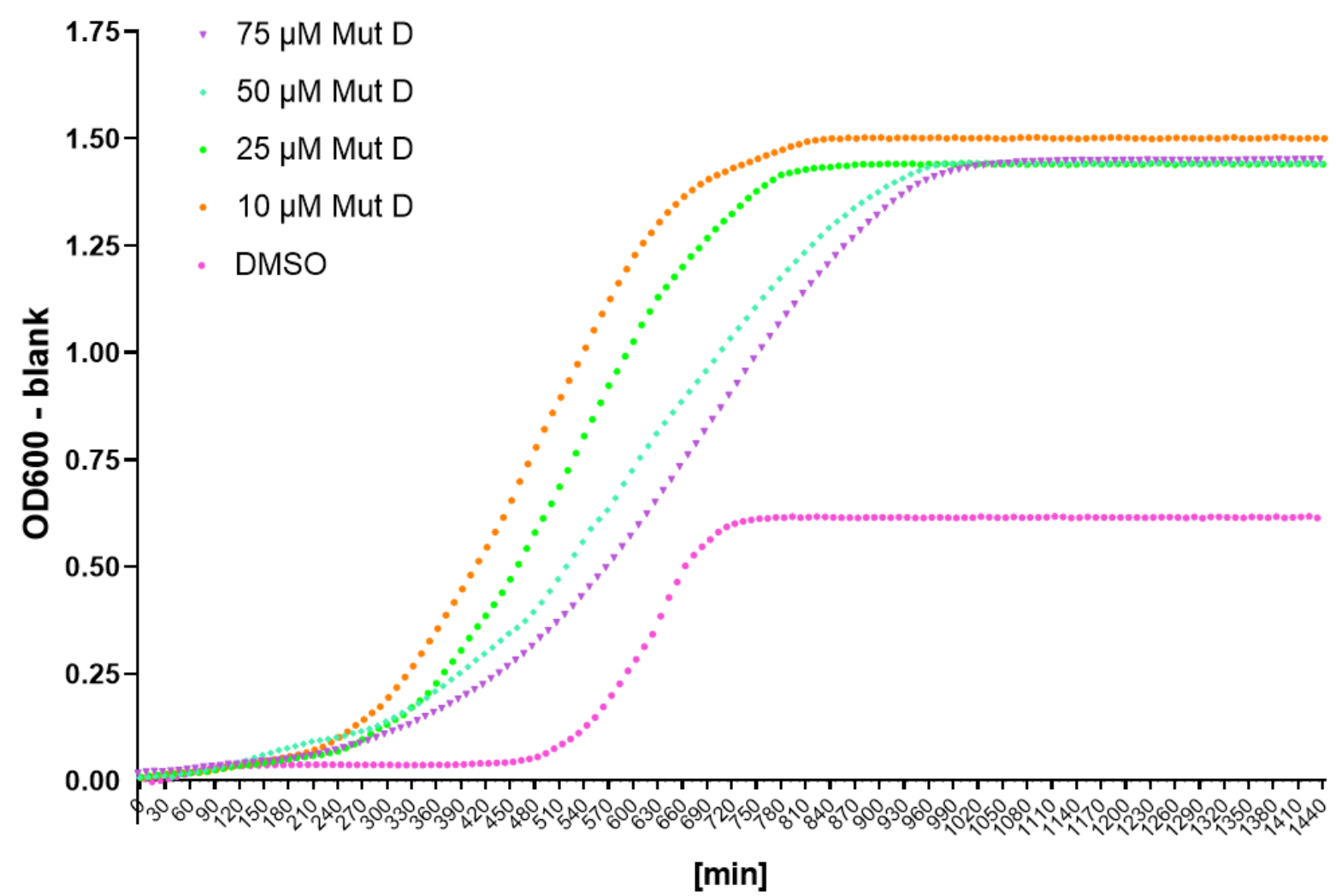

Figure 30. Growth enhancing effect of mutanobactin D (Mut D) on C. albicans strain SC5314. Experiment 1 (top) and experiment 2 (bottom). 


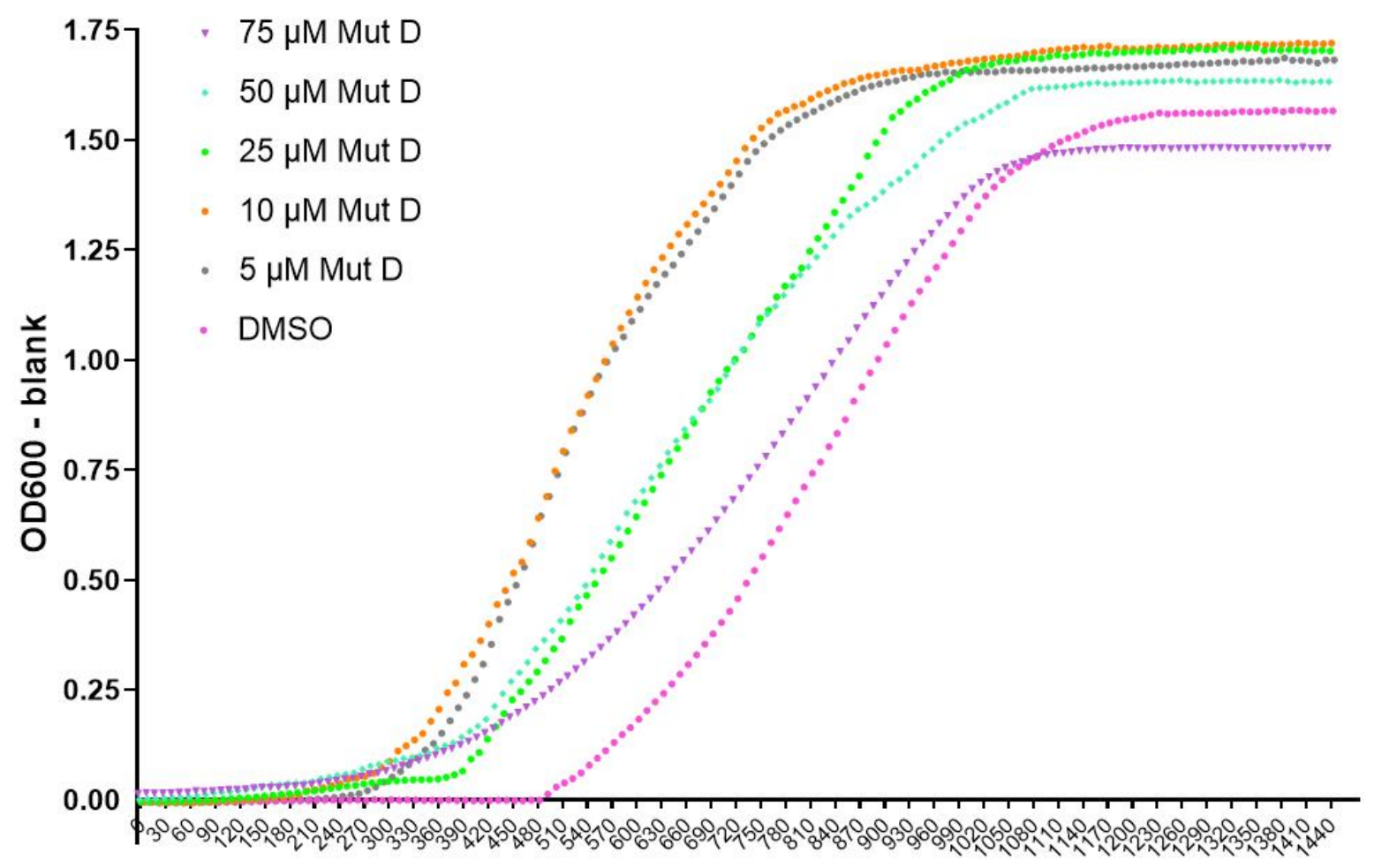

[min]

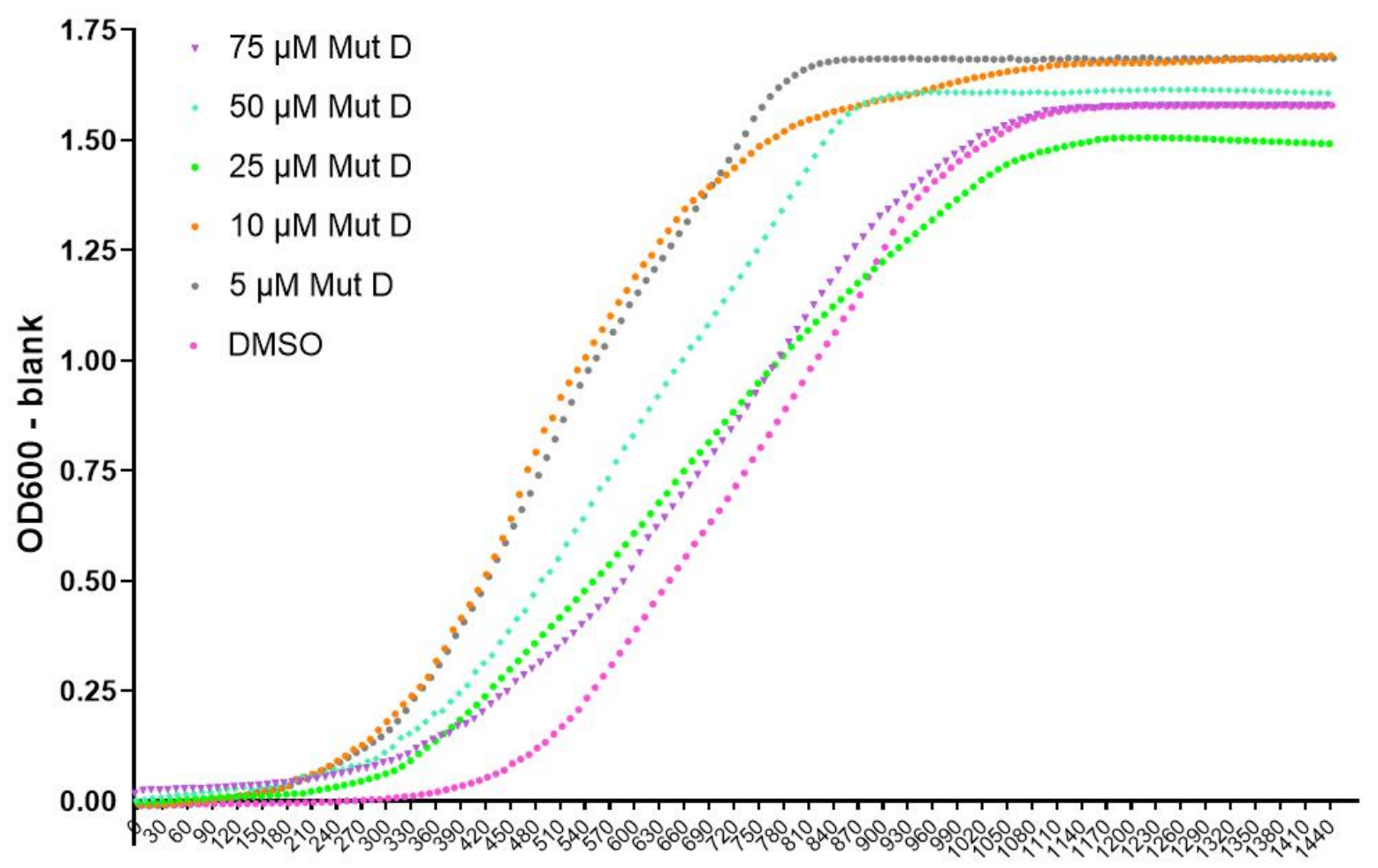

[min]

Figure 31. Growth enhancing effect of mutanobactin D (Mut D) on C. albicans strain 101. Experiment 1 (top) and experiment 2 (bottom). 


\subsection{Dose Response Curves for Biofilm Formation Inhibition (XTT)}

For all figures in this sub-section, statistical analysis via ANOVA (Bonferroni's multiple comparison test). Significance: $p<0.05=* ; p<0.01=* * p<0.001=* * * ; p<0.0001=* * * *$ vs. solvent control.

\section{Strain: ATCC 90028}

a)

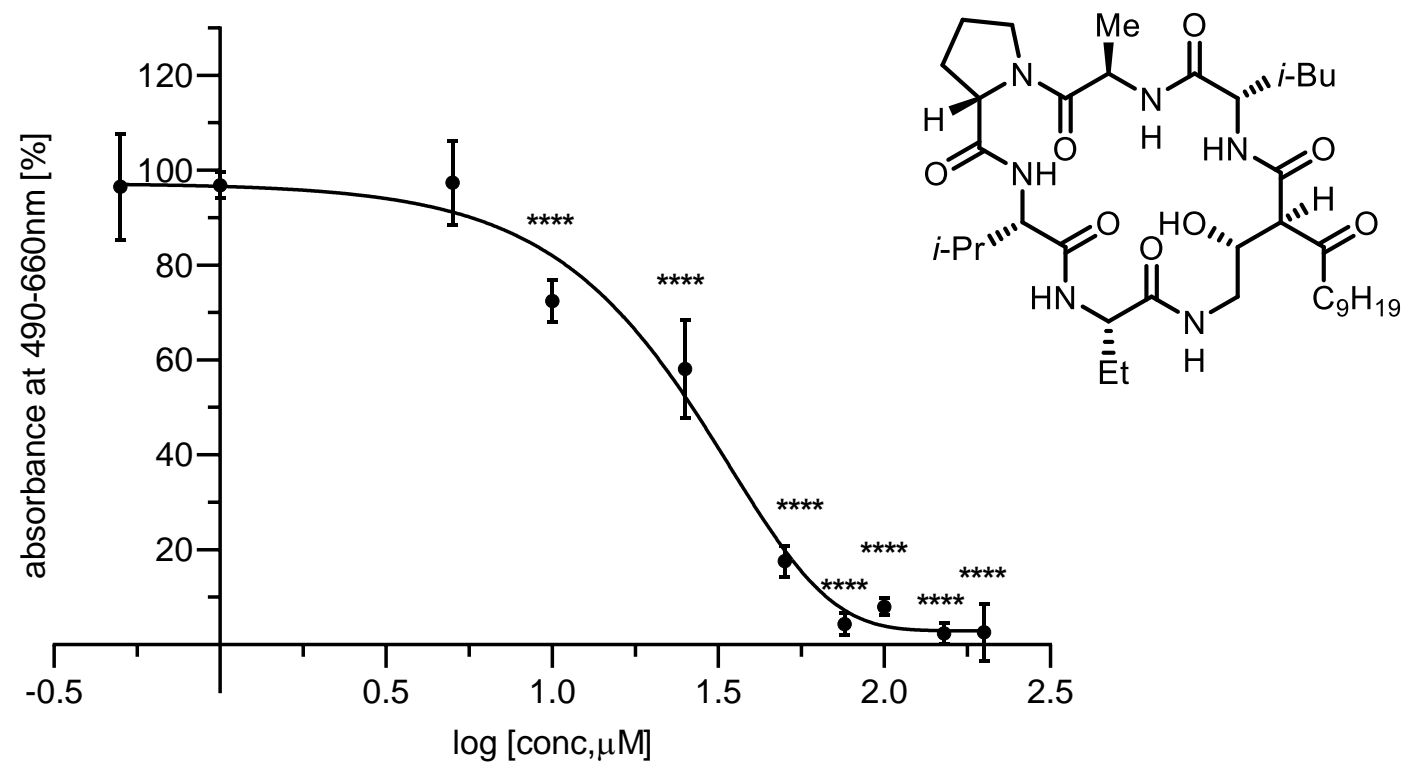

IC $_{50}: 26.39 \mu \mathrm{M}$
IC $_{50} 95 \% \mathrm{Cl}: 18.8-37.03 \mu \mathrm{M}$
R squared: 0.9881

b)

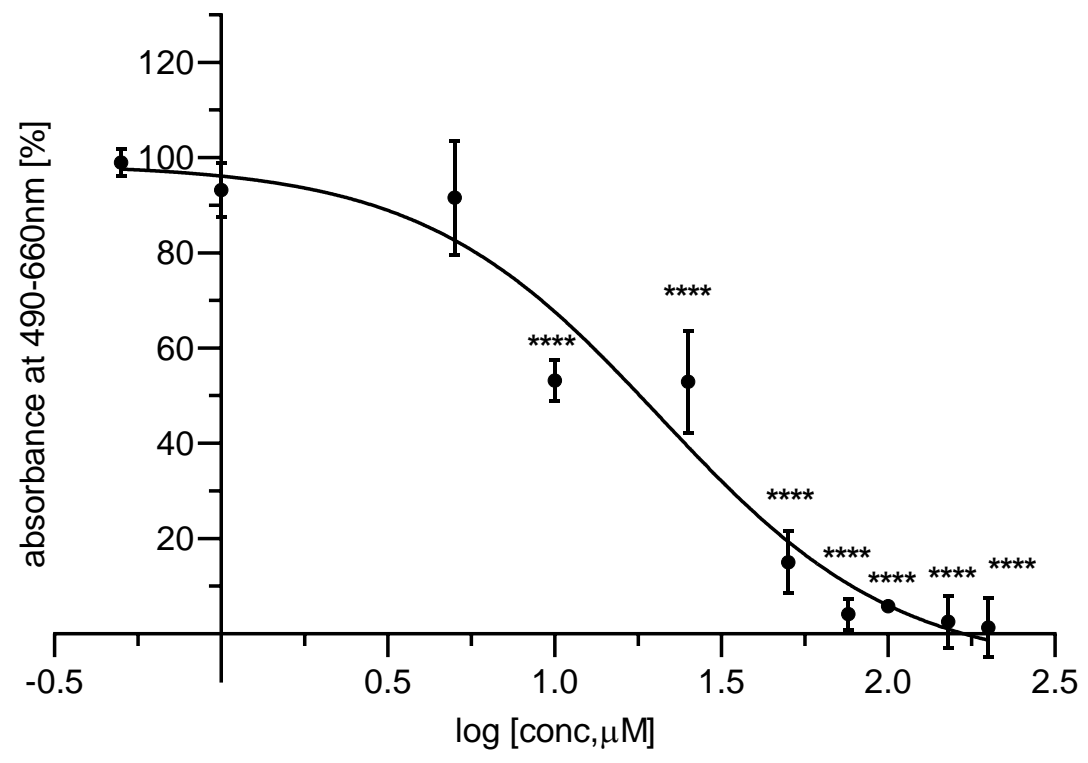

$\mathrm{IC}_{50}: 20.69 \mu \mathrm{M}$

$\mathrm{IC}_{50} 95 \% \mathrm{Cl}: 8.92-48.0 \mu \mathrm{M}$

R squared: 0.9637

Figure 32. Normalized (to solvent control) absorbance (490-660nm) displayed as a function of concentration of mutanobactin D (grouped by concentration), experiment 1 (a) and 2 (b). Strain: ATCC 90028. 
a)

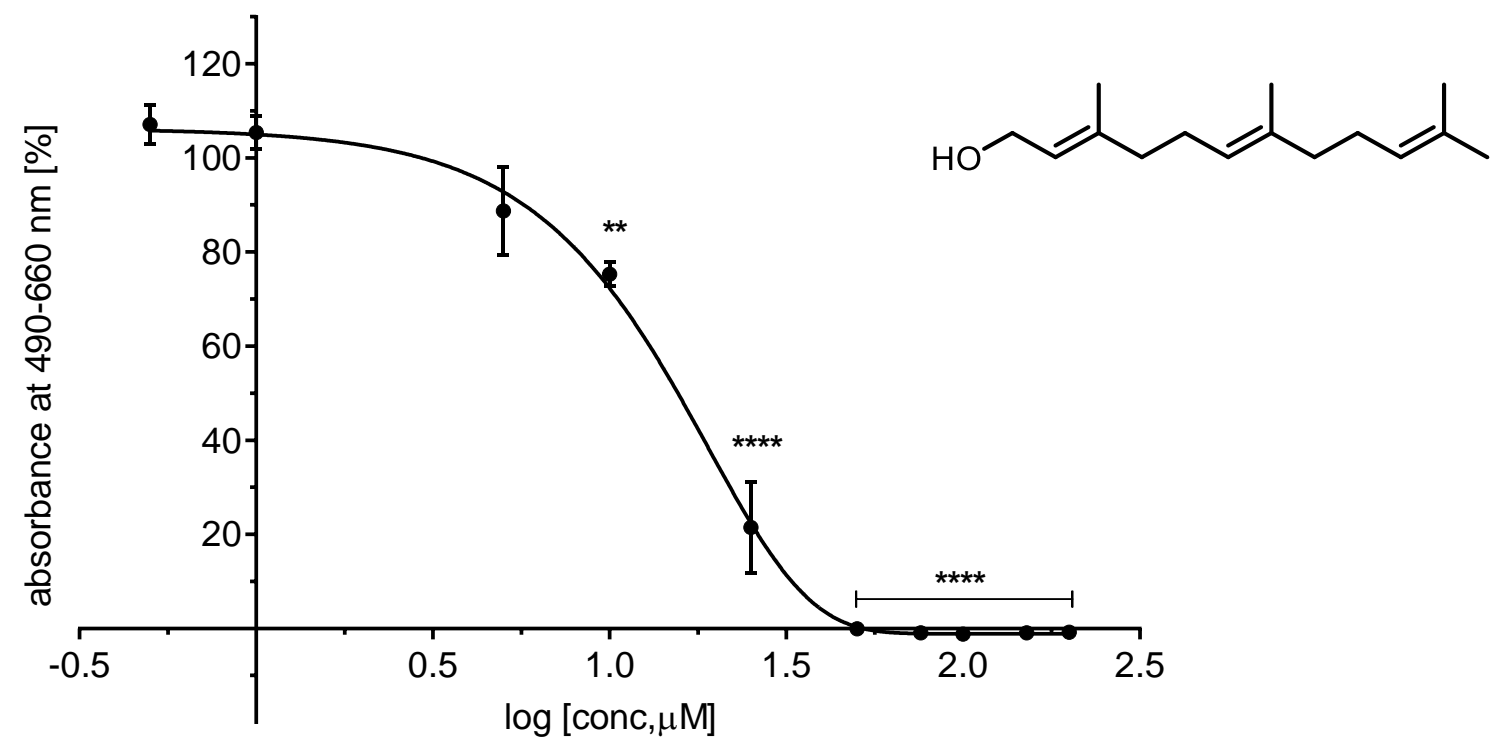

$I_{50}: 14.91 \mu \mathrm{M}$
$I_{50} 95 \% \mathrm{Cl}: 13.32-16.69 \mu \mathrm{M}$
R squared: 0.9987

b)

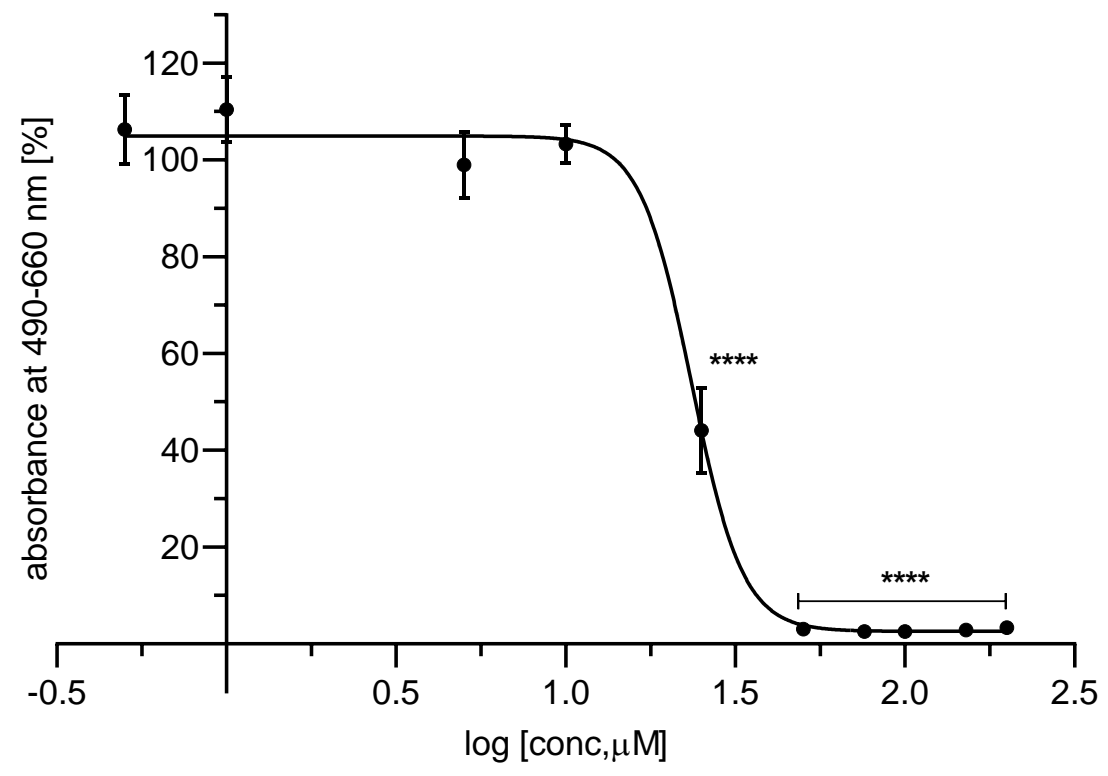

$I_{50}: 23.5 \mu \mathrm{M}$
$I_{50} 95 \% \mathrm{Cl}: 20.92-26.4 \mu \mathrm{M}$
$\mathrm{R}$ squared: 0.9970

Figure 33. Normalized (to solvent control) absorbance (490-660nm) displayed as a function of concentration of farnesol (grouped by concentration), experiment 1 (a) and 2 (b). Strain: ATCC 90028. 


\section{Strain: SC5314}

a)

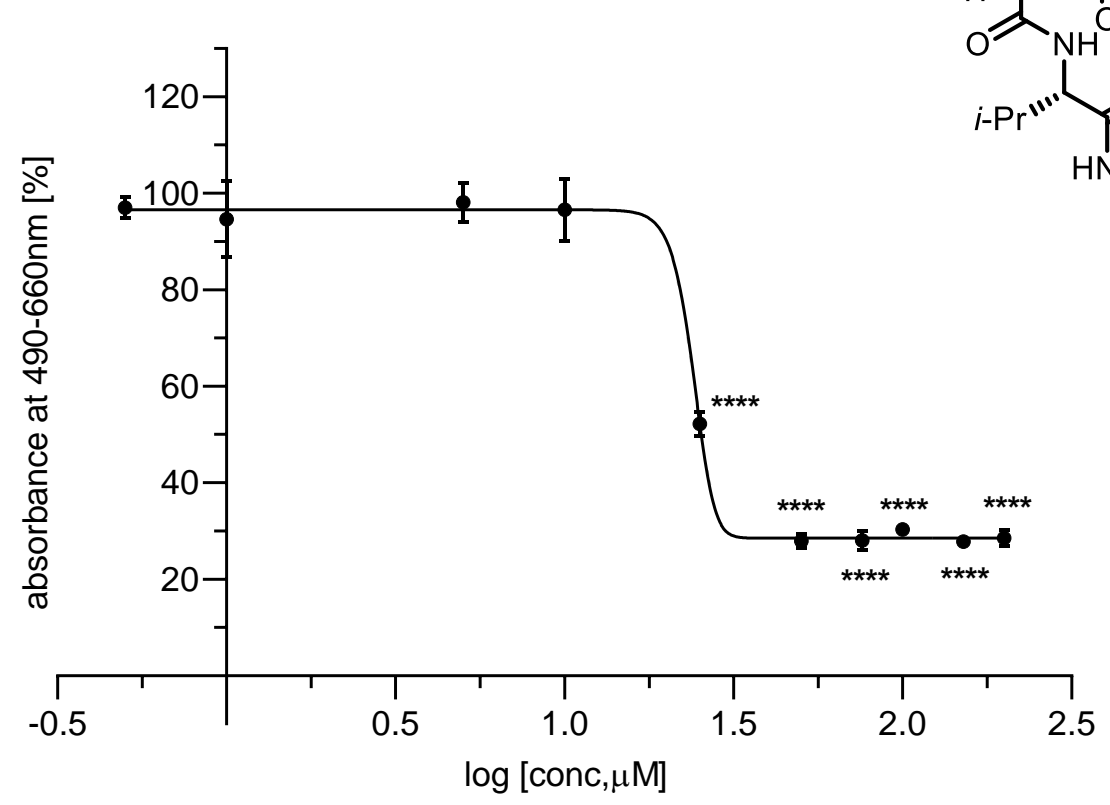

$\mathrm{IC}_{50}: 24.03 \mu \mathrm{M}$

$\mathrm{IC}_{50} 95 \% \mathrm{Cl}$ : very wide

R squared: 0.999

b)

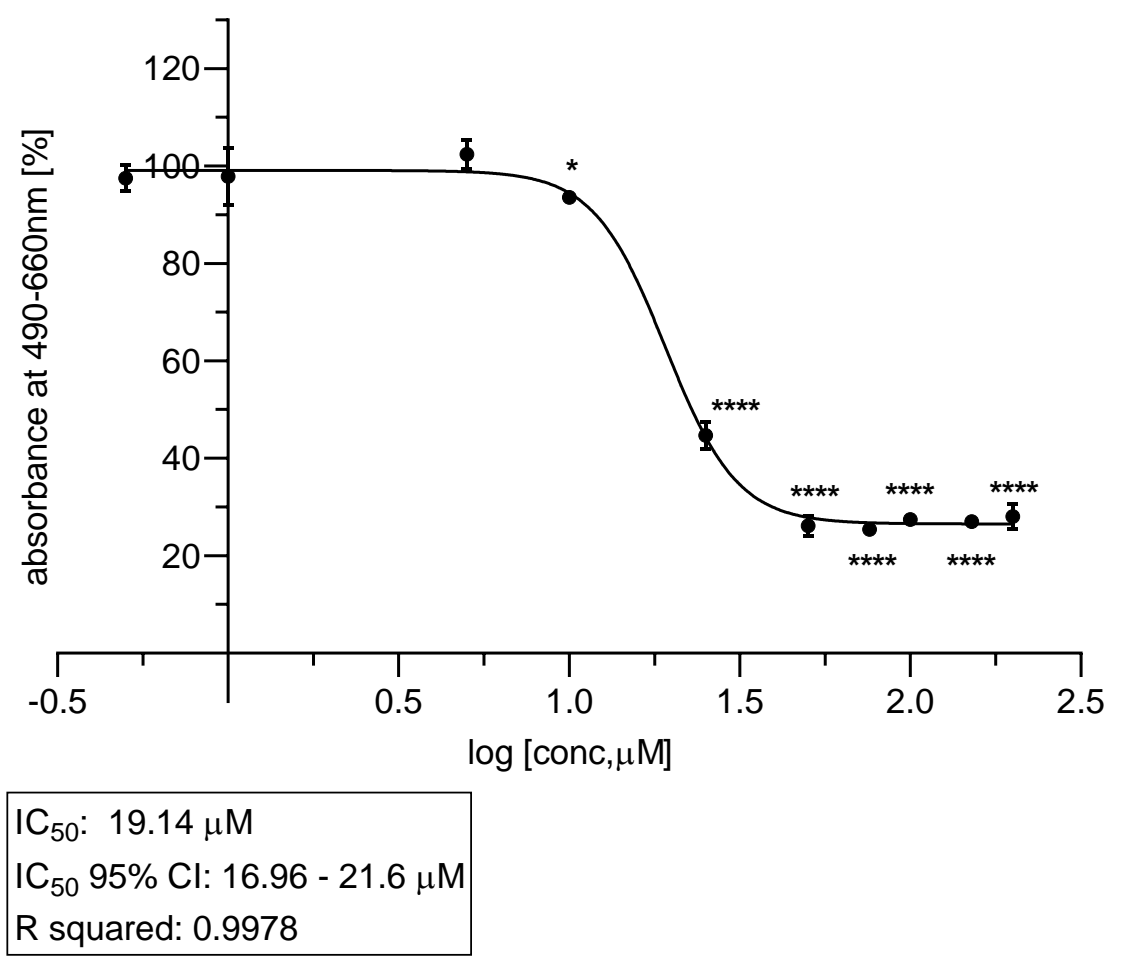

Figure 34. Normalized (to solvent control) absorbance (490-660nm) displayed as a function of concentration of mutanobactin D (grouped by concentration), experiment 1 (a) and 2 (b). Strain: SC5314. 


\section{Strain: 101}

a)

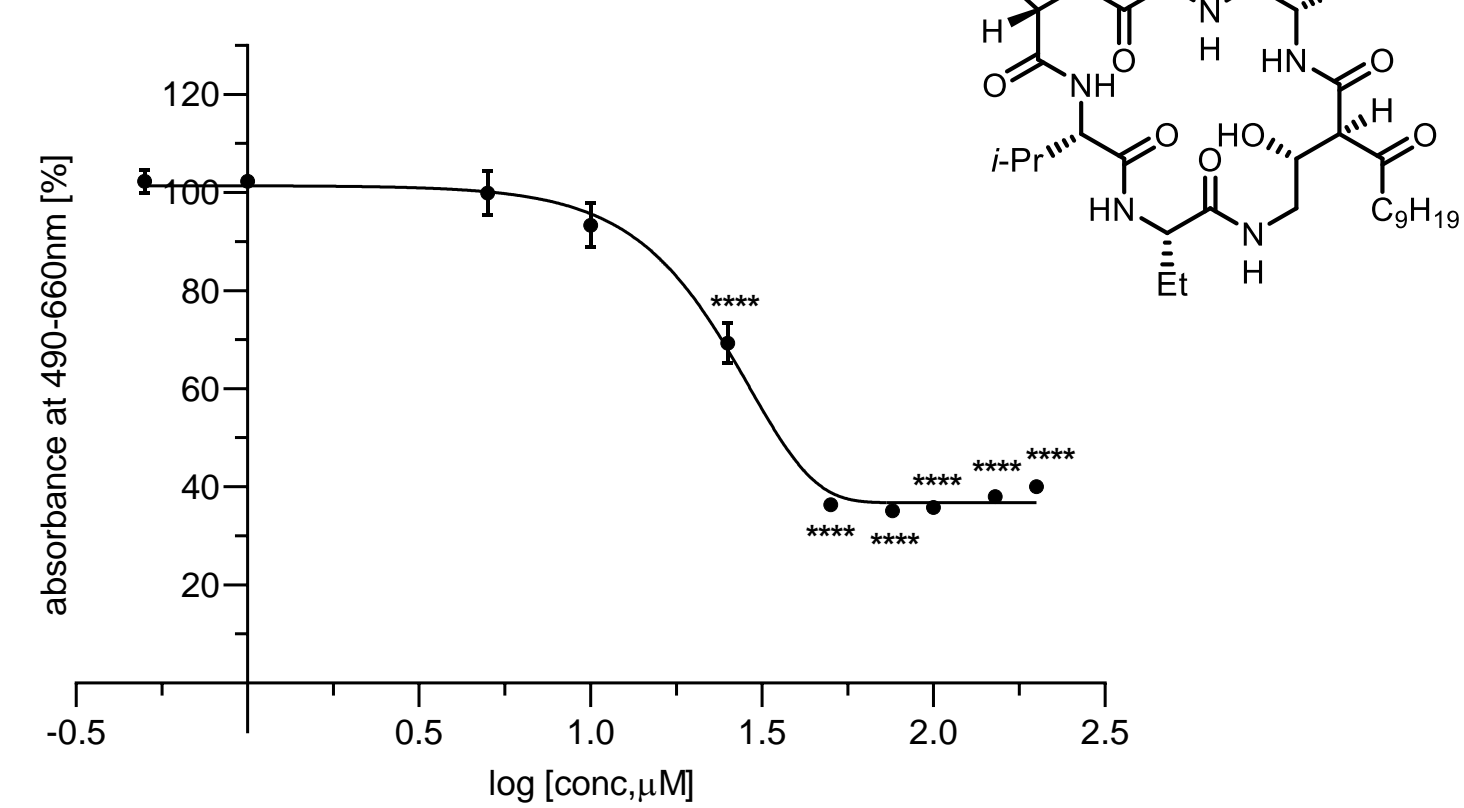

b)

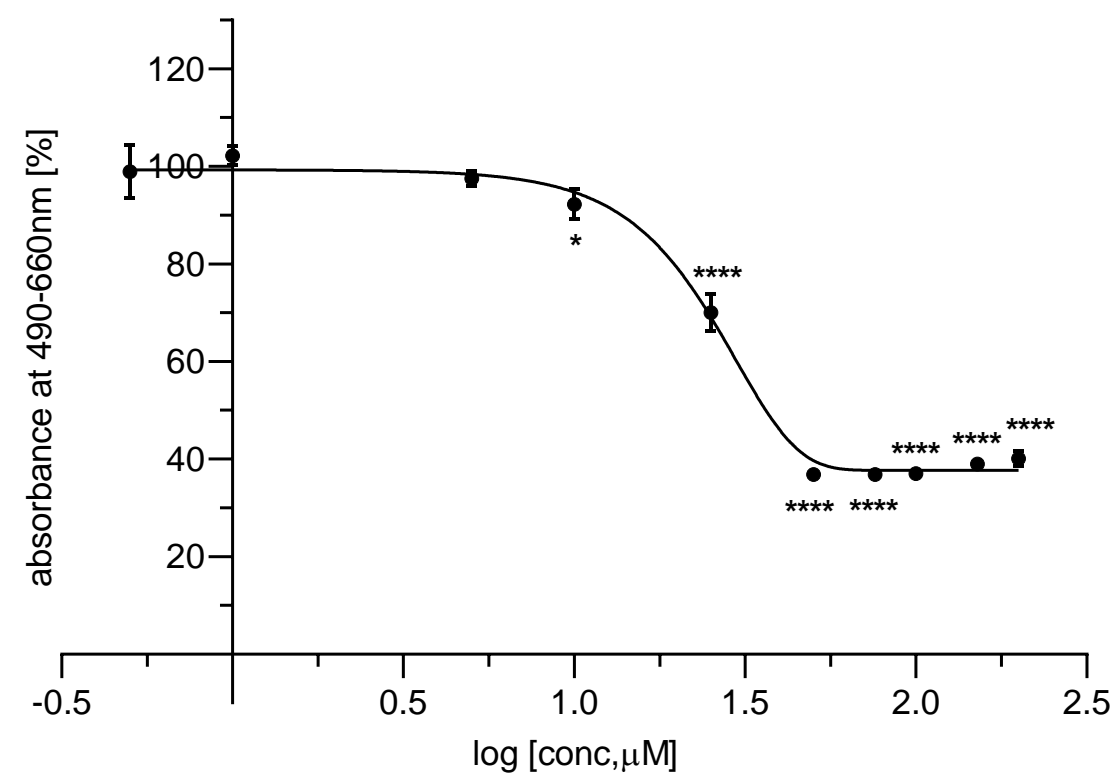

$I_{50}: 24.99 \mu \mathrm{M}$
$I_{50} 95 \% \mathrm{Cl}: 21.64-28.87 \mu \mathrm{M}$
R squared: 0.9958

Figure 35. Normalized (to solvent control) absorbance (490-660nm) displayed as a function of concentration of mutanobactin D (grouped by concentration), experiment 1 (a) and 2 (b). Strain: 101. 


\subsection{Dose Response Curves for Yeast Surface Area Reduction (Membranes Only, Confocal Microscopy)}

For all figures in this sub-section, statistical analysis via ANOVA (Bonferroni's multiple comparison test). Significance: $p<0.05=* ; p<0.01=* * p<0.001=* * * ; p<0.0001=* * * *$ vs. solvent control.

\section{Strain: ATCC 90028}

a)

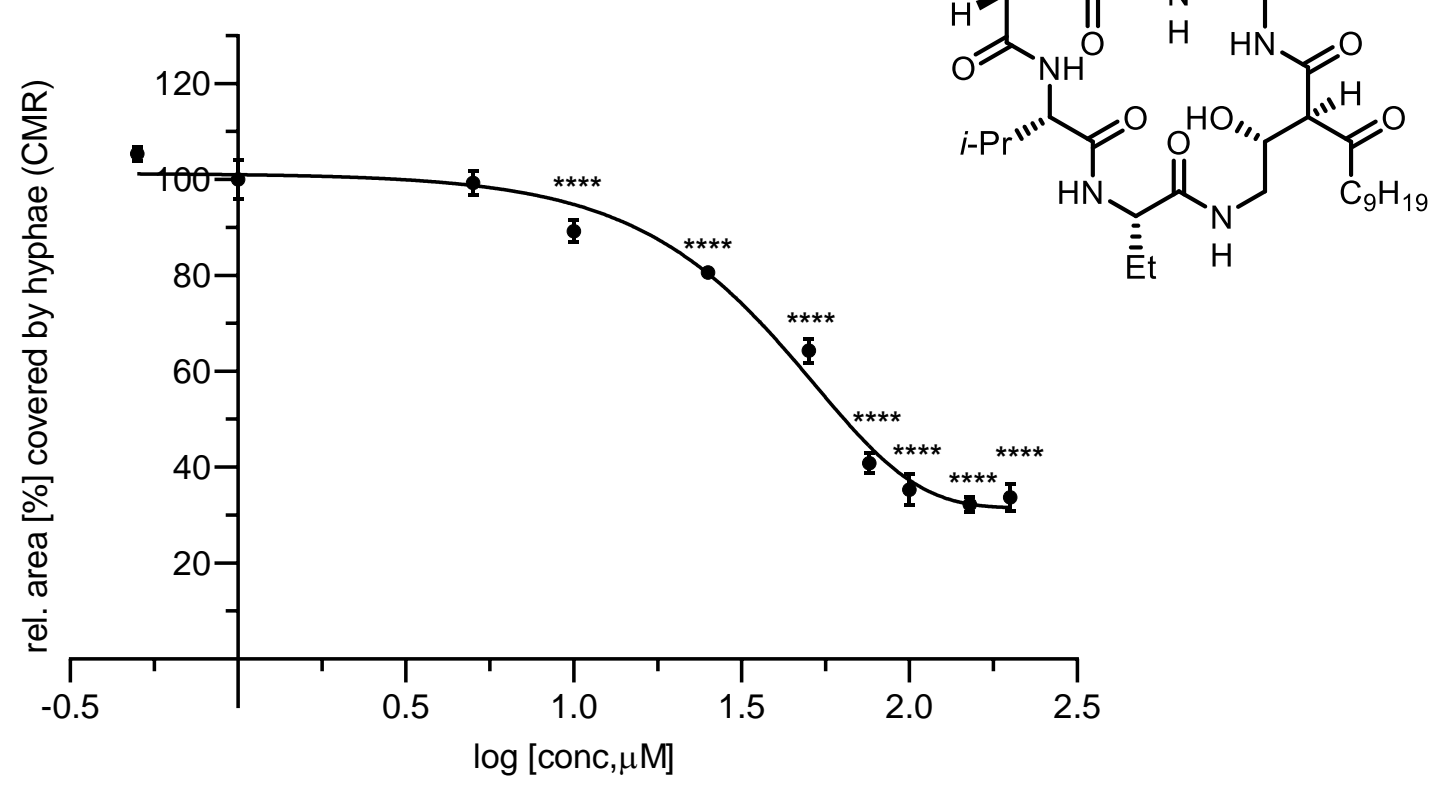

$I_{50}: 39.68 \mu \mathrm{M}$
$I_{50} 95 \% \mathrm{CI}: 28.80$ to $54.68 \mu \mathrm{M}$
R squared: 0.9876 
b)

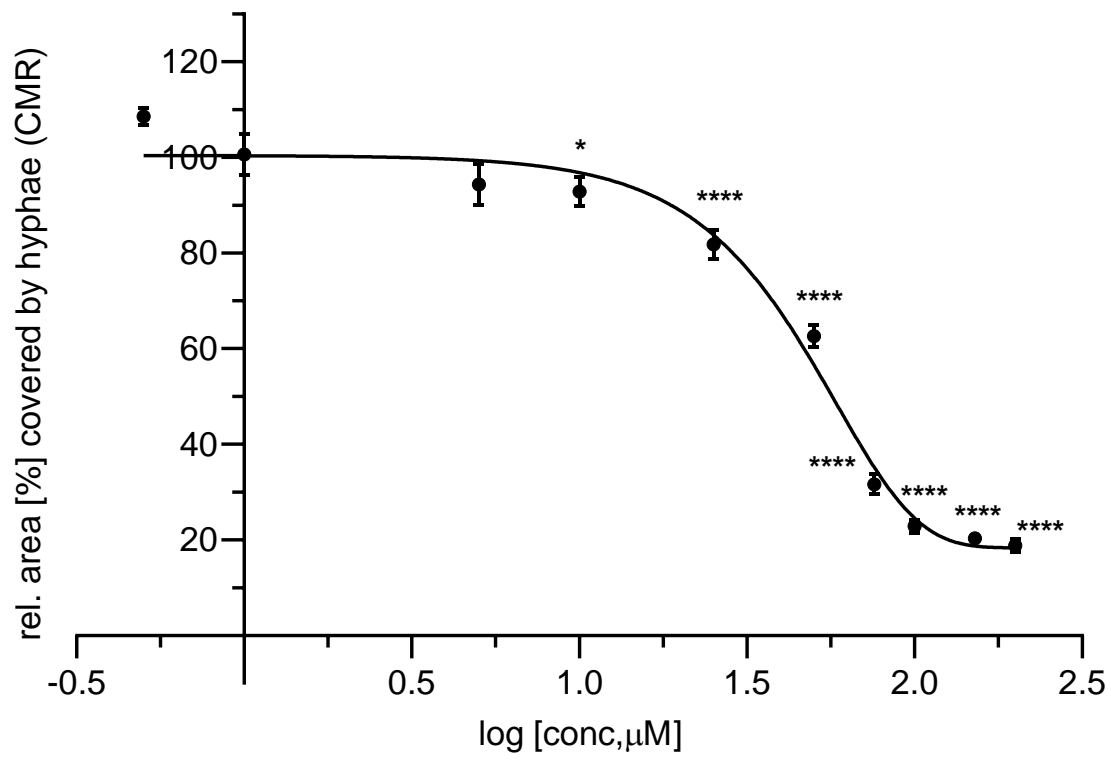

$\mathrm{IC}_{50}: 47.22 \mu \mathrm{M}$

$\mathrm{IC}_{50} 95 \% \mathrm{Cl}: 35.90$ to $62.12 \mu \mathrm{M}$

R squared: 0.9863

c)

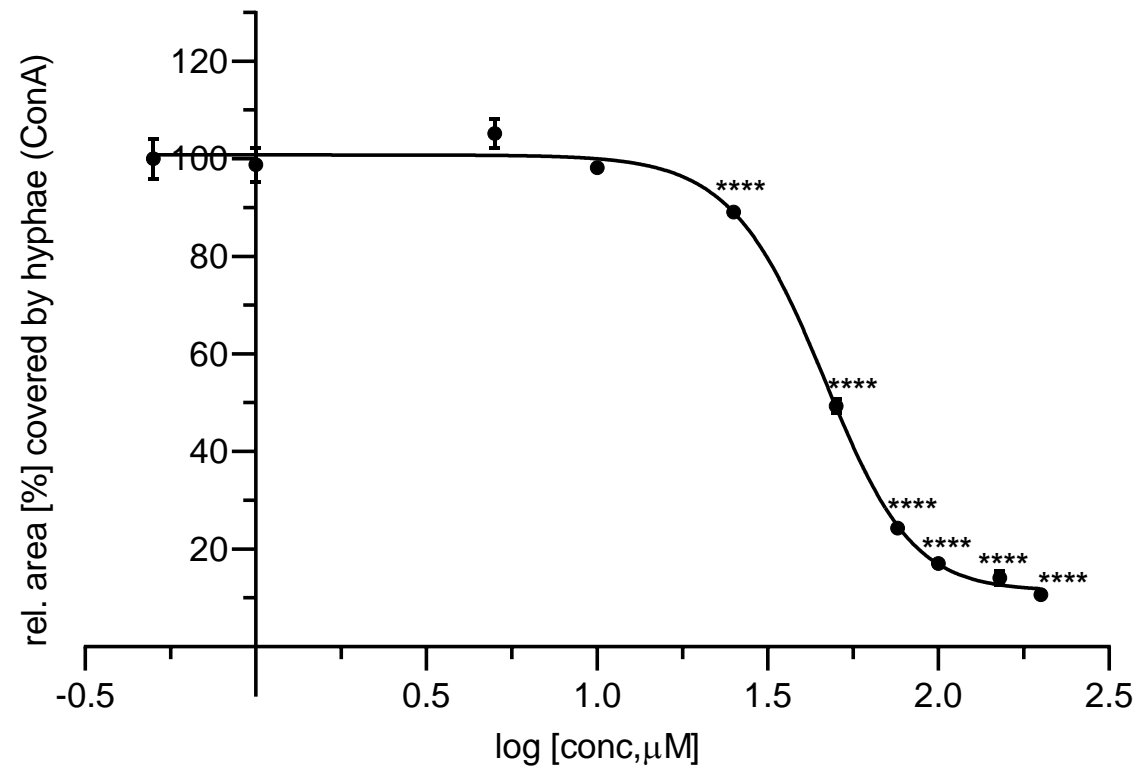

$I_{50}: 45.53 \mu \mathrm{M}$
$I_{50} 95 \% \mathrm{Cl}: 41.45$ to $50.01 \mu \mathrm{M}$
$\mathrm{R}$ squared: 0.9979

Figure 36. Area covered by Cell Mask Deep Red (CMR) or Concanavalin A (ConA) defined as hyphae $\left[\mu m^{2}\right]$ normalized to solvent control displayed as a function of concentration of mutanobactin D (grouped by dose), experiment 1 (a), 2 (b) and 3 (c). Strain: ATCC 90028. 
a)

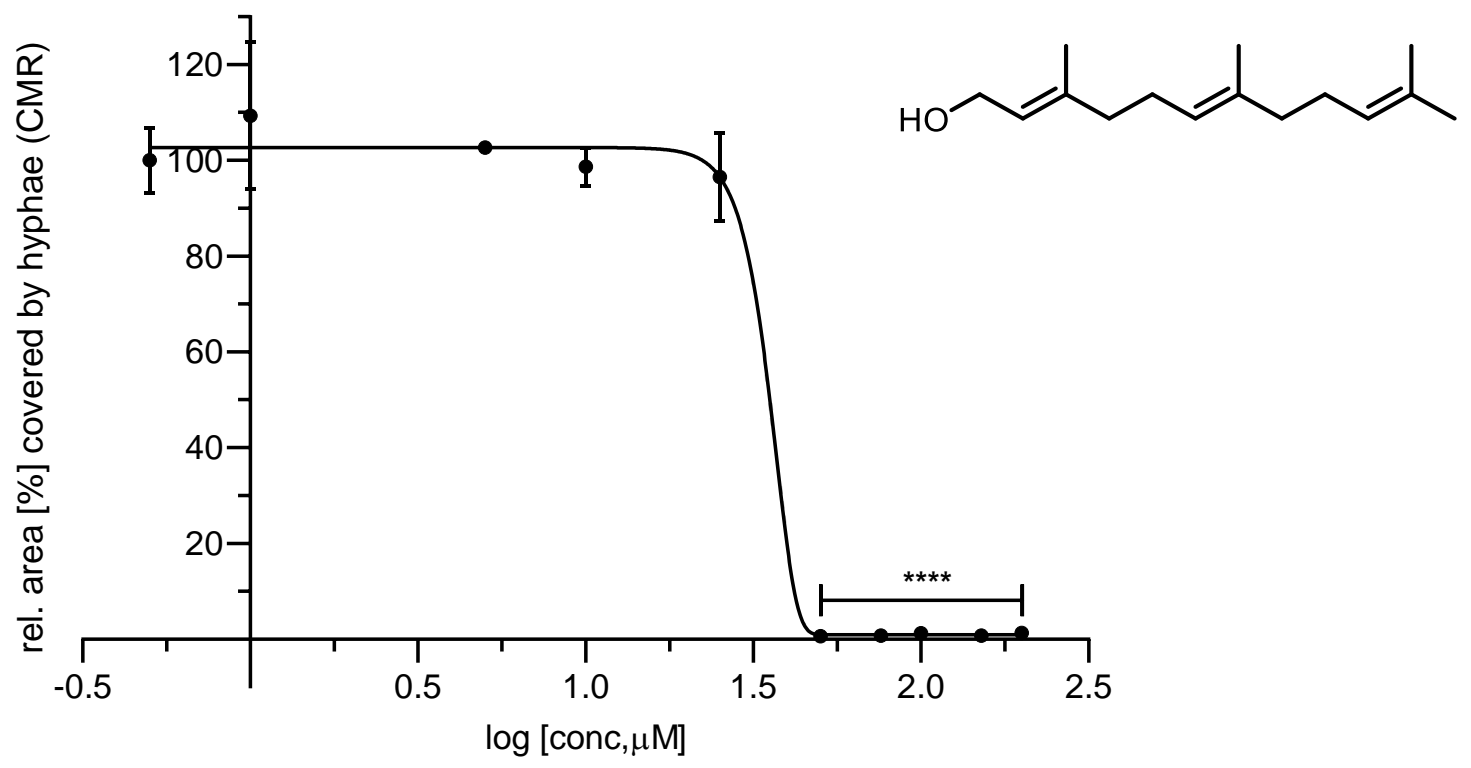

$\mathrm{IC}_{50}: 35.17 \mu \mathrm{M}$
$\mathrm{IC}_{50} 95 \% \mathrm{Cl}: 0.32$ to $3867 \mu \mathrm{M}$
$\mathrm{R}$ squared: 0.9974

b)

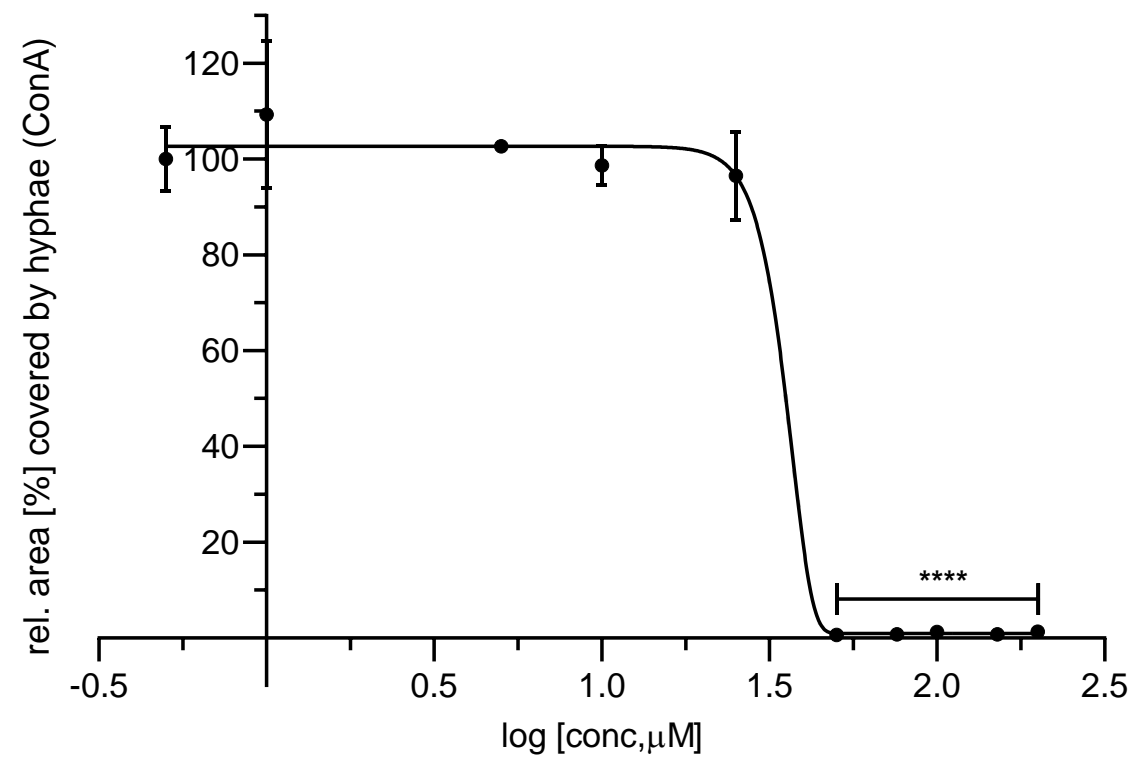

$\mathrm{IC}_{50}: 35.17 \mu \mathrm{M}$

$I_{50} 95 \% \mathrm{Cl}: 0.32$ to $3867 \mu \mathrm{M}$

R squared: 0.9974

Figure 37. Area covered by Cell Mask Deep Red or Concanavalin A (ConA) defined as hyphae $\left[\mu \mathrm{m}^{2}\right]$ normalized to solvent control displayed as a function of concentration of farnesol (grouped by dose), experiment 1 (a) and 2 (b). Strain: ATCC 90028. 


\section{Strain: SC5314}

a)

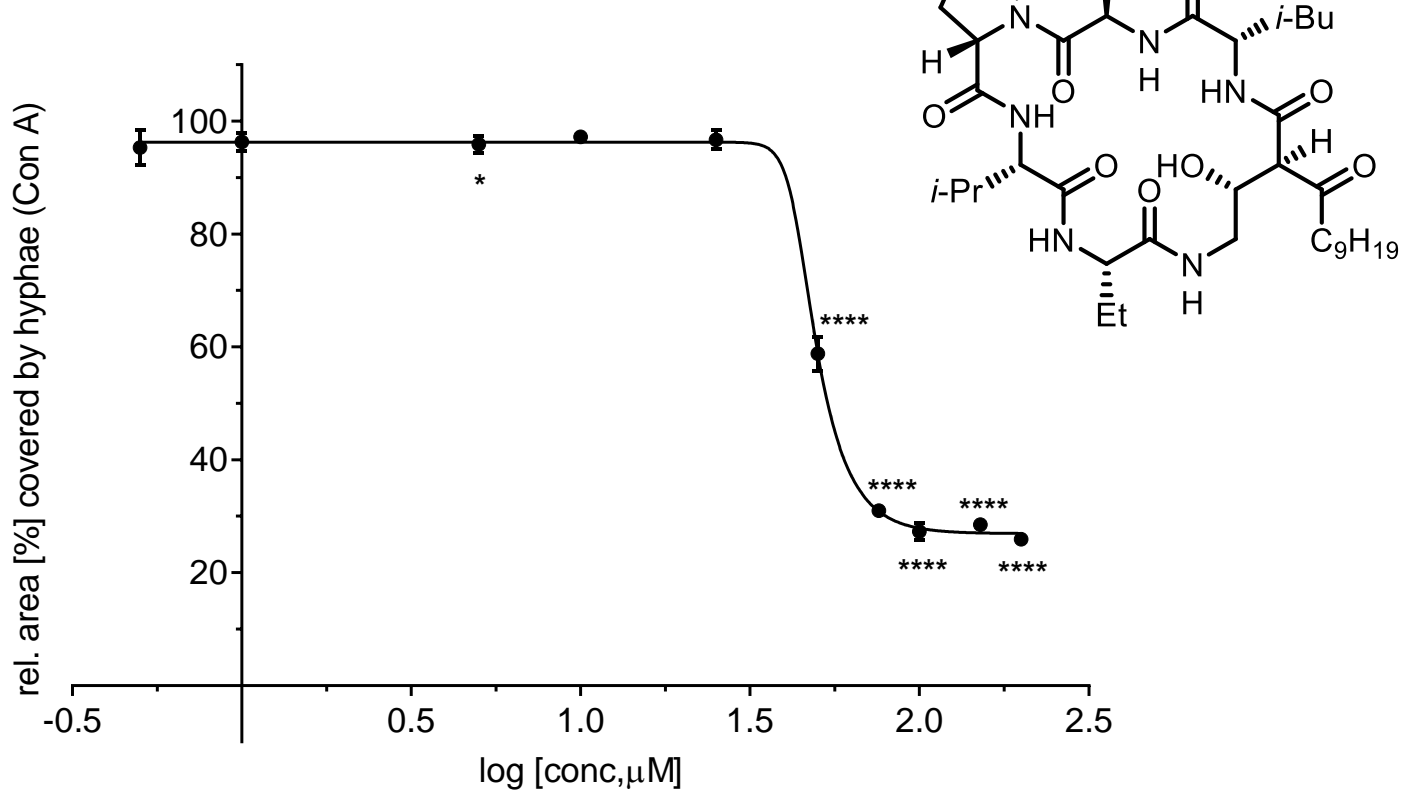

$\mathrm{IC}_{50}: 49.21 \mu \mathrm{M}$
$\mathrm{IC}_{50} 95 \% \mathrm{Cl}: 41.36$ to $58.54 \mu \mathrm{M}$
$\mathrm{R}$ squared: 0.9994

b)

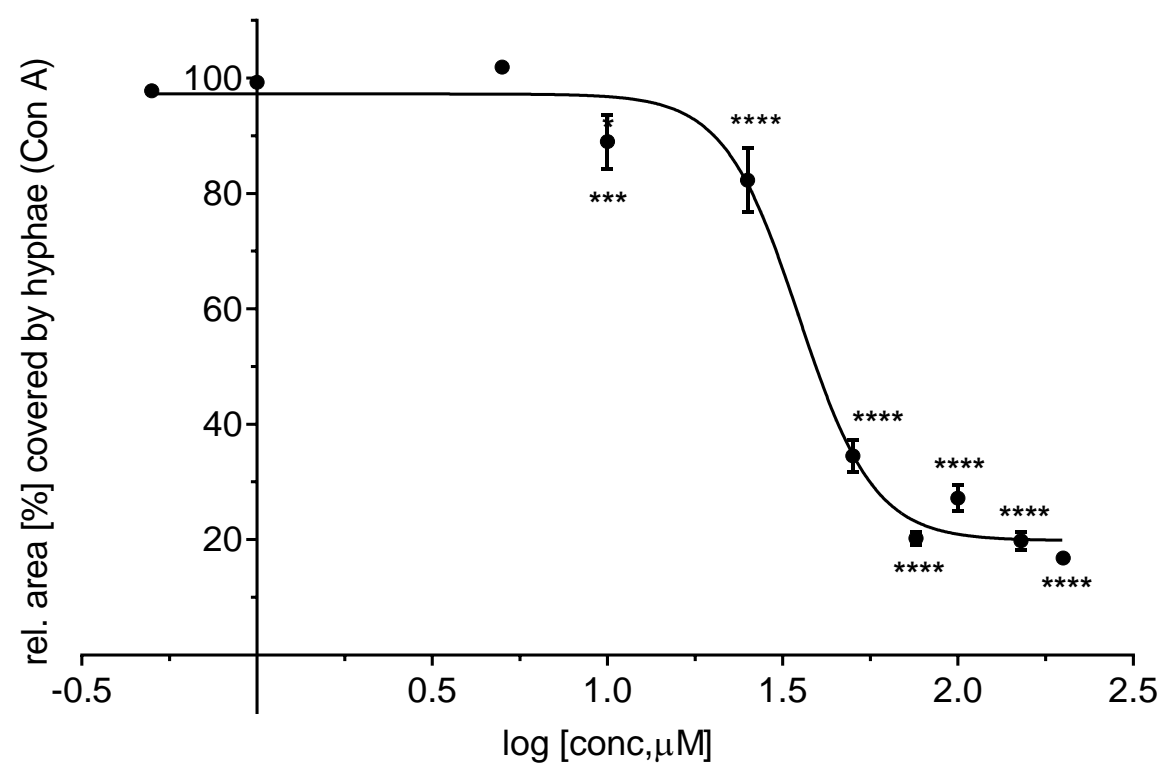

$\mathrm{IC}_{50}: 35.21 \mu \mathrm{M}$

$\mathrm{IC}_{50} 95 \% \mathrm{CI}: 28.86$ to $42.96 \mu \mathrm{M}$

R squared: 0.9887

Figure 38. Area covered by Cell Mask Deep Red (CMR) or Concanavalin A (ConA) defined as hyphae $\left[\mu \mathrm{m}^{2}\right]$ normalized to solvent control displayed as a function of concentration of mutanobactin D (grouped by dose), experiment 1 (a) and 2 (b). Strain: SC5314. 


\section{Strain: 101}

a)

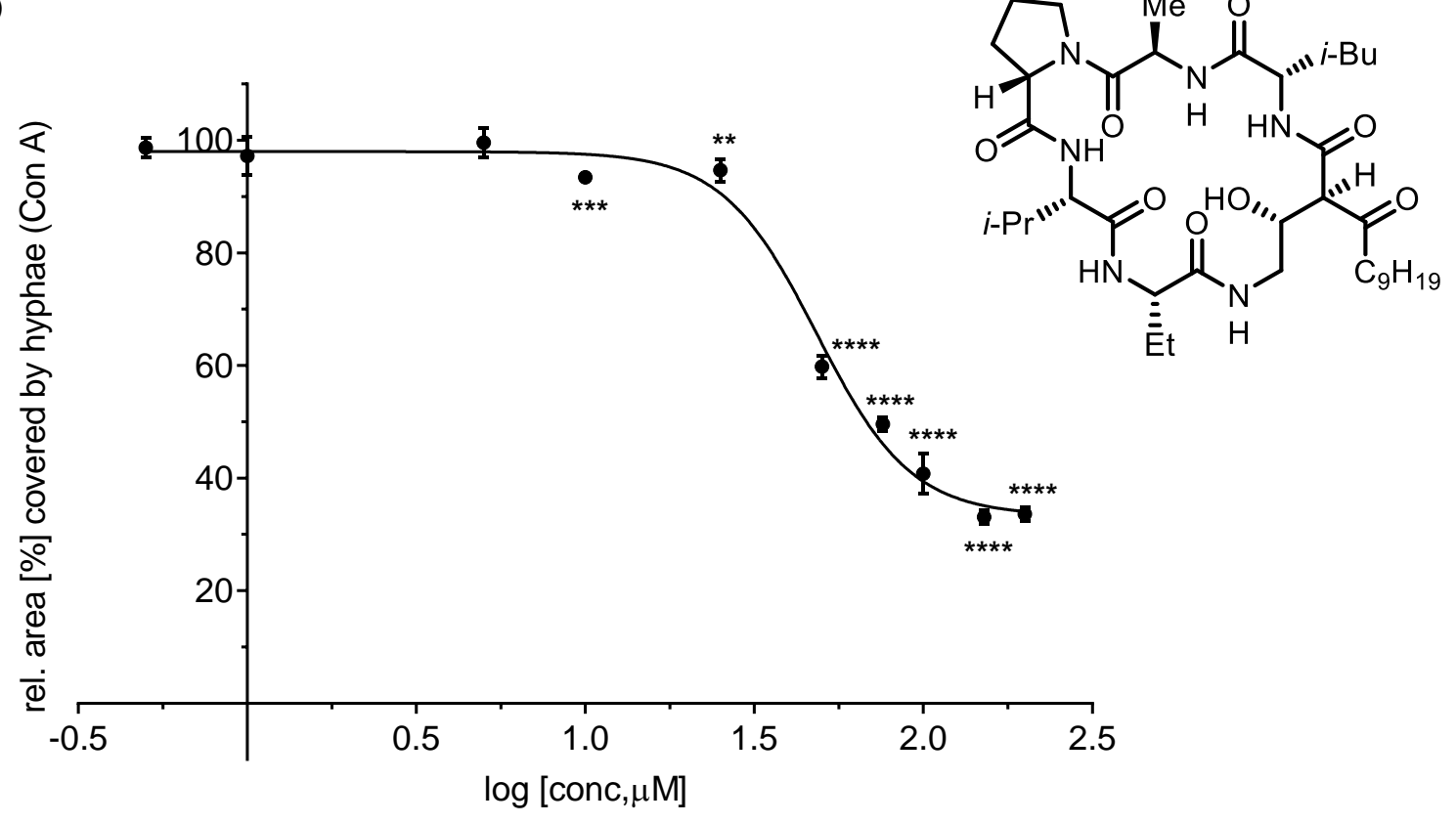

$I_{50}: 48.37 \mu \mathrm{M}$
$I_{50} 95 \% \mathrm{Cl}: 40.57$ to $57.68 \mu \mathrm{M}$
R squared: 0.9905 
b)

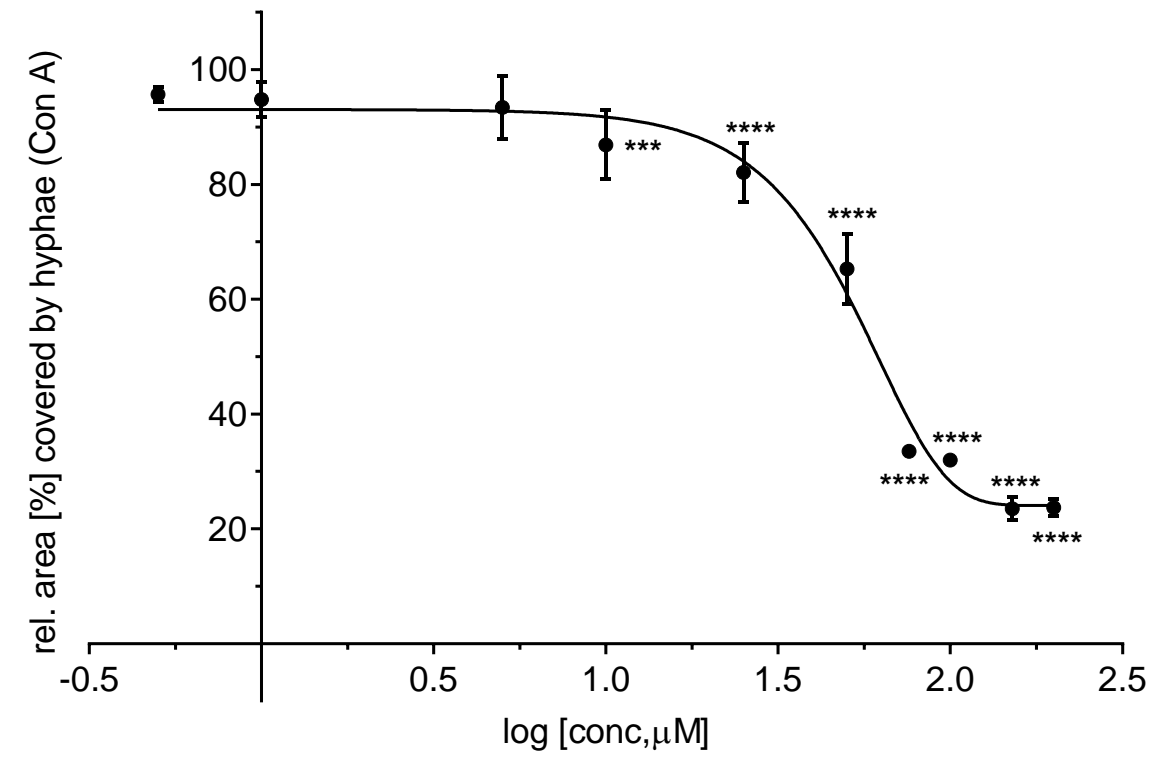

$\mathrm{IC}_{50}: 52.55 \mu \mathrm{M}$

$\mathrm{IC}_{50} 95 \% \mathrm{Cl}: 42.66$ to $64.74 \mu \mathrm{M}$

R squared: 0.9887

c)

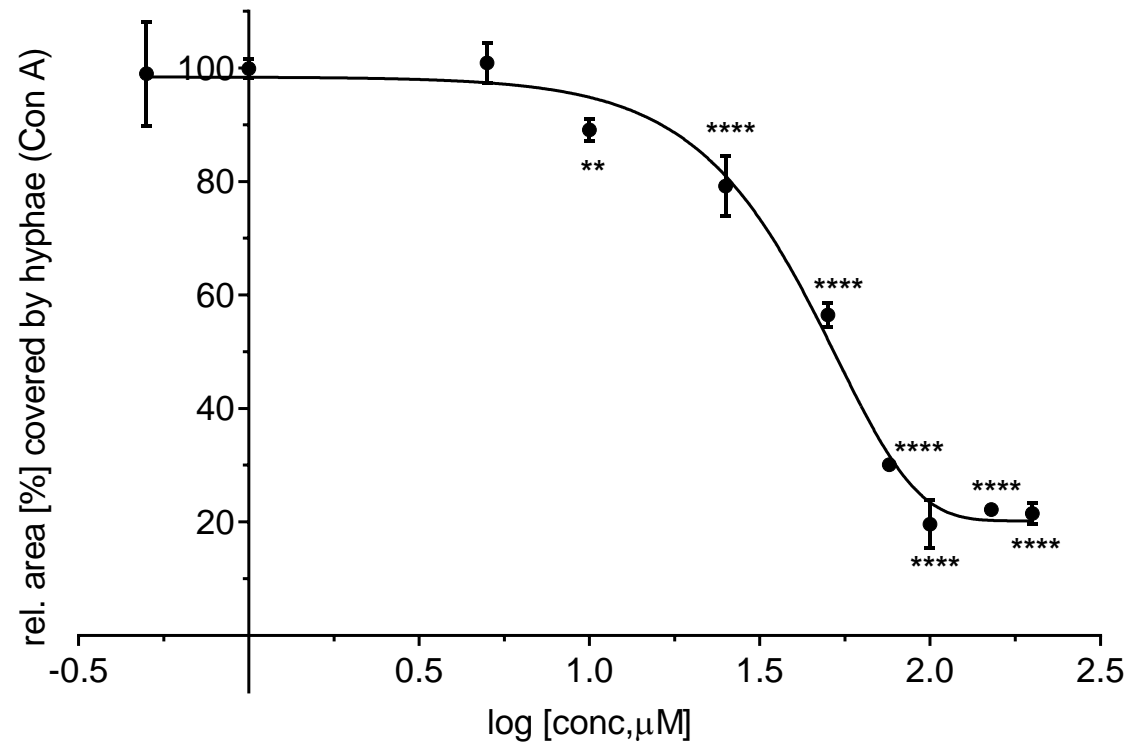

$\mathrm{IC}_{50}: 43.14 \mu \mathrm{M}$

$\mathrm{IC}_{50} 95 \% \mathrm{Cl}: 34.84$ to $53.41 \mu \mathrm{M}$

R squared: 0.9918

Figure 39. Area covered by Cell Mask Deep Red (CMR) or Concanavalin A (ConA) defined as hyphae $\left[\mu \mathrm{m}^{2}\right]$ normalized to solvent control displayed as a function of concentration of mutanobactin D (grouped by dose), experiment 1 (a), 2 (b) and 3 (c). Strain: 101 . 
10.6 Dose Response Curves for Yeast Surface Area Reduction (Membranes and Nuclei, Confocal Microscopy)

\section{Strain: ATCC 90028}

a)

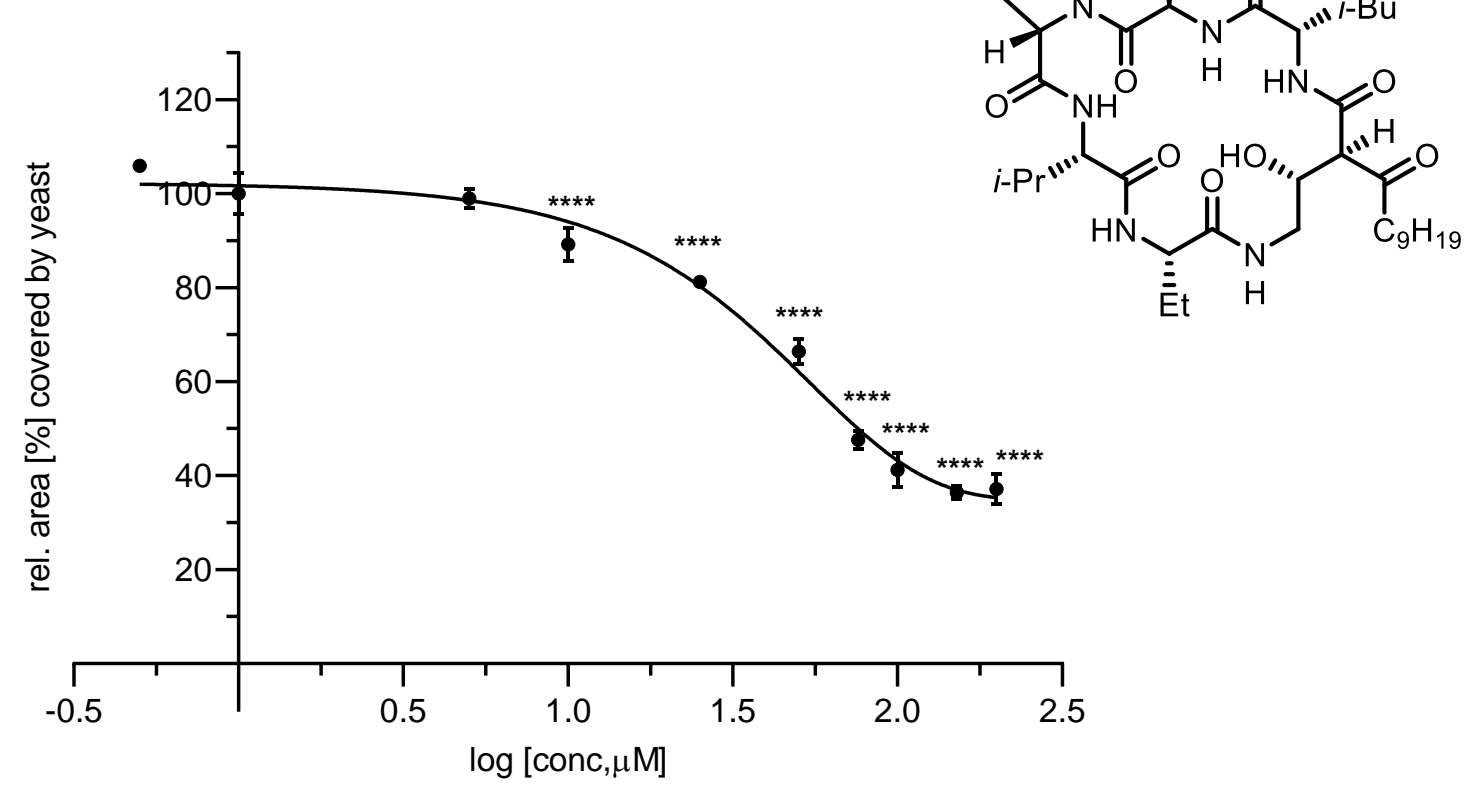

IC $_{50}: 40.17 \mu \mathrm{M}$
IC $_{50} 95 \%$ CI: 28.86 to $55.91 \mu \mathrm{M}$
R squared: 0.9895

b)

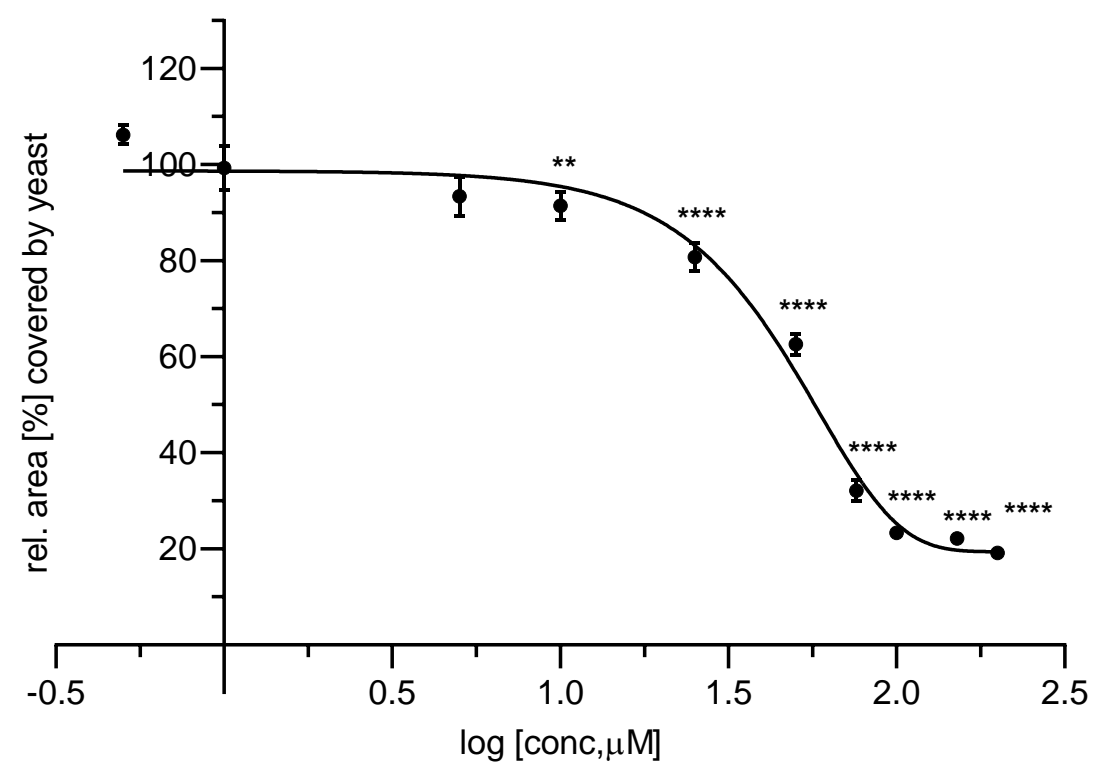

$I_{50}: 47.84 \mu \mathrm{M}$

$\mathrm{IC}_{50} 95 \% \mathrm{Cl}: 35.57$ to $62.58 \mu \mathrm{M}$

R squared: 0.9864 
c)

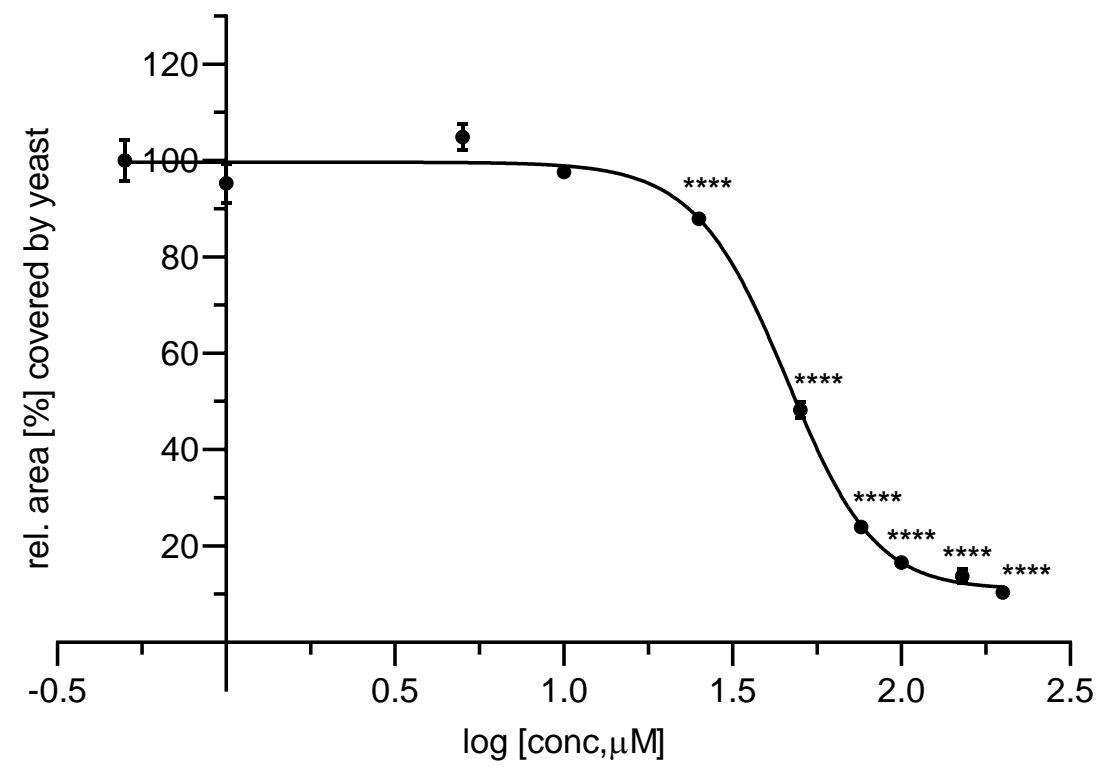

$I_{50}: 45.29 \mu \mathrm{M}$
$I_{50} 95 \% \mathrm{Cl}: 40.08$ to $51.17 \mu \mathrm{M}$
R squared: 0.9965

Figure 40. Area covered by Hoechst 33342 and Cell Mask Deep Red/Concanavalin A defined as yeast $\left[\mu \mathrm{m}^{2}\right]$ normalized to solvent control displayed as a function of concentration of mutanobactin D (grouped by dose), experiment 1 (a), 2 (b) and 3 (c). Strain: ATCC 90028. 
a)

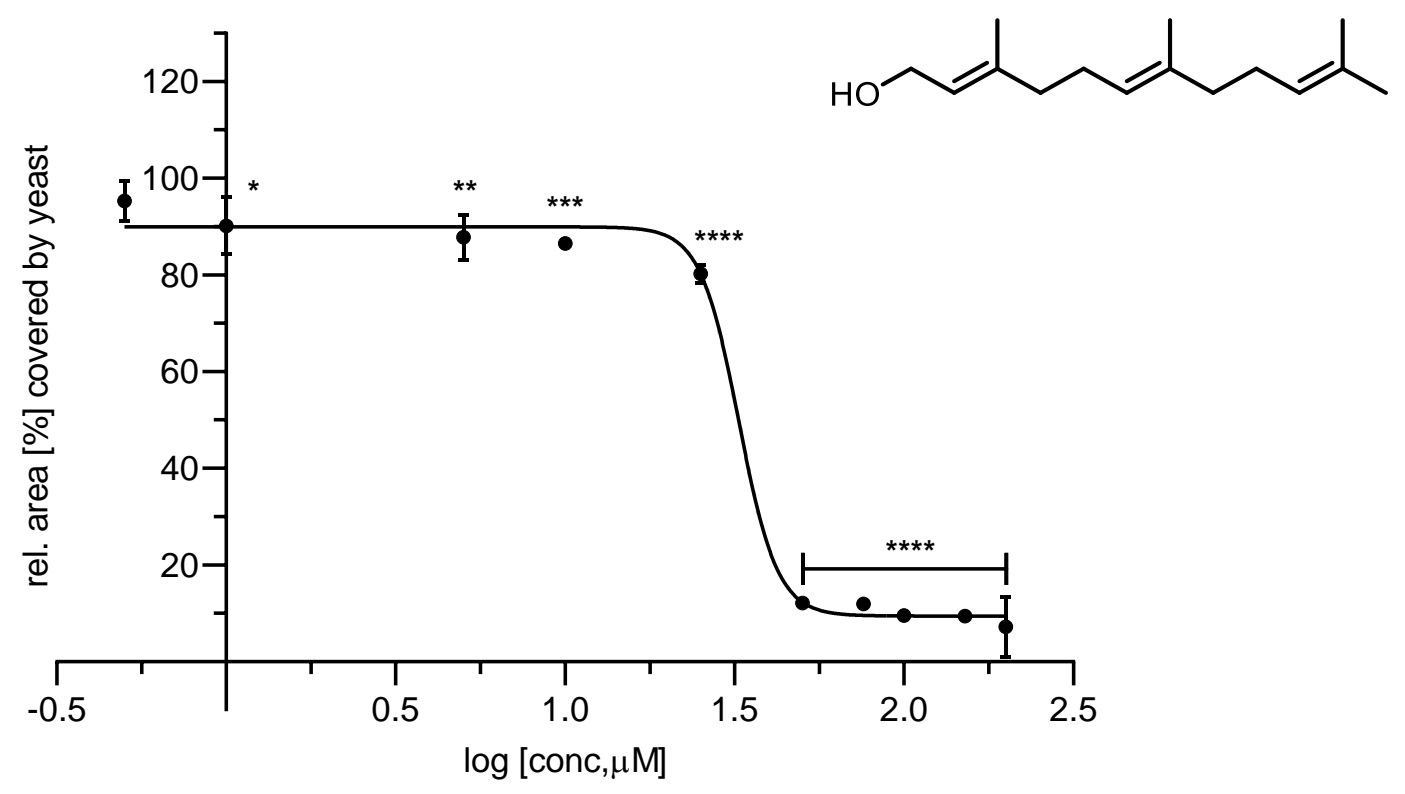

$\mathrm{IC}_{50}: 32.55 \mu \mathrm{M}$

$\mathrm{IC}_{50} 95 \% \mathrm{Cl}: 27.45$ to $38.6 \mu \mathrm{M}$

R squared: 0.9964

b)

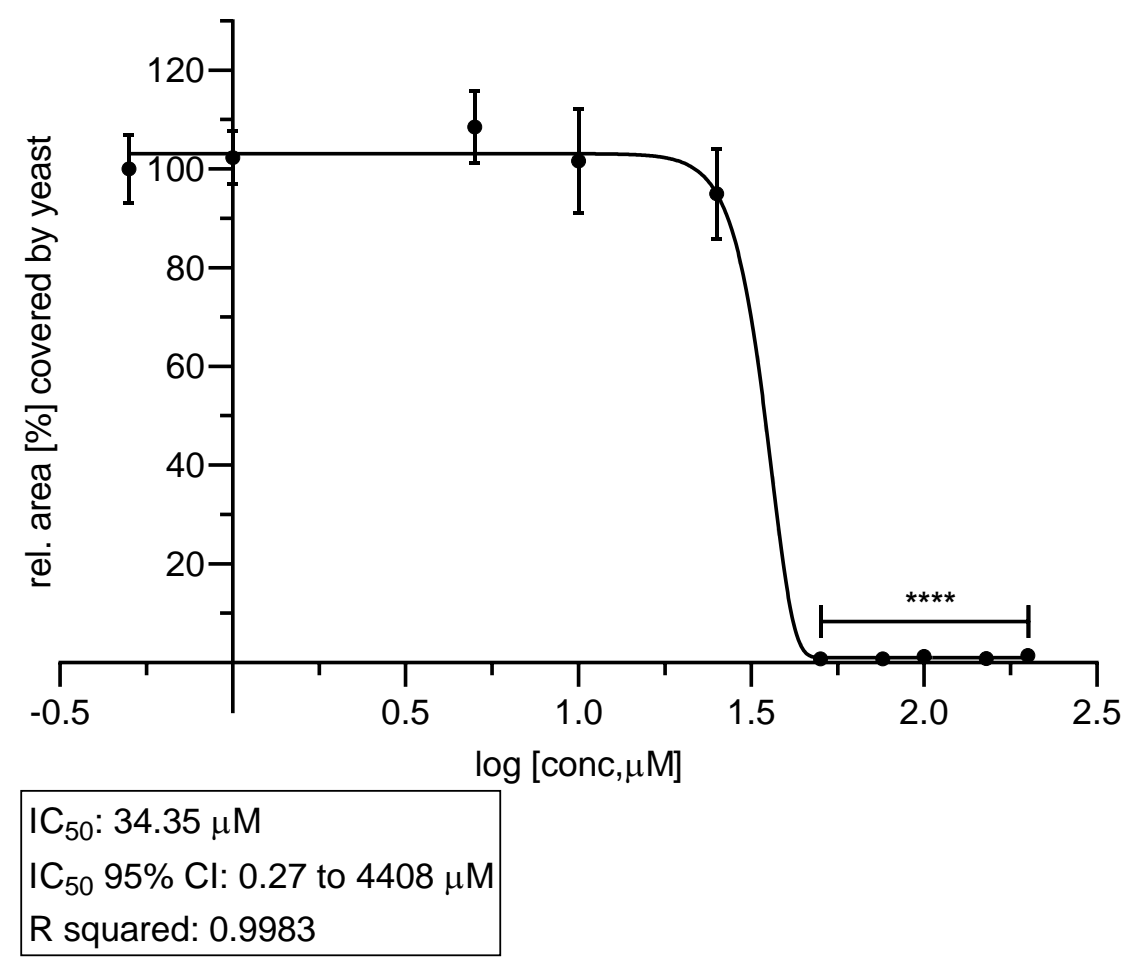

Figure 41. Area covered by Hoechst 33342 and Cell Mask Deep Red/Concanavalin A defined as yeast $\left[\mu \mathrm{m}^{2}\right]$ normalized to solvent control displayed as a function of concentration of farnesol (grouped by dose), experiment 1 (a) and 2 (b). Strain: ATCC 90028. 


\section{Strain: SC5314}

a)

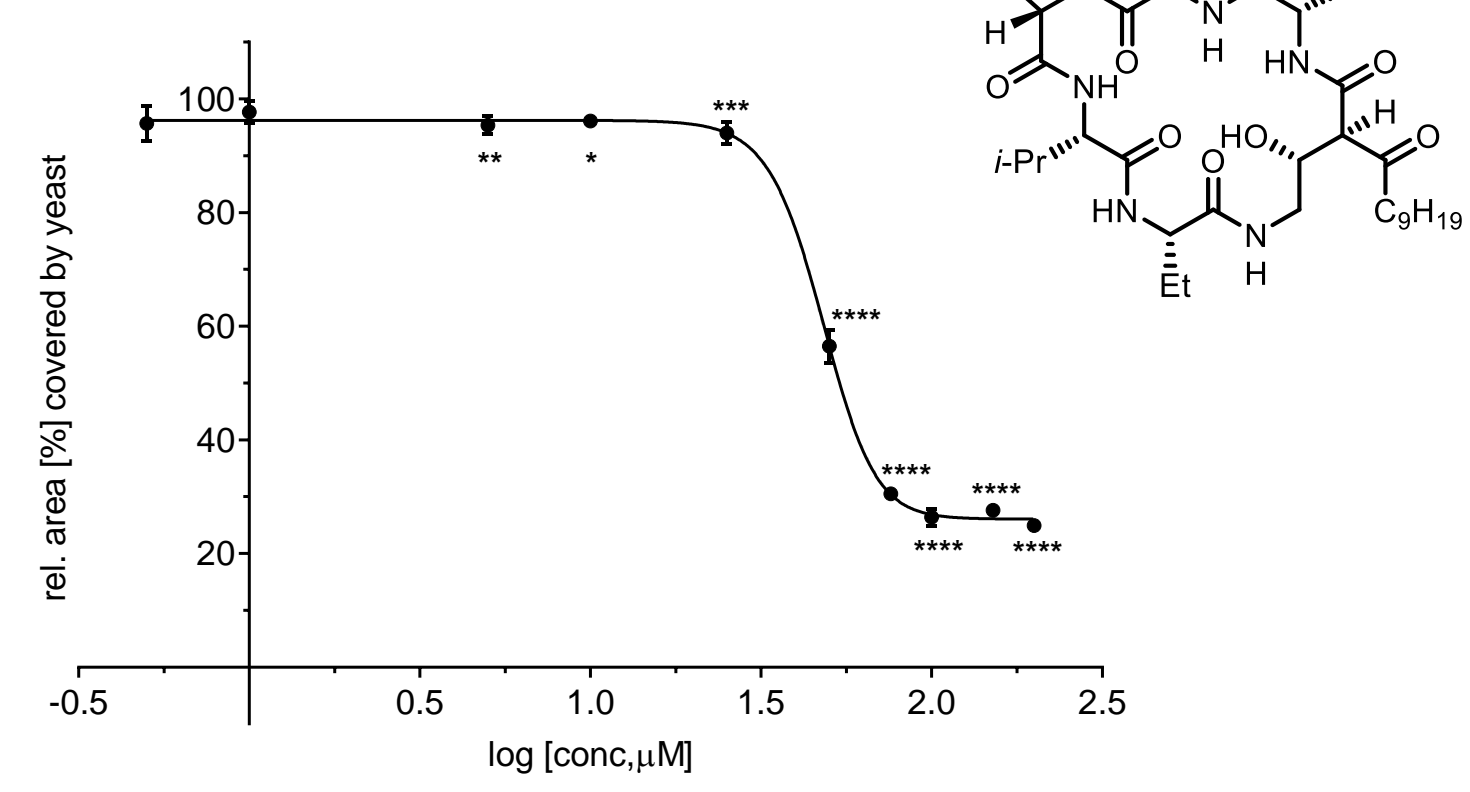

$I_{50}: 47.78 \mu \mathrm{M}$
$I_{50} 95 \% \mathrm{Cl}: 46.06$ to $49.57 \mu \mathrm{M}$
R squared: 0.9993

b)

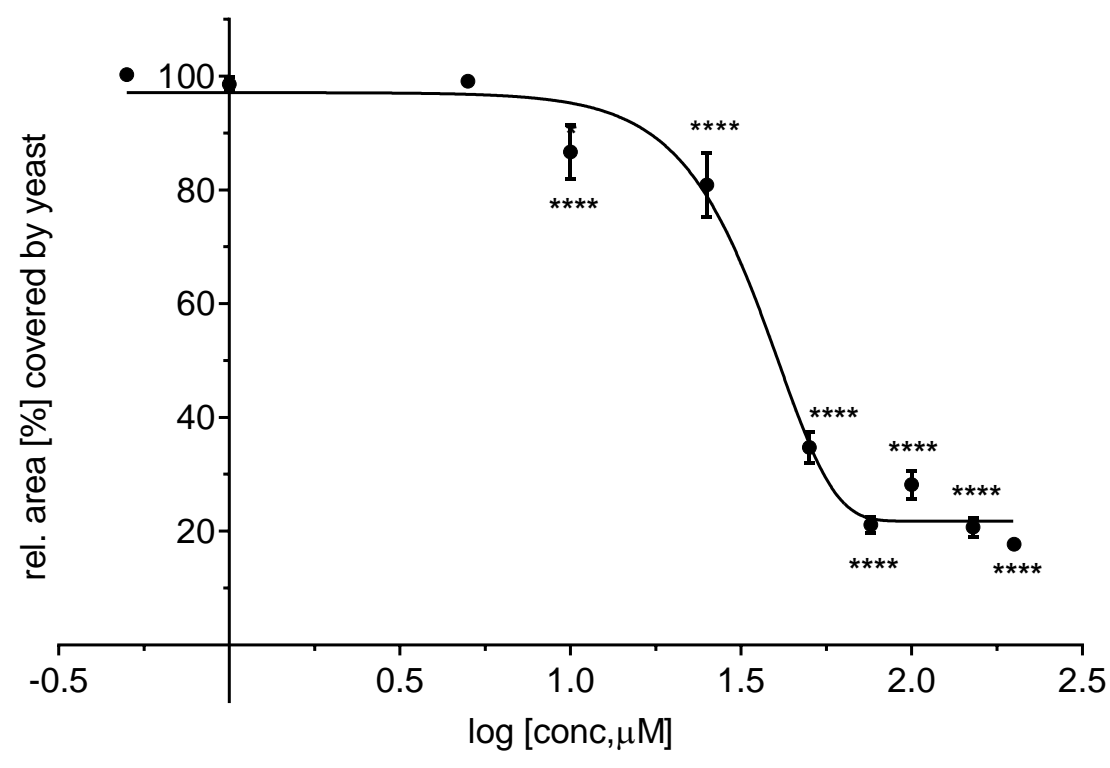

$\mathrm{IC}_{50}: 35.55 \mu \mathrm{M}$
$\mathrm{IC}_{50} 95 \% \mathrm{Cl}: 28.02$ to $45.11 \mu \mathrm{M}$
$\mathrm{R}$ squared: 0.9873

Figure 42. Area covered by Hoechst 33342 and Cell Mask Deep Red/Concanavalin A defined as yeast $\left[\mu \mathrm{m}^{2}\right]$ normalized to solvent control displayed as a function of concentration of mutanobactin D (grouped by dose), experiment 1 (a) and 2 (b). Strain: SC5314. 
Strain: 101

a)

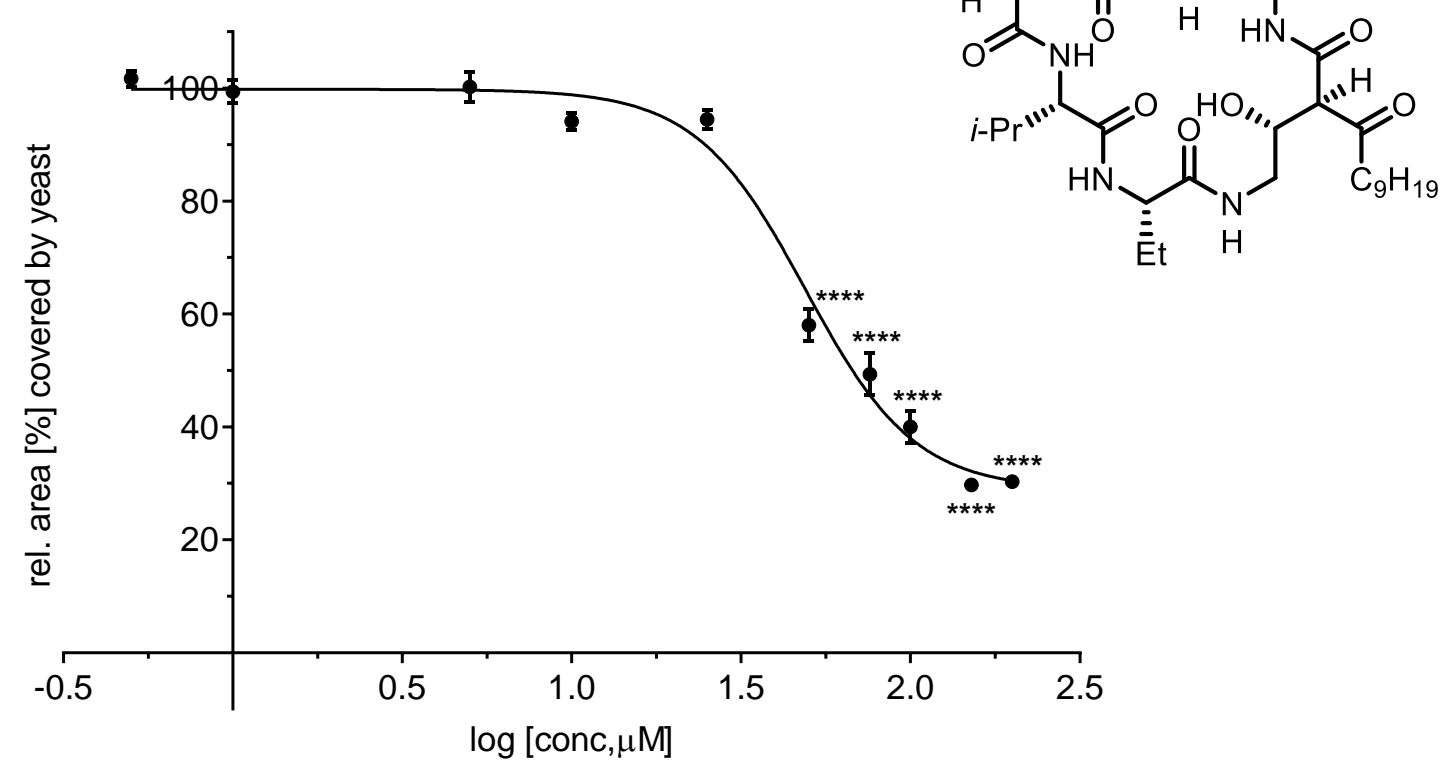

$\mathrm{IC}_{50}: 48.97 \mu \mathrm{M}$

$\mathrm{IC}_{50} 95 \% \mathrm{Cl}: 39.36$ to $60.92 \mu \mathrm{M}$

R squared: 0.9883

b)

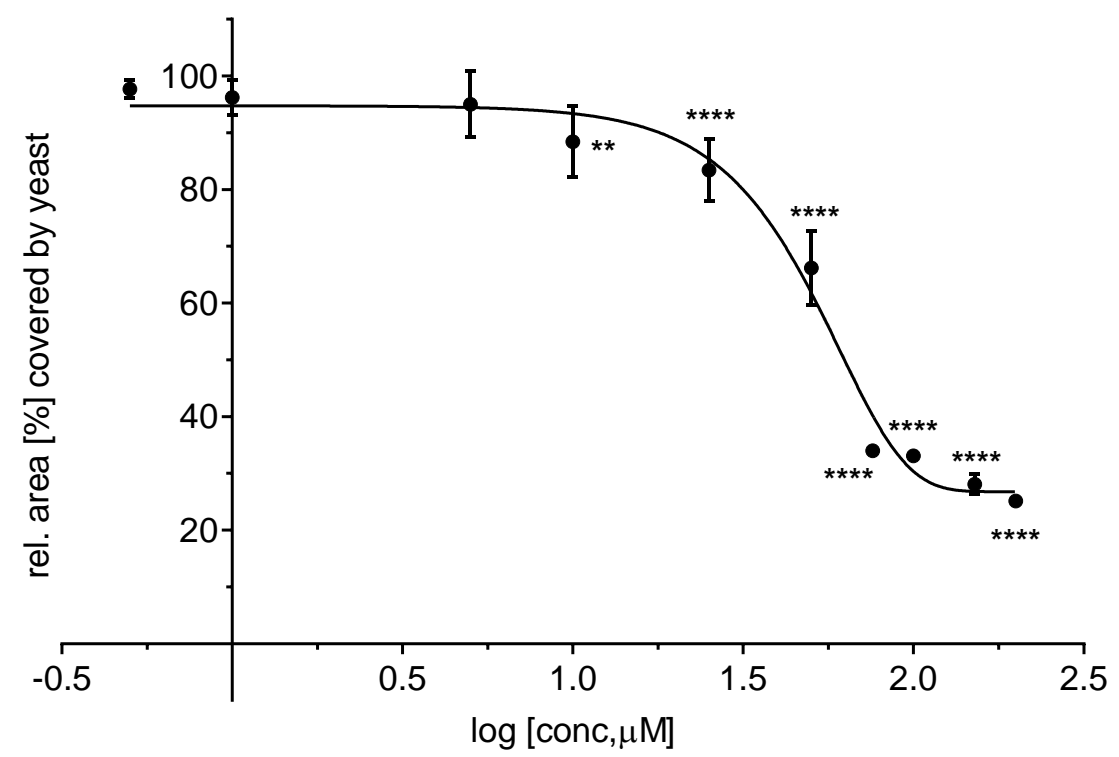

$\mathrm{IC}_{50}: 48.72 \mu \mathrm{M}$

$\mathrm{IC}_{50} 95 \% \mathrm{Cl}: 38.57$ to $61.55 \mu \mathrm{M}$

R squared: 0.9875

c) 


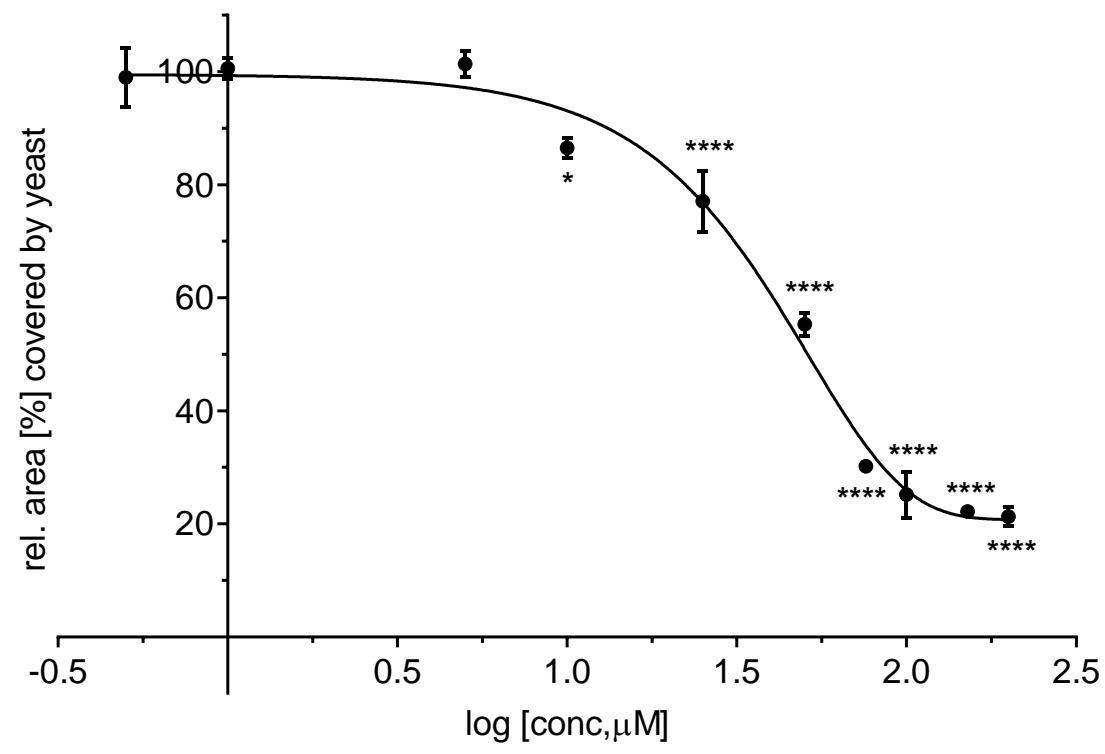

$\mathrm{IC}_{50}: 40.33 \mu \mathrm{M}$
$\mathrm{IC}_{50} 95 \% \mathrm{Cl}: 31.14$ to $52.22 \mu \mathrm{M}$
R squared: 0.9910

Figure 43. Area covered by Hoechst 33342 and Cell Mask Deep Red/Concanavalin A defined as yeast $\left[\mu \mathrm{m}^{2}\right]$ normalized to solvent control displayed as a function of concentration of mutanobactin D (grouped by dose), experiment 1 (a), 2 (b) and 3 (c). Strain: 101 . 


\subsection{Pictures from Hoechst/ConA double staining}

The images below were obtained from C. albicans ATCC 90028. 7500 yeast cells were incubated for $5 \mathrm{~h}$ in the presence (or absence) of mutanobactin D or farnesol. Staining with Hoechst 33342 or Concanavalin A (ConA) as well as the overlay of the two and brightfield images of the same area are shown.

Table 22. Images taken from untreated C. albicans ATCC 90028.

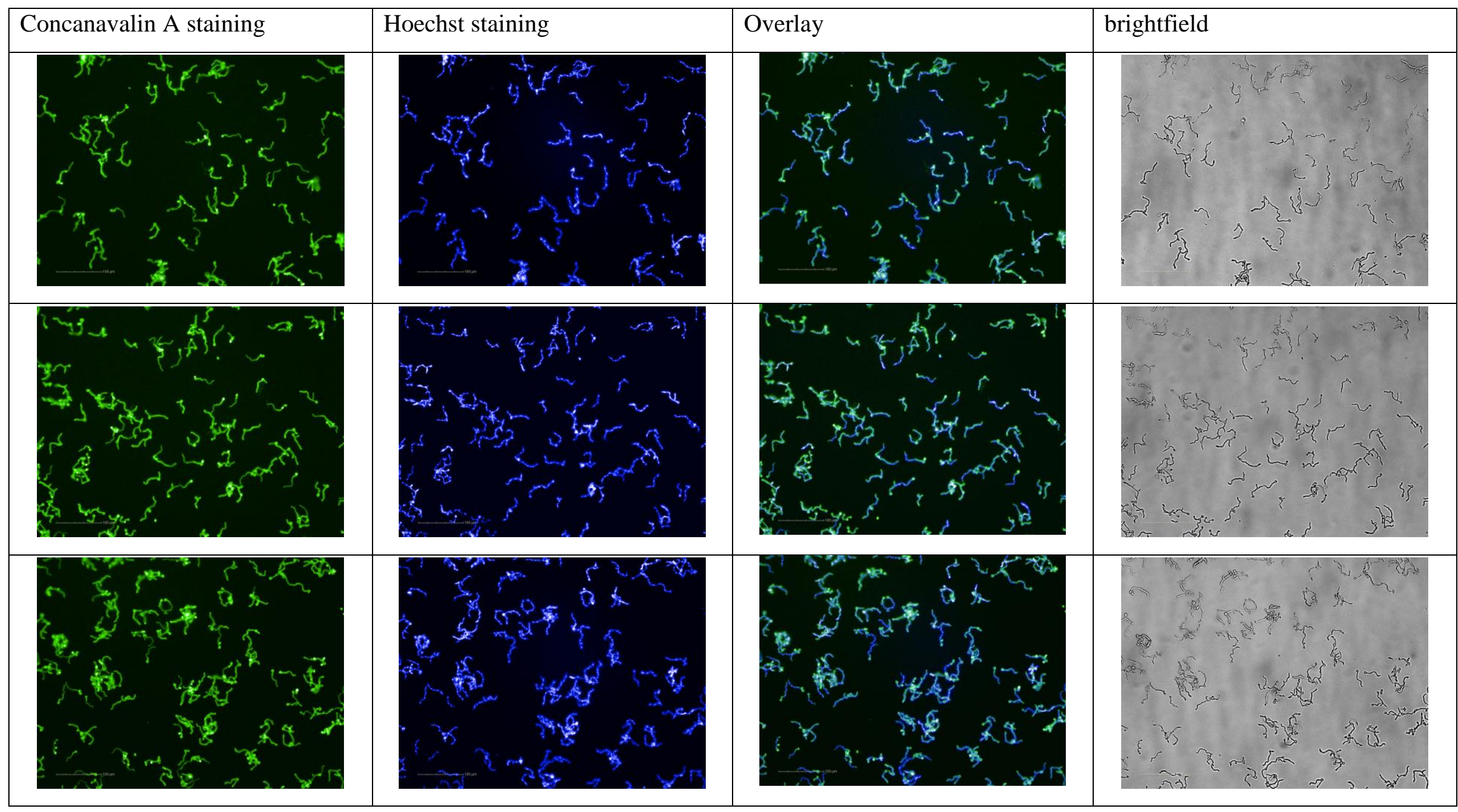


Table 23. Images taken from cells incubated with 1\% DMSO; C. albicans ATCC 90028.

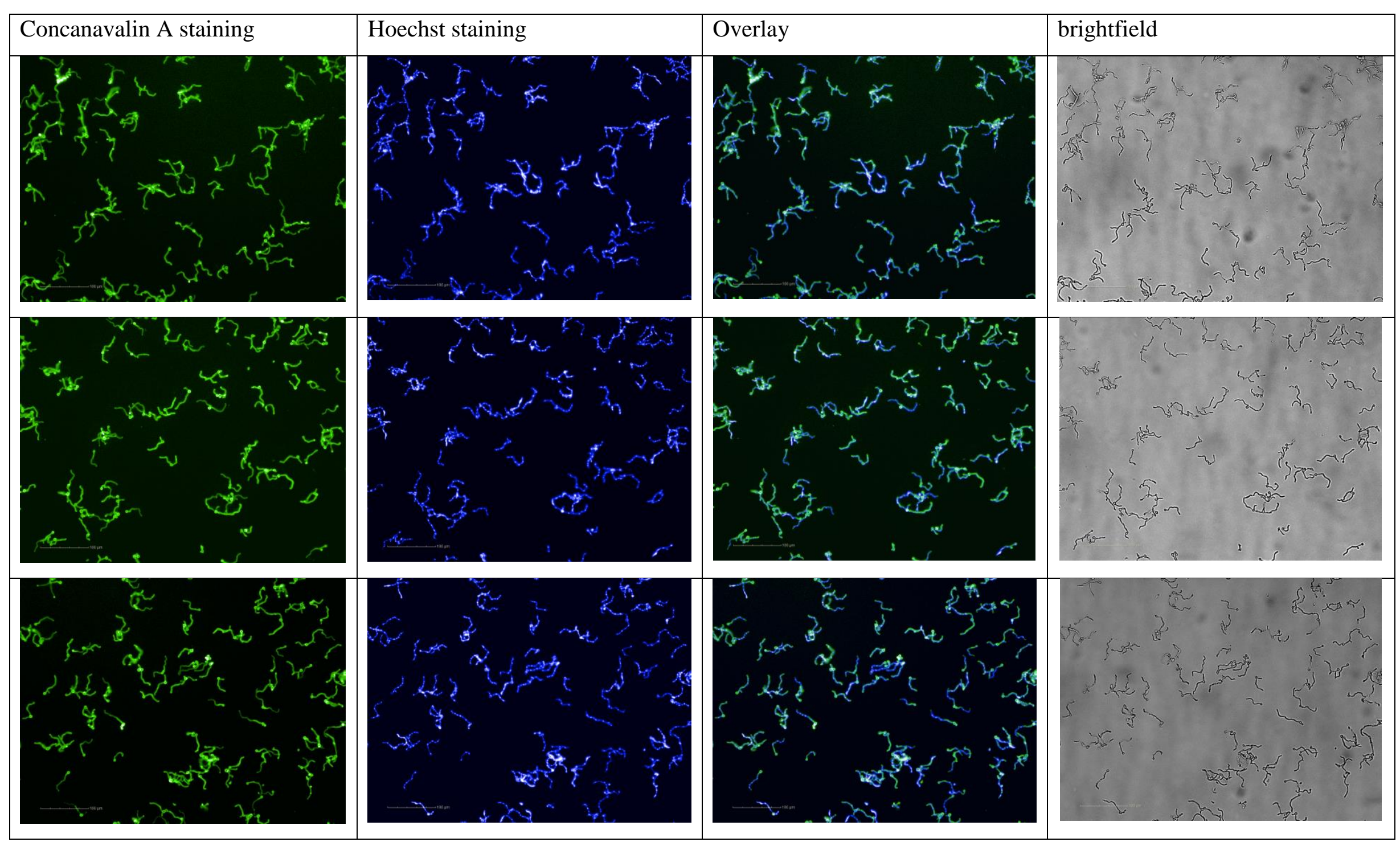


Table 24. Images taken from cells incubated with $100 \mu \mathrm{M}$ farnesol; C. albicans ATCC 90028.

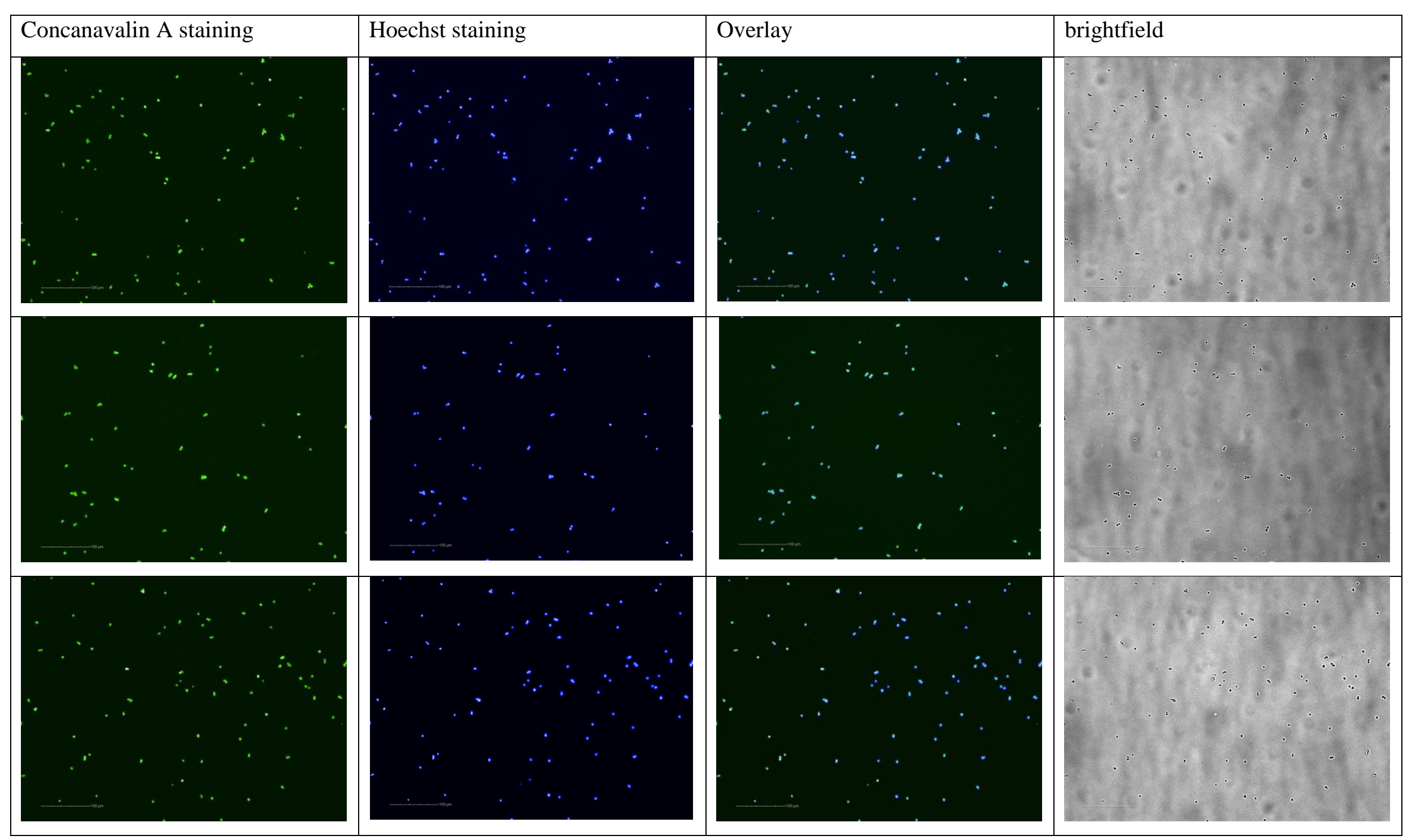


Table 25. Images taken from cells incubated with $200 \mu \mathrm{M}$ mutanobactin D; C. albicans ATCC 90028.

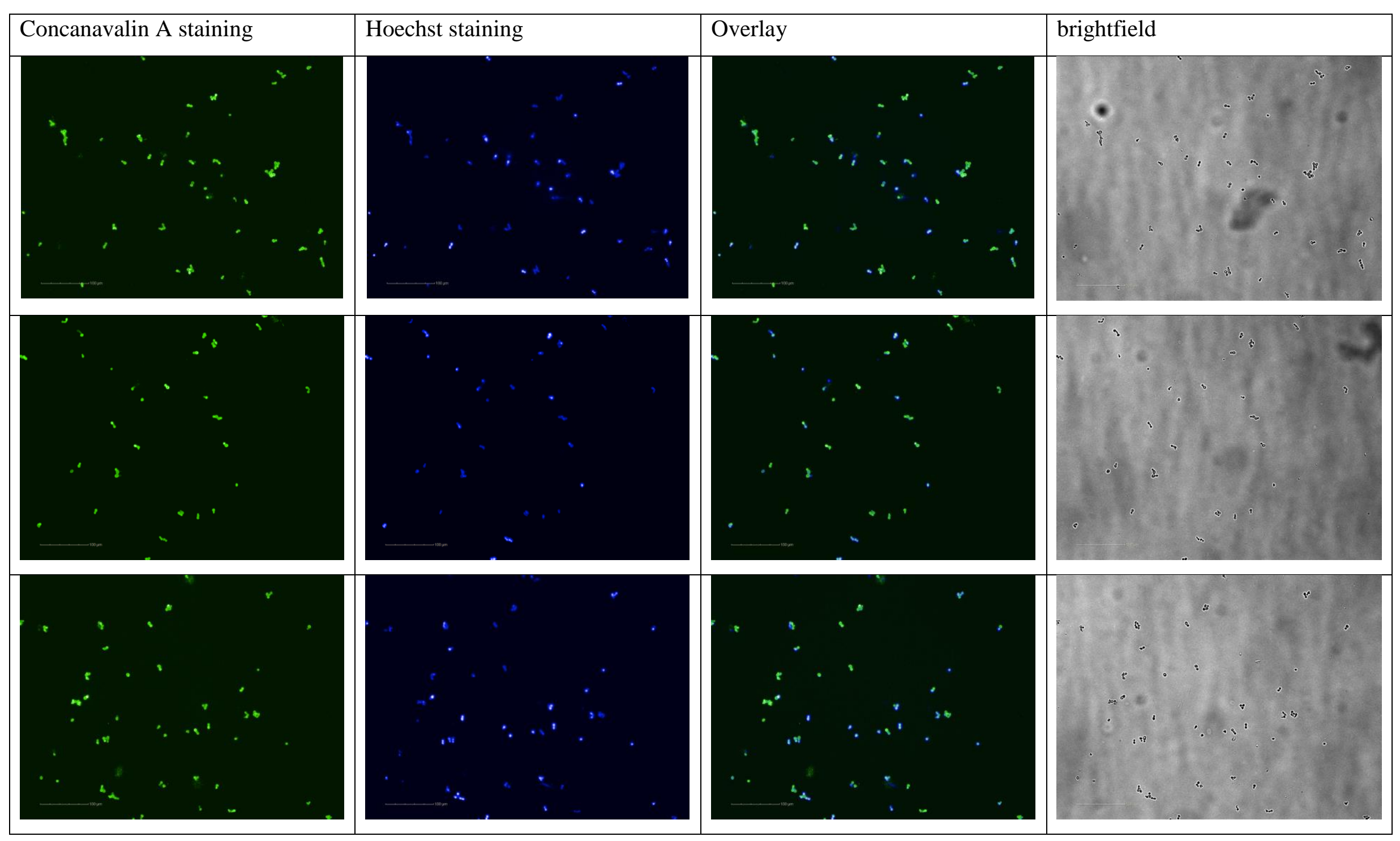


Table 26. Images taken from cells incubated with $100 \mu \mathrm{M}$ mutanobactin D; C. albicans 90028.
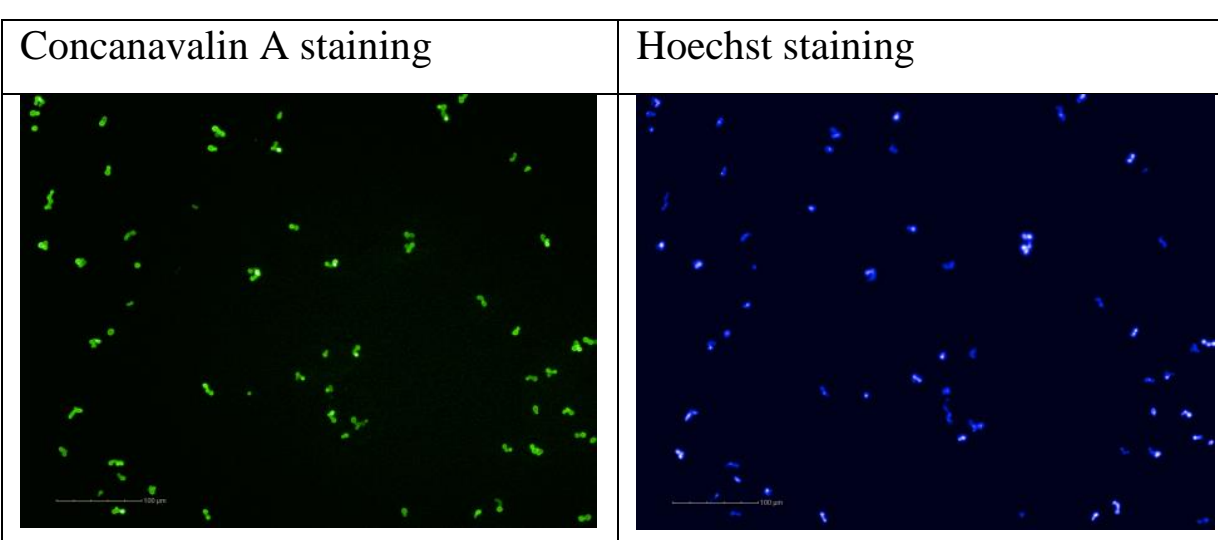

Overlay
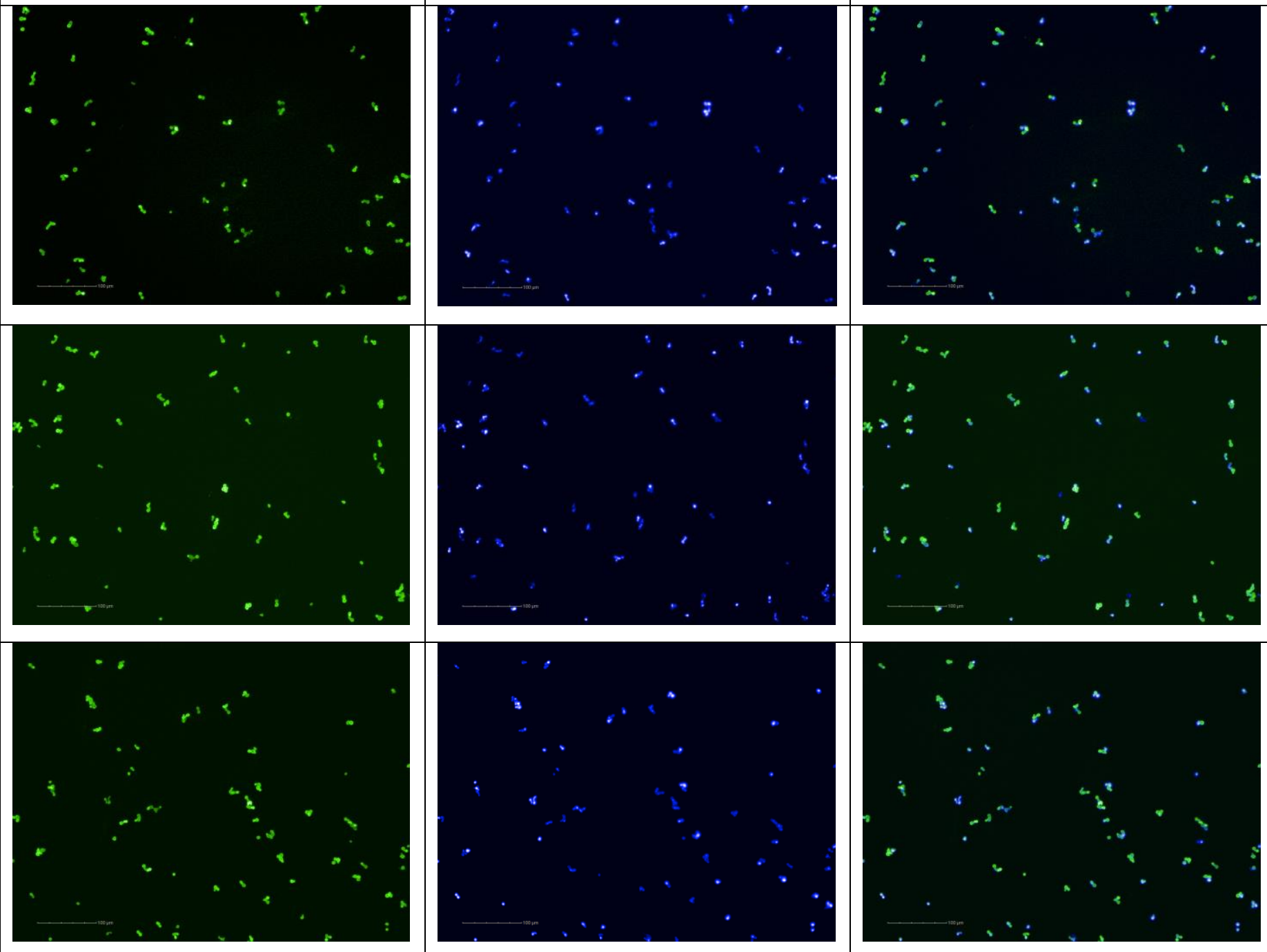

brightfield
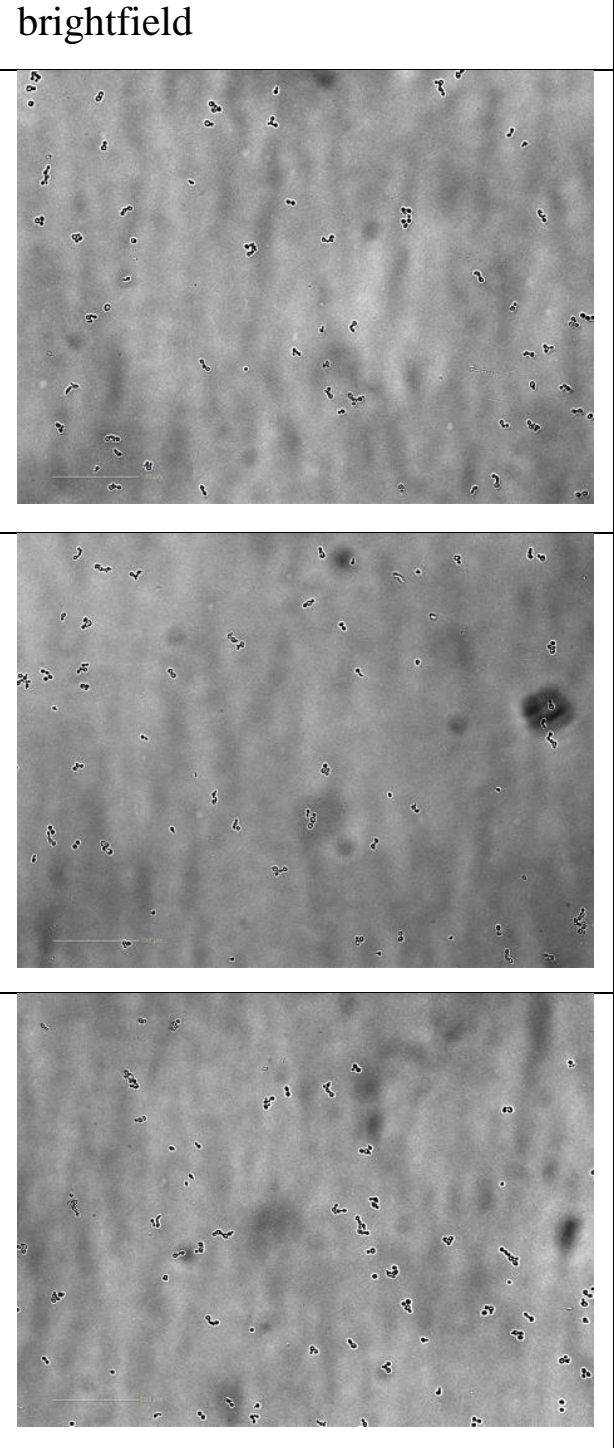
Table 27. Images taken from cells incubated with $75 \mu \mathrm{M}$ mutanobactin D; C. albicans ATCC 90028.

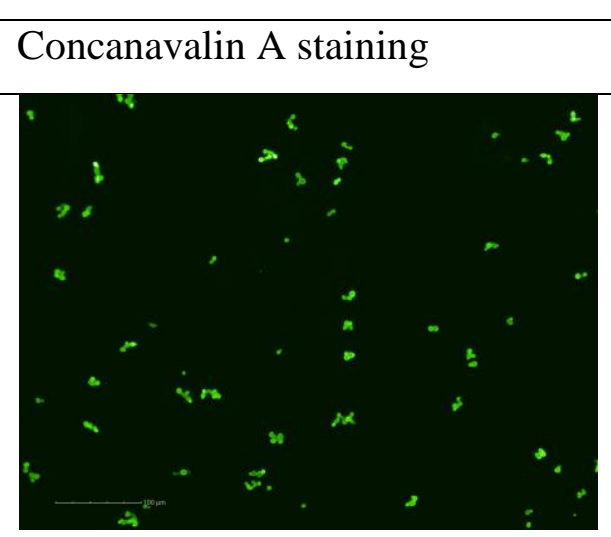

\section{Hoechst staining}

Overlay

brightfield
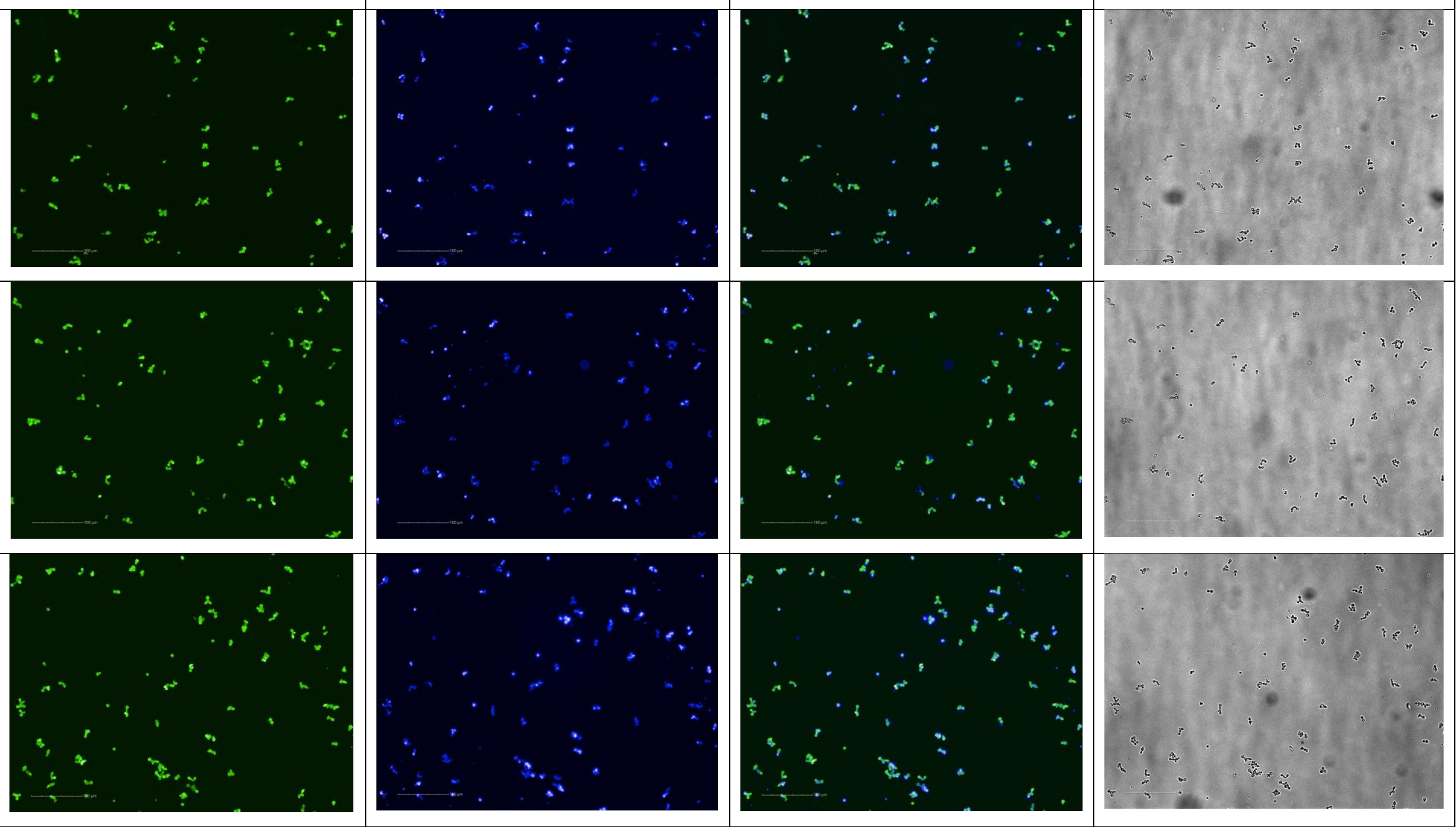
Table 28. Images taken from cells incubated with $50 \mu \mathrm{M}$ mutanobactin D; C. albicans ATCC 90028.

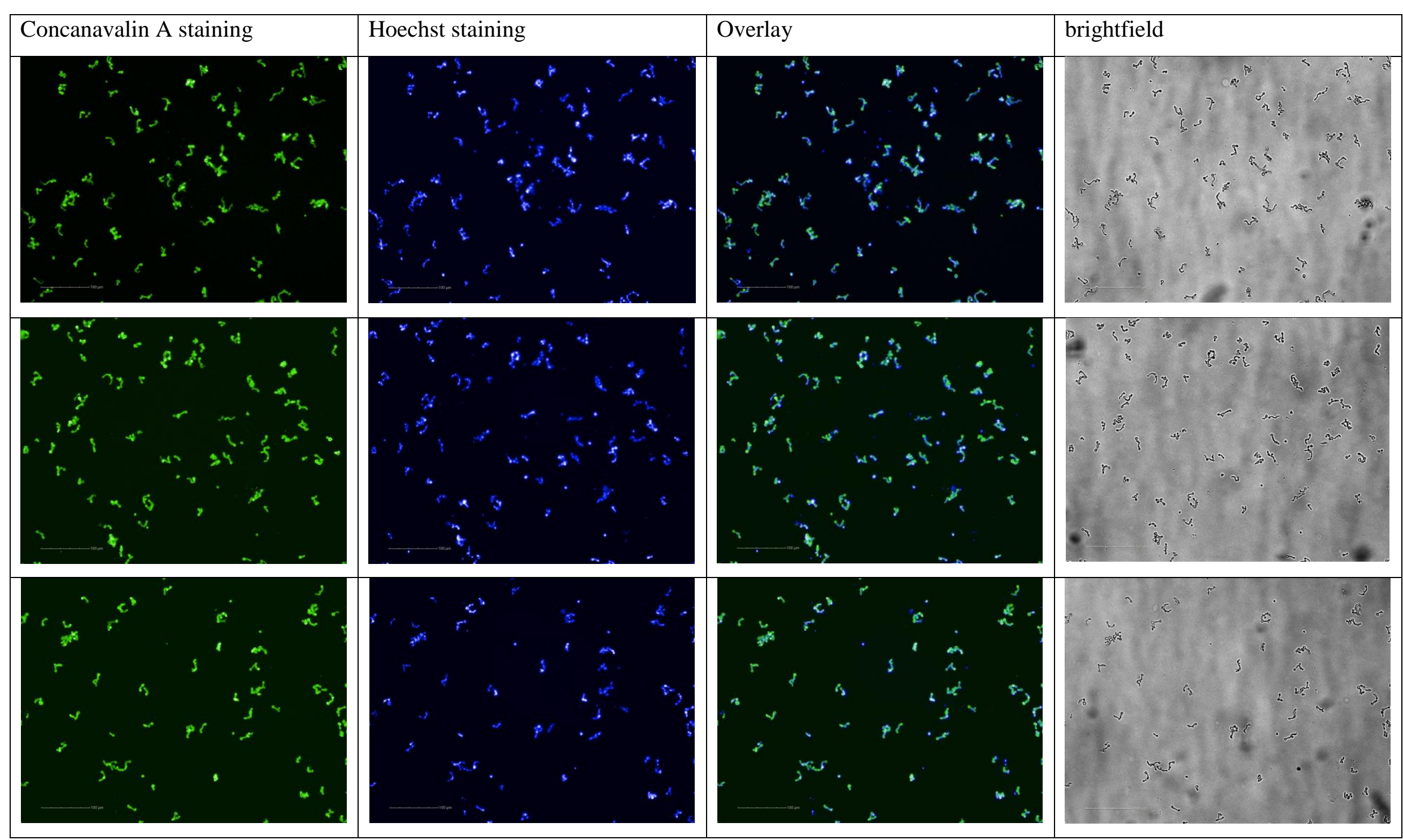


Table 29. Images taken from cells incubated with $25 \mu \mathrm{M}$ mutanobactin D; C. albicans ATCC 90028.

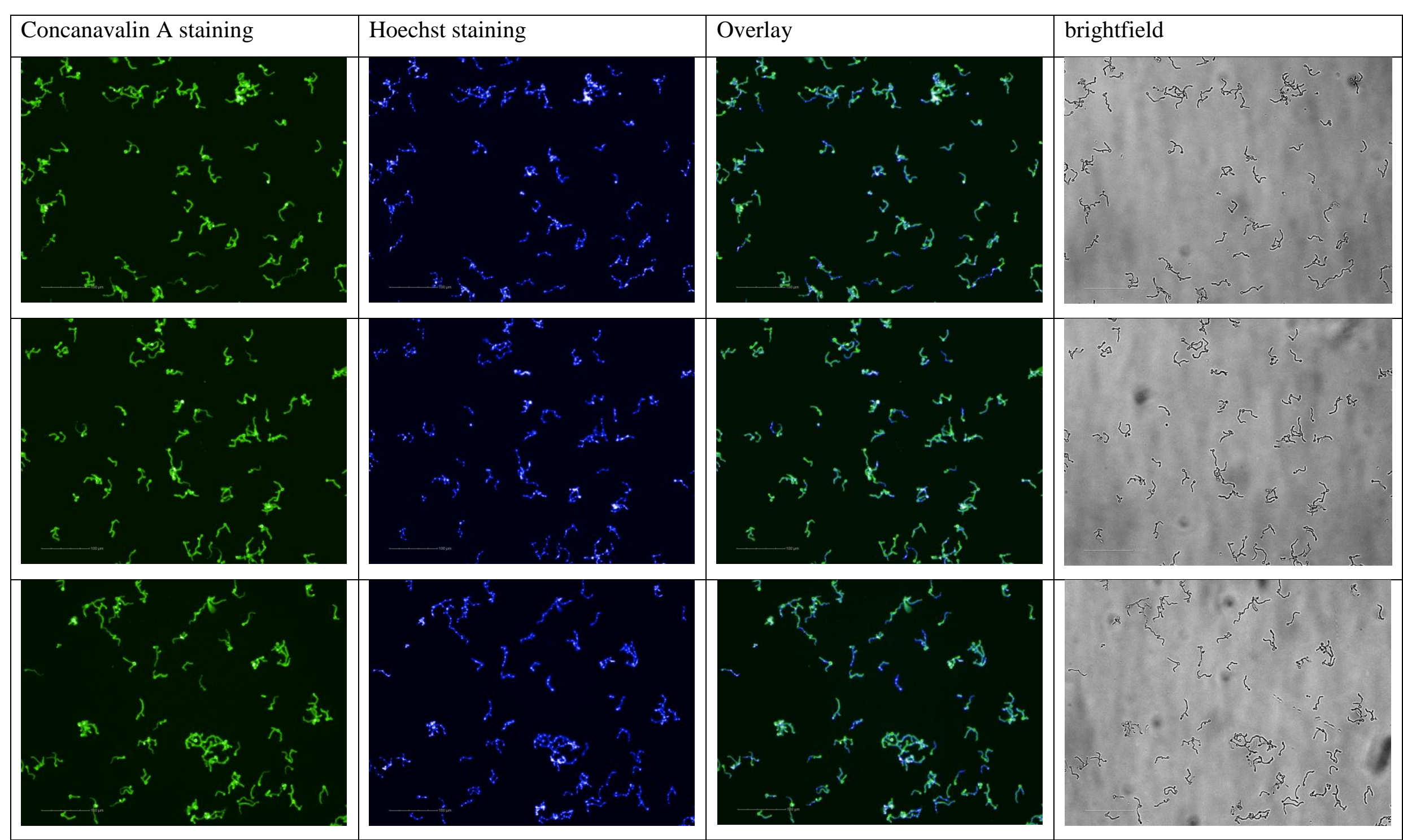


Table 30. Images taken from cells incubated with $10 \mu \mathrm{M}$ mutanobactin D; C. albicans ATCC 90028.
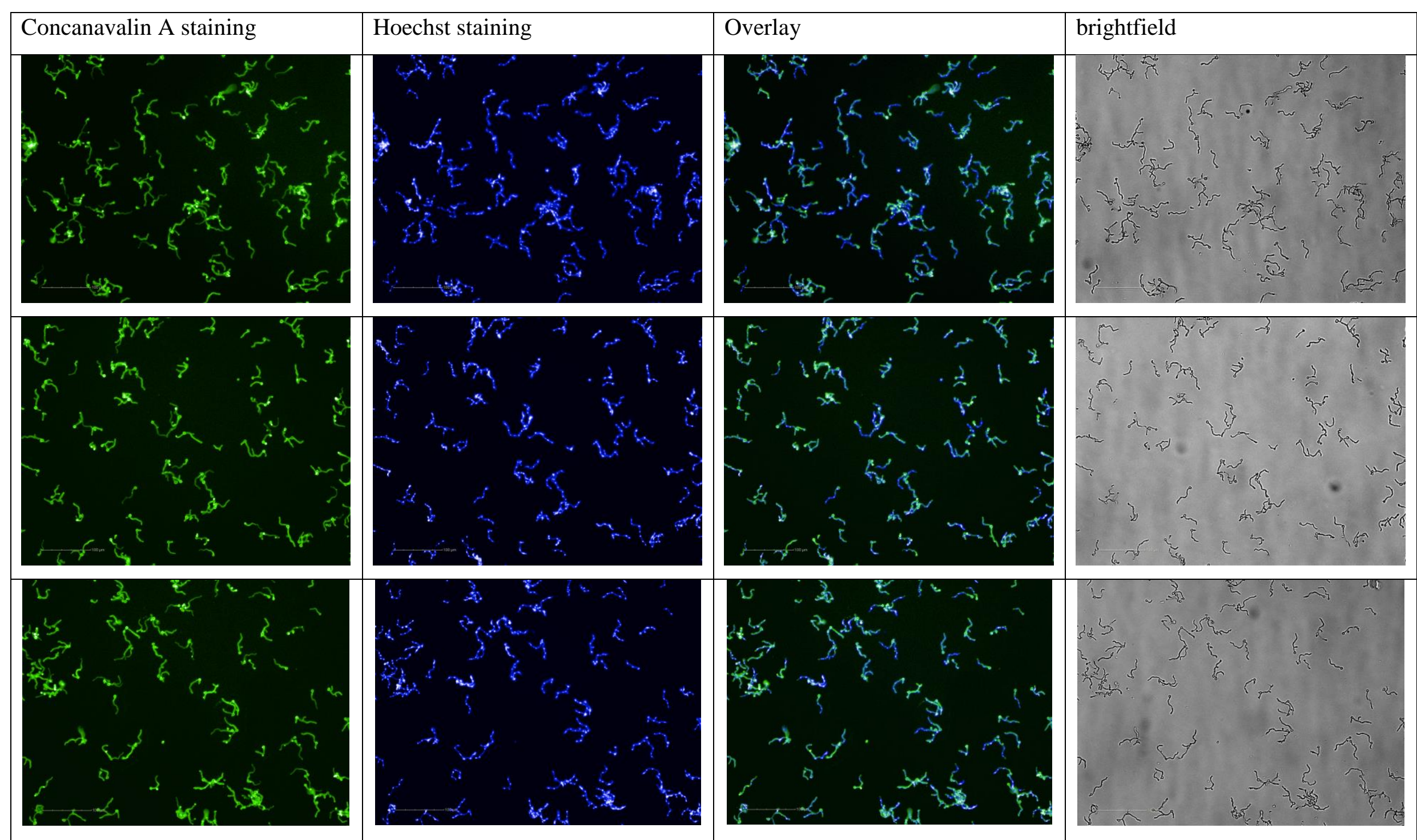
Table 31. Images taken from cells incubated with $1 \mu \mathrm{M}$ mutanobactin D; C. albicans ATCC 90028.
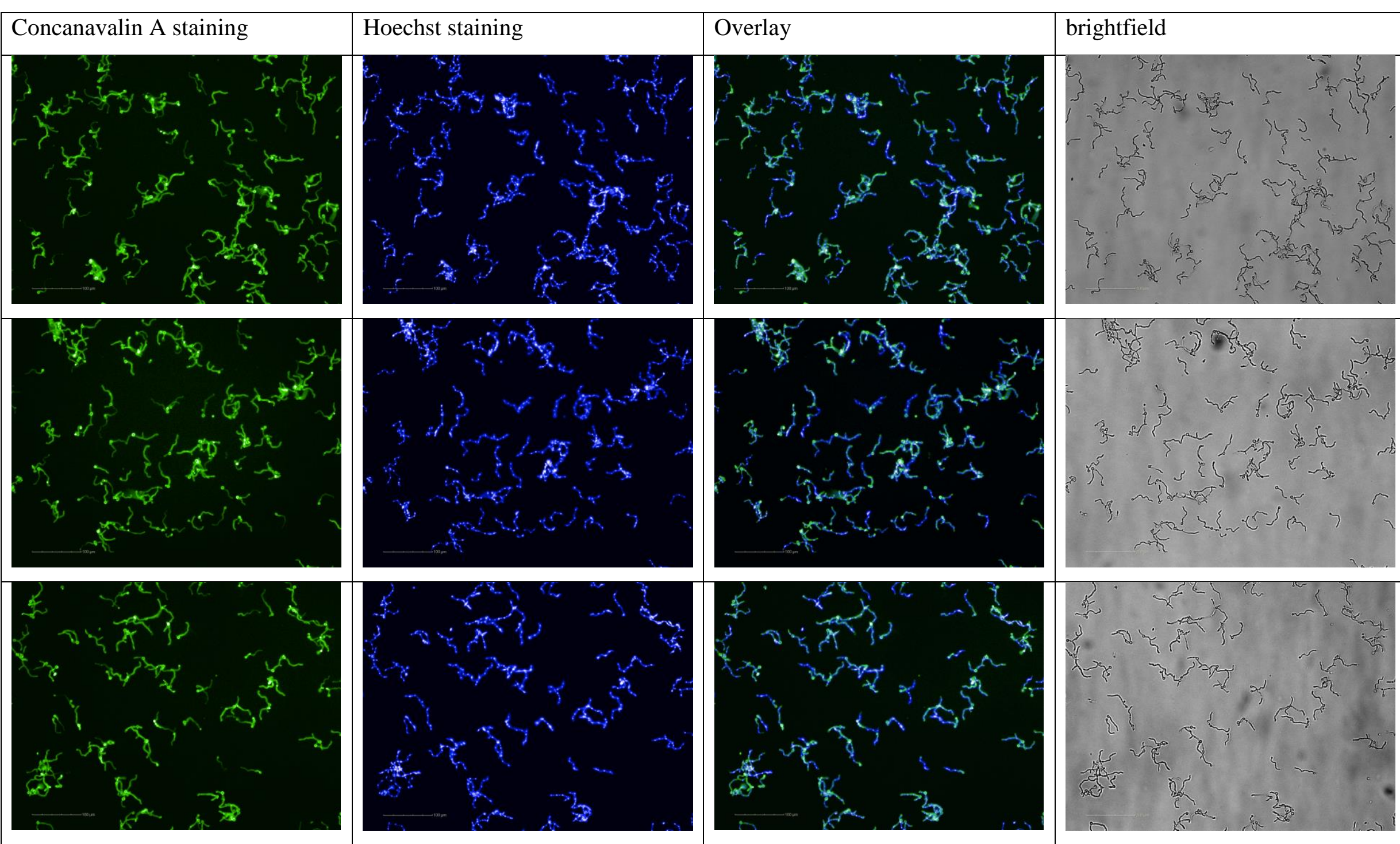
Table 32. Images taken from untreated C. albicans SC5314.

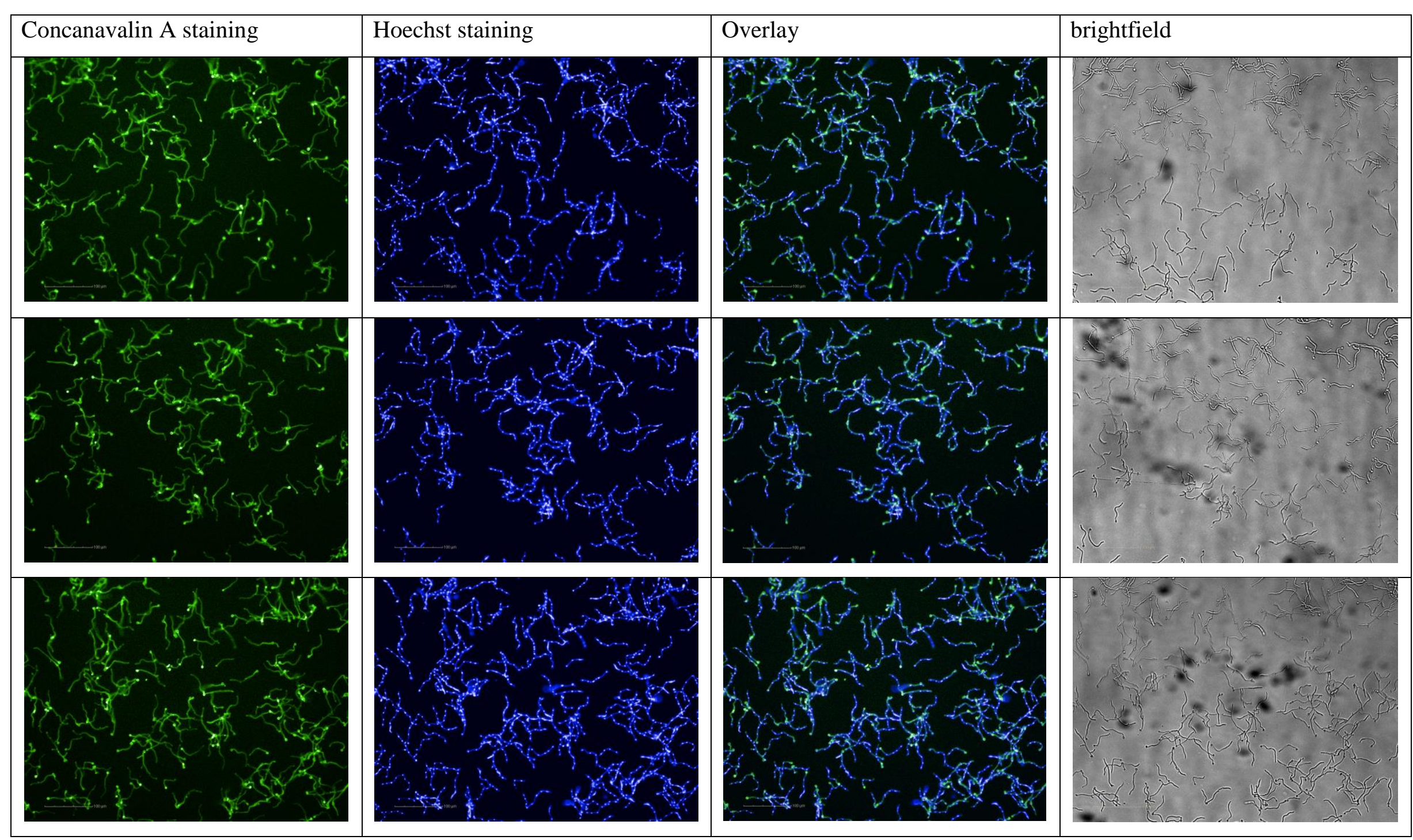


Table 33. Images taken from cells incubated with 1\% DMSO; C. albicans SC5314.
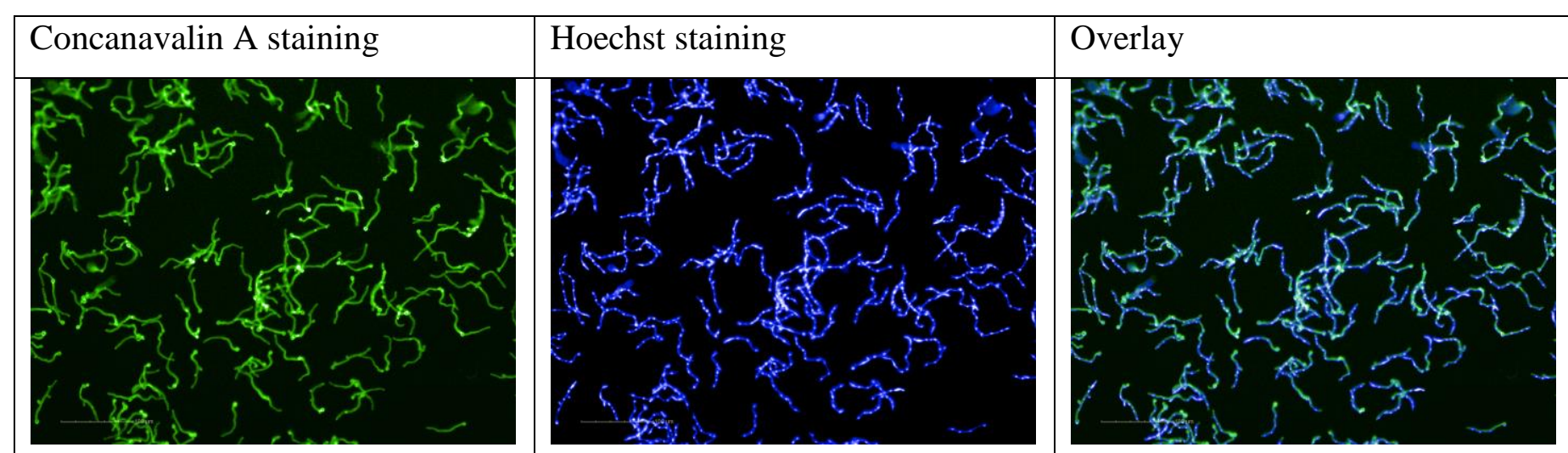

brightfield
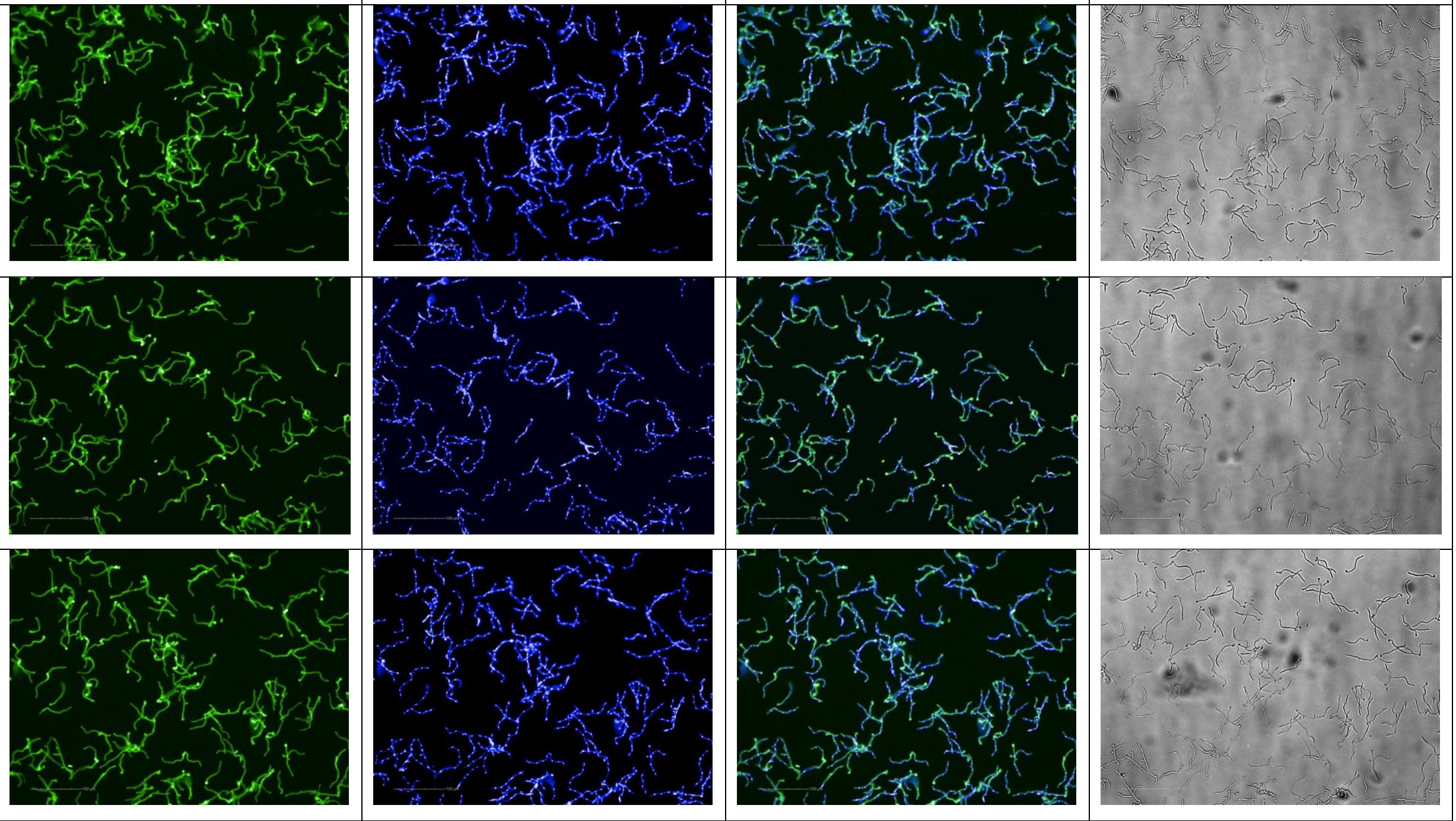
Table 34. Images taken from cells incubated with $100 \mu \mathrm{M}$ farnesol; C. albicans SC5314.

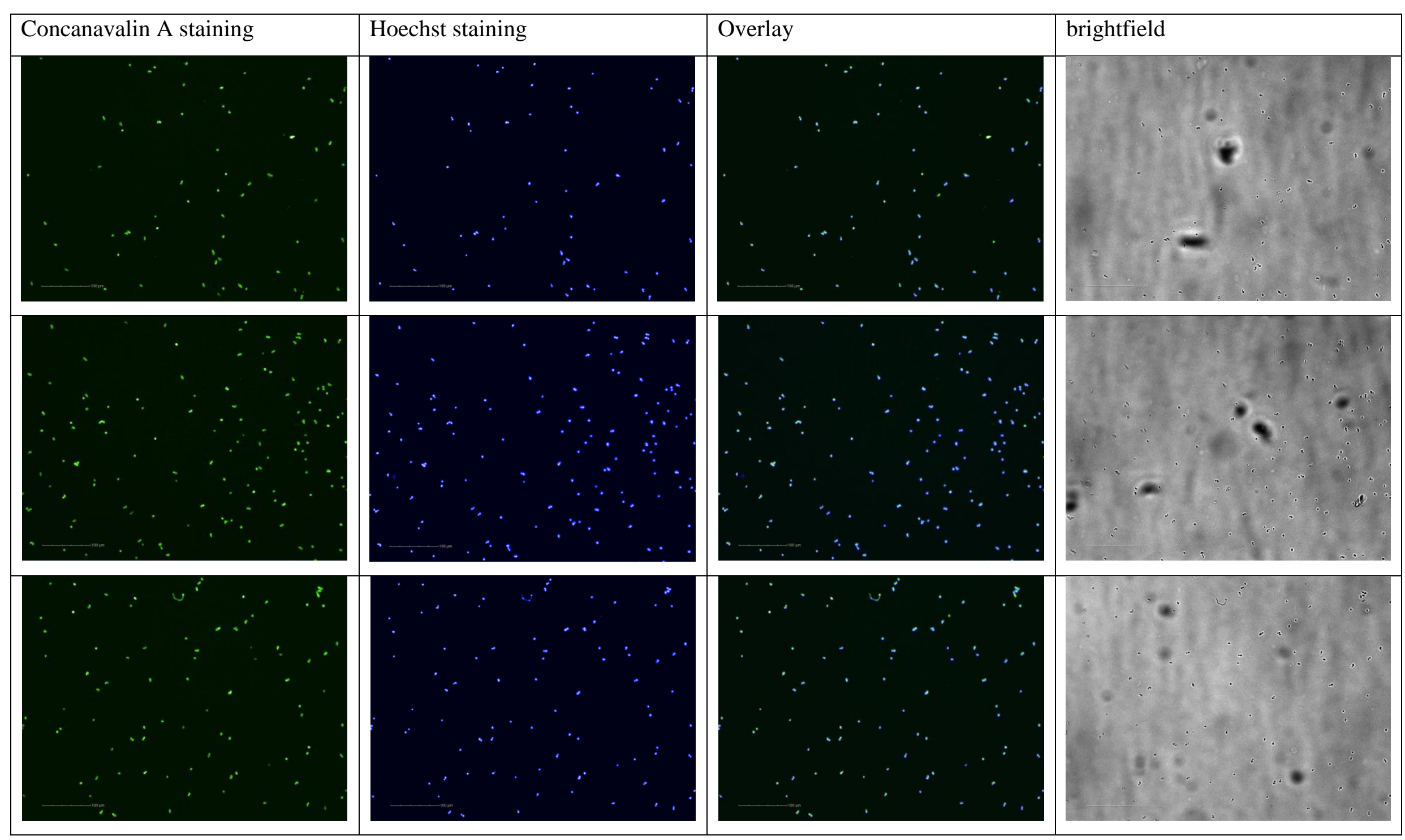


Table 35. Images taken from cells incubated with $200 \mu \mathrm{M}$ mutanobactin D; C. albicans SC5314.

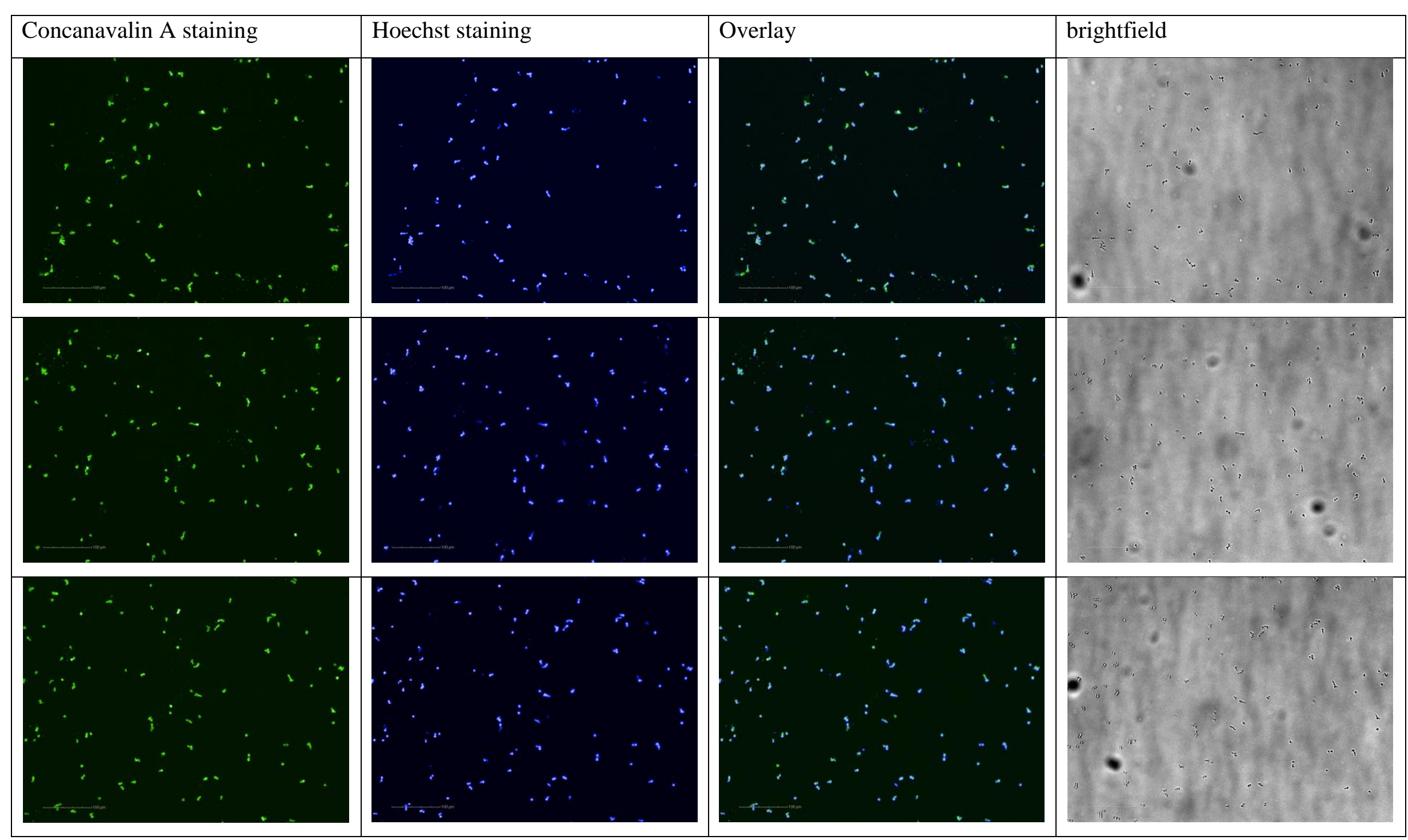


Table 36. Images taken from cells incubated with $100 \mu \mathrm{M}$ mutanobactin D; C. albicans SC5314.
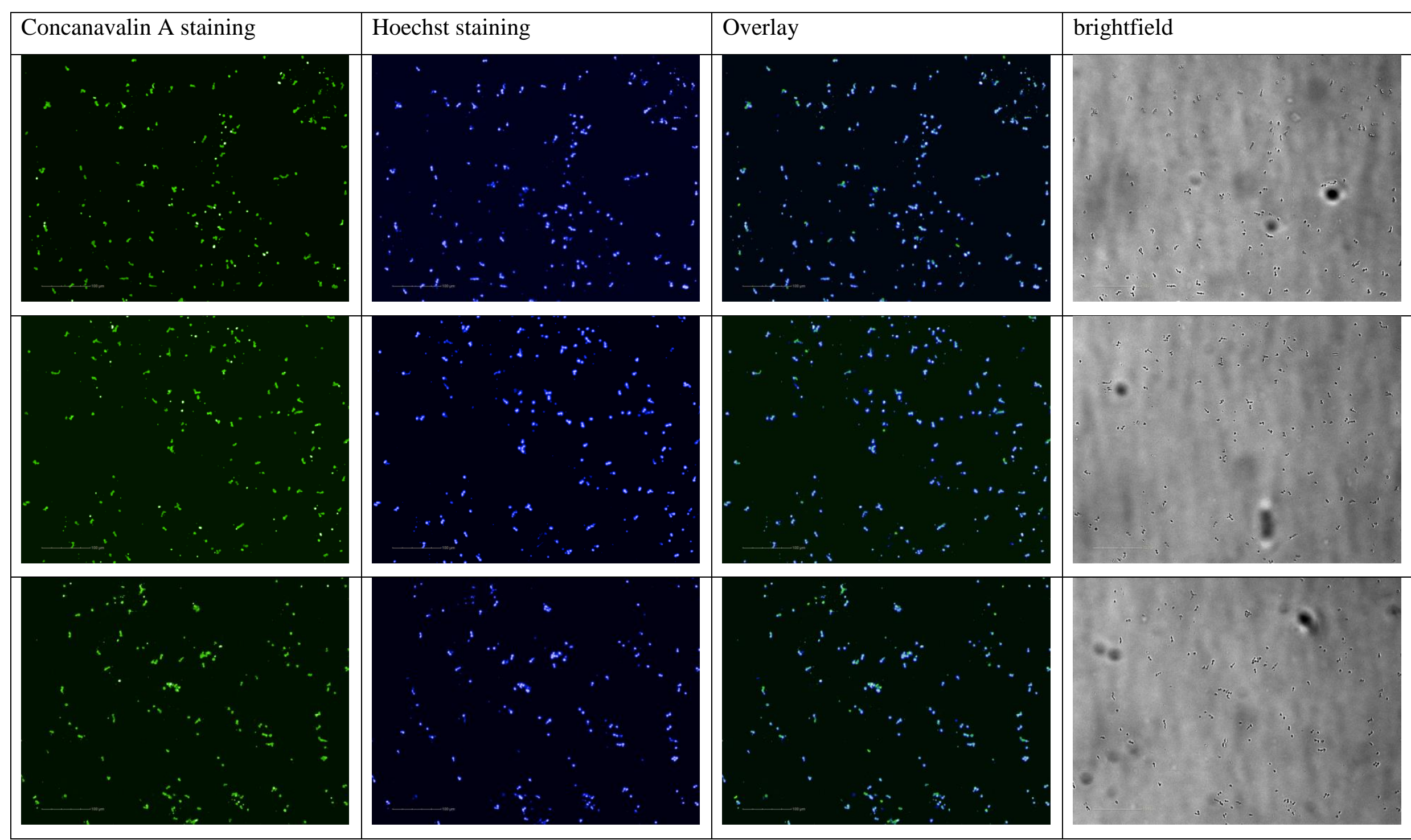
Table 37. Images taken from cells incubated with $75 \mu \mathrm{M}$ mutanobactin D; C. albicans SC5314.

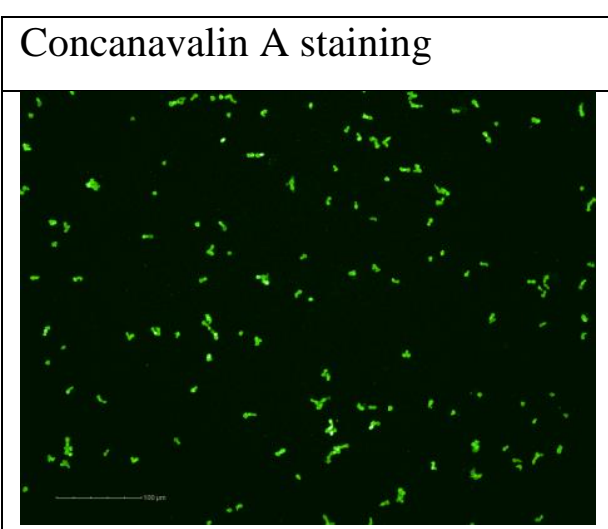

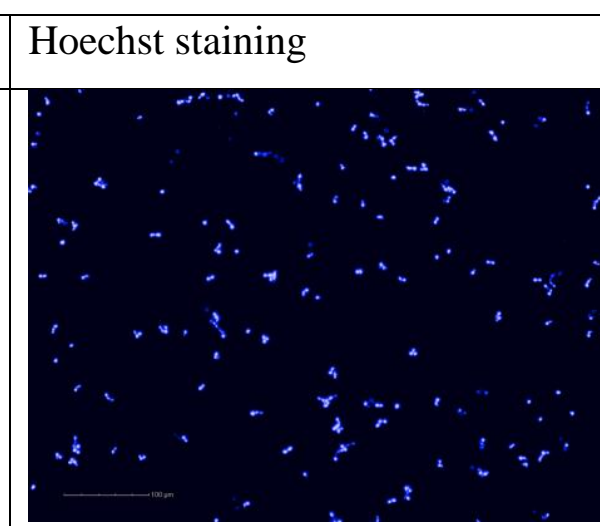

\section{Overlay}
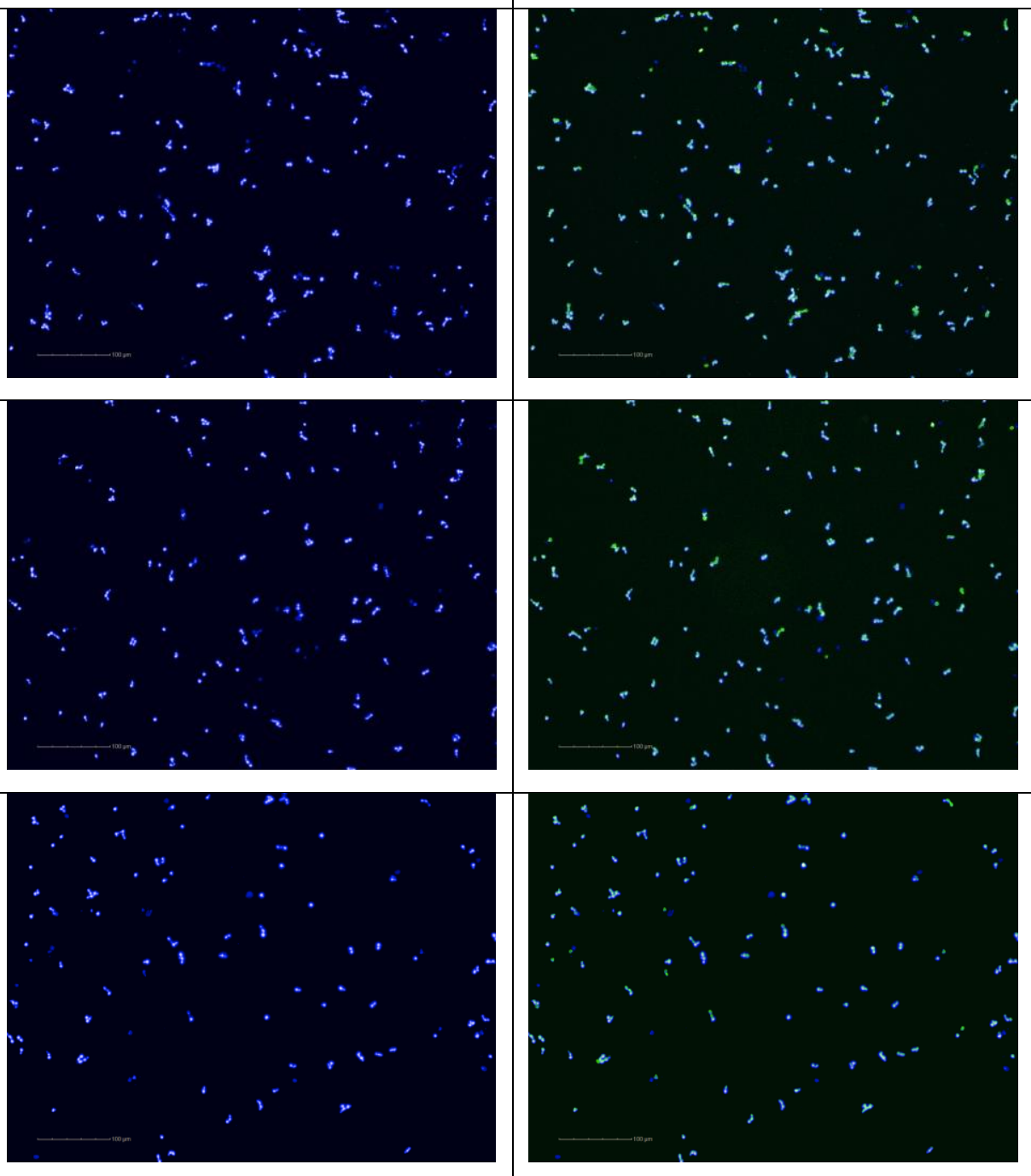

brightfield
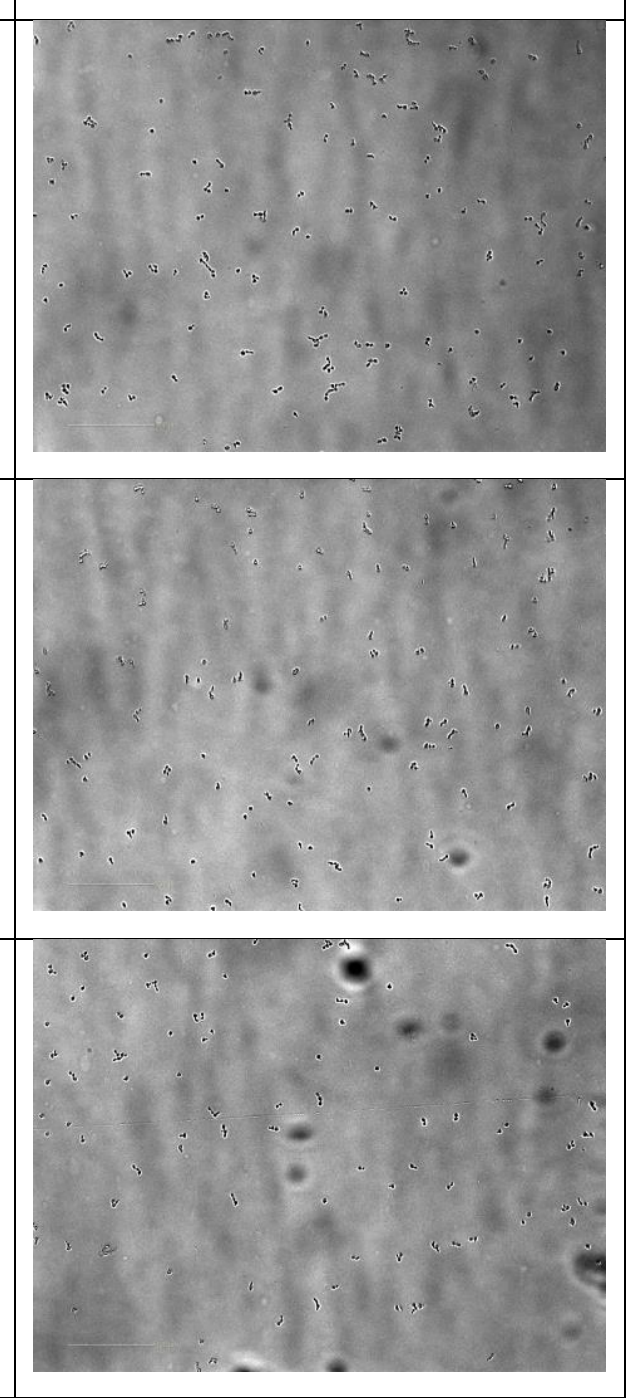

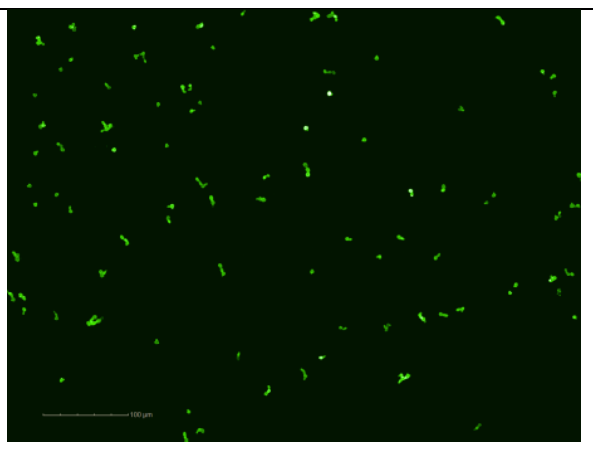


Table 38. Images taken from cells incubated with $50 \mu \mathrm{M}$ mutanobactin D; C. albicans SC5314.
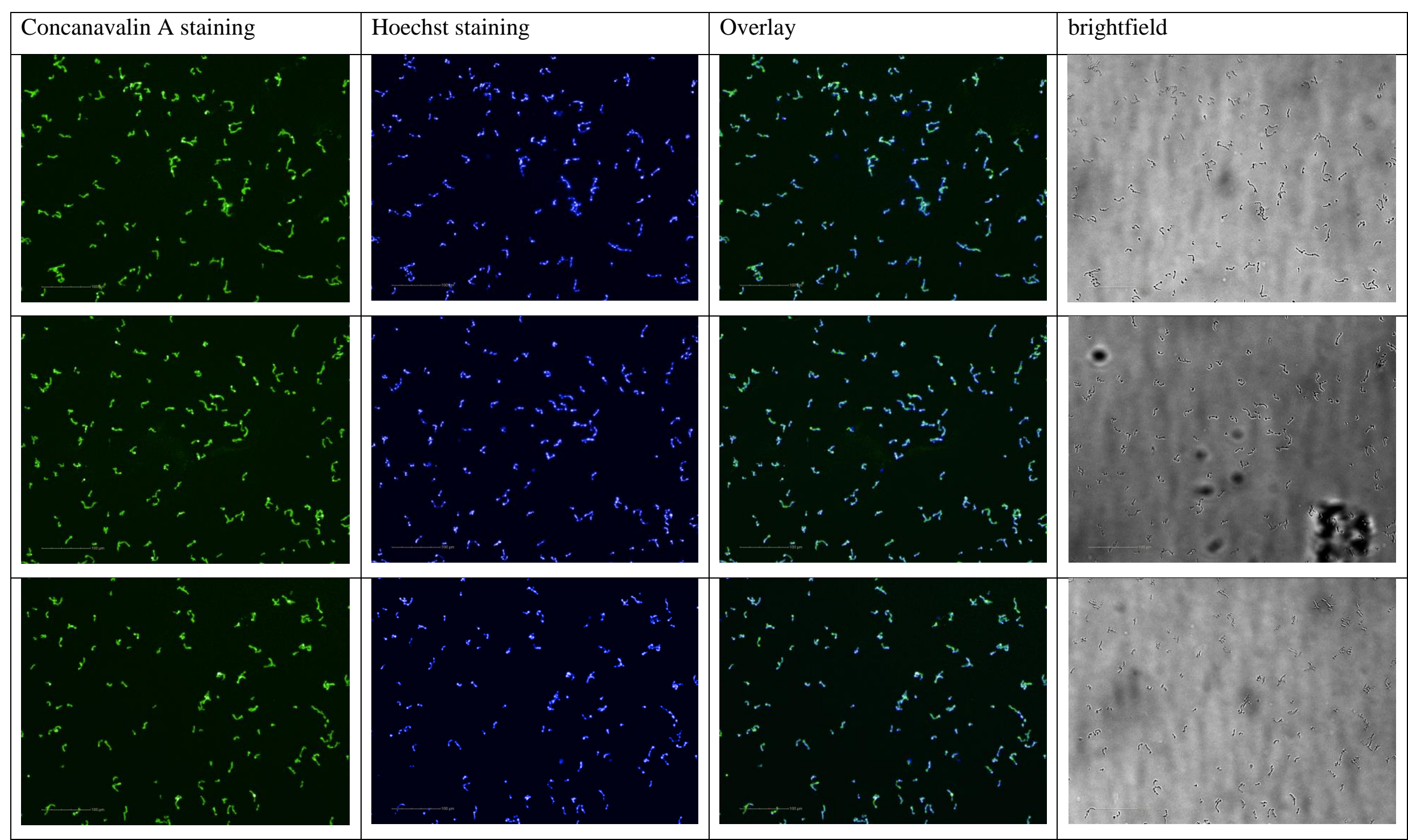
Table 39. Images taken from cells incubated with $25 \mu \mathrm{M}$ mutanobactin D; C. albicans SC5314.
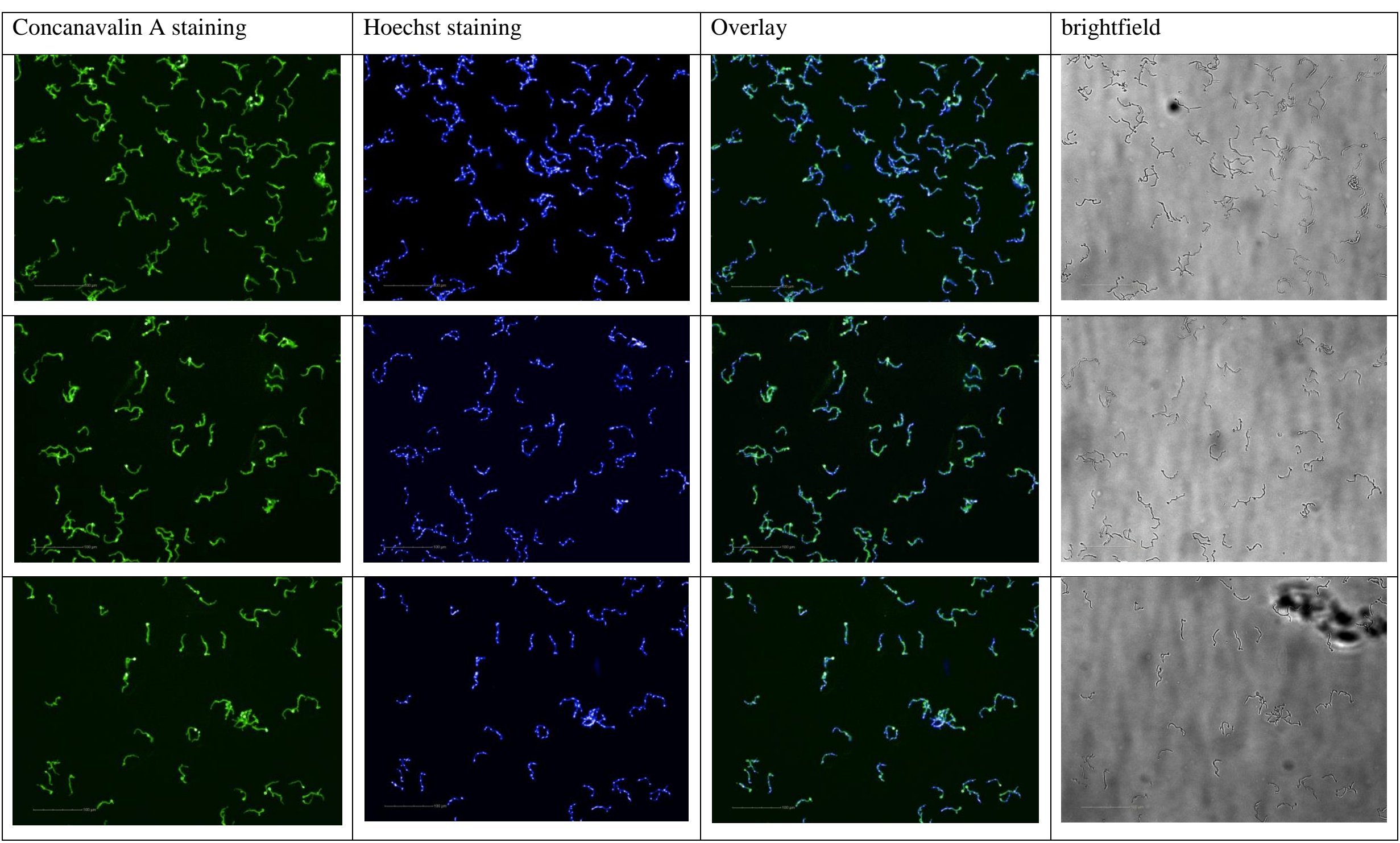
Table 40. Images taken from cells incubated with $10 \mu \mathrm{M}$ mutanobactin D; C. albicans SC5314.
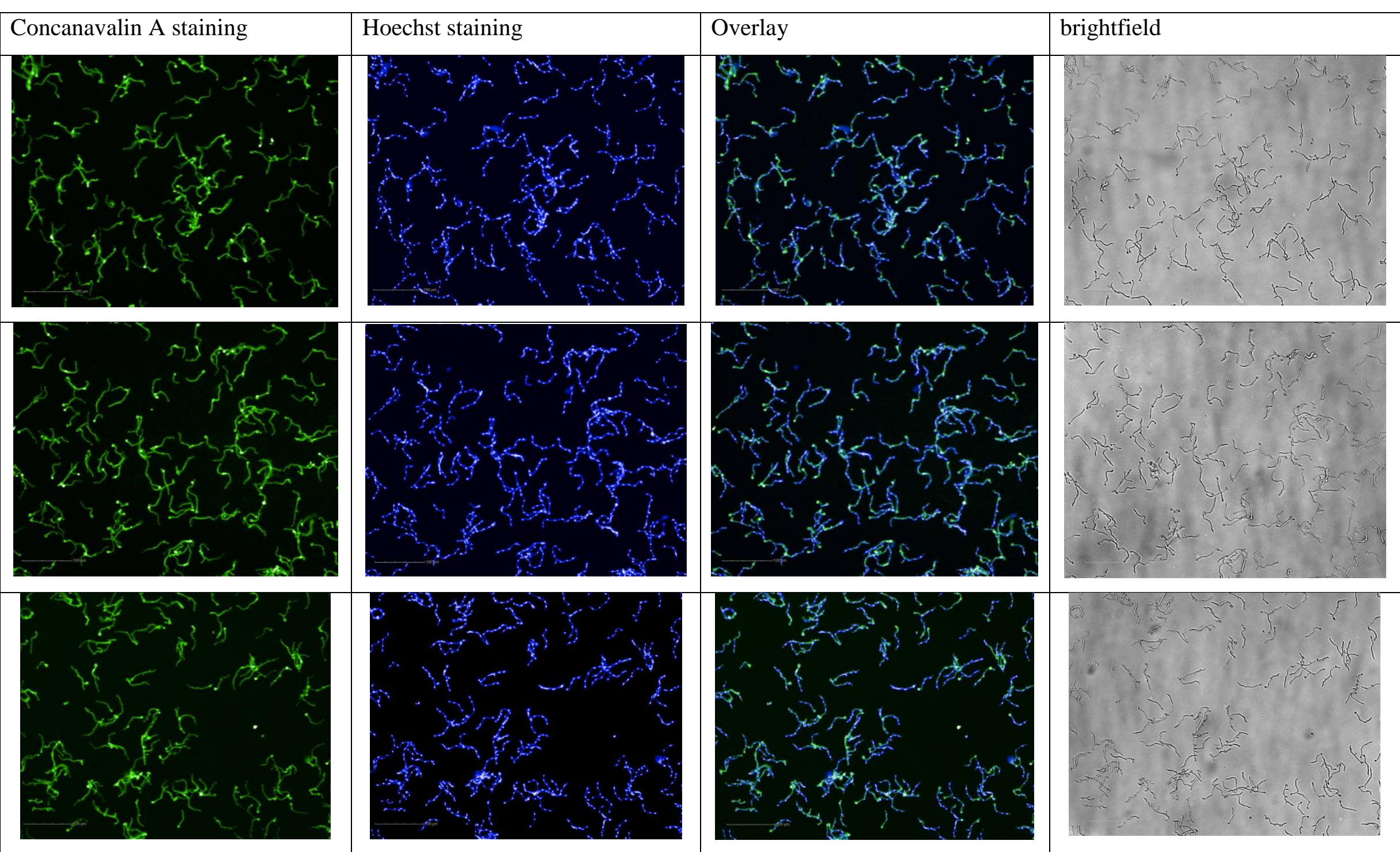
Table 41. Images taken from cells incubated with $1 \mu \mathrm{M}$ mutanobactin D; C. albicans SC5314.

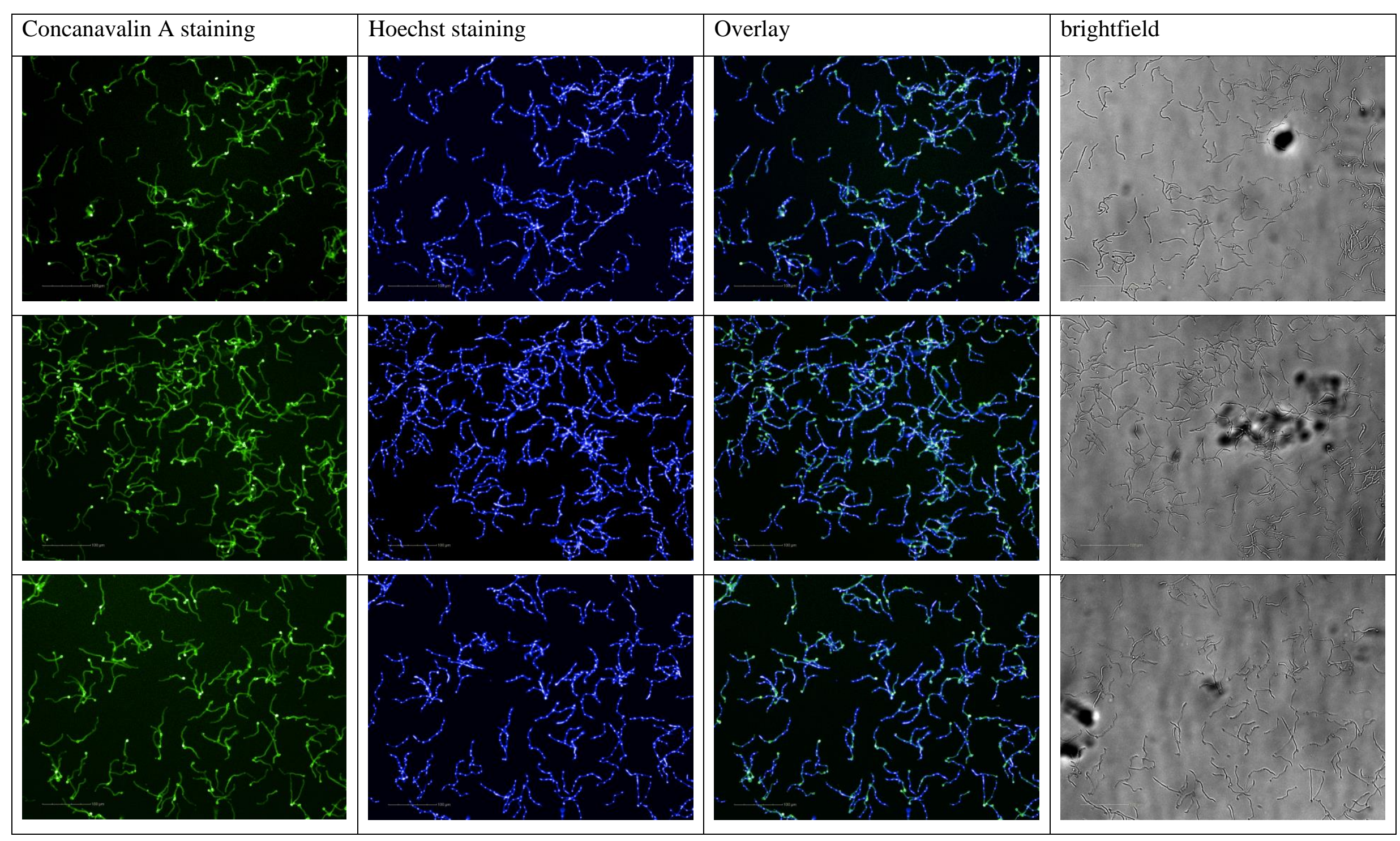


Table 42. Images taken from untreated C. albicans 101.

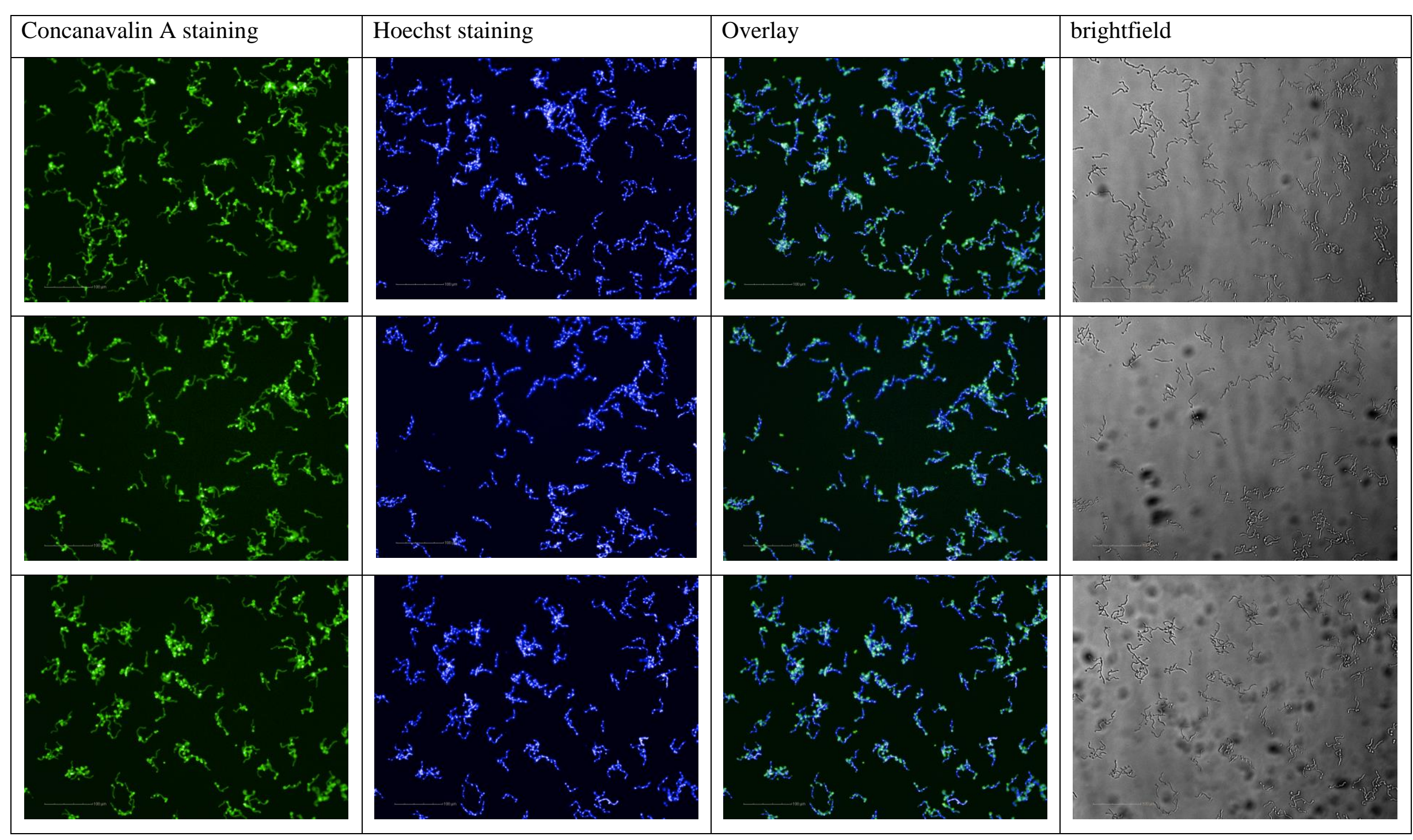


Table 43. Images taken from cells incubated with 1\% DMSO; C. albicans 101.
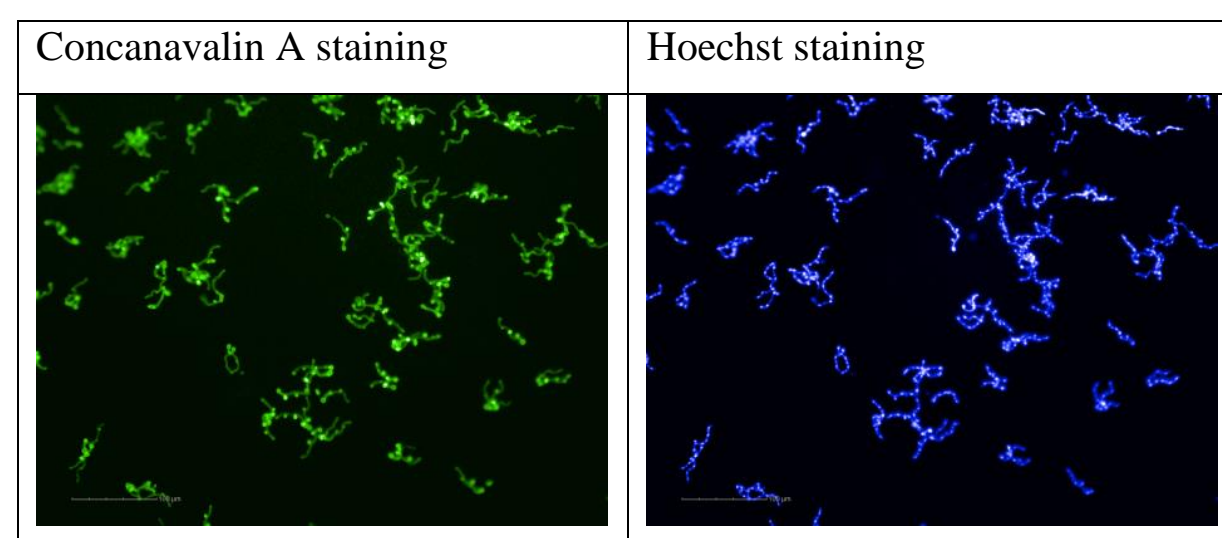

\section{Overlay}

brightfield
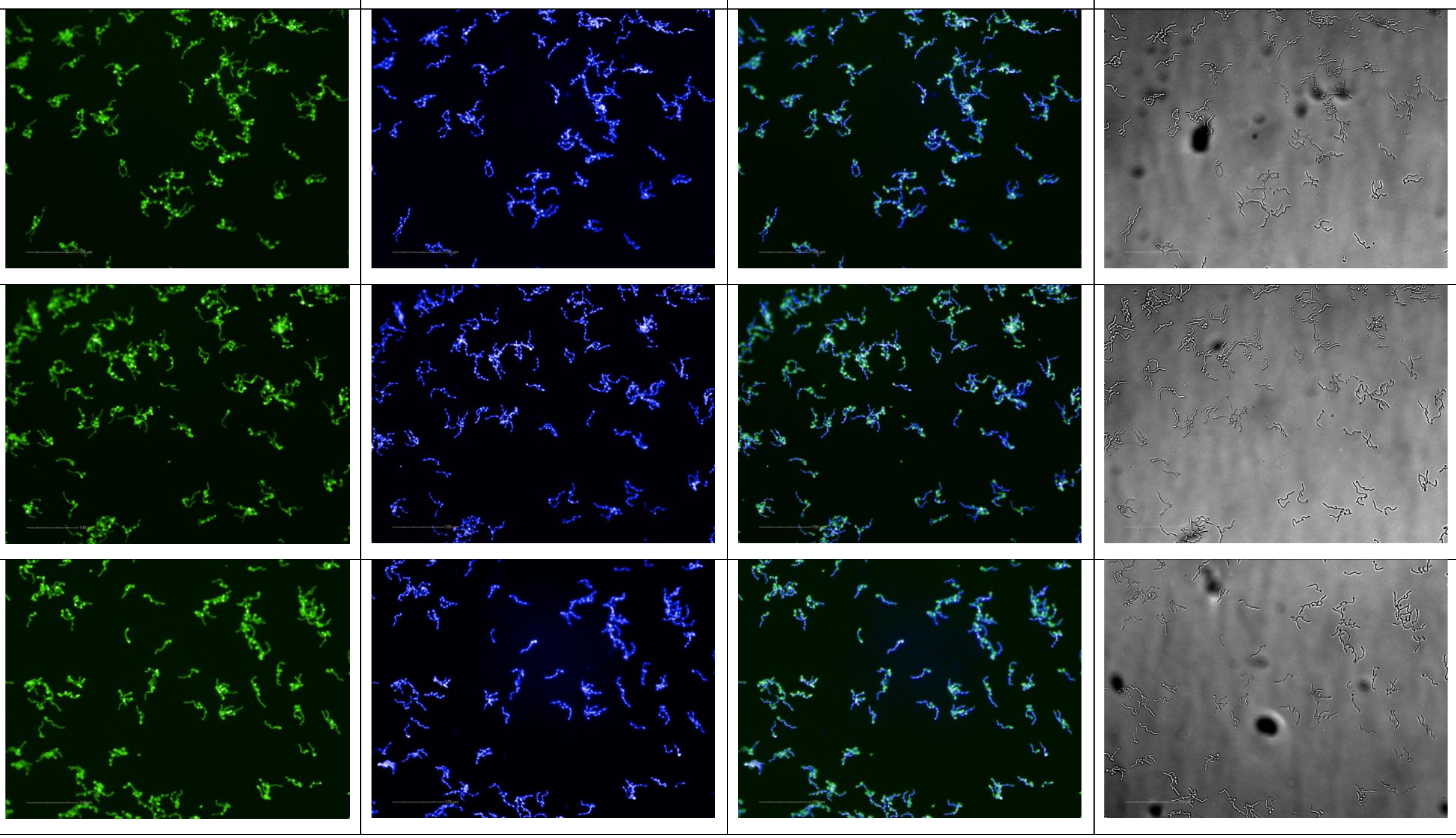
Table 44. Images taken from cells incubated with $100 \mu \mathrm{M}$ farnesol; C. albicans 101.

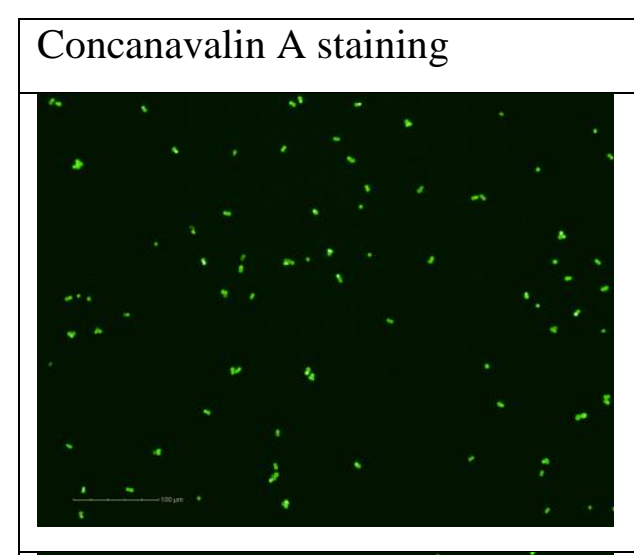

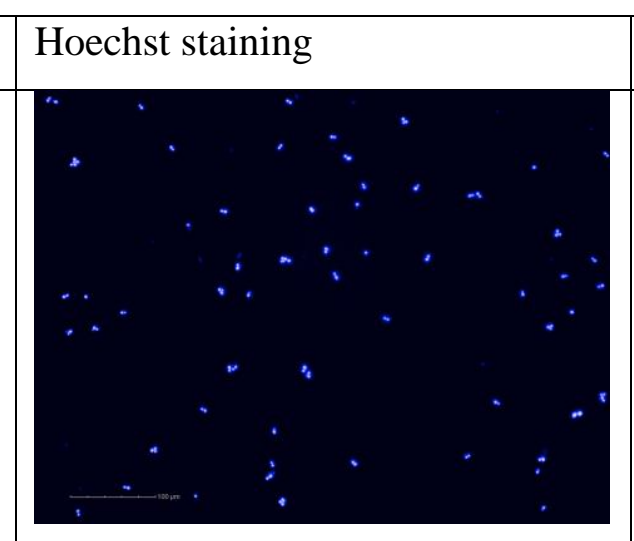

\section{Overlay}
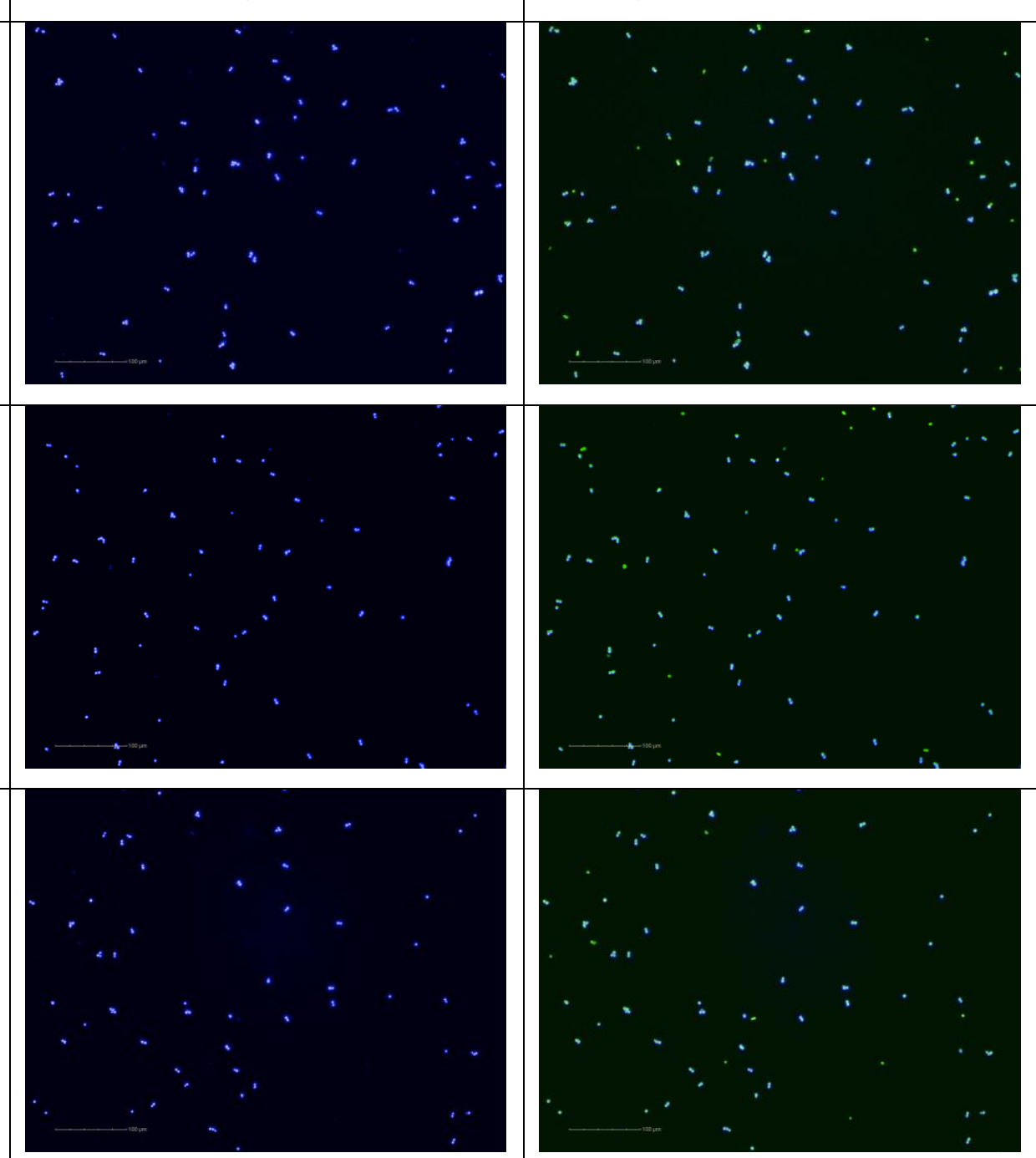

brightfield
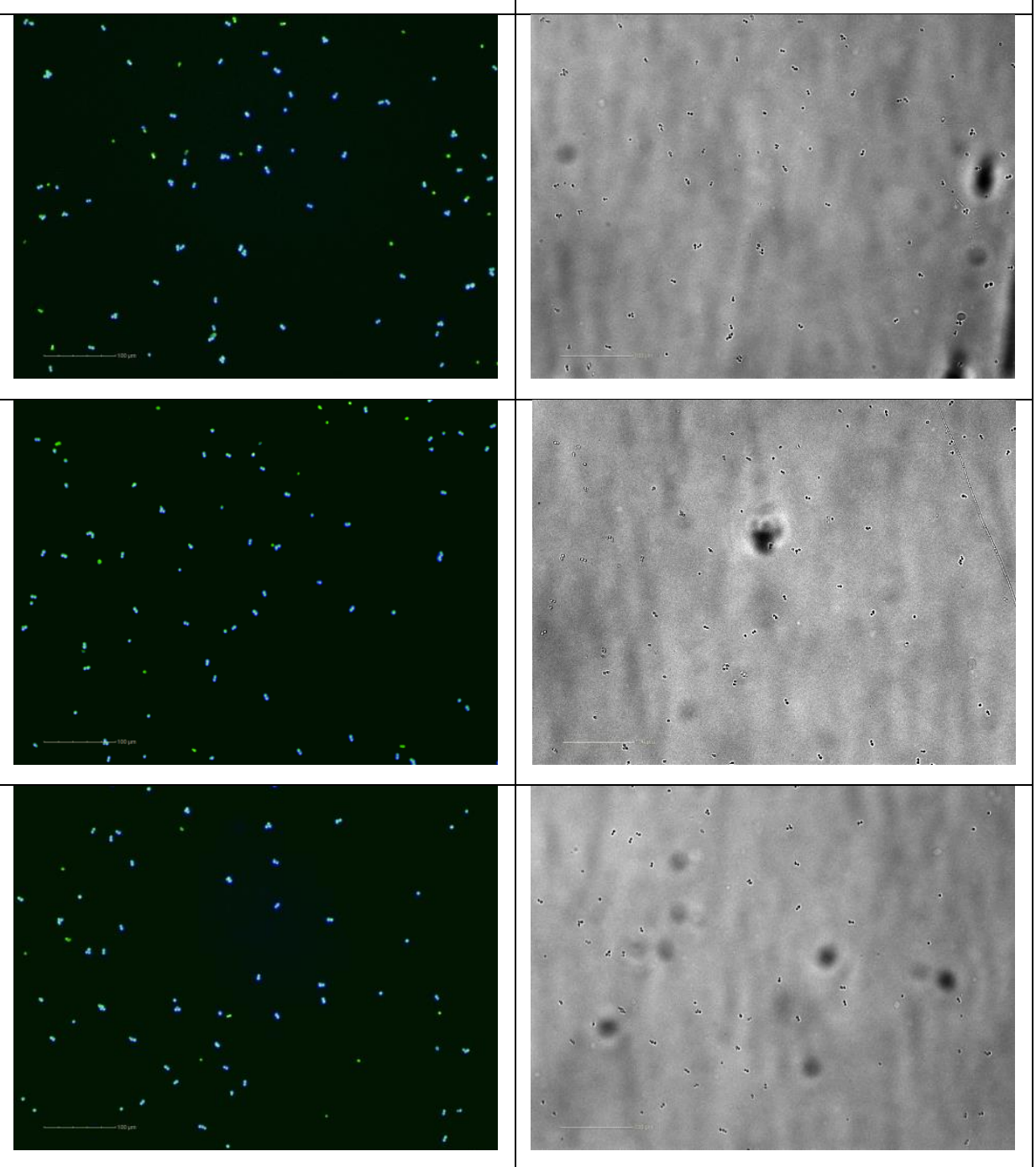
Table 45. Images taken from cells incubated with $200 \mu \mathrm{M}$ mutanobactin D; C. albicans 101 .

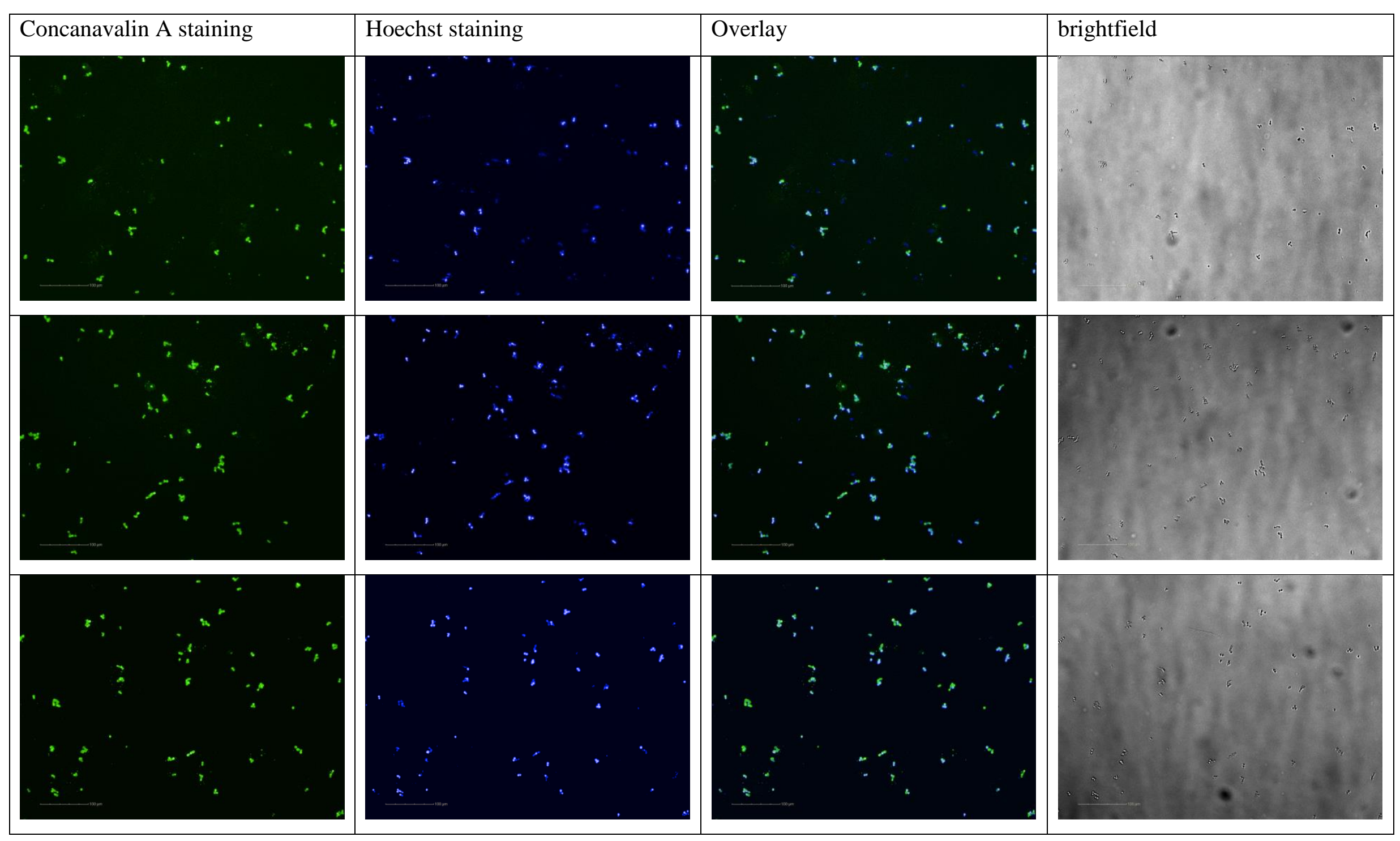


Table 46. Images taken from cells incubated with $100 \mu \mathrm{M}$ mutanobactin D; C. albicans 101 .

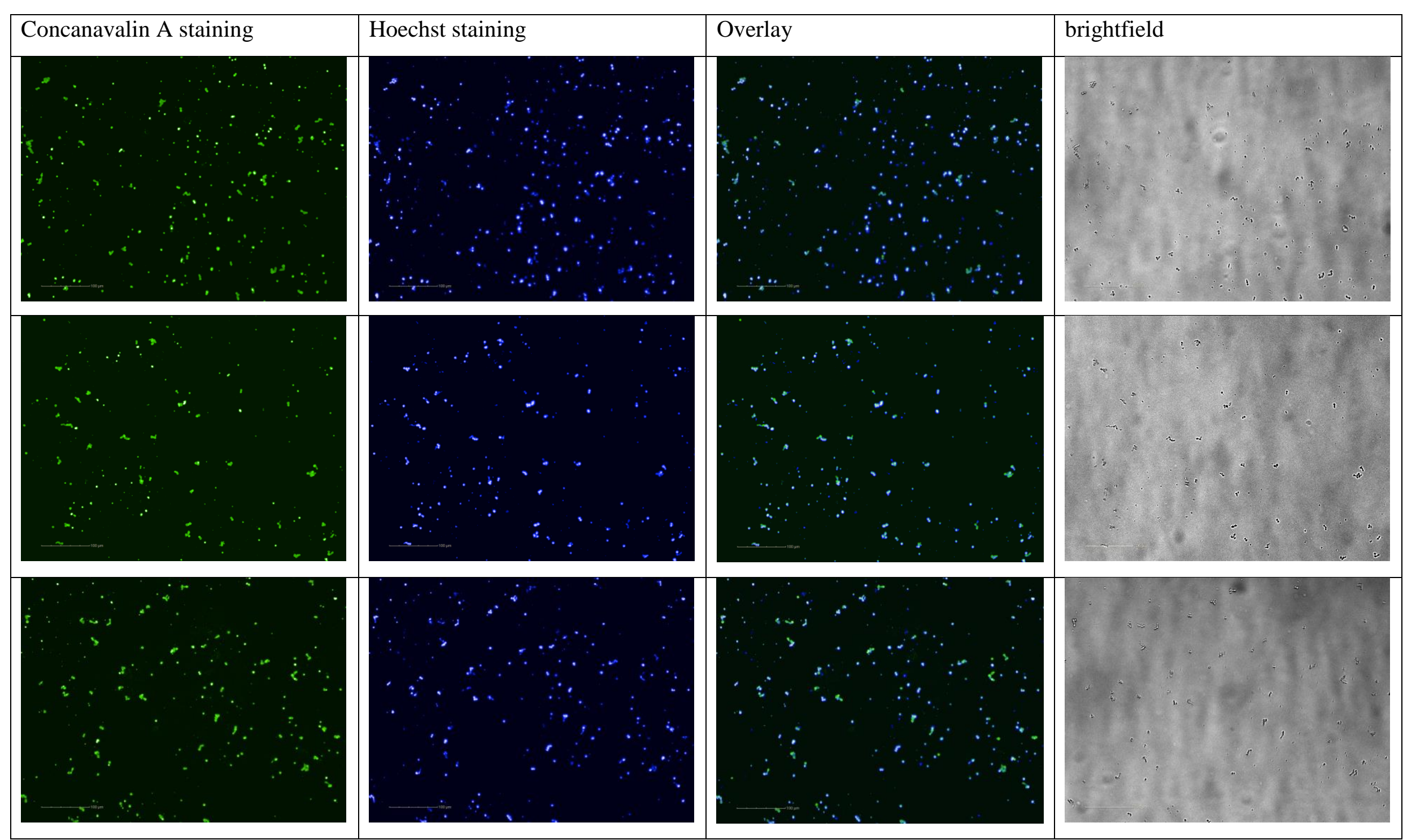


Table 47. Images taken from cells incubated with $75 \mu \mathrm{M}$ mutanobactin D; C. albicans 101.

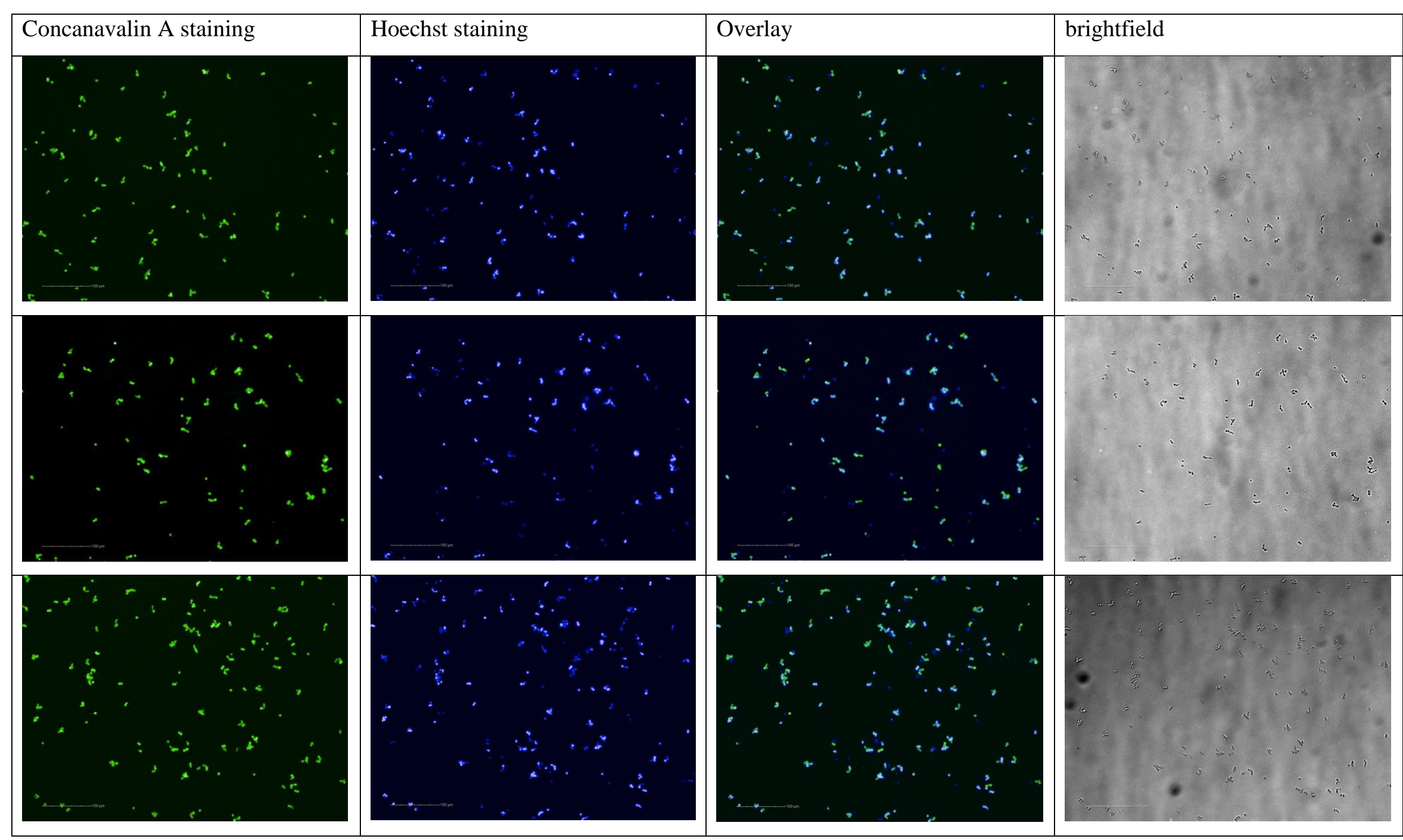


Table 48. Images taken from cells incubated with $50 \mu \mathrm{M}$ mutanobactin D; C. albicans 101.
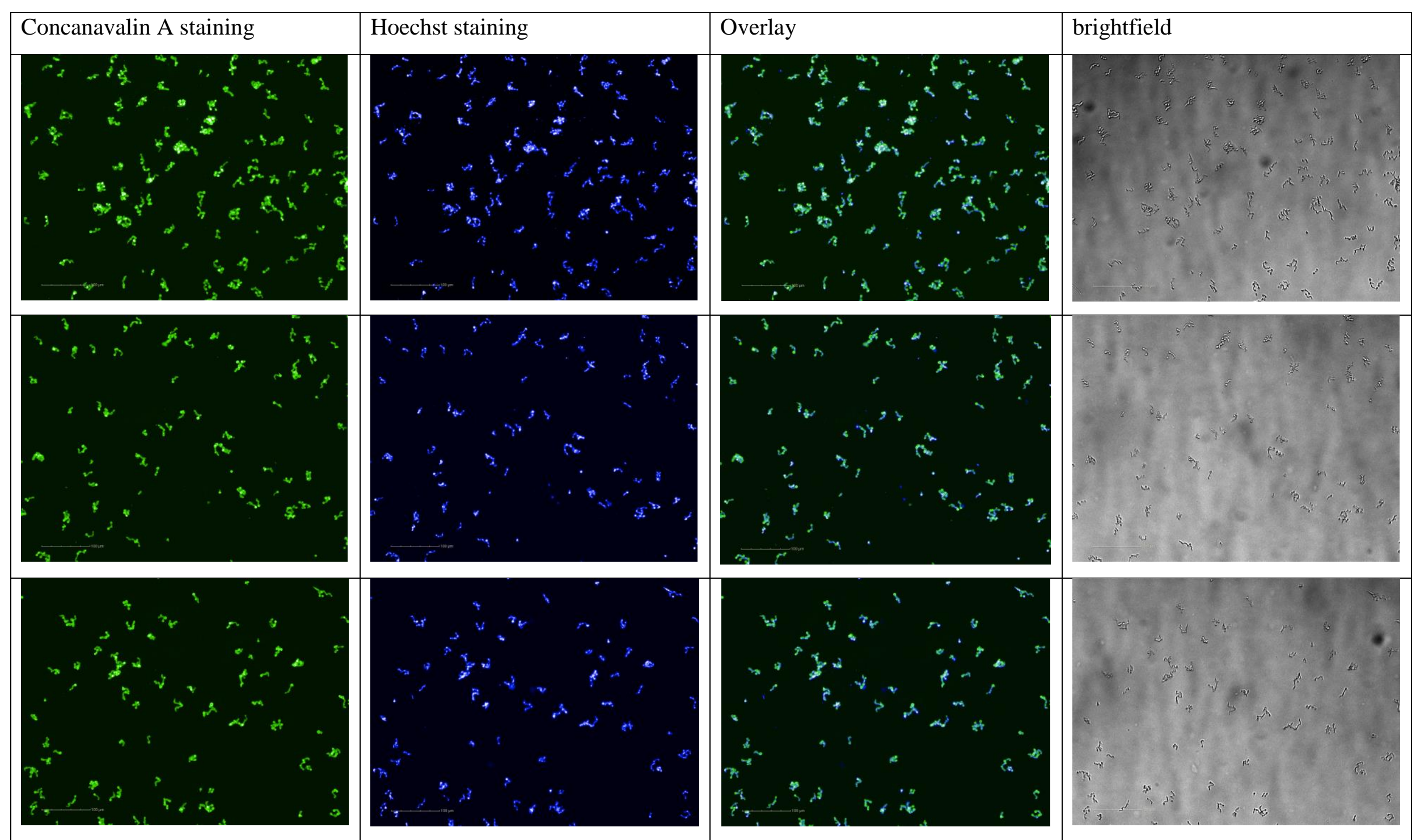
Table 49. Images taken from cells incubated with $25 \mu \mathrm{M}$ mutanobactin D; C. albicans 101.

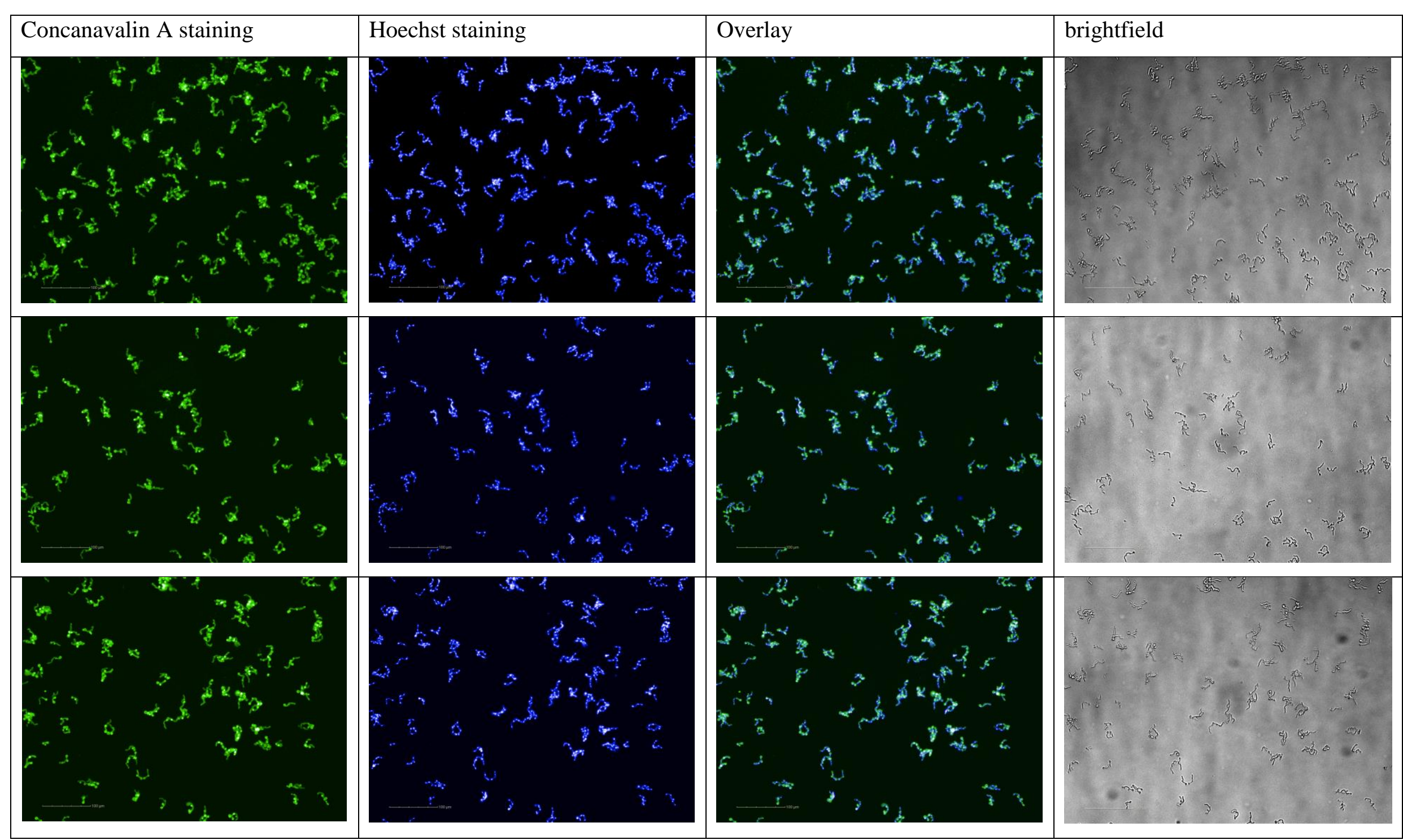


Table 50. Images taken from cells incubated with $10 \mu \mathrm{M}$ mutanobactin D; C. albicans 101.
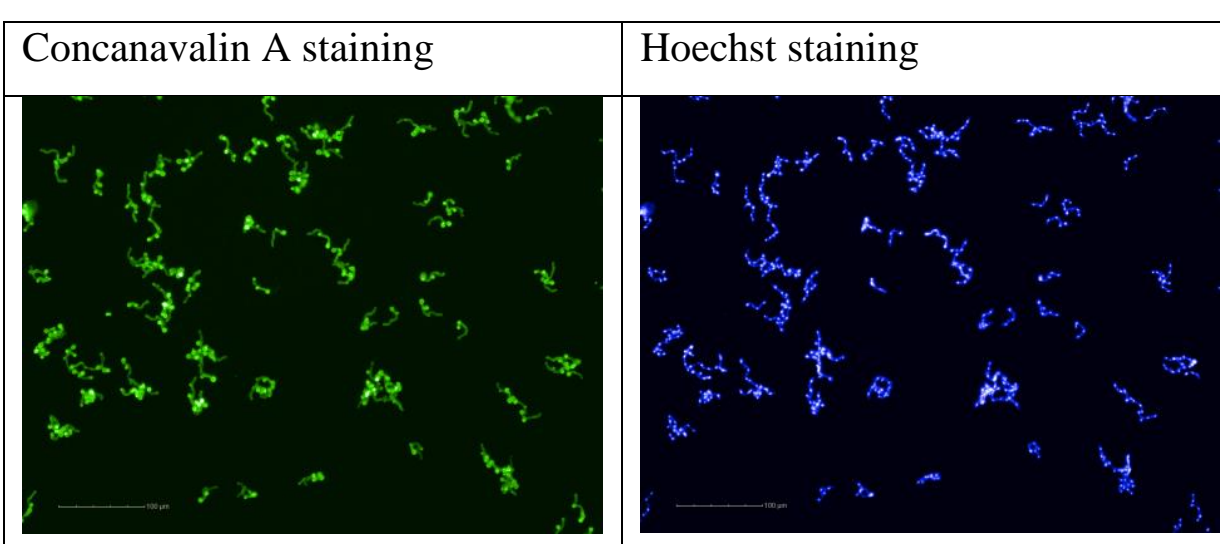

Overlay
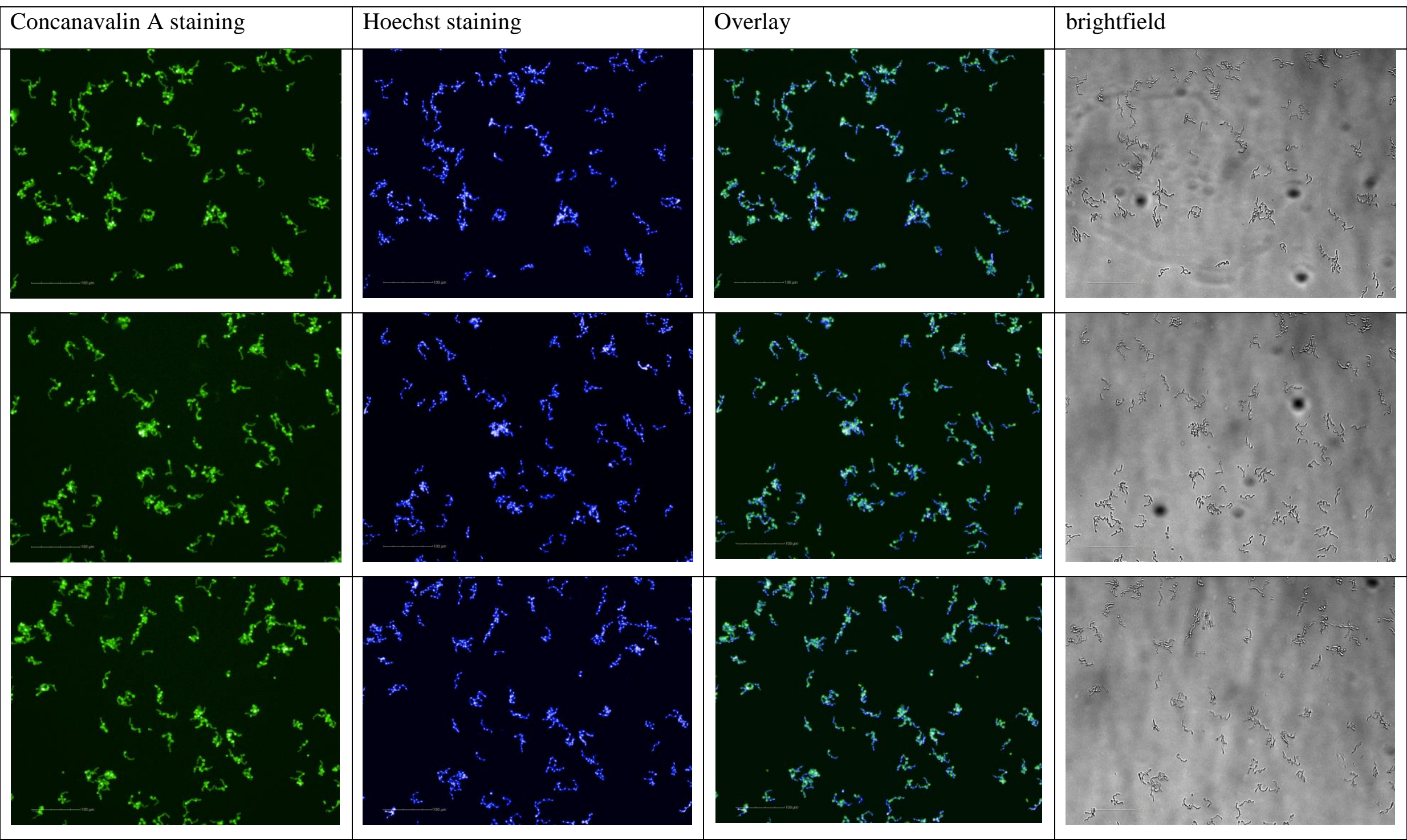
Table 51. Images taken from cells incubated with $1 \mu \mathrm{M}$ mutanobactin $\mathrm{D}$; C. albicans 101.
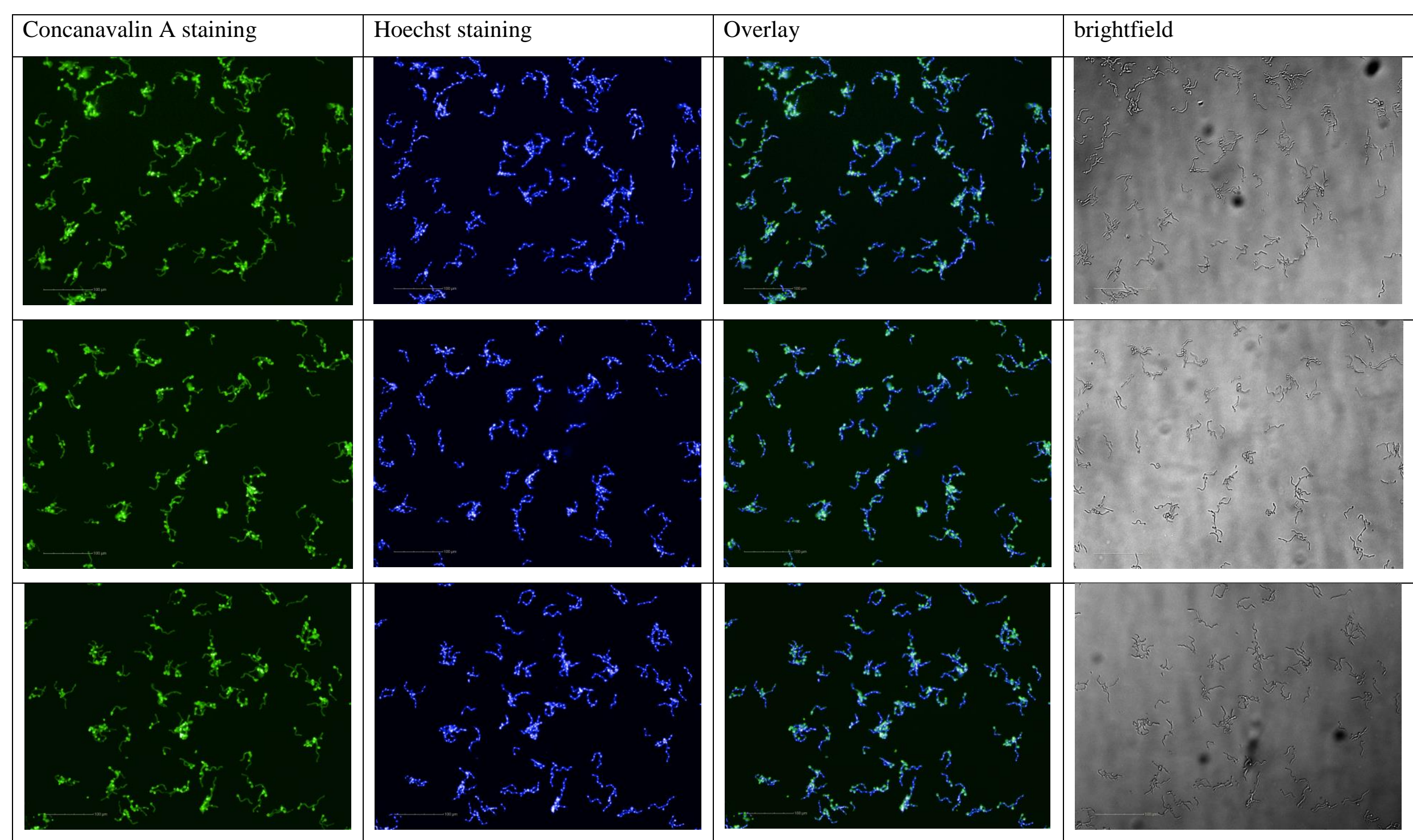


\section{Filamentation Assays and Virulence Gene Expression Analysis}

\subsection{General Consideration}

Fungal strains: Candida albicans strain ATCC 90028 was purchased from ATCC. Strains SC5314 and 101 were described previously. ${ }^{50,51}$

\section{Reagents:}

YPD medium was composed of 2\% (w/v) glucose (Sigma, Buchs, Switzerland), $1 \%$ (w/v) yeast extract (BD, Allschwil, Switzerland), and 2\% (w/v) bactopeptone (BD, Allschwil, Switzerland). For solid medium, 2\% (w/v) agar (Sigma-Aldrich, Buchs, Switzerland) was added prior to autoclaving.

Hams's Nutrient Mixture F12 medium (Sigma, Buchs, Switzerland) was supplemented with LGlutamine, Penicillin, Streptomycin, and 1\% FCS.

Paraformaldehyde 4\% was purchased from Santa Cruz Biotechnologies (Heidelberg, Germany), and Calcofluor White stain was from Sigma-Aldrich (Buchs, Switzerland).

Compound preparation: A stock solutions of mutanobactin D 1 was prepared in DMSO at $10 \mathrm{mM}$. Diluting this stock to the final concentration of $50 \mu \mathrm{M}$ in F12 medium yielded a final DMSO concentration of $0.5 \%$, which does not interfere with $C$. albicans filamentation (data not shown).

Microscopy: Fluorescence and Bright field images were acquired using a Zeiss Axio Observer $\mathrm{Z} 1$ inverted phase contrast fluorescence microscope.

Software: The hyphae length was quantified using ImageJ software. ${ }^{52}$ Gene expression and fold change calculations were done using Microsoft Excel. All graphs and statistical calculations were done with Graph Pad Prism 6.0.

\subsection{Experimental Procedures for Filamentation Assays and Virulence Gene Expression Analysis}

Culturing of yeast cells: C. albicans strains were maintained on YPD agar plates for short term and in glycerol-supplemented medium at $-80^{\circ} \mathrm{C}$ for long term storage. A preculture was prepared by inoculating $5 \mathrm{~mL}$ YPD medium with several yeast colonies from a fresh agar plate and by incubating it at $30{ }^{\circ} \mathrm{C}$ and $180 \mathrm{rpm}$ for $8 \mathrm{~h} .10 \mathrm{~mL}$ fresh YPD were then inoculated from the preculture at $\mathrm{OD}_{600} 0.1$ and grown at $30{ }^{\circ} \mathrm{C}$ and $180 \mathrm{rpm}$ for $18 \mathrm{~h}$. Yeast cells were washed 
in PBS and the concentration was determined by spectrophotometry, whereby $\mathrm{OD}_{600} 1=10^{7}$ yeast cells.

Measuring filamentation length: $5 \times 10^{4}$ yeast cells were seeded in F12 medium supplemented with $50 \mu \mathrm{M}$ compound 1 or solvent in a 24 well tissue-culture plate and incubated at $37{ }^{\circ} \mathrm{C}$ for 3.5 - 4 h. C. albicans was fixed in $4 \%$ PFA for $30 \mathrm{~min}$ at $4{ }^{\circ} \mathrm{C}$ and washed with PBS prior image acquisition. For imaging at 24 h, C. albicans was fixed in PFA as described above and stained with $10 \mu \mathrm{g} / \mathrm{mL}$ calcofluor white for $20 \mathrm{~min}$ at room temperature and protected from light. The samples were rinsed with water prior image acquisition. Images were acquired using a Zeiss Axio Observer Z1 inverted phase contrast fluorescence microscope. 4 fields per well were imaged. Hyphal length of $>450$ individual filaments per sample ( 2 replicate wells) was measured using the ImageJ software. ${ }^{52}$

Virulence gene expression analysis: $5 \times 10^{4}$ yeast cells were seeded in F12 medium supplemented with $50 \mu \mathrm{M}$ compound 1 or solvent in 3 replicate wells of a 24 well tissue-culture plate and incubated at $37{ }^{\circ} \mathrm{C}$ for $24 \mathrm{~h}$. Fungal RNA was isolated with the RNeasy® Mini Kit (Quiagen). Briefly, the medium was removed and C. albicans cells were harvested using lysis buffer (RLT) and homogenized with Tissue Lyzer (Qiagen) 7 times for 2 minutes at $30 \mathrm{~Hz}$ interrupted by $30 \mathrm{sec}$ cooling periods on ice. Cell debris were removed by centrifugation. One volume of $75 \%$ ethanol was admixed, and each sample was transferred to an RNeasy spin column. The loaded columns were washed using RW1 buffer and RPE buffer. RNA was eluted in $30 \mu 1$ RNAse-free water. cDNA was generated by RevertAid reverse transcriptase (Thermo Fisher). RT-qPCR was performed using SYBR Green (Roche) and a QuantStudio 7 Flex (Life Technology) instrument.

The primers were: ACT1 fwd 5'- TGCTGAACGTATGCAAAAGG -3', ACT1 rev 5'TGAACAATGGATGGACCAGA -3'; ECE1 fwd 5'- CCAAAATTGCCTGTGCTACTG -3', ECE1 rev 5'- CTCTTCATGTTGAATTCTGGAGC -3'; SAP2 fwd 5'GGGTTCCTGATGTTAATGTTGATTG -3', SAP2 rev 5'GAAACACCACCAAATCCAACG -3'.

All RT-qPCR assays were performed in duplicates and the relative expression of each gene was determined after normalization to ACTI transcript levels. The fold change relative to the mean of the relative expression levels of solvent-treated samples was calculated for each sample. Results are shown in Figure 45. 
Statistical analysis: Statistical significance was determined by two-tailed unpaired Student's t-test using GraphPad Prism (GraphPad Software Inc., La Jolla, CA) with *P 0.05; **P 0.01; $* * * \mathrm{P} 0.001 ; * * * * \mathrm{P} 0.0001$.

\subsection{Representative Images of $C$. albicans Filaments}

A.

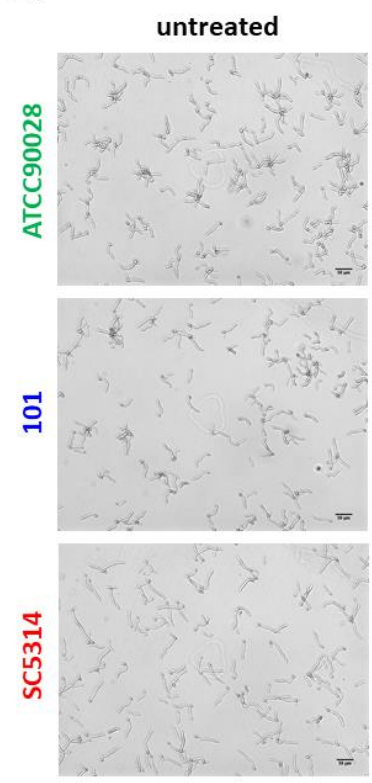

B. $50 \mu \mathrm{M}$ Mutanobactin D
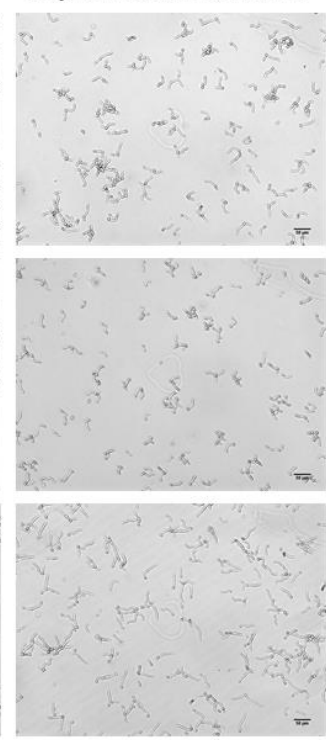

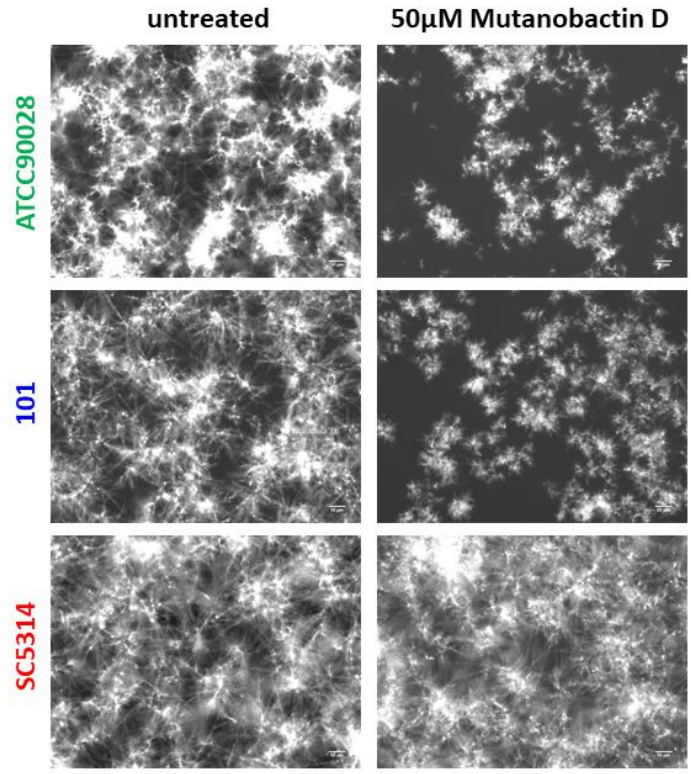

Figure 44. (A) Representative images for each C. albicans strain treated with $50 \mu \mathrm{M}$ compound 1 or solvent for $3.5-4 \mathrm{~h}$, which were used for quantification of filament length shown. Size bar, $50 \mu \mathrm{m}$; (B) Representative images for each C. albicans strain treated with $50 \mu \mathrm{M}$ compound 1 or solvent for $24 \mathrm{~h}$. At this time point, C. albicans cells and filaments formed dense clusters that could not be quantified. Size bar, $50 \mu \mathrm{m}$.

\subsection{Virulence Gene Expression Analysis}
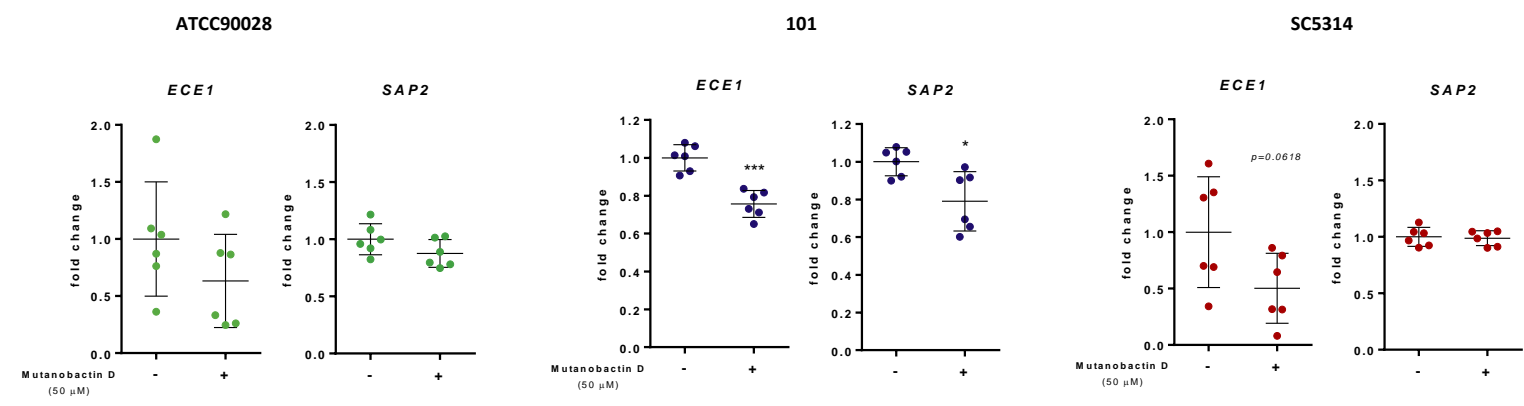

Figure 45. 1 affects $C$. albicans virulence genes beyond filamentation. ECE1 and SAP2 transcripts were quantified in $C$. albicans strains ATCC90028 (green), 101 (blue) and SC5314 (red) after $24 \mathrm{~h}$ of incubation in F12 medium supplemented with $1 \mathrm{D}(+)$ or not $(-)$, as indicated. Each dot represents one sample, data were pooled from 2 independent experiments with 3 samples each. 


\section{Influence of Mutanobactin D on Bacteria of the Oral Microbiome}

The effect of synthetic mutanobactin $\mathrm{D}$ on the planktonic growth of other members of the oral consortium was investigated. Therefore, in addition to $S$. mutans UA159 (OMZ 918) and $C$. albicans ATCC90028, six additional species, all representatives of the supragingival plaque that is linked to cariogenic biofilm formation, were chosen, namely, Actinomyces oris MG1 (OMZ 745), Streptococcus oralis SK248 (OMZ 607), Streptococcus anginosus ATCC 9895 (OMZ 871), Streptococcus gordonii (DSM6777), Veillonella dispar ATCC 17748 (OMZ 493), and Fusobacterium nucleatum ATCC 1095 (OMZ 598).

The bacterial strains were routinely cultivated anaerobically at $37{ }^{\circ} \mathrm{C}$ in brain-heart infusion broth (Oxoid). V. dispar was cultivated in BHI containing 1\% sodium lactate (Sigma). C. albicans was cultivated in yeast nitrogen base without amino acids (Sigma Aldrich) containing $0.1 \%$ glucose and $0.2 \%$ maltose at $30{ }^{\circ} \mathrm{C}, 200 \mathrm{rpm}$. The effect of mutanobactin $\mathrm{D}$ on the planktonic growth was assessed in a microtiter assay. In brief, $100 \mu \mathrm{L}$ of brain heart infusion broth containing the appropriate growth additives for each strain and either 0.5\% DMSO for the untreated control or mutanobactin D at concentrations of $100 \mu \mathrm{M}, 50 \mu \mathrm{M}, 30 \mu \mathrm{M}, 20 \mu \mathrm{M}$ and $10 \mu \mathrm{M}$ were inoculated with bacteria to an $\mathrm{OD}_{600}$ of 0.1 . Plates were incubated anaerobically for $64 \mathrm{~h}$ at $37^{\circ} \mathrm{C}$ and the optical density was measured using a Tecan microplate reader Infinite M200. C. albicans was cultivated aerobically at $37^{\circ} \mathrm{C}$ in RPMI (Sigma Aldrich). For each strain and culture condition, three independent experiments with three technical replicates were performed. Analysis of variance (ANOVA) in conjunction with Dunnett's multiple comparison test was used to evaluate the differences between the control and each experimental group $(\mathrm{P} \leq 0.05)$. Furthermore, bacterial growth was analyzed through bright-field phase contrast microscopy using a TE2000-S Nikon epifluorescence microscope. Bacteria were incubated with $0.5 \%$ DMSO or mutanobactin D at $100 \mu \mathrm{M}$ as described above. After centrifugation, the supernatant was removed and the cells were washed once in 1x PBS, prior to microscopic analysis (Table 52). 
Table 52. Bright-field phase contrast images of bacteria treated with $100 \mu \mathrm{M}$ mutanobactin D compared to the untreated control (0.5\% DMSO). 40x objective; scale bar $200 \mu \mathrm{m}$.

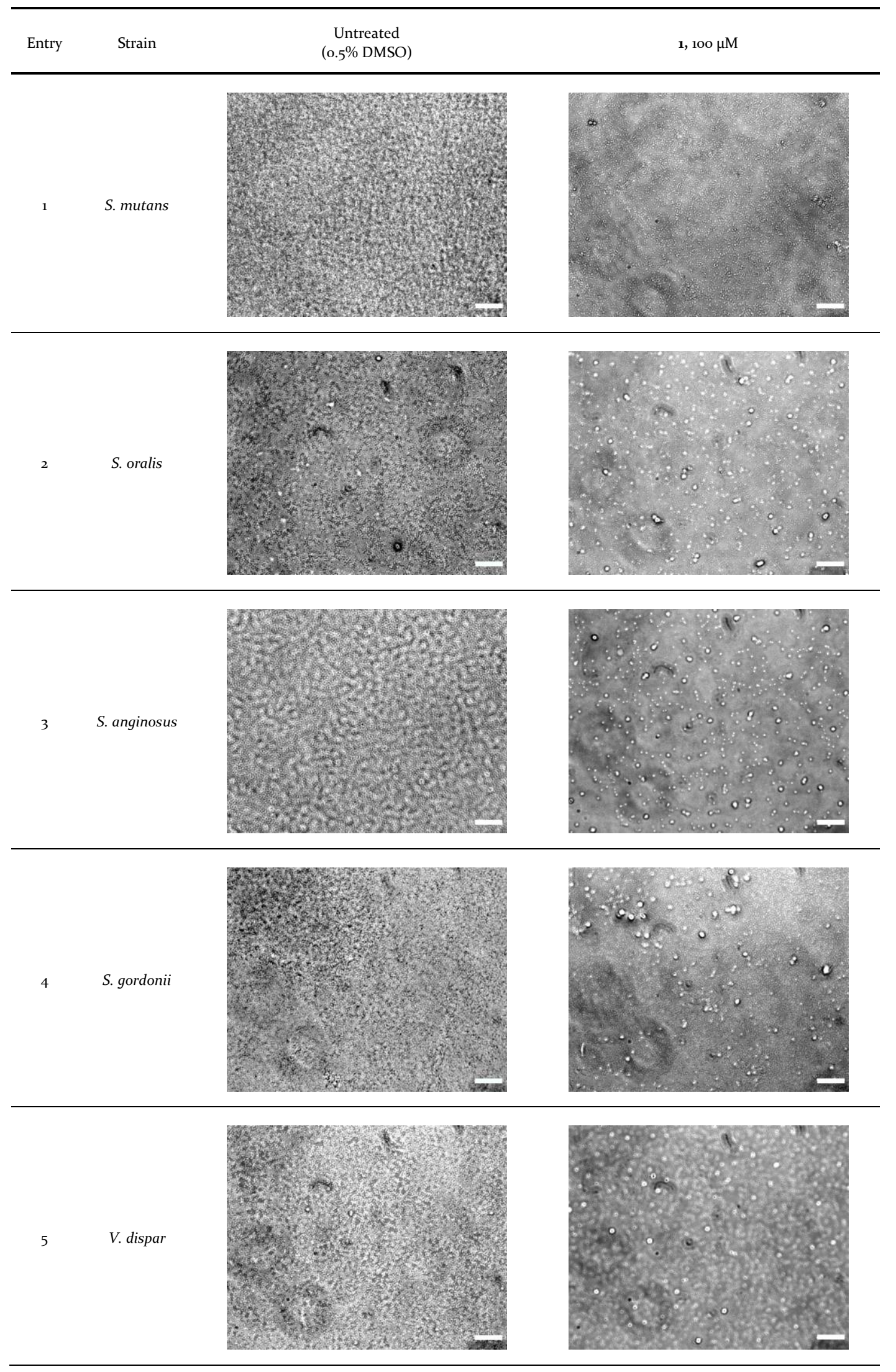




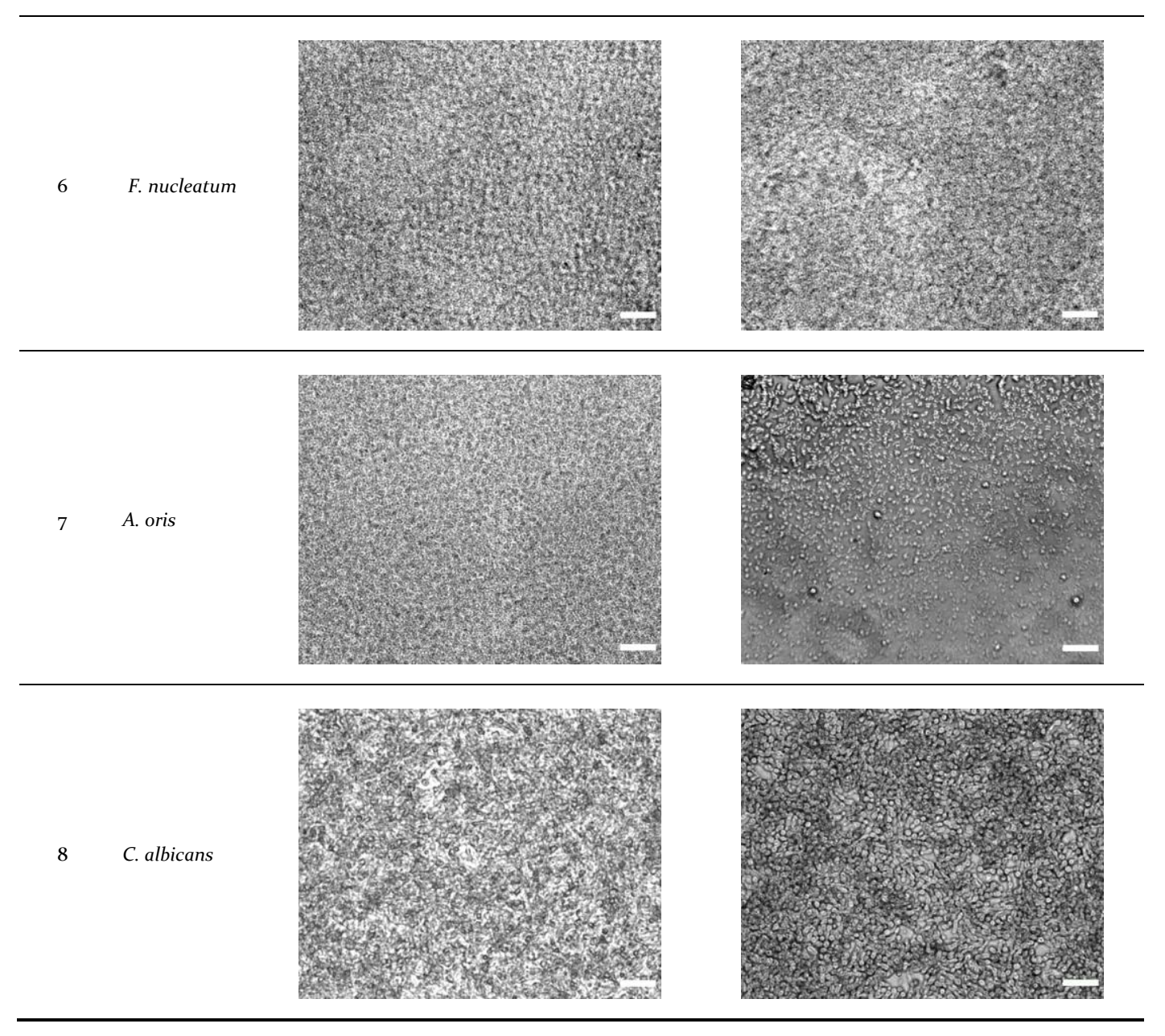




\section{References}

(1) Biraboneye, A. C.; Madonna, S.; Maher, P.; Kraus, J.-L. Neuroprotective Effects of N Alkyl-1,2,4-Oxadiazolidine-3,5-Diones and Their Corresponding Synthetic Intermediates $\mathrm{N}$-Alkylhydroxylamines and $\mathrm{N}$-1-Alkyl-3-Carbonyl-1-Hydroxyureas against in Vitro Cerebral Ischemia. ChemMedChem 2010, 5 (1), 79-85. https://doi.org/10.1002/cmdc.200900418.

(2) ETHYL 4-HYDROXYCROTONATE. Org. Synth. 1986, 64, 104. https://doi.org/10.15227/orgsyn.064.0104.

(3) Kubas, G. J.; Sluys, L. S. Van Der; Doyle, R. A.; Angelici, R. J. Tricarbonyltris(Nitrile) Complexes of Cr, Mo, and W. Inorg. Synth. 2007, 28, 29-33. https://doi.org/10.1002/9780470132593.ch6.

(4) Seebach, D.; Imwinkelried, R.; Stucky, G. Optisch Aktive Alkohole Aus 1,3-Dioxan-4Onen: Eine Praktikable Variante Der Enantioselektiven Synthese Unter Nucleophiler Substitution an Acetal-Zentren. Helv. Chim. Acta 1987, 70 (2), 448-464. https://doi.org/10.1002/hlca.19870700226.

(5) Bräse, S.; Mende, M.; Jobelius, H. H.; Scharf, H.-D. Hydrazoic Acid and Azides. In Ullmann's Encyclopedia of Industrial Chemistry; Wiley-VCH Verlag GmbH \& Co. KGaA: Weinheim, Germany, 2015; pp 1-11. https://doi.org/10.1002/14356007.a13_193.pub2.

(6) Gutmann, B.; Obermayer, D.; Roduit, J.-P.; Roberge, D. M.; Kappe, C. O. Safe Generation and Synthetic Utilization of Hydrazoic Acid in a Continuous Flow Reactor. J. Flow Chem. 2012, 2 (1), 8-19. https://doi.org/10.1556/jfchem.2012.00021.

(7) Conrow, R. E.; Dean, W. D. Diazidomethane Explosion. Org. Process Res. Dev. 2008, 12 (6), 1285-1286. https://doi.org/10.1021/op8000977.

(8) Kesornpun, C.; Aree, T.; Mahidol, C.; Ruchirawat, S.; Kittakoop, P. Water-Assisted Nitrile Oxide Cycloadditions: Synthesis of Isoxazoles and Stereoselective Syntheses of Isoxazolines and 1,2,4-Oxadiazoles. Angew. Chem. Int. Ed. 2016, 55 (12), 3997-4001. https://doi.org/10.1002/anie.201511730.

(9) Yang, K.; Zhang, F.; Fang, T.; Zhang, G.; Song, Q. Stereospecific 1,4-Metallate Shift Enables Stereoconvergent Synthesis of Ketoximes. Angew. Chem. Int. Ed. 2019, 58 (38), 
13421-13426. https://doi.org/10.1002/anie.201906057.

(10) Shimizu, M.; Ukaji, Y.; Inomata, K. Catalytic Asymmetric 1,3-Dipolar Cycloaddition of Nitrile Oxides to an Achiral Allyl Alcohol Utilizing Diisopropyl Tartrate as a Chiral Auxiliary. Chem. Lett. 1996, 25 (6), 455-456. https://doi.org/10.1246/cl.1996.455.

(11) Yoshida, Y.; Ukaji, Y.; Fujinami, S.; Inomata, K. Asymmetric 1,3-Dipolar Cycloaddition of Nitrile Oxides to $\gamma$-Substituted Allylic Alcohols. Chem. Lett. 1998, 27 (10), 10231024. https://doi.org/10.1246/cl.1998.1023.

(12) Corey, E. J.; Venkateswarlu, A. Protection of Hydroxyl Groups as TertButyldimethylsilyl Derivatives. J. Am. Chem. Soc. 1972, 94 (17), 6190-6191. https://doi.org/10.1021/ja00772a043.

(13) Olsson, T.; Stern, K.; Sundell, S. Asymmetric 1,3-Dipolar Cycloadditions of Nitrile Oxides Using Simple Chiral Auxiliaries. J. Org. Chem. 1988, 53 (11), 2468-2472. https://doi.org/10.1021/jo00246a014.

(14) Tang, H.; Yusuff, N.; Wood, J. L. Progress toward the Total Synthesis of Ingenol: Construction of the Complete Carbocyclic Skeleton. Org. Lett. 2001, 3 (10), 1563-1566. https://doi.org/10.1021/o1015855a.

(15) Crossland, R. K.; Servis, K. L. Facile Synthesis of Methanesulfonate Esters. J. Org. Chem. 1970, 35 (9), 3195-3196. https://doi.org/10.1021/jo00834a087.

(16) Scriven, E. F. V.; Turnbull, K. Azides: Their Preparation and Synthetic Uses. Chem. Rev. 1988, 88 (2), 297-368. https://doi.org/10.1021/cr00084a001.

(17) Molteni, G.; Buttero, P. Del. A Bicyclo[3.1.1]Heptano[4,3-c]Pyrazole Derived Chiral Auxiliary for Dipolar Cycloadditions. Tetrahedron: Asymmetry 2005, 16 (11), 19831987. https://doi.org/10.1016/j.tetasy.2005.04.014.

(18) McKinney, W. Data Structures for Statistical Computing in Python; 2010; pp 56-61. https://doi.org/10.25080/Majora-92bf1922-00a.

(19) Hunter, J. D. Matplotlib: A 2D Graphics Environment. Comput. Sci. Eng. 2007, 9 (3), 90-95. https://doi.org/10.1109/MCSE.2007.55.

(20) Pedregosa, F.; Varoquaux, G.; Gramfort, A.; Michel, V.; Thirion, B.; Grisel, O.; Blondel, M.; Prettenhofer, P.; Weiss, R.; Dubourg, V.; et al. Scikit-Learn: Machine Learning in Python. J. Mach. Learn. Res. 2011, 12 (85), 2825-2830. 
(21) Harris, C. R.; Millman, K. J.; van der Walt, S. J.; Gommers, R.; Virtanen, P.; Cournapeau, D.; Wieser, E.; Taylor, J.; Berg, S.; Smith, N. J.; et al. Array Programming with NumPy. Nature 2020, 585 (7825), 357-362. https://doi.org/10.1038/s41586-0202649-2.

(22) Zhao, M.; Li, J.; Song, Z.; Desmond, R.; Tschaen, D. M.; Grabowski, E. J. J.; Reider, P. J. A Novel Chromium Trioxide Catalyzed Oxidation of Primary Alcohols to the Carboxylic Acids. Tetrahedron Lett. 1998, 39 (30), 5323-5326. https://doi.org/10.1016/S0040-4039(98)00987-3.

(23) Hanessian, S.; Haskell, T. H. Sugar Lactams. II. 4-Amino-4-Deoxy-d-Erythronolactam and Related Products. J. Heterocycl. Chem. 1964, 1 (1), 57-58. https://doi.org/10.1002/jhet.5570010114.

(24) Liotta, C. L.; Harris, H. P. The Chemistry of "Naked" Anions. I. Reactions of the 18Crown-6 Complex of Potassium Fluoride with Organic Substrates in Aprotic Organic Solvents. J. Am. Chem. Soc. 1974, $96 \quad$ (7), 2250-2252. https://doi.org/10.1021/ja00814a044.

(25) Cook, F. L.; Bowers, C. W.; Liotta, C. L. Chemistry of "Naked" Anions. III. Reactions of the 18-Crown-6 Complex of Potassium Cyanide with Organic Substrates in Aprotic Organic Solvents. J. Org. Chem. 1974, 39 (23), 3416-3418. https://doi.org/10.1021/jo00937a026.

(26) Barlos, K.; Gatos, D.; Kallitsis, J.; Papaphotiu, G.; Sotiriu, P.; Wenqing, Y.; Schäfer, W. Darstellung Geschützter Peptid-Fragmente Unter Einsatz Substituierter Triphenylmethyl-Harze. Tetrahedron Lett. 1989, $30 \quad$ (30), 3943-3946. https://doi.org/10.1016/S0040-4039(00)99290-6.

(27) Wang, Y.; Han, L.; Yuan, N.; Wang, H.; Li, H.; Liu, J.; Chen, H.; Zhang, Q.; Dong, S. Traceless $\beta$-Mercaptan-Assisted Activation of Valinyl Benzimidazolinones in Peptide Ligations. Chem. Sci. 2018, 9 (7), 1940-1946. https://doi.org/10.1039/C7SC04148A.

(28) Davies, J. S. The Cyclization of Peptides and Depsipeptides. J. Pept. Sci. 2003, 9 (8), 471-501. https://doi.org/10.1002/psc.491.

(29) Albericio, F.; Cases, M.; Alsina, J.; Triolo, S. A.; Carpino, L. A.; Kates, S. A. On the Use of PyAOP, a Phosphonium Salt Derived from HOAt, in Solid-Phase Peptide Synthesis. Tetrahedron Lett. 1997, 38 (27), 4853-4856. https://doi.org/10.1016/S0040- 
4039(97)01011-3.

(30) Guarna, A.; Guidi, A.; Goti, A.; Brandi, A.; De Sarlo, F. Cleavage of Isoxazolines with Tricarbonyltris(Acetonitrile)Molybdenum and Silica Gel. Synthesis of 1-(2Oxoalkyl)Cyclopropanols from Lsoxazoline-5-Spirocyclopropanes. Synthesis 1989, 1989 (03), 175-178. https://doi.org/10.1055/s-1989-27185.

(31) Risley, J. M.; Van Etten, R. L. An Oxygen-18 Isotope Shift upon Carbon-13 NMR Spectra and Its Application to the Study of Oxygen Exchange Kinetics. J. Am. Chem. Soc. 1979, 101 (1), 252-253. https://doi.org/10.1021/ja00495a059.

(32) Lambert, K. M.; Cox, J. B.; Liu, L.; Jackson, A. C.; Yruegas, S.; Wiberg, K. B.; Wood, J. L. Total Synthesis of ( \pm )-Phyllantidine: Development and Mechanistic Evaluation of a Ring Expansion for Installation of Embedded Nitrogen-Oxygen Bonds. Angew. Chem. Int. Ed. 2020, 59 (24), 9757-9766. https://doi.org/10.1002/anie.202003829.

(33) Sondermann, P.; Carreira, E. M. Stereochemical Revision, Total Synthesis, and Solution State Conformation of the Complex Chlorosulfolipid Mytilipin B. J. Am. Chem. Soc. 2019, 141 (26), 10510-10519. https://doi.org/10.1021/jacs.9b05013.

(34) Kessler, H. Conformation and Biological Activity of Cyclic Peptides. Angew. Chemie Int. Ed. 1982, 21 (7), 512-523. https://doi.org/10.1002/anie.198205121.

(35) Haasnoot, C. A. G.; de Leeuw, F. A. A. M.; Altona, C. The Relationship between ProtonProton NMR Coupling Constants and Substituent Electronegativities-I. Tetrahedron 1980, 36 (19), 2783-2792. https://doi.org/10.1016/0040-4020(80)80155-4.

(36) Altona, C. Vicinal Coupling Constants and Conformation of Biomolecules. In Encyclopedia of NMR; Harris, R. K., Wasylishen, R. E., Eds.; John Wiley \& Sons, Inc.: New York, 2012; pp 5364-5377.

(37) Bystrov, V. F. Spin-Spin Coupling and the Conformational States of Peptide Systems. Prog. Nucl. Magn. Reson. Spectrosc. 1976, 10 (2), 41-82. https://doi.org/10.1016/00796565(76)80001-5.

(38) Dorman, D. E.; Bovey, F. A. Carbon-13 Magnetic Resonance Spectroscopy. Spectrum of Proline in Oligopeptides. J. Org. Chem. 1973, 38 (13), 2379-2383. https://doi.org/10.1021/jo00953a021.

(39) Cierpicki, T.; Otlewski, J. Amide Proton Temperature Coefficients as Hydrogen Bond 
Indicators in Proteins. J. Biomol. NMR 2001, 21 (3), 249-261. https://doi.org/10.1023/A:1012911329730.

(40) Wang, A. C.; Bax, A. Determination of the Backbone Dihedral Angles $\varphi$ in Human Ubiquitin from Reparametrized Empirical Karplus Equations. J. Am. Chem. Soc. 1996, 118 (10), 2483-2494. https://doi.org/10.1021/ja9535524.

(41) Neese, F. Software Update: The ORCA Program System, Version 4.0. Wiley Interdiscip. Rev. Comput. Mol. Sci. 2018, 8 (1), 4-9. https://doi.org/10.1002/wcms.1327.

(42) Hawkins, P. C. D.; Skillman, A. G.; Warren, G. L.; Ellingson, B. A.; Stahl, M. T. Conformer Generation with OMEGA: Algorithm and Validation Using High Quality Structures from the Protein Databank and Cambridge Structural Database. J. Chem. Inf. Model. 2010, 50 (4), 572-584. https://doi.org/10.1021/ci100031x.

(43) Feyereisen, M.; Fitzgerald, G.; Komornicki, A. Use of Approximate Integrals in Ab Initio Theory. An Application in MP2 Energy Calculations. Chem. Phys. Lett. 1993, 208 (5-6), 359-363. https://doi.org/10.1016/0009-2614(93)87156-W.

(44) Becke, A. D. Density-Functional Exchange-Energy Approximation with Correct Asymptotic Behavior. Phys. Rev. A 1988, 38 (6), 3098-3100. https://doi.org/10.1103/PhysRevA.38.3098.

(45) Weigend, F.; Ahlrichs, R. Balanced Basis Sets of Split Valence, Triple Zeta Valence and Quadruple Zeta Valence Quality for H to Rn: Design and Assessment of Accuracy. Phys. Chem. Chem. Phys. 2005, 7 (18), 3297-3305. https://doi.org/10.1039/b508541a.

(46) Grimme, S.; Antony, J.; Ehrlich, S.; Krieg, H. A Consistent and Accurate Ab Initio Parametrization of Density Functional Dispersion Correction (DFT-D) for the 94 Elements H-Pu. J. Chem. Phys. 2010, 132 (15), 154104. https://doi.org/10.1063/1.3382344.

(47) Kesharwani, M. K.; Brauer, B.; Martin, J. M. L. Frequency and Zero-Point Vibrational Energy Scale Factors for Double-Hybrid Density Functionals (and Other Selected Methods): Can Anharmonic Force Fields Be Avoided? J. Phys. Chem. A 2015, 119 (9), 1701-1714. https://doi.org/10.1021/jp508422u.

(48) Böselt, L.; Sidler, D.; Kittelmann, T.; Stohner, J.; Zindel, D.; Wagner, T.; Riniker, S. Determination of Absolute Stereochemistry of Flexible Molecules Using a Vibrational Circular Dichroism Spectra Alignment Algorithm. J. Chem. Inf. Model. 2019, 59 (5), 
1826-1838. https://doi.org/10.1021/acs.jcim.8b00789.

(49) Böselt, L.; Dötzer, R.; Steiner, S.; Stritzinger, M.; Salzmann, S.; Riniker, S. Determining the Regiochemistry and Relative Stereochemistry of Small and Druglike Molecules Using an Alignment Algorithm for Infrared Spectra. Anal. Chem. 2020, 92 (13), 91249131. https://doi.org/10.1021/acs.analchem.0c01399.

(50) Schönherr, F. A.; Sparber, F.; Kirchner, F. R.; Guiducci, E.; Trautwein-Weidner, K.; Gladiator, A.; Sertour, N.; Hetzel, U.; Le, G. T. T.; Pavelka, N.; et al. The Intraspecies Diversity of C. Albicans Triggers Qualitatively and Temporally Distinct Host Responses That Determine the Balance between Commensalism and Pathogenicity. Mucosal Immunol. 2017, 10 (5), 1335-1350. https://doi.org/10.1038/mi.2017.2.

(51) Odds, F. C.; Brown, A. J. P.; Gow, N. A. R. Candida Albicans Genome Sequence: A Platform for Genomics in the Absence of Genetics. Genome Biol. 2004, 5 (7), 230. https://doi.org/10.1186/gb-2004-5-7-230.

(52) Schneider, C. A.; Rasband, W. S.; Eliceiri, K. W. NIH Image to ImageJ: 25 Years of Image Analysis. Nat. Methods 2012, 9 (7), 671-675. https://doi.org/10.1038/nmeth.2089. 